\title{
A Study of the Relationship between Syntactic Development and Concrete Operations in Deaf Children
}

David Dolman

Loyola University Chicago

Follow this and additional works at: https://ecommons.luc.edu/luc_diss

Part of the Education Commons

\section{Recommended Citation}

Dolman, David, "A Study of the Relationship between Syntactic Development and Concrete Operations in Deaf Children" (1982). Dissertations. 2182.

https://ecommons.luc.edu/luc_diss/2182

This Dissertation is brought to you for free and open access by the Theses and Dissertations at Loyola eCommons. It has been accepted for inclusion in Dissertations by an authorized administrator of Loyola eCommons. For more information, please contact ecommons@luc.edu. (c) $($ ) $\Theta \Theta$

This work is licensed under a Creative Commons Attribution-Noncommercial-No Derivative Works 3.0 License. Copyright @ 1982 David Dolman 


\section{A STUDY OF THE RELATIONSHIP BETWEEN SYNTACTIC DEVELOPMENT AND CONCRETE OPERATIONS IN DEAF CHILDREN}

by

David Dolman

A Dissertation Submitted to the Faculty of the Graduate School of Loyola University of Chicago in Partial Fulfillment of the Requirements for the Degree of Doctor of Phi Tosophy

JuTy 
David Dolman

Loyola University of Chicago

\section{A STUDY OF THE RELATIONSHIP BETWEEN SYNTACTIC DEVELOPMENT AND CONCRETE OPERATIONS IN DEAF CHILDREN}

Tremaine in 1975 found that bilingual hearing children made gains in native and second language comprehension when they reached the concrete operational level. Building upon this finding, the present study examined the linguistic and cognitive ski11s of 59 severe-to-profound and profoundly deaf children between the ages of seven and 12. Through manually coded English, students were administered four Piagetian operational tasks in the areas of conservation, classification, seriation, and numeration and a test of syntactic comprehension. Students and teachers were also given a sociolinguistic questionnaire to determine the hearing status of the child's parents, the age the child learned signs, and the sign consistency at home. Teachers and students showed a high degree of agreement in their responses to this questionnaire.

Results indicated that operational deaf children performed significantly better than non-operational deaf children on the test of syntactic comprehension, although both groups of children had poorer English skills and a lower rate of operational thinking than did the younger hearing students in Tremaine's sample. A relationship was found among operational thinking, age, and IQ of the subjects as well as between age and syntactic skills, but no relationship was indicated between syntactic skills and IQ. 
Students whose parents consistently signed to them showed greater English syntactic comprehension than did students whose parents signed less consistently. Children with more consistent sign exposure at home also tended to have more advanced operational skills, though not to a statistically significant degree. In both operational level and English syntactic skills, a slight advantage was found for those children using American Sign Language at home rather than manually coded English. This finding may be explained by the greater degree of sign consistency likely to be experienced by those children whose deaf parents use American Sign Language. Finally, a multiple regression analysis indicated that over half of the total variability on the test of syntactic comprehension could be predicted from success or failure on two of the operational tasks (numeration and seriation) and the child's overall signing ability, with age and IQ much poorer predictors of English skills. 
A STUDY OF THE RELATIONSHIP BETWEEN SYNTACTIC DEVELOPMENT AND CONCRETE OPERATIONS IN DEAF CHILDREN

by

David Dolman

A Dissertation Submitted to the Faculty of the Graduate School of Loyola University of Chicago in Partial Fulfillment of the Requirements for the Degree of Doctor of Philosophy 


\section{ACKNOWLEDGEMENTS}

I would like to express appreciation to each of my advisors. Dr. Ronald Morgan's scholarship and expectations of academic excellence from his students have been an example and a challenge. Dr. Carol Harding's insightful comments and suggestions helped in broadening my deafness-oriented perspective to consider issues of general developmental psychology. Dr. Todd Hoover's friendly questions and statistical expertise contributed to my appreciation of the rigors of quantitative research. Dr. Patricia Scherer's ability to convey to others her understanding of the implications of deafness has been a source of inspiration for many years. In addition, I would like to thank Mr. Ruben Rakow of the Special Education District of Lake County (I1linois) and Dr. Kenneth Brasel of the Wisconsin School for the Deaf for providing the subjects who made this study possible. 


\section{VITA}

David Dolman was born on August 17, 1951 in Oklahoma City, Oklahoma.

He spent his elementary school years in east Texas and graduated from Memorial High School in Tulsa, Oklahoma in 1969. He attended the College of Wooster, where he majored in psychology and graduated as a member of Phi Beta Kappa in 1973. Earning a master's degree in deaf education from Northwestern University in 1976, he enrolled in Loyola University's Ph.D. program in General Educational Psychology three years later. As part of that program, he served a one year school psychology internship through the Special Education District of Lake County (I17inois).

He has worked as a high school teacher of the deaf and currently teaches English to deaf students and sign language to hearing students at William Rainey Harper College in Palatine, Illinois.

His publications include "English Instruction in a Community College Hearing Impaired Program" (Teaching English to the Deaf, Spring, 1978) and "English Remediation and the 01der Deaf Student: the Computer as a Tool" (American Annals of the Deaf, September, 1980). 
TABLE OF CONTENTS

Page

ACKNOWLEDGEMENTS . . . . . . . . . . . . . . . . . . $i_{i}$

VITA . . . . . . . . . . . . . . . . . . $i i_{i}$

LIST OF TABLES . . . . . . . . . . . . . . . . . . . . . vi vi

LIST OF FIGURES . . . . . . . . . . . . . . . . . viji

CONTENTS OF APPENDICES . . . . . . . . . . . . . . . . . ix

Chapter

I. INTRODUCTION . . . . . . . . . . . . . . . . . 1

II. REVIEW OF RELATED LITERATURE . . . . . . . . . . . . 5

Theoretical Framework . . . . . . . . . . . 5

The Relationship between Thought and Language . . . 12

Characteristics of the Deaf ......... 17

The Relationship between Deafness and Thought . . . 22

A Description of Manual Communication Systems of the Deaf .................... . . . 31

Concrete Operations, Syntax, and Deafness ..... 37

Recapitulation............. . . 45

III. METHOD . . . . . . . . . . . . . . . . 48

Hypotheses . . . . . . . . . . . . . . 48

Subject Selection Procedures ........... . . 49

Procedure ............... . . 52

Instrumentation ......... . . 53

Screening Test.......... 53

Test of Operational Level ...... . 54

Test of Syntactic Comprehension ... . 57

Method of Scoring ......... 58

Design and Statistical Analysis ...... 58

IV. RESULTS . . . . . . . . . . . . . . . 62

Results Related to Hypothesis 1......... 64

Results Related to Hypothesis 2.......... 74

Results Related to Hypothes is 3 ........ 78 
Results Related to Hypothes is 4......... . 86

Results Related to Hypothesis 5.......... 86

Results Related to Hypothes is 6......... 89

Results Related to Hypothesis 7 ......... 89

Results Related to Multiple Regression Analysis... 89

Summary of Results ............. . . 91

V. DISCUSSION . . . . . . . . . . . . . . . . 94

Discussion Related to Hypothes is 1 . . . . . . . 96

Discussion Related to Hypothesis 2........ 100

Discussion Related to Hypothes is 3....... 103

Discussion Related to Hypothes is 4........ 105

Discussion Related to Hypothes is 5........ 106

Discussion Related to Hypothes is 6 ........ 107

Discussion Related to Hypothesis 7....... 107

General Discussion and Implications for Further

Research

SUMMARY

REFERENCES ................................ 114

APPENDIX A ..................................... 129

APPENDIX B ...................................... 132

APPENDIX C . . . . . . . . . . . . . . . . . 135

APPENDIX D . . . . . . . . . . . . . . . . . . 137

APPENDIXE .............................. 143

APPENDIX F ............................. 231

APPENDIX G . . . . . . . . . . . . . . . . . 234

APPENDIX H............................... 238

APPENDIX I . . . . . . . . . . . . . . . . . 240

APPENDIX J . . . . . . . . . . . . . . . . . 253 


\section{LIST OF TABLES}

Table

Page

1. IQ Data for 50 Subjects . . . . . . . . . . . . . 51

2. Analytic Paradigm .............. . . 59

3. Relationships between Child- and Teacherreported Data and between Methods 1 and 2 Scoring Systems..................

4. Results Related to Hypothesis 1: T-tests

for the Total Score on the Test of

Syntactic Comprehension in Relation to Operational Tasks.................

5. Results Related to Hypothesis 1: T-tests

for the Total Score on the Test of

Syntactic Comprehension for Predominantly

Operational and Predominantly

Non-operational Children ...............

6. Mean Errors on the Syntactic Structures

Section of the Test of Syntactic

Comprehension ..................

7. Results Related to Hypothesis 2: Analysis

of Variance for the Total Score on the

Test of Syntactic Comprehension in

Relation to the Child's Sign Language

Background ( $A S L$, MCE, or NCL), according

to the Teacher

8. Results Related to Hypothesis 2: HSD

Test for Differences among ASL, MCE, and

NCL Groups in the Total Score on the

Test of Syntactic Comprehension .............

9. Results Related to Hypothesis 2: T-test

for the Total Score on the Test of

Syntactic Comprehension in Relation to

the Child's Sign Language Background

( $A S L$ and MCE versus NCL), according to

the Teacher 
10. Results Related to Hypothesis 3: Analys is

of Variance for Operational Tasks in

Relation to the Child's Sign Language

Background (ASL, MCE, or NCL), according

to the Teacher ...................

11. Results Related to Hypothesis 3: HSD

Test for Differences among ASL, MCE, and

NCL Groups on the Conservation Task ...........

12. Results Related to Hypothesis 3: T-tests

for Operational Ability in Relation to the

Child's Sign Language Background (ASL and

MCE versus NCL), according to the Teacher

13. Results Related to Hypothes is 4: The

Relationship between IQ and Operational

Ability

14. Results Related to Hypothes is 5: The

Relationship between Age and Operational

Ability . . . . . . . . . . . . . . . . 88

15. Stepwise Multiple Regression Analysis

for the Best Predictors of the Total

Score on the Test of Syntactic

Comprehension (Method 1 Scoring System,

Teacher-reported Information) 
Figure

1. Mean Syntactic Structures Errors for the Tremaine and Present Study . . . . . . . . . . .

2. Mean Syntactic Structures Errors for the Conservation Task . . . . . . . . . . . . . . .

3. Mean Syntactic Structures Errors for the Classification Task . . . . . . . . . . . . .

4. Mean Syntactic Structures Errors for the Seriation Task ..................

5. Mean Syntactic Structures Errors for the Numeration Task . . . . . . . . . . . . . . .

6. Mean Syntactic Structures Errors for Predominantly Operational and Predominantly Non-operational Children 
CONTENTS FOR APPENDICES

Page

APPENDIX A Parental Consent . . . . . . . . . . . 129

I. Letter to Parents . . . . . . . . . . . . 130

II. Parental Permission Slip . . . . . . . . . . 131

APPENDIX B Saciolinguistic Questionnaire . . . . . . . 132

APPENDIX C Screening Items . . . . . . . . . . . . 135

APPENDIX D Thinking Tasks................. 137

APPENDIX E Grammar Test ................. 143

I. Scoring Form ................. 144

II. Test Items .. . . . . . . . . . . . . . . . 149

APPENDIX $F$ Report to Teachers of Grammar Test

Results ............... 231

APPENDIX G Report of the Findings of the Study . . . . . . . 234

I. Report to Parents .............. 235

II. Report to School Personne1 . . . . . . . . . . . 236

APPENDIX $H$ Methods 1 and 2 Scoring Systems for

Operational Tasks ............. 238

APPENDIX I Additional Statistical Tables ........... 240

I. Results Related to Hypothesis 2: Analysis of Variance for the Total Score on the Test

of Syntactic Comprehension in Relation to the Child's Sign Language Background, according to the child 
II. Results Related to Hypothes is 2: Tukey's HSD Tests for Differences among ASL, MCE, and NCL Groups, according to the Child, in the Total Score on the Test of Syntactic Comprehension ................

III. Results Related to Hypothesis 3: Analys is of Variance for Operational Tasks (Method 2 Scoring) in Relation to the Child's Language Background (ASL, MCE, or NCL), according to the Teacher .............

IV. Results Related to Hypothesis 3: Analysis of Variance for Operationa 1 Tasks (Method 1 Scoring) in Relation to the Child's Language Background (ASL, MCE, or NCL), according to the Child ..............

V. Results Related to Hypothesis 3: Analysis of Variance for Operational Tasks (Method 2 Scoring) in Relation to the Child's Language Background (ASL, MCE, or NCL), according to the Child .............

VI. Results Related to Hypothesis 3: Tukey's

HSD for Differences among ASL, MCE, and NCL Groups, according to the Teacher, on the Conservation and Numeration Tasks under Method 2 Scoring ............. 246

VII. Results Related to Hypothes is 3: Tukey's HSD Tests for Differences among ASL, MCE, and NCL Groups, according to the Child, on the Conservation and Classification Tasks under Method 2 Scoring ...........

VIII. Results Related to Hypothes is 4: The Relationship between IQ and Operational Ability under Method 2 Scoring . . . . . . . . . 248

IX. Results Related to Hypothesis 5: The Relationship between Age and Operational Ability under Method 2 Scoring 
X. Stepwise Multiple Regression Analysis

for the Best Predictors of the Total

Score on the Test of Syntactic

Comprehension (Method 2 Scoring

System, Teacher-reported Information) . . . . . . 250

$X I$. Stepwise Multiple Regression Analysis

for the Best Predictors of the Total

Score on the Test of Syntactic

Comprehension (Method 1 Scoring

System, Child-reported Information) . . . . . . . .

XII. Stepwise Multiple Regression Analys is

for the Best Predictors of the Total

Score on the Test of Syntactic

Comprehension (Method 2 Scoring

System, Child-reported Information) . . . . . . . 252

APPENDIX $\mathrm{J}$ Scores on the Four Operational

Tasks for All Subjects, according

to the Method 1 Scoring System ........... 253 


\section{CHAPTER I}

\section{INTRODUCTION}

Deaf education is not a field known for its lack of passion and controversy. For over a hundred years, a raging battle related to the oral versus manual methods of communication has taken place. The major focus of this controversy has centered on the issue of whether deaf children should be forced to depend solely on lipreading and speech or whether they should be allowed to sign and, as a consequence, never to integrate completely into a hearing society. However, this controversy has subsided substantially in the last several years (Jordan et al., 1976) for a variety of reasons. About the time that Chomsky was questioning the value of diagramming sentences, conjugating verbs, and declining nouns, Piaget's findings that the child does not think like a miniature adult were becoming more widely circulated and accepted. A new field, psycholinguistics, was born, and deaf educators, who have more at stake than most in acquiring knowledge of how language is learned, began to pay attention. Teachers of the deaf threw away their Fitzgerald Keys (the deaf education counterpart to sentence diagramming) and, instead, attended to the findings of Lenneberg (1967), who emphasized a critical age range (21 to 36 months) for learning language. They found hope in the writings of Furth (1966), 
who claimed that deaf children think essentially like hearing children and would benefit from intensive exposure to language and who, like Lenneberg, recommended the use of signs.

Although sign language usage in educational settings has become widely accepted, the oral-manual controversy has been replaced with the issue of which type of sign system to use. Deaf people point to studies showing the superiority of those who use American Sign Language (Stuckless and Birch, 1966; Meadow, 1966; Vernon and Koh, 1970), while hearing parents and educators, many of whom are recently converted oralists, emphasize the importance of rendering signs in exact English word order. One well-known investigator (Quigley, 1979) noted that deafness encourages evangelism for one's cause rather than hard-nosed research, but the reasons for this are not difficult to understand. Unlike some other fields of academic interest, deafness is a human field dealing with human emotions. The grief of hearing parents hoping to produce a child in their likeness is counterbalanced by the dynamics of a minority group proud of, yet sometimes insecure about, their differences from the majority. However, one thing is certain; after more than 150 years of formal deaf education in this country, after a plethora of educational practices have come and gone, after millions of dollars have been spent and thousands of people have devoted their lives to teaching efforts, the average deaf adult still cannot fully comprehend the front page of today's newspaper. Whether the primary reasons for this marginal level of reading performance are poor educational practices, as some 
imply (Lenneberg, 1967; Ottem, 1980), or can be better explained by the organismic deficit of deafness (Myklebust, 1960; Russell et al., 1976) is debateable. What is not debateable is that the problem exists.

The present study attempted to systematically delineate the relationship between thinking and language in the deaf child. That is, while many studies proposing to use the deaf as a test case for proving the existence of thought without language have been rightly criticized (Blank, 1965; Moores, 1978), it is nonetheless instructive to determine as precisely as possible what relationships exist between thinking and language in the deaf child. Essentially, the present research project was built upon a study by Tremaine (1975), who found that a relationship exists between the attainment of concrete operations and syntactic comprehension in a group of bilingual, hearing, primary age children. Although studies have investigated the syntactic abilities of the deaf child (Russell et al., 1976), the relationship of the deaf child's sign and spoken language exposure to performance on Piagetian tasks (Best, 1970), the relative superiority of manually coded English over American Sign Language and the oral method for promoting English skills (Brasel and Quigley, 1975), and the relationship between conservation ability and metaphor comprehension in deaf children (Rittenhouse et a1., 1981), no systematic investigation has been reported in the literature which explores the relationship between the attainment of concrete operations and syntactic ability in deaf children and attempts to relate these 
findings to age, IQ, and, most important for education, sign language background. The present study was such an attempt.

The subjects, 59 deaf students in grades two through nine, were evaluated in terms of cognitive and syntactic skills. The following questions were addressed: 1) Do deaf children reach the concrete operational stage at the same time as hearing chitdren? 2) Does a relationship exist between operational level and syntactic comprehension in deaf children? 3) Does a background in American Sign Language or manually coded English or the lack of a consistent language background affect the attainment of concrete operations? 4) Do these varying backgrounds affect English syntactic comprehension? 5) Is there a relationship between IQ and operational level or IQ and syntactic development? 6) Is there a relationship between age and syntax or age and cognitive level? 


\section{REVIEW OF RELATED LITERATURE}

This chapter outlines the major theories and empirical studies which serve as a framework for the present study. In addition to examining the linguistic theory of Noam Chomsky and the cognitive theory of Jean Piaget, studies which attempt to delineate the relationship between thought and language are explored. After investigating the characteristics of deafness, the inappropriateness of utilizing the deaf to solve the thoughtlanguage issue is discussed. Characteristics of various manual communication systems are then presented, followed by a review of the problems of English syntax common to many deaf people. Research analyzing the relationship between syntactic development and thinking skills in hearing children is discussed, as well as a study investigating the relationship between thinking and metaphor comprehension in deaf children.

\section{Theoretical Framework}

A revolution of sorts took place in the late fifties and early sixties. Unlike other revolutions, which often bring bloodshed and terror, this revolution was relatively placid. It was a revolution of concepts, a revolution in the world of linguistics. For it was at this time that Noam Chomsky and his theory of transformational grammar appeared on the intellectual scene. Rejecting 
the imitation-reinforcement view of language learning offered by behaviorists, Chomsky $(1959,1971)$ argued that the empiricist approaches to language analysis must fail because they only look at the surface features of the language, whereas most regularities appear only in the grammatical deep structure. The deep structure is represented in the mind and is rarely indicated in the physical signal. It is highly abstract, as are the rules which determine it and its relationship to surface structure. Any language, then, contains a set of semantic-phonetic percepts which differ from other languages. But, according to Chomsky, the general properties of percepts, their forms and mechanisms, are remarkably similar across languages.

These percepts reach the surface level by a sequence of operations called grammatical transformations. Chomsky (1968) invoked the image of children as theory constructors to explain how language is learned. Children discover the theory of their language with minimal data. Normal speech consists of fragments, false starts, blends, and other distortions of the underlying idealized forms, yet as seen from the study of the mature use of language, children learn the underlying idealized theory without explicit instruction and at a time when they are incapable of complex intellectual achievements in other areas. Furthermore, this achievement is relatively independent of intelligence or highly specific experiences.

How does such competence occur? It is inconceivable, said Chomsky, that an abstract, tightly organized language system comes 
by accident into the mind of every four year-old child. If there were no innate restrictions on the form of grammar, children could employ any theory to account for their linguistic experiences, and no one system would be exclusively acceptable or preferable. A restriction on the form of grammar is a precondition for linguistic experience, and this is the critical factor in determining the course and result of language learning. While children cannot know at birth which language they are to learn, they do "know" that its grammar must be of a predetermined form that excludes many imaginable languages. How does the child "know" this? Chomsky offered no answer. It is a mystery, he said, which may be attributed to evolution, though explaining it in these terms amounts to nothing more than the belief that surely there is some naturalistic explanation for the process.

Chomsky's views have been supported by many other researchers. Lenneberg (1970) approached the issue from a biological point of view by noting the relationship between language development and physical growth. He postulated that language begins when the brain has reached $65 \%$ of its full maturation and that the capacity for learning a language is greatest during childhood. Lenneberg (1967, p. 126) pointed out the regularity in sequence of certain Tanguage milestones and their correlation with age and other developmental factors, and he suggested that the acquisition of a first language after puberty should be virtually impossible. Bellugi (1970) noted that a11 children are systematic, regular, and productive in their use of language from the time they begin to make two- 
word utterances. They analyze regularities in the language, segment novel utterances into component parts, invent new combinations, and develop rules of maximum generality, applying them too broadly initially and only later learning their proper restrictions. By the age of three, most children have mastered basic sentence patterns, including many inflections. Between two and three comes the development of prepositions, demonstratives, auxiliaries, articles, conjunctions, possessive and plural pronouns, the past tense suffix, the plural suffix, and the possessive suffix. The average number of spoken words in one study was listed as 272 at age two, 896 at age three, and 2,562 at age six (Gustason et al., 1972, p. 2). Chomsky's view that linguistic knowledge is an innate property of the human species contrasts with that of Jean Piaget, who regarded language skills as a reflection of a more general underlying cognitive competence that manifests itself in various activities, including language behavior. Chomsky saw the mind as a set of preprogrammed units equipped from birth to realize its full complement of rules and needing very modest triggering from the environment. Language is divorced from other forms of thinking, with each intellectual faculty a separate domain of mentation possibly located in a separate region of the brain, exhibiting many of its own processes, and maturing at its own rate (Piattelli-Palmarini, 1980). According to Chomsky (1968), the acquisition of language is relatively independent of intelligence or the particular course of experience. For Piaget, on the other hand, the child is an active, constructive agent that slowly inches forward in a perpetual 
bootstrap operation. Thought is a broad set of capacities, with identical mental operations underlying a range of abilities. "Linguistic progress is not responsible for logical or operational progress," he wrote $(1972, p .14)$. "It is rather the other way around. The logical or operational level is likely to be responsible for a more sophisticated language level."

Operation is a central concept in Piaget's theory. Knowledge is not a copy of reality. To know an object involves not merely looking at it and making a mental image of it; instead, to know is to act upon, to transform, to understand the process of transformation, and consequently, to understand how the object is constructed. An operation is the essence of knowledge -- an interiorized action which modifies the object of knowledge. Examples of operations include joining objects in a class to form a classification, putting things in a series, and counting and measuring. An operation never stands in isolation; it is always linked to other operations and, as a result, is always part of a total structure. In addition, it is reversible, taking place in both directions, as in adding or subtracting, joining or separating (Piaget, 1964).

Operations develop through time based on maturation, experience, social transmission, and equilibration. Piaget emphasized equilibration as the fundamental factor which leads to changes in operational thinking. In the act of knowing, the child, faced with an "external disturbance", in order to compensate will react through the process of assimilation (the incorporation of external 
stimuli into the organism's aiready existing cognitive structure) or through accomodation (the revision of the organism's already existing structure to match the external object) (Piaget, 1967, p. 8). These processes lead to psychological equilibrium and to the development of higher-order thinking processes.

Piaget's theory is a stage theory, which holds that all children pass through a series of qualitatively different levels of organization. Piaget (1973) listed several characteristics of stages: The ordering of the levels is constant, the structures constructed at a given age become an integral part of the structures of the following age, a stage includes both a level of preparation and a level of completion, and the forms of a stage's final equilibrium constitute a "structure of the whole", in which several distinct operations are integrated. The movement from one stage to another is not dramatic. Transitions are gradual and, in fact, a person may function at more than one developmental stage at any particular time. Emmerich (1968, p. 674) pointed out that, during a transition period, the previous behavior may be completely displaced, the previous behavior may still occur with some regularity, or the previous behavior may occur only infrequently. By the time a given stage has almost completely displaced a previous stage as a person's dominant level of functioning, another stage may be beginning to displace this now dominant stage. This "stage mixture" (Turiel, 1969) leads to an extremely complex developmental picture but, according to theorists like Piaget, a picture which accurately reflects reality. 
In spite of the lack of clear-cut boundaries between stages, Piaget claimed that distinct levels of cognitive organization do, indeed, exist. The first he called the sensorimotor period, which characterizes children from about birth to two years old. A major accomplishment here is the attainment of the idea (or schema) of object permanency. This representational ability serves as the foundation for the next stage, the preoperational, which lasts from about two through six years. Here, children employ language, symbolic play, and delayed imitation, though their thought is still dominated by rigid, unidirectional schematic structures. It is only when children reach the concrete operational stage at about age six that logical operations appear. Thought is no longer dominated by perceptions. Children can attend to transformations and solve problems involving conservation, in which one aspect of an array has remained unchanged though other aspects have changed.

Unlike preoperational children, those in the concrete operational stage are beginning to extend their thought from the actual to the potential (Inhe1der and Piaget, 1958, p. 248). Nevertheless, several limitations of this period should be noted. Concrete operations are concrete, with their structuring and organizing activity oriented toward concrete things and events in the immediate present. Ordering to the not-present is something children will do when necessary, but this extrapolation is a special-case activity. Because concrete operational children are still bound to the present, they must consider the various physical properties of objects and events (mass, weight, length, 
area, time) one by one. This cognitive equipment is, at this point, insufficiently detached from the subject matter to permit contentfree structuring. For example, after achieving an understanding of conservation of mass (there is as much clay in $A$ as in $B$, despite differences in shape), the child may still be incapable of achieving conservation of weight and volume, even with the same clay objects. If the child's cognitive system were more independent of the specific reality it organizes, such horizontal decalages would not occur. In addition to the concept of conservation, children during this period also attain the concepts of classification and seriation. Classification is the process that results in the logical combination of similar items into homogeneous groups, while seriation is the ability to combine items in logical order based on the differences between them (Meadow, 1980, p. 58). These various concrete operational systems exist as essentially separate patterns of organization; they do not form a simple, integrated system by which the child can easily pass from one substructure to another in the course of a single problem (Flavel1, 1963, pp. 203-204).

The last stage is the formal operational, which appears at about age twelve in many children. At this point, the child begins to think counterfactually and hypothetically and constructs operations of propositional logic rather than simply the operations of classes relations, and numbers (Piaget, 1964).

The Relationship between Thought and Language

One of the most widely discussed issues in developmental psychology has been the relationship between thought and language. 
Huttenlocher (1976) noted that the term "language" is used in two ways -- to denote the linguistic code and to denote the role of symbolization in thought. Whereas the linguistic code includes sound patterns of its lexical elements and rules for combining those elements into grammatical sequences, the preservation of information about events occurs through the symbolic process. Huttenlocher and others (for example, 01son, 1977) concern themselves primarily with the linguistic code, while Piaget, Bruner, and Vygotsky deal with the symbolic aspects of language.

Piaget (1967, p. 91) posited the existence of a symbolic function which encompasses both language and other symbol systems, such as mental imagery, symbolic play, and drawing. Because language is only one form of symbolic function, Piaget concluded that thought precedes language and that, once acquired, language is not sufficient to assure the transmission and development of operatory structures (1973, p. 118). This does not mean, however, that language plays no role in the development of mental operations. The presence of nouns in the language, for example, may stimulate children to think in terms of discrete classes, and the ability to verbalize a thought structure may help to consolidate and generalize it (Ginsburg and Opper, 1969, p. 211). Once children have acquired language, their thought may range beyond present activity, and they may simultaneously handle many elements in an organized fashion. As they mature, language takes on an increasingly important role. At the level of formal (hypothetico-deductive) reasoning, operations are no longer related to the objects themselves, as at the concrete operational 
level, but to verbally expressed statements and hypotheses, While Piaget $(1967$, p. $119 ; 1973$, p.94) admitted the necessary role of language for the formation of formal operations, he questioned whether language is sufficient in itself to bring about this development. He felt, on the contrary, that its role is limited to allowing the fulfillment of structures which originate at the level of symbolic function.

These views contrast with those of many other theorists. "Sentences have a compelling power to control both thought and action," said Miller and Chomsky (1963), and this viewpoint was echoed by Bruner and Vygotsky. In a seminal paper written in 1964, Bruner set forth the view that language mediates between external events and the child's own responses. Hierarchical classification, grouping that goes beyond perceptual inclusion, is evident in the structure of language. As children master this classification system, they also shift from dependence on the associative principles that operate in classical perceptual organization to increasingly abstract rules of grouping. According to Bruner, language shapes, augments, and supercedes the child's earlier modes of processing information. The translation of experience into symbolic form (which leads to the achievement of remote reference, transformations, and combinations) opens up intellectual possibilities far beyond that of the most powerful image forming system. Once language becomes a medium for translating experience, there is a progressive release from immediacy. Language permits productive, combinatorial operations in the 
absence of what is represented, and children learn to delay gratification by representing to themselves what lies beyond the present. How does this process of internalization occur? Bruner (1964, p. 14) offered no definitive answer, but he speculated that interaction with others, "the need to develop corresponding categories and transformations for communal action," is the key.

No less influential than Bruner's ideas have been the writings of Vygotsky (1962), who emphasized that thought and speech have different roots. Just as a preintellectual stage may be found in the speech development of children, a prelinguistic stage may be seen in their thought development. Children move through stages. At first, they put ideas together in unorganized heaps, with words denoting only a vague syncretic conglomeration of individual objects that have coalesced into an image. At a later point, which Vygotsky termed "thinking in complexes", individual objects are united in the child's mind not only by subjective impressions but also by bonds existing between these objects, even if these bonds lack logical unity. Finally, the child thinks in concepts, a skill which requires synthesis combined with analysis. This operation is guided by the use of words as a means of actively centering attention, abstracting certain traits, synthesizing those traits, and symbolizing them by a sign. Although this process begins in earliest childhood, true concept formation, in which thought is not merely expressed in words but comes into existence through them, develops only at puberty.

Supporting the view that language brings thought into exis- 
tence are Wertsch and Blank, both of whom deal with the relationship between asking questions and the development of thought. Wertsch ("Thinking in Questions", 1980) proposed that the child who is guided by questions and answers learns how to think. Children who are led through a task by a series of commands merely respond to directions. They do not learn from the social interaction and do not generalize from what was commanded in similar situations. When children are asked questions, however, they ask themselves similar questions on related tasks and begin to reason. Blank(1975) studied one child's acquisition of the abstract word "why" and also concluded that the development of conceptual skills results not from encounters with the physical world but from encounters with certain forms of complex dialogue. Blank noted that the child first used "why" only in response to an adult statement and never as a means of describing or questioning perceived events. Thus, from the beginning, "why" was tied to the linguistic and not to the physical world. Over a period of months, the child pursued the meaning of the word "why" through hypothesis testing, a process in which she matched the word she was attempting to comprehend with a concept. Arguments have been raised against such a concept-formation view of early language development, because it assumes that the child can hold in memory both the instances of the word and all the relevant attributes of these instances until the invariance common to all has been extracted. While this view assumes a capacity for problem-solving skills that is seldom attributed to the infant, Blank, nevertheless, 
felt that this type of cognitive activity is uniquely demanded, and therefore uniquely fostered, by aspects of language acquisition. These cognitive skills may be potentially available for use in all situations, but they are rarely mobilized except to meet the demands of certain language tasks.

Thus, while Piaget's views fall within the thought-precedeslanguage camp, many other theorists, including Bruner, Vygotsky, Wertsch, and Blank, emphasized the primacy of language. By its nature, however, either position is difficult to prove, and it is for this reason that psychologists have looked to the deaf. Why the deaf? Hans Furth (1975, p.70) provided an answer. "Many profoundly deaf youngsters," he wrote, "have no knowledge of language; they do not know the language of society, e.g., English, in any adequate sense, or the so-called 'sign language' of the deaf community of which they are not yet a part; therefore, they provide a unique opportunity to observe what, if any, influence the absence of a language has on the development of intelligent thinking." It is to this special population that we now turn. Characteristics of the Deaf

According to Dale (1976), the deaf form one of the most segregated minorities in the population. Although approximately ninety percent of hearing impaired children in the United States are born to hearing parents (Rawlings, 1973), most have little contact with hearing people after leaving school. About half of all deaf individuals are genetically deaf due to a recessive gene. While a hearing parent may carry such a gene, it occurs more fre- 
quently, of course, through deaf parents. In some ways, genetically deaf children are the most fortunate, since they are least likely to have other medical problems. Another source of deafness, accounting for about ten percent of all cases, is maternal rubella. A1though not serious for the mother, it can have severe consequences for the developing fetus, with deafness one of several possibilities. Rubella is gradually decreasing, but a 1963-65 epidemic produced large numbers of deaf children in the general population. Less frequently, deafness is acquired after birth from diseases like meningitis and encephalitis, which attack the nervous system. These diseases, like rubella, are often accompanied by other problems as we11. Historically, acquired deafness has been very common, though in recent years, the development of antibiotics and other medical techniques has made it a rarer phenomenon. At the present time, the majority of deaf children are congenitally deaf. This change has implications for the education of the deaf, as there is clearly a difference between a child who has never heard language and one who has (Dale, 1976).

Another consideration is the low incidence of deafness in the general population. Most sources indicate an average of one profoundly deaf or severely hard of hearing child in a population of one thousand children. Considering that these children may range from first through twelfth grades, one might expect to find, in a public school program serving ten thousand children, seven elementary age deaf children and three of secondary age. If distributed proportionally, this would result in less than one deaf 
child for each of the twelve grades (Brill, 1975).

Their success in school programs, however, is often less than desirable. A 1959 survey (Wrightstone, Aronow, and Moskowitz) designed to develop reading norms for the deaf considered a 4.9 grade level as a minimum reflection of functional literacy. The administration of the Metropolitan Achievement Test, Elementary Level, Form B resulted in a score of 4.9 or better by one percent of deaf children ages 10.5 to 11.5 , seven percent of those 13.5 to 14.5 , and 12 percent of those 15.5 to 16.5 (Furth, 1966a). The Office of Demographic Studies of Gallaudet College in 1969 and 1971 analyzed the Stanford Achievement Test scores of about 17,000 hearing impaired children. While the average age of the children was 12.5 and the median grade level was 6.5 , the mean achievement level on arithmetic computation subtests was grade 4.1 and, on paragraph-meaning subtests, grade 3.0. The highest scores on these two subtests, achieved by the 19 year-old group, were 4.4 and 6.7 respectively (Gentile and DiFrancesca, 1969; DiFrancesca and Carey, 1972; DiFrancesca, 1972; Trybus, Buchanan, and Difrancesca, 1973; Ries et al., 1973). This lack of progress between the twelfth and nineteenth years was underscored by a follow-up testing effort of the Office of Demographic Studies, which found the mean increment in reading achievement to be slightly less than .3 grade equivalents per year. In addition, this study found that students with no handicaps in addition to deafness showed more reading gains than those with multiple handicaps, girls showed more gains than boys, increments in reading 
achievement were inversely related to hearing loss, and early school entrance was related to accelerated reading gains (Trybus and Karchmer, 1977).

This dismal progress in reading and other academic areas is probably not a reflection of lower intelligence. Early studies of deaf children, reported by Pintner and Paterson (1919), indicated a general lowering of mental capacity in the deaf, rather than inferiority in specific traits. Yet, for every study indicating lower intelligence (Peterson, 1948; Shirley and Goodenough, 1932; Graham and Shapiro, 1953; Springer, 1938; Zeckel and Kalb, 1939), another study pointed to average intellectual potential (MacPherson and Lane, 1932; Scyster, 1936; Myklebust, 1948; Ross, 1953; Goetzinger and Rousey, 1957). Levine (1956) investigated deaf adolescent girls and concluded that although quantitatively they were equal to hearing subjects, they were deficient in patterns of thinking and reasoning, in conceptual maturation, and in levels of abstractive ability. Vernon (1969) reviewed a large number of studies and concluded that deaf and hard of hearing children have essentially the same distribution of intelligence as the general population, even though the mean score for deaf children was slightly below that of hearing children. All of these findings must be accepted cautiously, however, due to problems in testing deaf children. Reliable norms for deaf children are available for the Nebraska Test of Learning Aptitude (Hiskey, 1941) and the Wechsler Intelligence Scale for Children - Revised (Wechsler, 1974) but for few other tests. 
Many studies have noted the difficulties of administering these kinds of tests to deaf children (Levine, 1960, 1969; Vernon and Brown, 1964). Anastasi (1976, p. 281) stated that because of their general retardation in linguistic development, deaf children are often handicapped on verbal tests, even when the verbal content is presented visually. She pointed out that special adaptations of the Wechsler scales are sometimes made in testing the deaf, such as typing oral questions on cards. When such modifications are made, however, one cannot assume that reliability and validity remain unchanged, a point reinforced by the studies of Glowatsky (1953) and Myklebust (1960). Brill (1974, p. 170) contended that the only valid measures of the intelligence of of deaf children are non-language or performance-type tests. Yet, even with these tests, problems abound. Knowledge of a language or some kind of symbol system may play a part in the ability to respond to supposedly non-verbal items. An individual who can subvocally code items on test of these types will score higher than those who cannot (Bri11, 1977).

Most studies have found, however, that deaf children of deaf parents score consistently higher than deaf children of hearing parents in achievement. Stevenson (1964) compared 134 deaf students of deaf parents to 134 deaf students of hearing parents and discovered higher educational achievemnt for those with deaf parents in 90 percent of the comparisons. While 38 percent of the students with deaf parents went to college, only nine percent of the students with hearing parents did so, Balow 
and Brill (1972) surveyed students at one school between 1956 and 1971 and concluded that mean grade level scores were 7.0 for students with hearing parents, compared to 8.4 for students of deaf parents. Stuckless and Birch (1966) discovered superior reading, speechreading, and written language for the deaf students with deaf parents, with no differences in speech or psychosocial development. Meadow (1966) reported higher self-image and academic achievement for students of deaf parents, and Quigley and Frisina (1961) found higher vocabulary levels and better speech for these students. Vernon and Koh (1970) compared groups and found that deaf students of deaf parents were superior in reading, vocabulary, and written language.

The Relationship between Deafness and Thought

A large body of research has been done concerning deaf children's achievement on conceptual tasks. Much of it has been reviewed by Furth $(1964,1971)$, who summarized the results of 84 studies with subjects ranging from preschool age to middle adulthood. Furth's two reviews listed 62 points of similar performance between deaf and hearing subjects and 44 points of difference, mostly in the form of a slight but statistically significant inferiority. These differences were evenly spread throughout various problem areas and were not limited to narrowly defined specific tasks or age levels. In a 1961 study, Furth looked at the classification skills of 180 deaf and 180 hearing subjects of elementary school age and found that the two groups were equal in their ability to classify similar objects and objects that were 
the same, but that the deaf group had more problems in classifying objects with opposite characteristics. On conservation tasks, a general retardation was found, al though deaf children eventually mastered the concept. Furth (1966) studied conservation of weight in deaf children with a mean age of 8.5 and discovered that the performance of the deaf children was like that of hearing children about two years younger. Oleron and Herren (1961) examined conservation of weight and volume and found a six year lag for the deaf students. Templin (1967) also looked at conservation of weight and detected, at one point, a two year $1 \mathrm{ag}$ among 12 and 14 year-old deaf subjects, while a second test administration revealed a six year lag among 14 year-old deaf children.

Differences that exist between the two groups can be attributed to two main factors (Meadow, 1980, p. 57). The first reflects the communication difficulties that deaf children experience in the testing situation, which affect the children's understanding of the directions and their responses. Researchers like Furth (1966) and Vernon (1967) felt that this difficulty in communication was the critical problem, and they rejected the second hypothesis -- that thinking skills are related to linguistic ability. Furth (1975) found that the differences between deaf and hearing children in their knowledge of language was almost absolute. While hearing children were at home in a language that was constantly used for all kinds of purposes, deaf children, he said, possessed a meager knowledge of only a few words and simple sentence constructions. Yet, Furth's studies showed no consistent inferiority among deaf 
children. In a few areas (such as discovery and shift tasks), developmental differences were observed, with deaf children showing a slight lag in comparison with hearing children. The majority of his studies, however, demonstrated no differences at a11. On rote learning, visual perception, immediate memory, logical classification, and logical symbol tasks, the deaf performed almost as well as the hearing. Even when deaf children did perform poorer on some tasks, their scores fell fully within the range of hearing children. Furth believed that the pattern of relative failure and success on the part of the deaf was inconsistent with any psychological exlanation linking linguistic deficiency to the thinking process. Many studies showed that the same deaf children have succeeded on one, but not on another, task, while a general linguistic influence would have predicted failure on both tasks (1966, p. 145). Noting the wide range of areas tested (rule learning, discrimination and classification tasks, combinatorial and probability thinking, spatial thinking, logical symbols, memory recal1, and Piagetian conservation problems), Furth (1975) concluded, "There is just no evidence of any clear-cut deficit or any specific intelligent behavior that can be empirically and theoretically related to the clear-cut deficit in knowledge of a language."

But why did the deaf perform worse on some tasks? Furth attributed it not to the linguistic environment but to the social environment. Thinking, he said, develops through living contact with the environment, regardless of the presence or absence of a ready-made linguistic symbol system. Deaf children are deficient 
in many ordinary experiences and occasions which motivate other children to ask questions, reason, and organize mentally, and they perform poorer on tasks requiring discovery and initiative than on those dealing with comprehension or application of concepts. There seems to be an inability to look for reasons, not an inability to reason. Furth $(1966$, p. 152) called this deficit "an intellectual laziness or rigidity", which may at times resemble intellectual incapacity.

To test his idea that the social rather than linguistic environment was the key to poorer performance, Furth (1966, p. 155) compared the deaf sample to a group of culturally deprived children, defined as those attending a school in a rural area with limited cultural advantages and coming from homes where the father was a farm laborer or unskilled worker. On a conservation of liquid amount task, the rural group fell midway between the deaf and hearing control group. While most hearing children had successfully mastered this task by age 11 or 12 , the rural group average was 13 or 14 , with many in the deaf group not mastering the task until the age of 16 or 17 . In the symbolic logic task, which required intel lectual initiative, the rural sample did as badly as the deaf. Because both the rural sample and the control group had achieved linguistic competence while the deaf group had not, Furth attributed test score similarities between the deaf and rural samples to a lack of environmental stimulation, which had the effect of dulling curiosity.

Yet, the views of Furth have not gone unchallenged. Moores 
(1978, p. 133) believed that some of Furth's statements were categorical assertions of facts rather than presentations of debateable hypotheses. For example, Furth claimed that deaf people do not have the tool of language, a finding which he based on the dismal reading achievement scores of most deaf individuals. But, in equating reading scores with linguistic competence, Furth was, in effect, saying that deaf people are deficient in standard American English. Lack of such competence, however, must not be equated with a lack of language for, as Furth (1974, p. 267) himself pointed out, "Sign language is the natural language of the deaf." Blank (1965) noted that many deaf children have been in special language enrichment programs since two or three years of age, yet Furth (1964) ignored this fact by failing in his studies to control for the age at which the children entered school. Blank also complained that when deaf subjects did as well as hearing, Furth concluded that language was not required, but when they did worse, he blamed it on lack of understanding the directions, possession of pseudo-concepts by the hearing, larger numbers of subnormal children in schools for the deaf, personal biases of the experimenter, motivational characteristics, or environmental restrictions in the deaf child's early life. While Blank felt that some of these criticisms might be valid, she found that Furth invoked them whenever the deaf scored worse.

Lenneberg (1967, p. 326) believed that man's propensity for language learning is so powerful that it occurs even in children who are cut off from a normal linguistic environment. Some deaf 
children may not come into contact with language until an age when other children have fully mastered the skill and when the most formative period for language acquisition is on the decline. Even at this age, their contact with language samples is reduced in amount compared to the amount to which a hearing child is exposed. Yet, considering the obstacles to language proficiency, Lenneberg (1970) felt that deaf children showed amazing competence. Subtleties of English syntax, many of which are not taught in school, are found in compositions. While some of the teacher's instructions are forgotten, many aspects of language are automatically absorbed by the students. Lenneberg used that fact as support for his biologically based view of language acquisition.

The propensity to use language does, indeed, appear strong. Furth (1975) himself pointed out that all deaf children spontaneously use gestures and pantomime for purposes of communication and that these gestures follow linguistic principles. Goldin-Meadow and Feldman (1975) studied four deaf children of hearing parents. Since the children were profoundly deaf and the parents did not know sign language, the children essentially received no language input. Each child, however, created his own sign language, with signs to specify objects and actions and, in two cases, to specify relations between objects and actions by combining gestures in rule-governed ways. And, as Benderly has stated, even deaf individuals who are not allowed to sign in school programs will, when among themselves, develop their own argot. She quoted a deaf man as saying, "If you cut off our arms, we will sign with 
our shoulders", and she noted that initiation into sign language when a student enters school has traditionally represented one of the most important steps in the development of identity. Benderly wrote:

The established students quickly begin the new arrival's induction into sign language. Mary's adolescent son learned his first standard signs in the entrance lobby of the Lexington School (an oral school) in New York. The first student he met when he set foot inside began teaching him. Behind the backs and under the noses of school authorities, the children handed on their precious but forbidden 'tongue' (1980, p. 56).

Other studies have suggested that language differences exist among deaf children which do affect their cognitive abilities. Best (1970) compared the performance of three groups of deaf children with varying exposure to signed and spoken language with the performance of hearing children on several classification tasks. Performance correlated with language exposure, with hearing children performing most effectively and deaf children with better language skills performing better than the other deaf children. Best also found that the groups progressed through the same stages of cognitive development and used the same problem-solving strategies, although the hearing children progressed more rapidly than the deaf. Silverman (1967) matched deaf and hearing children on the basis of reading achievement scores and found that this procedure eliminated differences in their ability to engage in complex abstract thinking. Schlesinger and Meadow (1976) discovered that deaf children with better communication skills performed better on those aspects of cognition measured by intelligence tests than 
deaf children whose communication skills were less well-developed, in spite of the fact that efforts were made to reduce the verbal skills necessary for understanding and responding to the tasks. Meadow (1980, p. 62) warned, however, of the dangers of making causal inferences from correlated results. She felt that a reciprocal relationship exists; the more intelligent the child, as measured by IQ score, the better the child will be at learning to communicate, and the more proficiency the child has in communication, the higher the IQ score will appear.

Aside from the difficulties of characterizing the deaf as a homogeneous, non-linguistic population, Bever (1975) found other difficulties in Furth's using deaf populations to resolve the thinking-language controversy. Bever believed that developing organisms are self-compensating, so that the effects of a deficit in one area may be obscured by a partial take-over by another system which does not ordinarily organize the behavior in question. Since human intelligence involves both language and thought, it is likely that a deficit in one area would be masked by compensation in the other. Bever offered an analogy. Kangaroos generally hop by the application of both legs and tail. If one argues that the basis for hopping is really the legs, one could remove the legs, find that the kangaroo does a terrible job of hopping, and thus conclude that legs are central to hopping. One could perform the same experiment on the tail, find similar results, and conclude that the tail is central to hopping. Finally, one could cut off a little of the tail and reach a conclusion analogous to those of the previous 
two experiments. If these experiments were considered immoral, however, observations would be limited to hopping-impaired kangaroos. These kangaroos would rely on whatever organs remain intact, which would lead to aberrant hopping but hopping, nevertheless. Whatever the clinically observed results, Bever argued that we would know little more than before about the organization of hopping in a normal kangaroo. If one found that legless kangaroos compensate by hopping on their front paws, that would not prove that the legs and tail are irrelevant to hopping in a kangaroo. Similarly, it is difficult to understand the implications of data from special populations, and this is particularly difficult with respect to language and cognition, insofar as they can be separated.

The difficulty in separating the two as well as in understanding their relative importance has been pointed out by Menyuk (1975), who reviewed a study by DeZwart (1971). DeZwart, in an attempt to determine whether language is a condition either sufficient or necessary for the achievement of cognitive accomplishments, compared students who were conservers of liquid, non-conservers, and transitional in their ability to understand quantitative and dimensional terms and comparatives. While all three groups of children understood coordinated sentences containing the terms, there were statistical differences in the conservers' and nonconservers' ability to produce them. An attempt was made to teach non-conservers to use the terms in a manner similar to that of conservers. Of those who succeeded linguistically, few succeeded in the conservation task. This experiment indicated that mastery 
of a given linguistic structure is not a necessary or sufficient condition for the mastery of a given linguistic structure. Menyuk concluded that, at both early and later stages of development, the relationship between language and cognition remains undefined. Just as it is unproven that certain cognitive accomplishments are prerequisites to certain linguistic accomplishments, it is also unproven that language is a prerequisite to cognitive strategies in every instance. The nature of the specific task requirements, according to Menyuk, renders language useful, non-useful, or inerfering in carrying out these tasks.

The debate continues. Whether, as Piaget and Furth asserted, language plays only a minor role in the development of cognition or whether, as Bruner and Vygotsky claimed, the role of language is central, remains a theoretical issue with inconclusive data on each side. It does seem clear, however, that because of their linguistic heterogeneity, the deaf do not make a good test case to resolve the thinking-language controversy. Just how heterogeneous their linguistic environments are will be the focus of the next section.

\section{A Description of Manual Communication Systems of the Deaf}

Numerous studies have shown that deaf children go through similar developmental stages of language acquisiton as hearing children (Quigley et a1., 1976; Bonvillian et al., 1976). Babbling begins at around six months in hearing children (Dale, 1976), and deaf children begin to "babble" manually at about the same age. The first spoken and first sign words appear at about 12 months, 
while two-word manual and spoken utterances emerge at 18 to 24 months (Caccamise et al., 1978). These findings are compatible with Kessler's (1971) research with bilingual English-Italianspeaking children. She found that similar structures in the two languages developed in the same sequential pattern and at the same rate, which suggests that they share the same deep structure. Bellugi and Klima (1972) studied one deaf child of deaf parents. They discovered that, at age three, her sign vocabulary covered the ful1 range of concepts expressed by hearing children of the same age and that she was using sentences of approximately the same length. In addition, the child had discovered the general possibility for changing the direction of a sign and had extended it to cases where an adult signer would not. Bellugi and Klima found this analogous to a hearing child's use of the words "bringed", "holded", or "digged", and they concluded that the milestones of language development are the same in sign language as for spoken 1anguages.

When the term "sign language" is used, however, a distinction must be made among its many varieties. American Sign Language, also known as ASL or Ameslan, is used by approximately 75 percent of all deaf adults (Rainer et al., 1969) and is the third most widely used non-English language in the United States (O'Rourke et a1., 1975). ASL is a complexly structured language with a highly articulated grammar. While in spoken languages, words follow one another in an arbitrarily determined sequence, ASL permits the presentation of signs in a much looser order. Two 
signs may be presented simultaneously without impairment of intelligibility, although the direction in which many signs move may alter the meaning. Only three handshapes exist for all pronouns, and there are no articles or "be" verbs. No formal tenses exist; instead, time indicator signs ("finish", "up till now", "later", "not yet", "will", "past", "long time ago") indicate what tense a verb sign is in. Most signs are negated by simply shaking the head while the sign is being made, and facial expressions and head jerks indicate that a question is being asked. In short sentences of three or four signs, order of presentation is unimportant ("I like movie", "movie I like", "like movie I", "like I movie", "I movie like"). But as the sentence length increases, ideas or information are presented in a sequence which reflects how they occured in real life (Fant, 1974).

Klima and Bellugi (1979, p. 2) found it interesting that such an independent language would develop. Deaf people do not form a geographic community, and educational efforts with deaf people are usually directed toward instilling English in every possible form. Whereas spoken languages are kept alive by being passed from one generation to another, few deaf children have deaf parents; most deaf children learn ASL from their peers in a residential school setting. Nevertheless, analysis of the structure of ASL shows that, despite all these obstacles, a separate language has developed. Bellugi (1980) stated, in fact, that because of its use of inflections, ASL is less like English than it is like Navajo, Greek, or Russian. 
In contrast to the features which make ASL a unique language, manually coded English sign systems use English word order and English inflectional endings. Over the past 15 years, many such systems have developed -- Seeing Essential English (Anthony, 1971), Linguistics of Visual English (Wampler, 1971), Signing Exact English (Gustason et al., 1972), and Signed English (Bornstein et a1., 1973). All of these systems can be described as manually coded English (MCE), which can be loosely defined as any sign system other than ASL (Cokely, 1978). Inventors of these systems note that MCE is a tool rather than a language (Gustason, 1974; Bornstein et al., 1980), but they also note its advantages: It is easy for a very young child to perceive and use, it can reasonably parallel speech, it follows English syntax, and it is much easier for hearing parents to learn than ASL (Bornstein, 1974).

The popularity of MCE systems in educational settings can be seen by examining some statistics. A 1976 survey (Jordan et a1.) revealed that roughly two-thirds of all classes for the hearingimpaired were using MCE systems, with the other third using the oral-aural method. Of the 343 programs employing MCE, 302 of them had previously been oral classes. An update of the survey (Jordan et al., 1979) showed that the trend toward MCE in the classroom has continued, though the rate of change from oral programs has leveled off since the early 1970 's.

The widespread use of this system by educators, however, does not mean that it is universally praised. Gustason (1980) pointed out that little information, other than anecdotal reports, 
has been available as to the effectiveness of various sign systems. Schreiber (1974) complained that the new sign systems have brought chaos, with people from different regions unable to understand each other because they use a different MCE system than is used in another region. Stokoe (1974) claimed that MCE leads to deviations from standard English usage. He advocated first gaining competence in ASL, "the natural language the deaf themselves use", and then Tearning English as a second language.

The controversy over MCE systems versus ASL divides the field of deafness much like the oral-manual controversy did a generation ago, with most deaf people favoring ASL and most hearing parents and teachers supporting MCE systems (Schreiber, 1974). The use of one method or the other could have important educational implications but, in spite of this fact, few studies have systematically investigated the merits of one system over the other (Meadow, 1980). Evidence is often offered for the superiority of ASL over MCE by reference to those studies noting the academic superiority and better emotional adjustment of deaf children of deaf parents, most of whom use ASL (Stevenson, 1964; Balow and Bri11, 1972; Stuckless and Birch, 1966; Meadow, 1966; Quigley and Frisina, 1961; Vernon and Koh, 1970). However, as Knight (1979) pointed out, the apparent advantage exhibited by these deaf children may be due not so much to the use of ASL as to the fact that that the child is exposed to a natural language in a natural environment that supports normal parent-child communication and its accompanying cognitive and linguistic development. 
Brasel and Quigley (1975) studied children of four groups of parents. The parents were categorized on the basis of the language they used with their deaf child: MCE, ASL, intensive oral practice, or no special method. Each group contained 18 deaf students, with a mean age for each group of 14.8 years. The results showed that the MCE and ASL groups were superior to the other two groups on a test of English syntax and on four subtests of the Stanford Achievement Test (Language, Paragraph Meaning, Word Meaning, and Spelling). Although the MCE group outscored the ASL group in 211 areas of the syntax test, only one of those differences (relative clauses) was significant. No differences were found between the oral group and the group without special training on any of the subtests of the test of syntax. On the Stanford Achievement Test, the MCE group was superior to the other three groups on all four subtests, with the nearest competitor, the ASL group, from one to four grade levels behind. Brasel and Quigley concluded that "the greatest advantage appears to come when the parents are competent in Standard English and use Manual English with and around the child, as witnessed by the marked superiority of the (MCE) group over both Oral groups on nearly every test measure employed" (1975, p. 133). They also found some advantage in using a manual communication system (that is, ASL) which, although it deviates significantly from English syntax, presents information in a concrete, visual way.

Determining the deaf child's preferred mode of communication, however, can be a difficult task. According to Spragins and Cokely 
(1980), there are no quantifiable screening devices to ascertain whether the child is most comfortable using ASL, MCE, or speech. Many younger deaf children of hearing parents and some deaf children of deaf parents do not use ASL. Woodward (1973) suggested that ASL proficiency may be related to sign language acquisition, the agent of the sign language acquisition (for example, family or friends), and the type of school attended. Nevertheless, at the present time, evaluators are forced to rely on information from parents, teachers, the child, and observations to determine the child's normally used mode of communication.

Concrete Operations, Syntax, and Deafness

Deaf children's difficulties with English syntax have been we11-documented. Heider and Heider (1940) analyzed over a thousand written compositions of deaf and hearing children and concluded that the deaf use shorter sentences, more simple sentences, and less difficult forms of sentence subordination, and while the compositions of the two groups did not vary in length, the deaf children's work, in general, resembled that of less mature hearing children. Myklebust (1960, pp. 306-318) administered the Picture Story Language Test to 200 deaf and 200 hearing children, matched for age and IQ. The deaf subjects used more nouns, which may indicate more concrete language than that of hearing counterparts. Adjectives and prepositions were used much less frequentiy by the deaf children, and virtually no adverbs were used, while hearing children began using them at age nine. Other studies have found that about half of the syntactic errors of deaf children 
consists of the omission of necessary words and the use of wrong words (Thompson, 1936; Myk lebust, 1965).

Perhaps the largest body of research in the area of syntactic structures used by the deaf has been done by Quigley and his associates at the University of Illinois. They concluded that deaf children possess a set of consistent grammatical rules which frequently deviate from those of standard English (Russell et a1., 1976, p. 37). With time, these rules come into closer and closer conformity to the adult model although, even at age 18, most deaf children have not achieved English competence in many language structures. While deaf children appear to have relatively little difficulty in learning the more general phrase structure rules of English, they have many more problems with their more subtle manifestations in surface structure. Deaf students have considerable difficulty with the determiner and auxiliary systems, with as many as 30 to 40 percent of them leaving school wi thout having gained control of their use in standard English constructions. On the other hand, broad aspects of word order and word use come under increasing control and are mastered reasonably well by many deaf children by the age of 12 (Russell et a1., 1976, p. 69).

These same researchers (1976, p. 96) found that the comprehension and production of passive voice sentences by deaf children parallels that of hearing children but is greatly delayed. Many deaf children appear not to have grasped the meaning of passive voice markers up to 10 years after the point at which virtualiy all hearing children have done so. Quigley, Smith, and Wilbur 
(1974) also discovered that deaf students had significantly less understanding of all aspects of relative clauses than did hearing children of much younger ages. For example, on a basic comprehension test, the oldest hearing subjects (10-12 years) produced 83 percent correct responses, while the oldest deaf students (18-19 years) got only 76 percent correct. Deaf chi 7 dren seemed to differ from hearing children in the acquisition of the question transformation primarily in rate rather than in sequence of acquisition. Eighteen year-old deaf students studied by Quigley, Wilbur, and Montane11i (1974) did not have mastery of this structure common in 10 year-old hearing subjects. The use of conjunctions by deaf students demonstrated a pattern of retardation in comparison to hearing children, as well as the presence of structures not found in standard English. Concerning pronominalization, differences between deaf and hearing children appeared in rate of acquisition rather than in consistent errors (Russell et al., 1976, pp. 151-153). This same pattern held for the acquisition of the negative transformation, and Taylor (1969) found many deviancies from standard English complement forms. These included confused marking of tense in infinitives ("The ant liked to played with the insect", "The man began screamed") and confusion about the relationship between infinitives and gerunds ("He cannot know how to swimming", "The hunter missed to shoot the dove"). These errors were of the same type as those reported by Menyuk (1969) for young hearing children, but in deaf children, they persisted to a much later age, appearing even in the writings of 16 year-olds, the oldest children evaluated by Taylor. 
Charrow (1974) has suggested that the written language of deaf persons is a dialect of English, but Russell et al. (1976, pp. 198201) pointed out several differences between the English of deaf people and dialects. First, dialects are generally based on spoken language, and any written form of them would be based on a spoken form, which is not the case with the written language of deaf people. Even if their writing were based on ASL, which remains unproven, most researchers of ASL (Stokoe, 1960; Klima and Bellugi, 1979) have claimed that it is a language completely distinct from English rather than a dialect of it. Second, with a dialect, most language features are shared by users of the dialect. Yet, while widespread use of certain syntactic structures can be seen in the writing of deaf people, none are common to all, and most were used by less than half of the subjects studied. Third, dialects are acquired by individuals as a result of exposure to those dialects in their childhood environments. But it is unlikely that any deaf child was ever exposed to structures such as "John like to Alice but John will can't play with Alice" or "Yesterday Jack go to home because Jack sore his toe" (Charrow, 1974). In addition, most deaf children are born to hearing parents who have no knowledge of sign language, and differences between ASL structure and the structure of deaf persons' written language are at least as great as the similarities. Finally, a dialect serves as a stable means of communication among speakers of that dialect. It seems unlikely that the written language of most deaf people serves such a purpose since, in fact, most deaf people rely on writing as a means of 
communication only as a last resort. Russell et al. (1976) summarized their position by comparing deaf children to black children. Black children will acquire a particular dialect not because their skin is black but because they are exposed to that dialect in their formative years; blacks raised among speakers of standard English wil1, of course, acquire that dialect. Deaf children, on the other hand, have language problems not for social and cultural reasons but because they are deaf; the causative factor is organismic rather than cultural.

The possibility that those organismic differences extend to the area of brain hemispheric laterality has been investigated by Kelly and Tomlinson-Keasey (1977). They examined the hemispheric laterality of 39 deaf children in the upper primary and intermediate grades. An analysis of the results of the experimental task, which involved processing word and picture stimuli presented singly to left and right visual hemifields, suggests that young deaf children do not develop the same lateral specialization that has been found in hearing populations. This difference is attributed to an early severe hearing loss, which precludes the normal acquisition of spoken language. Without the auditory processing of speech, the authors hypothesized that the left hemisphere does not develop a specialization for language. Since the deaf children in this study processed high image words significantly faster in the right hemisphere and showed similar tendencies for low image words, concrete pictures, and abstract pictures, it was suggested that the deaf process all stimuli with a visual code. 
In addition to the syntactic variations demonstrated by deaf children, hearing children as well show differences in syntactic ability as they advance through cognitive stages. Some studies suggest that major progress in aspects of language development occurs during the age ranges which mark the transition from preoperational thought to concrete operations (Hornby et a1., 1970; Francis, 1972; Swartz and Hall, 1972; Vasta and Liebert, 1973) and from concrete operations to formal operations (Paris, 1973). None of these studies, however, tested subjects on Piagetian tasks; instead, the authors simply noted that changes in linguistic performance seemed to coincide with transitions between stages in Piagetian theory.

To investigate the possibility that concrete operational thought and the comprehension of syntax in the bilingual child are based on the same abilities, Tremaine (1975) administered Piagetian tasks and syntactic comprehension tests in French and English to English-speaking first, second, and third graders. These children were either enrolled in a French immersion curriculum or a curriculum which included 75 minutes of instruction in French per day. Piagetian tasks were chosen over IQ scores because IQ is based on the concept of mental age, which increases as a linear function of age until about age 18. Operational intelligence, on the other hand, does not improve as a linear function of age but involves plateau periods punctuated by sudden and rapid improvements. It was predicted that when children showed operational reasoning defining the stage of concrete operations, their compre- 
hension of syntax in both languages would improve greatly. This prediction was based on the notion that rule stabilization in syntax may be the same kind of process as equilibration in Piagetian theory. Languge acquisition was viewed by Tremaine as a rule-based process, with acquisition of specific structures resting on the stabilization of rules governing those structures. Piaget used the concept of equilibration to explain the sequential character of cognitive development; each stage is defined by the achievement of a relatively stable equilibrium in the organization of mental structures, and each successive stage defines greater stability over the previous (Tremaine, 1975, p. 12).

Tremaine carried out her research within the framework of case grammar theory, a system proposed by Fillmore (1968). Case grammar theory contrasts both with classical grammar, in which cases are defined as inflected forms of noun roots (accusative, genitive, dative, etc.) and with Chomsky's transformational theory (1968), which does not include any notion of case at all. Fillmore's theory rests on many of the assumptions of transformational grammar, including the idea of deep and surface structure. But while Chomsky would argue that case inflections are a phenomenon of the surface structure, Fillmore maintained that they are an integral part of the deep structure of all languages, realized in the surface structure sometimes as inflections, prepositions, or word order and defined as abstract relations between sentence components. In case grammar theory, the basic deep structure of a sentence, the "proposition", involves a tenseless set of relationships between 
a verb and an unordered array of noun phrases dominated by particular case categories, which include agentive, objective, source, goal, locative, benefactive, and time.

Tremaine discovered that when children learning a second language reached the level of concrete operations, syntactic comprehension of both their native and second language improves greatly. In 62 out of 65 independent analyses of variance, children classified as operational performed significantly better than children classified as non-operational. These results suggest that the abilities needed to solve problems posed by numeration, mass, and weight tasks are the same abilities needed for the comprehension of syntax and that these abilities are closely related to age and grade. Furthermore, Tremaine found that the numeration task was more closely related to syntactic comprehension in both languages than any other task used. This task required the child to reason about a seriated set of objects while, at the same time, imposing a hierarchy on the series. Similarly, syntactic comprehension requires the listener to impose a hierarchical structure (syntax) on a series of meaningful units which unfold in time. Tremaine admitted that attributing the acquisition of syntax to the principle of equilibration was going beyond the data gathered by her study, but she nonetheless suggested the possibility that such a relationship does, in fact, exist.

Although no studies are known to exist concerning the relationship between syntactic development and operational ability in deaf children, Rittenhouse et a1. (1981) found a relationship 
between conservation ability and the ability to comprehend metaphors in eight profoundly deaf and six hard of hearing children. All of the children, whose ages ranged from 11 years to 16 years nine months, were presented conservation of liquid and weight problems and 12 metaphor items. Each of the metaphor problems consisted of a short story and four possible interpretations of the story. A11 interpretations were non-literal, and one of the four was metaphorical. The results showed no differences based on extent of hearing loss for either conservation ability or ability to understand metaphors. While intelligence and age both affected conservation performance and metaphor comprehension, the closest association was found between metaphor comprehension and conservation ability. The researchers concluded that some underlying similarities may exist in both types of problems, though they did not spell out in any detail what those similarities might be.

\section{Recapitulation}

In this chapter, a theoretical framework was provided for the present research study. Acknowledged were the fields of psycholinguistics, through Noam Chomsky's theory of transformational grammar, and developmental psychology, through Jean Piaget's cognitive stage theory. According to Chomsky, linguistic knowledge is an innate property of humans and is relatively independent of intelligence or experience. He saw language as separate from other kinds of thinking, with each intellectual ability exhibiting its own processes, maturing at $i$ ts own rate, and perhaps located in a separate region of the brain. Piaget, on the other hand, believed 
that identical mental operations serve as a base for a broad range of abilities and that language skills are a reflection of a more general cognitive competence.

Piaget's view that a cognitive framework underlies any advancement in language skills has been disputed by other researchers. Bruner believed that language shapes thought by translating experience into symbolic form, which opens up intellectual possibilities beyond the present and immediate. Vygotsky hypothesized that conceptual thinking requires the use of words to abstract, synthesize, and symbolize certain traits. The question of whether thought precedes language or vice versa is difficult to prove, and some researchers, most notably Furth, have looked to the deaf to provide an answer.

Though studies indicate that deaf people have the same distribution of intelligence as the general population, they generally have had limited exposure to the language of their society and, for that reason, are considered by some to demonstrate what influence the absence of a language has on the development of thinking. Most of Furth's research has shown minor or inconsistent differences, which led him to conclude that cognitive skills are not related to language. Yet, Furth's basic assumption that young deaf children have essentially no language must be questioned in light of research findings that, in spite of great obstacles, rules of grammar emerge in the writing of deaf students and that some children without sign language exposure will create their own signs in rule-governed ways. The linguistic diversity of deaf people becomes apparent when one considers the number of sign language systems available. 
These range from American Sign Language, a complex language more like Navajo, Greek, or Russian than English in its use of inflections, to various forms of manually coded English, which use English word order and English inflectional endings. While American Sign Language is the language of most deaf adults, manual English codes are tools used by educators and parents to expose the deaf child to English syntax. In general, deaf children seem to have little difficulty learning general phrase structure rules of English but exhibit many problems with their subtle manifestations in the surface structure. Auxiliary, determiner, and passive voice systems are among the most difficult to master, and some studies have posited that, unlike hearing children, deaf children process language in the right brain hemisphere.

One study found that deaf children comprehend English metaphors when they begin to reason in the concrete operational manner described by Piaget. Tremaine discovered that a relationship existed between operational thinking and syntactic comprehension in a group of young hearing children for both their native language (English) and their second language (French). With Tremaine's work as a foundation, the present study examined the relationship between concrete operational skills and syntactic comprehension in a group of deaf children. 


\section{CHAPTER III}

METHOD

\section{Hypotheses}

The following null hypotheses were tested:

1. There are no significant differences on a test of English syntactic comprehension between deaf children classified as operational and deaf children classified as non-operational.

2. There are no significant differences on a test of English syntactic comprehension among deaf children classified as having a strong American Sign Language (ASL) background, children having a strong manually coded English (MCE) background, and children having no consistent language (NCL) background.

3. There are no significant differences on the operational tasks among deaf children classified as having a strong American Sign Language (ASL) background, children having a strong manually coded English (MCE) background, and children having no consistent language (NCL) background.

4. There is no significant relationship between IQ and operational thinking in deaf children.

5. There is no significant relationship between age and operational thinking in deaf children.

6. There is no significant relationship between age and 
syntactic development in deaf children.

7. There is no significant relationship between IQ and syntactic development in deaf children.

\section{Subject Selection Procedures}

Twelve students from the Special Education District of Lake county (SEDOL) at the John Powers Center for the Hearing Impaired in Vernon Hills, Illinois and 47 students from the Wisconsin School for the Deaf (WSD) in Delavan, Wisconsin participated in this study. The 59 subjects included 37 males and 22 females. While the populations of the SEDOL hearing impaired program and WSD are almost evenly divided between male and female students, males made up about 63 percent of the subjects in this study. A11 participants were Caucasian.

Each of the subjects met the following requirements:

1. grades 2-9 (chronological age range of 7-8 to 15-11; average age of 12.22 , with a standard deviation of 2.38 years). While the period of concrete operations is most often listed as between the ages of seven and 11 (for example, Wadsworth, 1979, p. 96), Furth (1966) and others have noted the general delay that deaf children experience in reaching this stage. For this reason, older children were included in the study.

2. sensorineural hearing impairment of not less than 85 $\mathrm{dB}$ (ISO) in the better ear at 500,1000 , and $2000 \mathrm{~Hz}$ (severe-toprofound deafness) or school records noting a severe-to-profound or profound hearing loss, if detailed audiological records were lacking. 
3. age at onset of deafness at two years or younger.

4. IQ of at least 88 on the Performance Scale of the WISC-R or a comparable test. Nine of the 59 subjects had missing IQ scores but were included in this study based on achievement test scores comparable to same-age peers and based on subjective judgments of school personnel. Of the remaining 50 students, 37 had been administered the WISC-R, eight the Hiskey-Nebraska Test of Learning Aptitude, four the Columbia Mental Maturity Scale, and one the Leiter International Performance Scale.

The 50 availáble IQ scores resulted in a mean performance score of 111.04. The five available IQ scores for the deaf children of deaf parents yielded an average score of 117.80. Perhaps because of the small number of children in this group, this score average was not significantly different from the 110.29 average achieved by the 45 children of hearing parents. In addition, no significant differences were noted between the six IQ scores taken from the Special Education District of Lake County (SEDOL) $(x=109.33)$ and the 44 scores from the Wisconsin School for the Deaf (WSD) $(X=111.27)$. Means and standard deviations for IQ scores may be found in Table 1.

5. no apparent disability (other than hearing impairment) which, in the judgment of school personnel, would interfere with learning.

6. simultaneous method of instruction (MCE plus speech) used in the educational setting. 
TABLE 1

IQ Data for 50 Subjects

$\begin{array}{lllll}\text { A11 } & \text { Deaf } & \text { Hearing } & \\ & & \\ \text { Pubjects } & \text { Parents } & \text { Parents } & \text { SEDOL } & \text { WSD }\end{array}$

$n=50 \quad n=5 \quad n=45 \quad n=6 \quad n=44$

Mean performance IQ

$\begin{array}{lllll}111.04 & 117.80 & 110.29 & 109.33 & 111.27\end{array}$

Standard deviation

12.58

10.03

12.70

9.91

12.98 


\section{Procedure}

Program administrators at SEDOL and WSD were consulted to ascertain those students who met the criteria for inclusion in this study. Letters requesting permission for testing were sent to parents of those children (see Appendix A). Of the 14 letters sent to parents of children at SEDOL, 12 responded affirmatively ( 86 percent response rate). At WSD, of the 53 letters sent to parents, 47 responded affirmatively ( 89 percent response rate). Four additional letters were received after the testing was completed, however, bringing the total WSD response rate to 96 percent.

Teachers were given a sociolinguistic questionnaire (see Appendix B) modeled after Hatfield et al. (1978), to determine the child's language background. Spragins and Cokely (1980) noted the lack of quantifiable measures to evaluate the child's sign language background, and they recommended the use of informant measures. Because of small class sizes and the close involvement many deaf programs have with the families of their students, teachers were considered a reliable source of information and likely to give more objective data than parents. However, as a crosscheck, students were themselves independently given the first page of this questionnaire through the use of manually coded English (MCE).

After each child was individually administered several screening items (see Appendix $C$ ), he or she was tested on four operational tasks (conservation, classification, seriation, and numeration) (see Appendix D), followed by a syntactic test (see Appendix E) and the sociolinguistic questionnaire. All tests were administered 
in MCE with the use of voice, with the entire procedure requiring between 30 and 45 minutes, depending on the age of the child. Forty of the children ( 12 at SEDOL and 28 at WSD) were tested by the principal evaluator, while the remaining 19 were evaluated by two certified interpreters for the deaf. Both interpreters had been trained by the principal evaluator, who was present at the time they were administering all tests to the students.

Later, after the data were organized, teachers were sent materials describing the results of the grammar test for individual children within their classes (see Appendix F), while both teachers and parents who requested them (56 out of 59) were mailed copies of the overall results of the study (see Appendix G). Instrumentation

\section{Screening Test}

A11 subjects were systematically presented with six questions, based on two nine inch by six inch cards. The first card, which contained five stars in one corner and three stars in the opposite corner, required that the child be able to count accurately the stars and to understand the concepts of more and same ("Are more stars here, or are more stars here, or are they the same -- equal?"). The second card was identical to the first, except that both corners contained an equal number of stars, (See Appendix $C$ for complete instructions and the scoring form.)

The screening test was administered as a safeguard, to ensure that the tests of concrete operational ability were not, in fact, a test of language proficiency. While not every concept utilized in 
the operational tasks was assessed by the screening test (color was ignored, for example), it was believed that a linguistic understanding of the concepts of "how many", "more", and "equal" was crucial to success on the operational tasks. Because all 59 children passed each of the six screening items, it may be concluded that, at least in a general sense, every subject understood the language used to describe the primary concepts employed in the tests of operational level. For this reason, no further statistical analys is involving the screening test was employed.

Tests of Operational Level

For the tests of concrete operational ability, four kinds of tasks were employed. (A complete copy of the instructions and scoring forms for each of these tasks may be found in Appendix D). A conservation of liquid task was used, based on Tremaine's (1975) finding that conservation tasks relate to syntactic ability in bilingual, hearing children. In the conventional procedure for the liquid conservation task, the child, after agreeing that two identical containers have an equal amount of liquid, must judge their amounts relative to each other after one of the containers has been poured into a different shaped container. Rittenhouse and Spiro (1979), however, noting that deaf children have difficulty with conventional Piagetian directions on conservation tasks, found a higher success rate using attribute-specific directions. In this procedure, instructions are specific and focus on the dimension under investigation. With the conservation of liquid task, the children were asked to imagine that they were very thirsty 
and that they must choose the glass of water which would best satisfy their thirst. If both glasses were equal and would equally satisfy their thirst, children were to respond that water levels were the same. After one of the glasses had been poured into a different sized glass, the children were presented with the same role-playing situation and asked to respond accordingly.

Inhelder and Piaget (1964) discussed the relationship of both classification and seriation to syntactic development. Words inevitably force a beginning of classification in that, for example, all nouns and adjectives divide reality into classes. Although Piaget concluded that the classification of animals is more abstract than the classification of other objects (such as flowers) because they are less common to the experience of children, it was believed that most deaf children, even as young as second grade, would know the names of many common animals. Therefore, a classification exercise, adapted from Piaget (1941), was utilized involving different types and colors of animals.

Children were shown pictures of 10 animals, four of which were different types of birds, and six of which were animals such as bears, rabbits, cats, and fish. In addition, four of the animals (two birds, a bear, and a rabbit) were white. Children were first asked to count the birds and then to count the white animals. According to conventional instructions, children would be asked if there were more birds or white animals and whether there were more birds (or white animals) or animals. Because of the problems deaf children experience with the words "more" and "same" (Ritten- 
house and Spiro, 1979), attribute-specific instructions were originally used. Children were asked how many birds were present, and then they were asked the number of white animals. They were then told to imagine that they must think of a name for all the animals and asked if they must think of more names for birds or more names for white animals. The children were then asked how many animals there were. After they replied, they were asked if they must think of more names for birds (or white animals) or for animals. In preliminary testing with hearing children, however, the attribute-specific instructions proved more difficult to understand than the conventional. Therefore, conventional instructions were used with a.11 deaf subjects (see Appendix D).

The final operational tasks to be considered involved seriation and numeration. While seriations are rarely completely elaborated in any language, they are sometimes suggested by grammatical forms like the comparative and the superlative. Tremaine's seriation procedure was used, in which children seriated a series of 10 slats (rectangular pieces of painted wood) from the shortest to the longest to form a "staircase". When this was done, children were given nine more slats of intermediate lengths and told to put them in the right place in the staircase. To do this task successfully, children had to coordinate transitive relations, so that each slat (Y) was represented as both larger and smaller than an adjacent slat $(X<Y<Z)$.

If the child successfully accomplished the seriation task, a numeration task was presented in which the first set of ten slats 
was placed in seriated order before the child, a plastic figure of a person was produced, and the child was questioned about how many stairs the person must climb to reach a particular stair. If this task was mastered successfully, the staircase was broken up so that the slats were disarranged, and the same type of questions were asked. Children were then asked how many stairs the person must climb to reach the top of the staircase, if he were already standing somewhere on the staircase (see Appendix D for complete instructions). It should be noted that, because the numeration task was assumed to be difficult for many of the subjects and might lead to frustration, it was presented last and discontinued if it became apparent that the child could no longer succeed.

Test of Syntactic Comprehension

The test of syntactic ability was also adapted from Tremaine (1975). While Tremaine's test consisted of an English section, a French section, and an across-languages section, only the English test was administered to the subjects in the present study. The test consisted of three sections, administered in consecutive order: six inflectional categories tested by 14 contrasts or 28 items (a picture test), 11 syntactic structures tested by 22 contrasts or 44 items (a picture test), and five syntactic variants tested by five contrasts or 10 items. (A complete copy of this test and scoring form are included in Appendix E.) 
Method of Scoring

On the four operational tasks (conservation of liquid, classification, seriation, and numeration), children were grouped as operational or non-operational according to Piaget's traditional criteria (Method 1 scoring). While correct items within failed tasks were also analyzed (Method 2 scoring), children's performances on the task as a whole, in agreement with Piaget's stage theory viewpoint, determined whether they would be considered operational or not. As Tremaine (1975, p. 18) pointed out, the difference between non-operational and operational thought is a qualitative difference which does not lend itself to quantification, especially in light of the fact that transitional periods are a poorly understood process. (Procedures used to derive scores under both Method 1 and Method 2 are Tisted in Appendix H.)

The syntactic test was scored by giving one point for each correct item and then totaling the correct items for each syntactic structure or inflectional category and for the test as a whole. Design and Statistical Analys is

The analytic paradigm for the study is presented in Table 2. In Hypothesis 1, syntactic skills were compared by means of t-tests for all children, who were considered either operational or nonoperational on each of the four operational tasks. In addition, a t-test was employed to compare syntactic skills of children considered predominantly operational or predominantly non-operational. T-tests were also used to determine significant differences between operational and non-operational children in comprehension 
TABLE 2

Analytic Paradigm

\section{LANGUAGE BACKGROUND}

Cognitive Level

$\underline{A S L}$

$\underline{\text { MCE }}$

$\underline{N C L}$

Other

Operational

Non-operationa 1

Independent Variables: Operational Ability, Sign Language Background, IQ, Age

Dependent Variables: Syntactic Comprehension Ability, Operational Ability 
of specific grammatical structures (for example, the for-to transformation). For Hypothesis 2, syntactic skills of children from each of the three language backgrounds (ASL, MCE, and NCL) were contrasted through a simple analysis of variance, followed by Tukey's HSD test, without regard to operational ability. A t-test was also employed to determine differences in syntactic ability between students receiving a consistent sign background (ASL and MCE groups) and students with no consistent sign background (NCL group). In Hypothesis 3 , children from each of the three language backgrounds were contrasted in each of the operational skill areas by means of four simple analyses of variance, followed by Tukey's HSD test for the conservation task. As in Hypothesis 2, four $t$ tests were used for Hypothesis 3 to determine differences between students receiving a consistent sign background (ASL and MCE groups) and students with no consistent sign background (NCL group). But while Hypothesis 2 compared children from consistent and nonconsistent sign backgrounds in syntactic ski11s, Hypothesis 3 compared these same children in operational abilities. (For both Hypotheses 2 and 3, children marked "Other", who could not be identified as belonging to one of the three language background groups, were excluded.)

Hypotheses $4,5,6$, and 7 required the use of correlation coefficients. For both Hypotheses 4 and 5, operational children were compared to non-operational children in IQ scores and age, respectively. With Hypotheses 6 and 7 , the children's ages and IQ scores, respectively, were compared to their syntactic skills. 
A multiple regression analysis was also undertaken to discover the best predictors of the total score on the test of syntactic comprehension. 
CHAPTER IV

\section{RESULTS}

The computerized programs found in the Statistical Analysis System (1979) were used for most statistical operations. As was noted in the previous chapter, operational tasks (conservation, classification, seriation, and numeration) were scored under two methods of scoring (see Appendix $H$ for details). Method 1 considered each child as either passing or failing a particular task, while Method 2 recognized quantitative differences within tasks. Stage theory supports the idea of qualitative rather than quantitative differences among children who attempt operational tasks (for example, see Flave11, 1963, pp. 264-266). Because this study was based on a Piagetian stage theory framework and because the two methods of scoring correlated with each other beyond the .0001 level of probability for all four operational tasks (see Table 3), only data utilizing Method 1 scoring procedures are presented in this chapter.

Similarly, the previous chapter noted that both teachers and children were asked questions from the sociolinguistic questionnaire (see Appendix B). Table 3 lists the relationships, beyond the .0001 level of probability, which exist between the children's and teacher's answers to the questionnaire. There- 
Relationships between Child- and Teacher-Reported Data and between Methods 1 and 2 Scoring Systems

$\begin{array}{cccccc}\text { Age Child Learned } & \text { Sign Consistency } & \text { Conservation- } & \text { Classification- } & \text { Seriation- } & \text { Numeration- } \\ \text { Signs-Teacher } & \text { at Home-Teacher } & \text { Method 1 } & \text { Method 1 } & \text { Method 1 } & \text { Method } 1 \\ \text { Report } & \text { Report } & \text { Scoring } & \text { Scoring } & \text { Scoring } & \text { Scoring }\end{array}$

$\begin{array}{ll}\text { Age Child } & x^{2} 93.67 \\ \text { Learned } & x^{2} \text { prob. } .0001 \\ \text { Signs-Child } & \text { Tau-B } .575 \\ \text { Report } & \end{array}$

Sign

Consistency

at Home-Child

$x^{2} 73.11$

$x^{2}$ prob. .0001

Report

Tau-B .647

Conservation-

Method 2

Scoring

$$
\begin{aligned}
& x^{2} 59.00 \\
& x^{2} \text { prob. } .0001 \\
& \text { Tau-C } .977^{-01}
\end{aligned}
$$

\section{Classification-}

Method 2

Scoring

$$
\begin{aligned}
& x^{2} 55.25 \\
& x^{2} \text { prob. } .0001 \\
& \text { Tau-C } .964
\end{aligned}
$$

Seriation-

Method 2

Scoring

$$
\begin{aligned}
& x_{2}^{2} 59.00 \\
& x^{2} \text { prob. } .0001 \\
& \text { Tau-C } .365
\end{aligned}
$$

Numeration-

Method 2

Scoring 
fore, only teacher-reported information is presented in Chapter IV, although Appendix I includes statistical analyses involving the Method 2 scoring system, as well as children's responses to the questionnaire.

\section{Results Related to Hypothes is 1}

This hypothesis stated that there are no significant differences on a test of English syntactic comprehension between deaf children classified as operational and deaf children classified as non-operational.

Children were classified as operational or non-operational on each of the four tasks: conservation, classification, seriation, and numeration. These scores for all 59 subjects may be found in Appendix J. Table 4 presents results from t-tests which focus on differences between operational and non-operational children in the total score obtained on the test of syntactic comprehension. Of the four operational tasks considered, null Hypothes is 1 was rejected at or beyond the .001 level for all except classification. On each of these tests, variances are considered equal.

Table 4 presents each of the operational tasks individually, and, as a result, some children, perhaps in a transitional period between pre-operational and operational thought, may have passed some tasks while failing others (see Appendix J). A more general perspective is assumed in Table 5 by comparing predominantly operational children, who passed all four tasks, with predominantly non-operational (pre-operational) children. Twelve children were considered operational while 14 children, five of whom failed all 


\section{TABLE 4}

Results Related to Hypothesis 1: T-tests for the Total Score on the Test of Syntactic Comprehension in Relation to Operational Tasks $(n=59)$

Conservation

Operational

Non-operational

Classification

Operational

Non-operationa 1

Seriation

Operational

Non-operationa 7

Numeration

Operational

Non-operationa 1

34

25

34

25

Mean

64.85

7.28

.0014

58.12

7.99

Std. Dev.

Sig.

$\begin{array}{ll}\text { N } & \text { Mean } \\ 34 & 64.85 \\ 25 & 58.12\end{array}$




\section{TABLE 5}

Results Related to Hypothesis 1: T-test for the Total Score on the Test of Syntactic Comprehension for Predominantly Operational and Predominantly Non-operational Children $(n=26)$

\begin{tabular}{lcccc}
\hline & $\underline{N}$ & Mean & Std. Dev. & Sig. \\
Operationa1 & 12 & 68.67 & 5.00 & .0010 \\
Non-operational & 14 & 56.21 & 9.46 & \\
\hline
\end{tabular}


tasks and nine of whom failed all except seriation were considered non-operational. Due to the ease with which almost all children accomplished the seriation task, it was not considered a good discriminator of general operational ability and, consequently, was not included in the criteria for determining predominantly operational or non-operational thinking. As Table 5 shows, differences between predominantly non-operational and predominantly operational children on the test of syntactic comprehension were significant at the .001 level.

Table 6 presents the mean number of errors made for each of the 12 grammatical categories of the syntactic structures section of the test of syntactic comprehension. This section, one of three, formed the middle part of the test and contained the most detailed and complete information regarding the children's receptive syntactic abilities (Tremaine, 1975, p. 122; see also Appendices $E$ and $F$ ). As is demonstrated in Table 6, the 59 subjects had the most difficulty with the for-to structure (e.g., "The baby gives the ball for the dog to the cat"), followed by the passive transformation (e.g., "The ball is hit by the boy"). The least number of errors was seen in the direct object-indirect object inversion (e.g., "The boy shows the cat the bird"), Table 6 also lists the mean number of errors according to whether the subjects were considered operational or non-operational and notes statistical significance between the number of errors made by the two groups of children for each of the grammatical categories evaluated. In 10 of the 12 categories, four errors were the maximum. 
Mean Errors on the Syntactic Structures Section of the Test of Syntactic Comprehension

\begin{tabular}{|c|c|c|c|c|c|c|c|c|c|c|c|c|}
\hline & $\begin{array}{l}0 \\
+ \\
1 \\
\vdots \\
\\
4\end{array}$ & 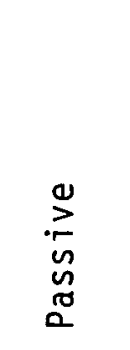 & 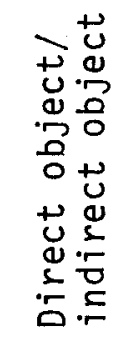 & 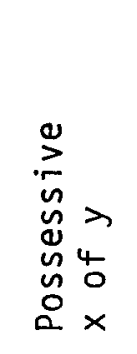 & 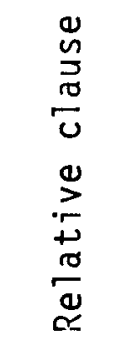 & 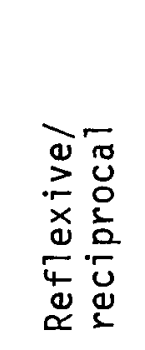 & 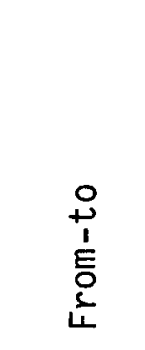 & 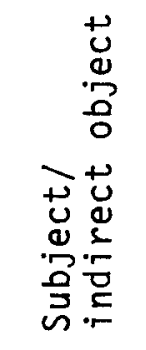 & 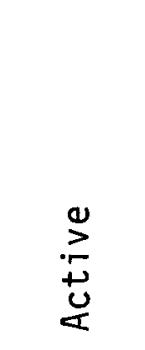 & 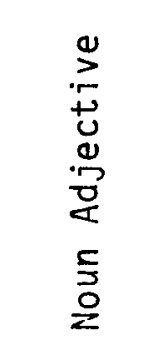 & 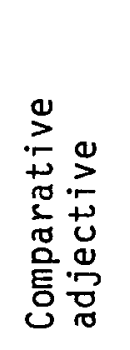 & 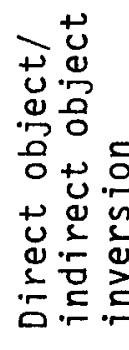 \\
\hline Total Sample (59) & 3.12 & 2.17 & 1.58 & 1.31 & 1.10 & 1.03 & .66 & .51 & .42 & .31 & .31 & .19 \\
\hline $\begin{array}{l}\text { Conservation } \\
\text { Operational } \\
\text { Non-operational } \\
\text { (25) }\end{array}$ & $\begin{array}{l}3.12 \\
3.12\end{array}$ & $\begin{array}{r}2.00 \\
* 2.40\end{array}$ & $\begin{array}{l}1.65 \\
1.48\end{array}$ & $\begin{array}{l}1.21 \\
1.44\end{array}$ & $\begin{array}{l}1.06 \\
1.16\end{array}$ & $\begin{array}{r}.85 \\
\star 1.28\end{array}$ & $\begin{array}{r}.32 \\
\star 1.12\end{array}$ & $\begin{array}{r}.18 \\
\star .96\end{array}$ & $\begin{array}{l}.29 \\
.60\end{array}$ & $\begin{array}{r}.12 \\
* .56\end{array}$ & $\begin{array}{r}.15 \\
\star .52\end{array}$ & $\begin{array}{l}.15 \\
.24\end{array}$ \\
\hline $\begin{array}{l}\text { Classification } \\
\text { Operational (34) } \\
\text { Non-operational (25) }\end{array}$ & $\begin{array}{l}3.00 \\
3.28\end{array}$ & $\begin{array}{l}2.18 \\
2.16\end{array}$ & $\begin{array}{l}1.50 \\
1.68\end{array}$ & $\begin{array}{l}1.29 \\
1.32\end{array}$ & $\begin{array}{r}.91 \\
1.36\end{array}$ & $\begin{array}{r}.82 \\
1.32\end{array}$ & $\begin{array}{l}.53 \\
.84\end{array}$ & $\begin{array}{l}.35 \\
.72\end{array}$ & $\begin{array}{l}.41 \\
.44\end{array}$ & $\begin{array}{l}.24 \\
.40\end{array}$ & $\begin{array}{l}.21 \\
.44\end{array}$ & $\begin{array}{l}.18 \\
.20\end{array}$ \\
\hline $\begin{array}{l}\frac{\text { Seriation }}{\text { Operational (53) }} \\
\text { Non-operational (6) }\end{array}$ & $\begin{array}{l}3.15 \\
2.83\end{array}$ & $\begin{array}{l}2.23 \\
1.67\end{array}$ & $\begin{array}{r}1.49 \\
\star 2.33\end{array}$ & $\begin{array}{l}1.32 \\
1.17\end{array}$ & $\begin{array}{r}.94 \\
\star 2.50\end{array}$ & $\begin{array}{r}.98 \\
1.50\end{array}$ & $\begin{array}{r}.53 \\
\star 1.83\end{array}$ & $\begin{array}{r}.43 \\
\star 1.17\end{array}$ & $\begin{array}{r}.36 \\
* 1.00\end{array}$ & $\begin{array}{r}.21 \\
* 1.17\end{array}$ & $\begin{array}{l}.26 \\
.67\end{array}$ & $\begin{array}{l}.15 \\
.50\end{array}$ \\
\hline $\begin{array}{l}\frac{\text { Numeration }}{\text { Operational }} \\
\text { Non-operational } 1 \text { (39) }\end{array}$ & $\begin{array}{l}2.95 \\
3.21\end{array}$ & $\begin{array}{r}1.75 \\
* 2.38\end{array}$ & $\begin{array}{l}1.80 \\
1.46\end{array}$ & $\begin{array}{r}.90 \\
\star 1.51\end{array}$ & $\begin{array}{r}.80 \\
1.26\end{array}$ & $\begin{array}{r}.80 \\
1.15\end{array}$ & $\begin{array}{r}.25 \\
\times .87\end{array}$ & $\begin{array}{l}.25 \\
.64\end{array}$ & $\begin{array}{r}.05 \\
\star .62\end{array}$ & $\begin{array}{l}.15 \\
.38\end{array}$ & $\begin{array}{l}.10 \\
.41\end{array}$ & $\begin{array}{l}.05 \\
.26\end{array}$ \\
\hline $\begin{array}{l}\text { Predominantly: } \\
\text { Operational (12) } \\
\text { Non-operational (14) }\end{array}$ & $\begin{array}{r}2.67 \\
\star 3.21\end{array}$ & $\begin{array}{l}1.92 \\
2.36\end{array}$ & $\begin{array}{l}1.67 \\
1.50\end{array}$ & $\begin{array}{r}.75 \\
\star 1.36\end{array}$ & $\begin{array}{r}.67 \\
* 1.64\end{array}$ & $\begin{array}{r}.58 \\
\star 1.43\end{array}$ & $\begin{array}{r}.17 \\
\times 1.29\end{array}$ & $\begin{array}{r}.17 \\
\times .93\end{array}$ & $\begin{array}{r}.00 \\
\times .50\end{array}$ & $\begin{array}{l}.25 \\
.64\end{array}$ & $\begin{array}{l}.17 \\
.64\end{array}$ & $\begin{array}{l}.08 \\
.21\end{array}$ \\
\hline
\end{tabular}


For the active transformation (e.g., "The baby sees the girl"), six errors were possible, while only two direct object-indirect object inversion errors could be made. With only four errors possible on the for-to transformation, it is noteworthy that both operational and non-operational chidren made an average of 3.12 errors.

Figure 1 graphically displays the mean number of errors made by the deaf students and compares them to the mean errors made by Tremaine's (1975) hearing group of first, second, and third graders. In spite of the younger age of the 60 hearing subjects (average age of 7.97 years, with a standard deviation of .97 years, compared to an average age of 12.22 years for the 59 deaf subjects, with a standard deviation of 2.38 years), the deaf children made more errors in all categories except the reflexive-reciprocal, with the direct object-indirect object category (e.g., "The girl shows the cow to the dog") showing a nearly equal number of errors between the two groups. Yet, the relative number of errors in most of the categories is fairly similar for the hearing and deaf groups.

Figure 2 contains mean syntactic structures errors for children classified as operational $(n=34)$ on the conservation task versus children considered non-operational $(n=25)$, and Figure 3 provides this information for those children who passed the classification task $(n=34)$ compared to those who did not $(n=25)$. Figure 4 presents differences in mean syntactic structures errors for the children passing $(n=53)$ and failing $(n=6)$ the seriation 
$R$

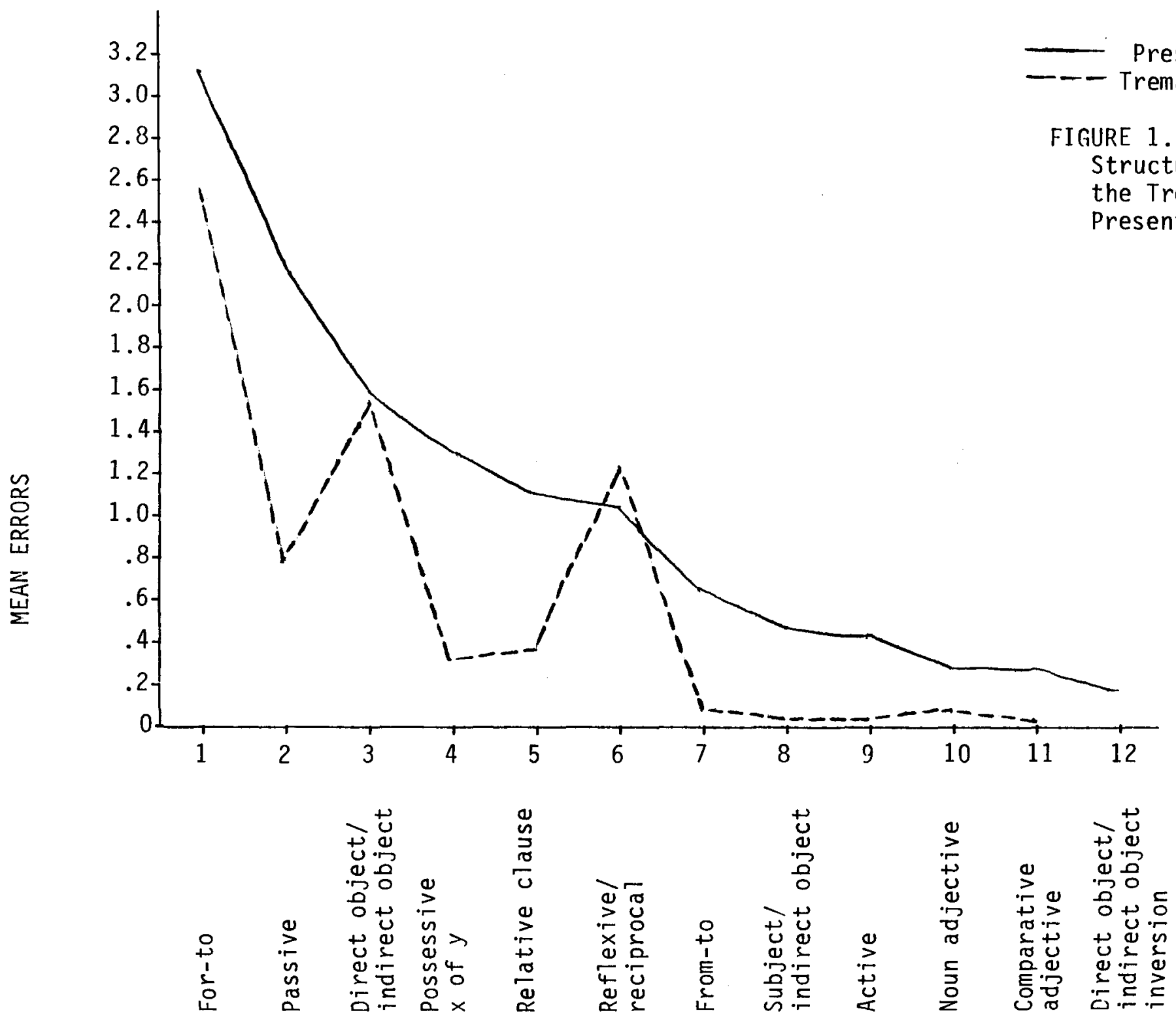




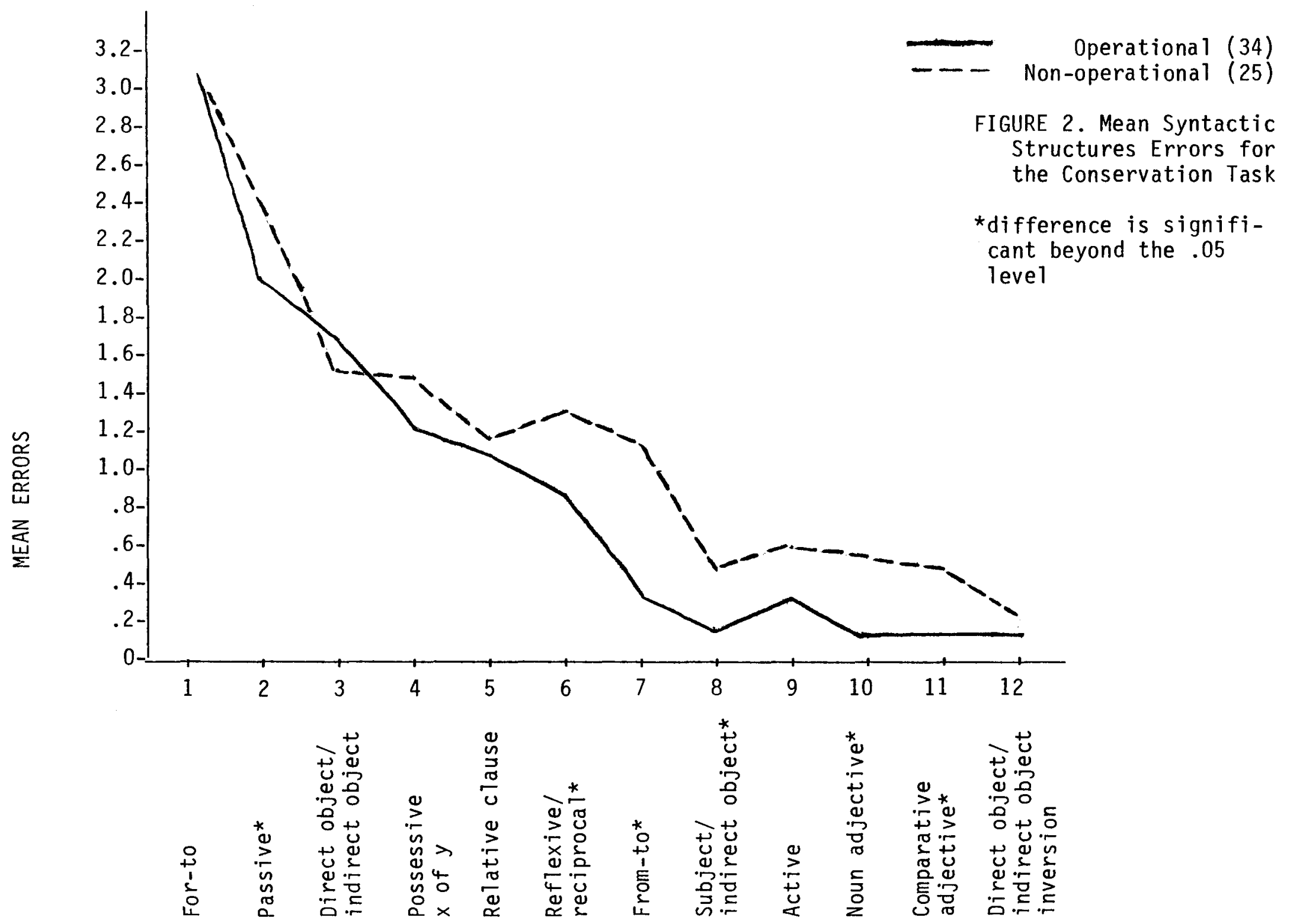




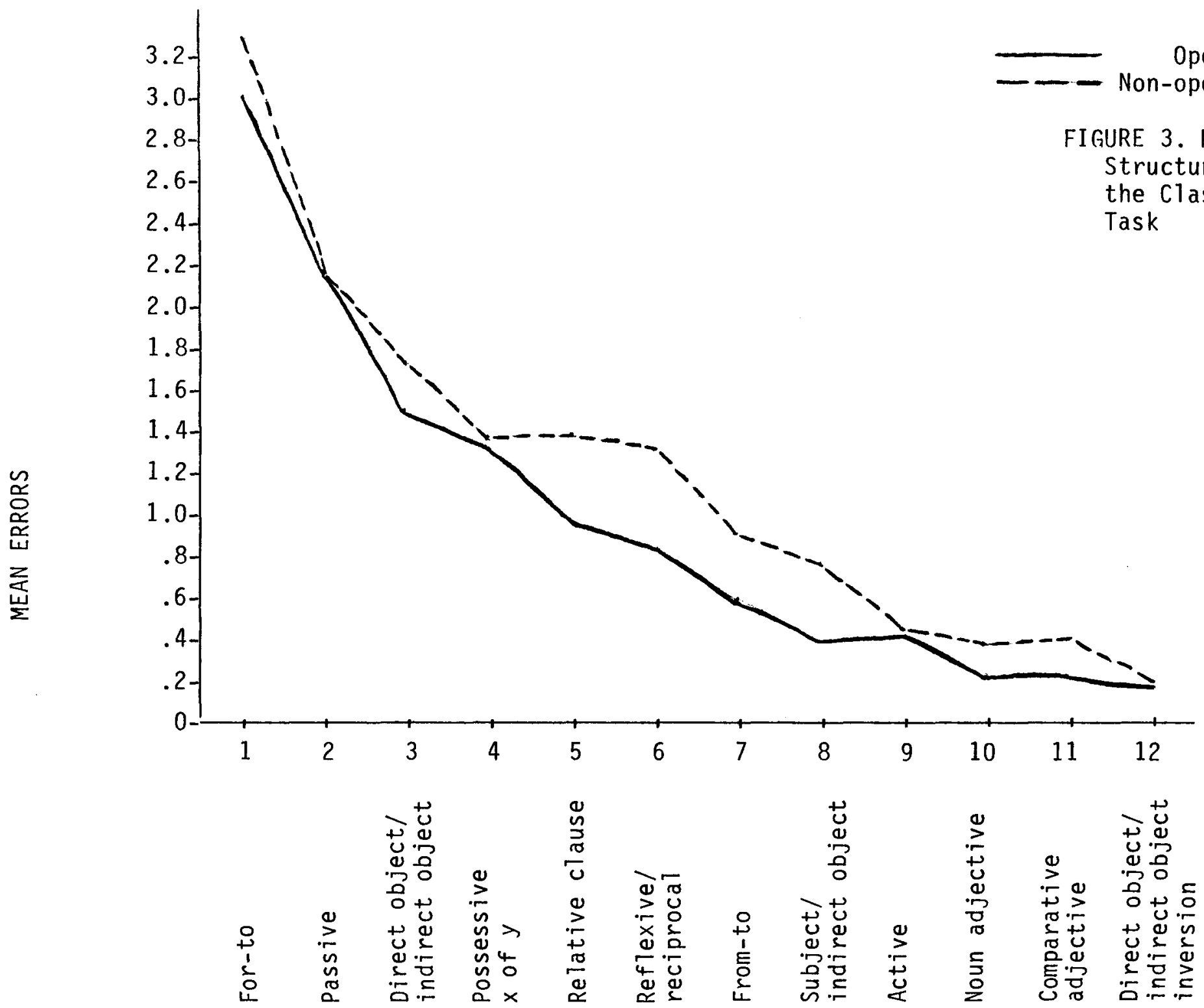




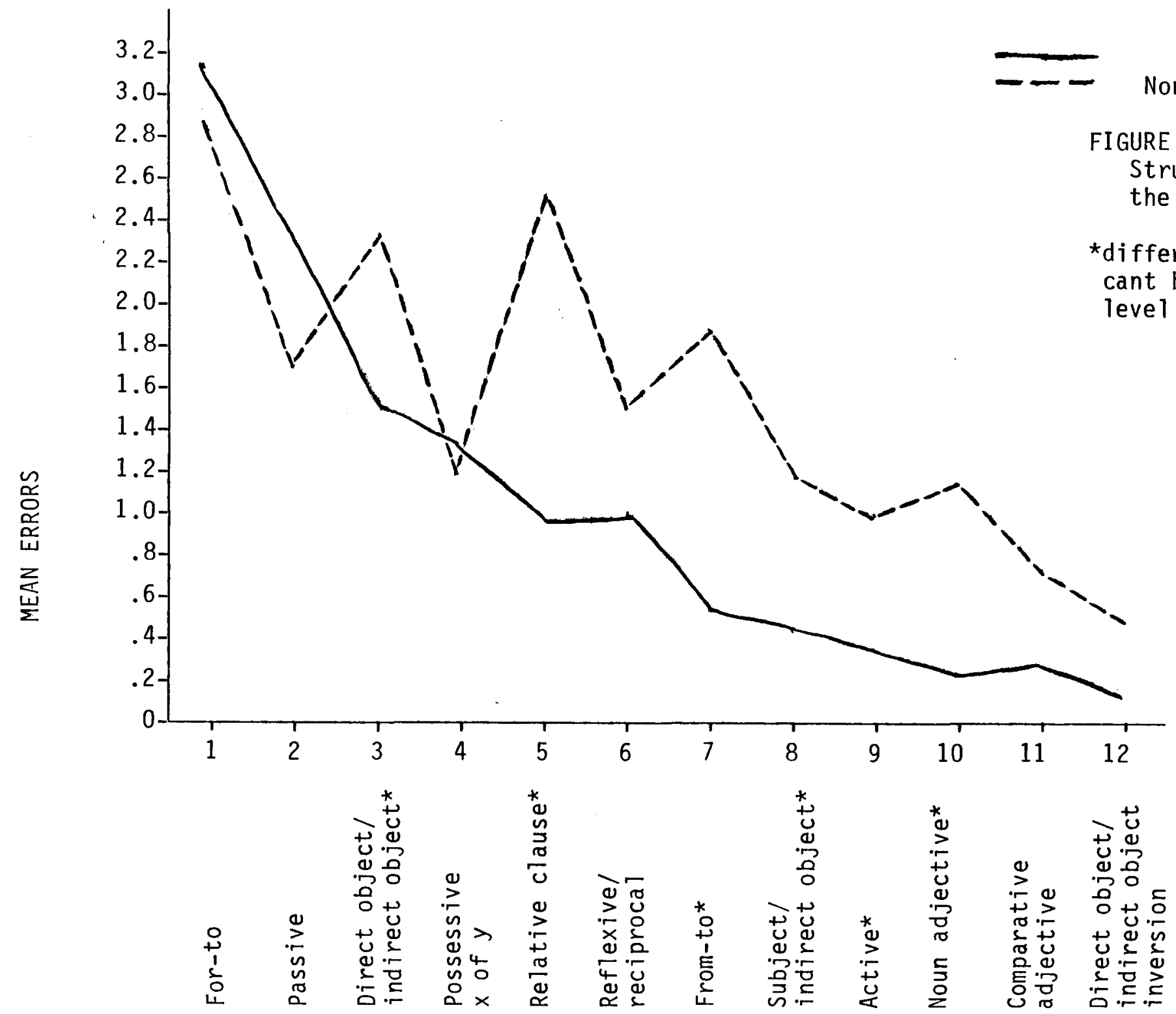


task, and Figure 5 presents the same data for those found operational $(n=20)$ and non-operational $(n=39)$ on the numeration task. Because the numeration task was a direct replication of Tremaine's study, her results are also included in Figure 5. On this task, operational deaf children made fewer errors on the reflexive-reciprocal structure than díd non-operational hearing children. Consistent with data from Figure 1, which lists total mean syntactic errors for the two studies, hearing children made fewer mistakes on all other structures.

Finally, Figure 6 presents differences in mean syntactic structures errors between the children $(n=12)$ considered predominantly operational (passing all four tasks) and children ( $n=14)$ classified as predominantly non-operational (failing all tasks or all except seriation). On all of these tasks in Figures 2-6, statistically significant differences are noted between operational and nonoperational children for each of the 12 grammatical categories. Children considered operational on the classification task did not perform significantly different from children considered non-operational (see Table 4); likewise, no statistical differences were noted in the mean number of errors earned by the two groups of children in any of the 12 gramatical categories (see Table 6 and Figure 3). In examining Figures 1-6, it should be remembered that on many tasks, most notably seriation, the number of subjects in each group differs considerably.

\section{Results Related to Hypothesis 2}

Hypothesis 2 stated that there are no significant differences on the test of English syntactic comprehension among deaf children 
$\stackrel{2}{\circ}$

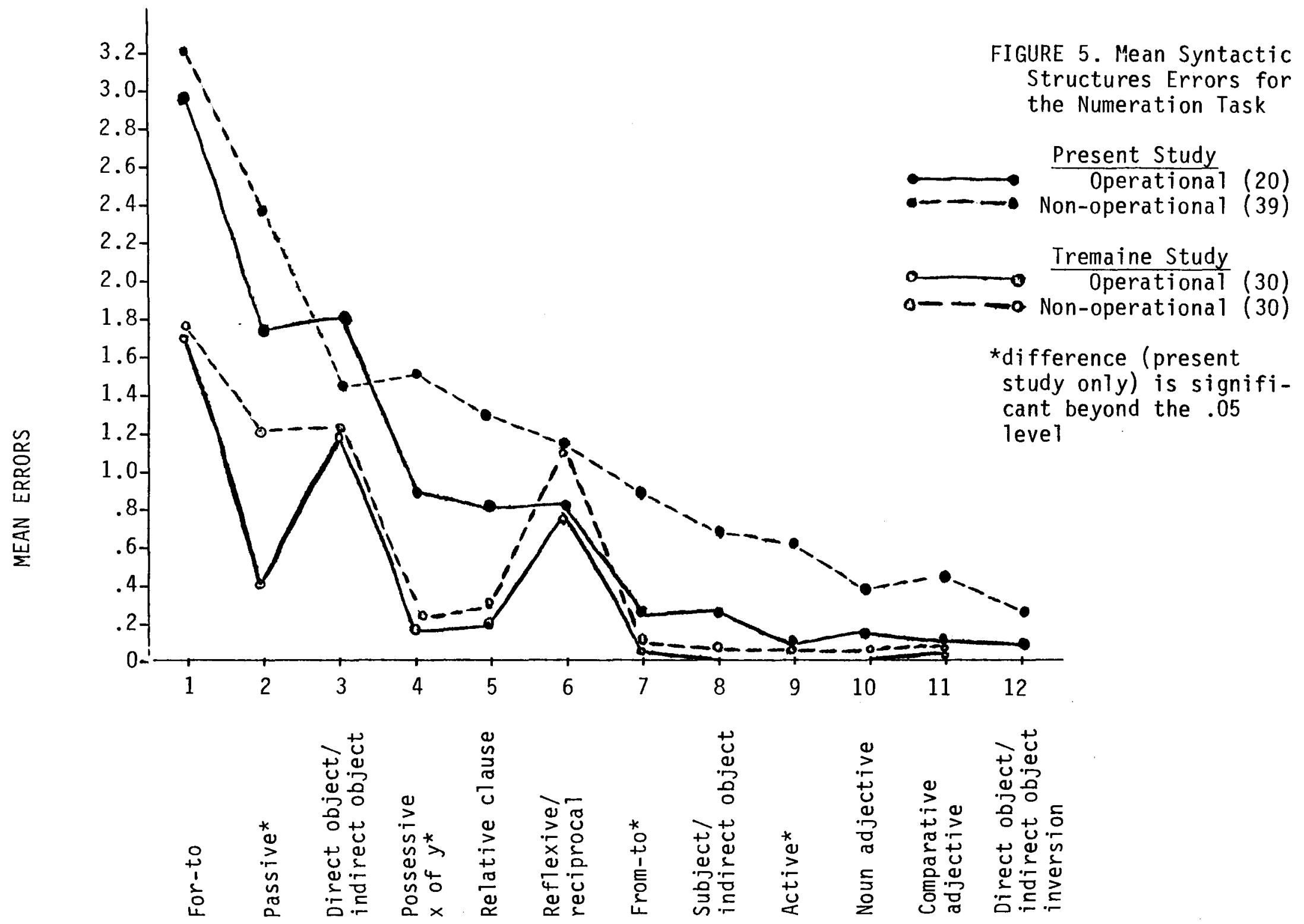




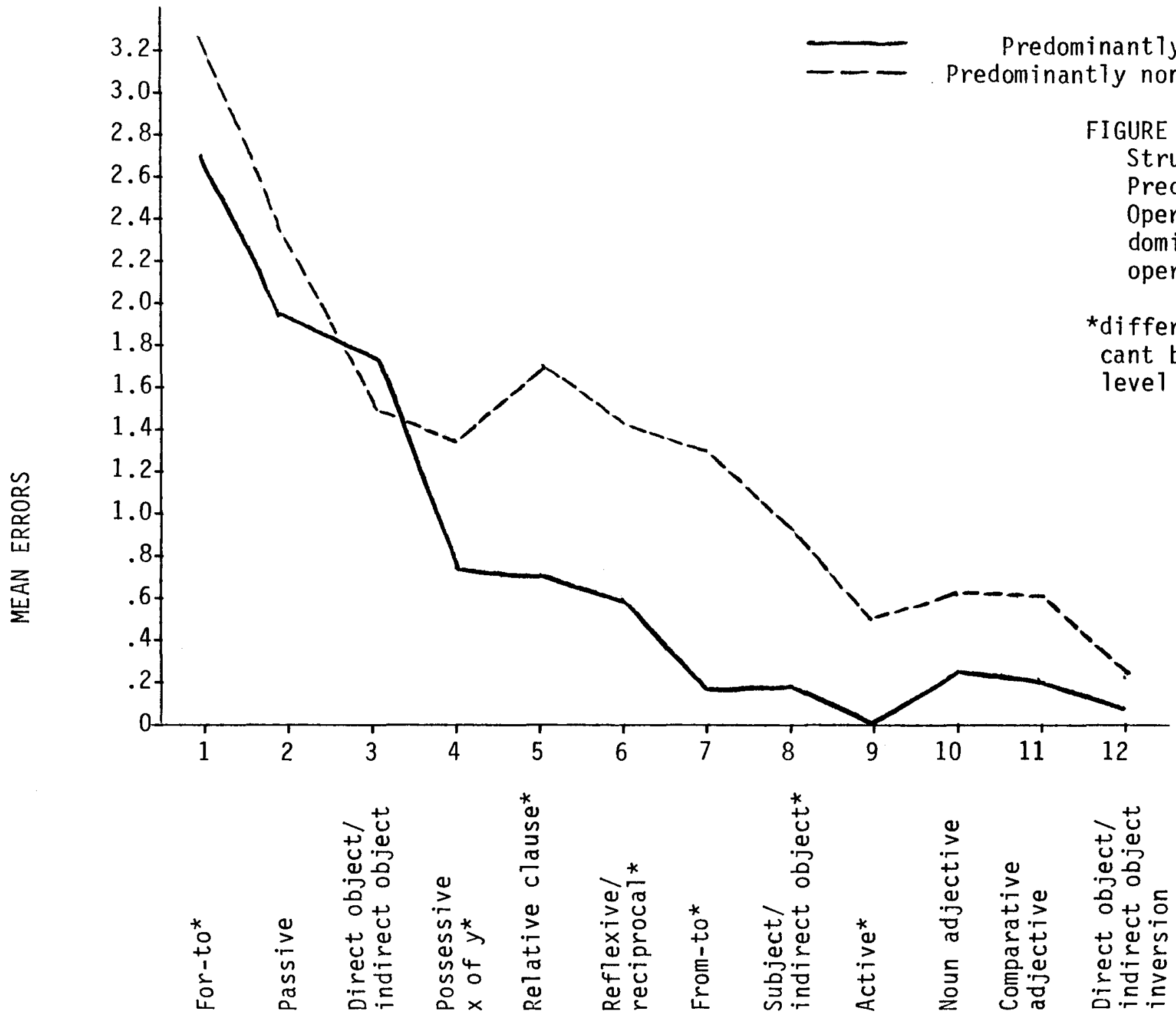


classified as having a strong American Sign Language (ASL) background, children having a strong manually coded English (MCE) background, and children having no consistent language (NCL) background.

A child was considered as having a strong ASL background (ASL group) if, on the sociolinguistic questionnaire given to the teacher (see Appendix B), responses indicated that both parents were deaf, the family signed consistently at home, and the child communicated most frequently with his or her parents through the use of ASL. All deaf children of deaf parents $(n=7)$ responded that their parents signed to them "very consistently" (\#5 on the questionnaire) and teachers related that, for all these children, ASL was the primary mode of communication (\#8 on the questionnaire). Children with a strong MCE background (MCE group) had hearing parents (\#1 on the questionnaire) who communicated "very consistently" (\#5) through signed English (\#8). Children with no consistent language background (NCL group) were those whose families communicated with them through signs "inconsistently", "almost never", or "never" (\#5). According to teacher responses on the sociolinguistic questionnaire, the ASL group contained seven students, the MCE group contained 17, and the NCL group contained 20, for a total of 44 . The 15 subjects who were not placed in any of the three groups were those whose families signed to them "somewhat consistently", according to \#5 of the questionnaire.

A simple one-way analysis of variance (ANOVA) found differences on the test of English syntactic comprehension among 
children judged as having consistent ASL language backgrounds, children with consistent MCE backgrounds, and children with no consistent language background. This finding led to a rejection of nu11 Hypothesis 2. ANOVA summary data for the relationship between the total score on the test of syntactic comprehension and the language background groups determined by the teachers may be found in Table 7 .

After the ANOVAs were calculated, a posteriori comparisons were figured by Tukey's HSD (honestly significant difference) test. This method, which is recommended for pairwise a posteriori comparisons (Kirk, 1968, pp. 88-90), was performed only on those ANOVAs which were significant at the .05 level or below and indicated that the ASL group differed beyond the .05 level of significance from the NCL group. A summary of the findings of Tukey's HSD test for Hypothesis 2 may be found in Table 8.

As shown in Table 8, differences in syntactic comprehension between the MCE and NCL groups were of similar magnitude to differences between the ASL and NCL groups. When ASL and MCE groups were combined into one group (consistent language background) and compared to the NCL group, the resulting level of significance (see Table 9) was similar to the level achieved when the ASL, MCE, and NCL groups were each treated separately (see Table 7). Results Related to Hypothesis 3

Hypothesis 3 stated that there are no significant differences on the four operational tasks (conservation, classification, seriation, and numeration) among deaf children classified as having a 


\section{TABLE 7}

Results Related to Hypothesis 2: Analysis of Variance for the Total Score on the Test of Syntactic Comprehension in Relation to the Child's Sign Language Background (ASL, MCE, or NCL), according to the Teacher $(n=44)$

Source

d.f. $\quad$ S.S. M.S. $\quad \underline{\text { Sig. }}$

Between

2

648.54

324.27

5.32 .0088

Within

41

2498.37

60.94 
TABLE 8

Results Related to Hypothesis 2: HSD Test for Differences among ASL, MCE, and NCL Groups in the Total Score on the Test of Syntactic Comprehension

Mean Difference

ASL/MCE groups

$66.14-65.88=.26$

n.s.

ASL/NCL groups

$66.14-58.25=7.89$

$<.05$

MCE/NCL groups

$65.88-58.25=7.63$

n.s. 
TABLE 9

Results Related to Hypothes is 2: T-test for the Total Score on the Test of Syntactic Comprehension in Relation to the Child's Sign Language Background (ASL and MCE versus NCL), according to the Teacher $(n=44)$

\begin{tabular}{ccccc}
\hline & $\underline{N}$ & Mean & Std. Dev. & Sig. \\
$\begin{array}{c}\text { Consistent Sign Background } \\
\text { (ASL and MCE) }\end{array}$ & 24 & 65.96 & 6.55 & .002 \\
$\begin{array}{c}\text { Inconsistent Sign Background } \\
(\mathrm{NCL})\end{array}$ & 20 & 58.25 & 8.92 & \\
\hline
\end{tabular}


strong ASL background, children having a strong MCE background, and children in the NCL group.

The method used to determine language background for $\mathrm{Hy}-$ pothesis 2 was used for Hypothes is 3 as wel1. Consequently, the teacher-chosen groups contained 44 subjects (seven in the ASL group, 17 in the MCE group, and 20 in the NCL group). A one-way ANOVA performed on the four operational tasks under the Method 1 scoring system led to a rejection of null Hypothesis 3 for the conservation task, but no group differences were found on the other three operational tasks. A summary of this ANOVA may be found in Table 10.

As with Hypothesis 2, Tukey's HSD test was indicated for the conservation task under Hypothes is 3 (see Table 11). When teachers judged the language backgrounds of students, the ASL group differed from the NCL group at the .01 level of significance. Again, as with Hypothesis 2, the ASL and MCE groups were combined into one group (consistent language background) and compared to the NCL group (see Table 12). Although the levels of significance on each of the four tasks changed from the levels attained when the three language background groups were treated separately (see Table 10), the conservation task remained the only task which differentiated groups with different language backgrounds beyond the .05 level of significance. A Fisher Exact Probability Test (for example, see Roscoe, 1969, pp. 219-221) was also administered to determine whether a relationship beyond chance existed between consistent (ASL or MCE) or inconsistent (NCL) sign language back- 


\section{TABLE 10}

Results Related to Hypothesis 3: Analys is of Variance for Operational Tasks in Relation to the Child's Sign Language Background (ASL, MCE, or $N C L)$, according to the Teacher $(n=44)$

$\underline{\text { Source }} \underline{\text { d.f. }}$ S.S. $\quad \underline{\text { M.S. }}$ F. Sig.

Conservation

Between

2

2.24

1.12

5.30

.0090

Within

41

8.67

.21

Classification

Between

2

.03

.01

.05

.9495

Within

41

10.95

.27

Seriation

Between

2

.12

.06

.56

.5775

Within

41

4.31

.11

Numeration

Between

2

.73

.37

1.55

.2249

Within

41

9.70

.24 


\section{TABLE 11}

Results Related to Hypothesis 3: HSD Test for Differences among ASL, MCE, and NCL Groups on the Conservation Task

\begin{tabular}{lll} 
ASL/MCE groups & $1.0-1.41=-.41$ & n.s. \\
ASL/NCL groups & $1.0-1.65=-.65$ & $<.01$ \\
MCE/NCL groups & $1.41-1.65=-.24$ & n.s. \\
\hline
\end{tabular}


TABLE 12

Results Related to Hypothesis 3: T-tests for Operational Ability in Relation to the Child's Sign Language Background (ASL and MCE versus $N C L)$, according to the Teacher $(n=44)$

Conservation

Consistent Sign Background (ASL and MCE)

Inconsistent Sign Background $(\mathrm{NCL})$

Classification

Consistent Sign Background

(ASL and MCE)

Inconsistent Sign Background (NCL)

Seriation

Consistent Sign Background (ASL and MCE)

Inconsistent Sign Background $(\mathrm{NCL})$

Numeration

Consistent Sign Background (ASL and MCE)

Inconsistent Sign Background (NCL)

$\underline{N}$ Mean St. Dev. Sig.

24

1.29

.46

.0169

20

1.65

.49

$\begin{array}{lll}24 & 1.46 & .51\end{array}$

.7889

20

1.50

.51

24

1.08

.28

.4992

20

1.15

.37

24

1.50

.51

.0939

20

1.75

.44 
ground and the presence of predominantly operational or nonoperational thinking. The relationship between these two variables did not reach the .05 level of statistical significance $(p=.336)$ for the 23 subjects considered.

\section{Results Related to Hypothesis 4}

This hypothesis stated that no significant relationship exists between IQ and operational thinking in deaf children. Table 13 lists the correlation coefficients indicating the strength of the relationship between IQ and operational thinking. The relationship between IQ and conservation ability was significant at the .0008 level, and a relationship beyond the .05 level was also indicated between IQ and classification and IQ and numeration. IQ and the predominance of operational or non-operational thinking were correlated at the .007 level of significance, but the relationship between IQ and seriation ability was not significant in this study.

\section{Results Related to Hypothesis 5}

Hypothesis 5 stated that no significant relationship exists between age and operational thinking in deaf children. Correlation coefficients, reported in Table 14, indicated a significant relationship between age and three of the four operational tasks. The relationship between age and the predominance of operational or non-operational thinking was significant at the .003 level, while the relationship between age and numeration ability did not reach the .05 significance level under Method 1 scoring. 
TABLE 13

Results Related to Hypothesis 4: The Relationship between IQ and Operational Ability $(n=50)$ 
TABLE 14

Results Related to Hypothesis 5: The Relationship between Age and Operational Ability $(n=59)$

Seriation 


\section{Results Related to Hypothesis 6}

This hypothesis stated that there is no significant relationship between age and syntactic development in deaf children. Null Hypothesis 6 was rejected. A relationship significant at the .007 level, with a correlation coefficient of .347 , existed between age and the total score on the test of syntactic comprehension for the 59 subjects.

\section{Results Related to Hypothes is 7}

The final hypothesis stated that there is no significant relationship between IQ and syntactic development in deaf children. With 50 performance IQ scores available, this null hypothesis was not rejected at the .05 level of significance since the relationship between these two variables, with a strength of .241 , was significant at the .092 leve1.

Results Related to Multiple Regression Analysis

A multiple regression analysis was undertaken to determine the best predictors of the total score on the test of syntactic comprehension. The variables included the child's age, IQ, overall signing ability, parents' hearing status (deaf or hearing), the age that the child learned signs according to the teacher, the teacher's report of how consistently the child's family signs at home, and Method 1 scores on the four operational tasks (conservation, classification, seriation, and numeration). Table 15, which presents the findings of this analysis, revealed numeration ability as the best single predictor of the total score on the test of syntactic comprehension, accounting for 37 percent of 
TABLE 15

Stepwise Multiple Regression Analysis for the Best Predictors of the Total Score on the Test of Syntactic Comprehension (Method 1 Scoring System, Teacher-reported Information)

\section{Variable}

Numeration

Overall Signing Ability

Seriation

Age Child Learned Signs,

Teacher Report

Sign Consistency at Home,

Teacher Report

Parents' Hearing Status

Classification

Conservation

IQ

Age
.004

.922

$-.782$

.564

$-8.401$

.370

$-3.390$

$-7.021$

1.273

$-.541$

2.067

.561

$$
.782
$$

.564

.000

.564 
of its variability. More than half (54 percent) of the total score could be predicted from three variables (numeration, the child's overall signing ability, and seriation). Other predictors are listed, in order of importance, in Table 15.

The finding that numeration was the best predictor of syntactic comprehension skills, with seriation a major predictor as we11, could be broadly interpreted as support for a stage theory viewpoint, since mastery of both of these tasks is considered characteristic of the operational stage of development. However, alternative interpretations to account for syntactic comprehension skills are also possible. Simple regression equations showed two of these possible alternatives, age $(R-S q u a r e=.120)$ and IQ ( $R$-Square $=.058)$, as inferior in predicting receptive grammatical skills in comparison to the numeration task.

$$
\text { Summary of Results }
$$

Because of the high correlation between Method 1 and Method 2 scoring systems and between teacher-reported and child-reported answers to the sociolinguistic questionnaire, only data from the Method 1 scoring system and from teacher responses were reported in this chapter.

Rejection of null Hypothesis 1 indicated that significant differences existed between deaf children considered predominantly operational and deaf children considered predominantly non-operational on a test of English syntactic comprehension. Of the four operational tasks considered, children classified as operational on the conservation, seriation, and numeration tasks differed significantly in 
grammatical ability from their non-operational counterparts, while children considered operational on the classification task did not. Furthermore, rejection of nul1 Hypothesis 2 indicated that significant differences existed among English syntactic abilities depending on the children's language backgrounds. The ASL and MCE groups showed essentially no difference in syntactic comprehension skills, but both groups were superior to the NCL group. Partial rejection of null Hypothesis 3 indicated that, for the conservation task, a significantly higher proportion of children in the ASL group were operational than were children in the MCE or NCL groups. However, no such relationship between language background and operational ability was found for the classification, seriation, or numeration tasks. Partial rejection of null Hypothesis 4 indicated that a relationship existed between IQ and operational thinking for the conservation, classification, and numeration tasks but not for the seriation task. In addition, predominantiy operational children (passing all four tasks) had higher IQs than predominantly non-operational deaf children. Partial rejection of null Hypothesis 5 indicated that age was related to operational thinking beyond the .02 level of significance for all tasks except numeration. Predominantly operational children were older than predominantly non-operational children. Rejection of null Hypothesis 6 indicated that a significant relationship existed between age and syntactic development. Nul1 Hypothesis 7 was not rejected. No significant relationship was found between IQ and syntactic comprehension skills. 
Finally, a multiple regression analysis indicated that numeration was the best single predictor of the total score on the test of syntactic comprehension and that numeration, the child's overall signing ability, and seriation accounted for over half of the total variability on this measure. 


\section{CHAPTER V}

\section{DISCUSSION}

Building upon Tremaine's (1975) finding that a relationship exists between the attainment of concrete operations and syntactic comprehension skills in hearing children, the present investigation found that this same relationship exists in deaf children. In addition, the study examined the role of sign language background in determining operational skills and syntactic abilities, the relationship among operational thinking, age, and IQ in deaf children, and the relationship among syntactic development, age, and IQ in this same group of children. Each of these relationships is discussed in some detail later in this chapter; for the present, however, it may be useful to acknowledge some general limitations of the project.

In almost any research involving deaf children, the recruitment of subjects presents a problem. As Brill (1975) noted, deaf and severely hard of hearing children form only about .01 percent of the school age population. Besides accepting only those children with severe-to-profound and profound hearing losses, this study required subjects to have performance IQ scores above 87 , with no additional handicapping conditions which might interfere with learning, and to be enrolled in grades two through nine. In the entire Lake County, Illinois area, which serves a school age popu- 
lation of almost 70,000 students, only 14 children met the requirements for inclusion in this study. For this reason, randomization of subjects was not possible and other problems (missing IQ scores, the lack of any minority children) were, of necessity, encountered. The decision was made, however, to include all subjects who met the minimal criteria (see Chapter III).

Within this small population of eligible deaf children, finding children of deaf parents presented an even greater problem. Rawlings (1973) stated that less than 10 percent of deaf children have deaf parents. While the present study, with seven deaf children of deaf parents out of 59 children, offered a slightly higher percentage (12 percent), it is nevertheless difficult to generalize results found with seven subjects to all students with American Sign Language (ASL) backgrounds, even though, as will be discussed, results from these seven students generally conformed to other studies dealing with deaf children of deaf parents.

It is also important to note that these students, along with the 52 deaf children of hearing parents, had higher mean performance IQ scores than are usually found in groups of deaf students. With a sample of about 1200 deaf children, Anderson and Sisco (1977) found a mean WISC-R Performance IQ for deaf children of deaf parents $(n=100)$ of 106.7 , with a standard deviation of 12.3 , and a mean WISC-R Performance IQ for deaf children of hearing parents $(n=1100)$ of 96.0, with a standard deviation of 15.7. IQ scores from the present study differed from those of the Anderson and Sisco study at the .05 level for children with deaf parents and beyond the 
.01 level for children with hearing parents. Although these scores cast some doubt on the generalizability of the present findings to all deaf children, it should be remembered that students with IQS below 88 were automatically excluded, as were students with other recognized learning problems. Because of these subject selection procedures, it is perhaps best to generalize the present results only to non-minority deaf children with average or above average IQs. With this caveat, a discussion of results found for each of the seven hypotheses follows, after which a general discussion along with suggestions for future research is presented.

\section{Discussion Related to Hypothes is I}

The first hypothesis found that differences exist between deaf children considered operational and deaf children considered non-operational in their comprehension of English syntax, with differences in favor of the operational children on tasks of conservation, seriation, and numeration at or beyond the .001 level of significance. Significant differences also existed between children considered predominantly operational (passing all tasks) and predominantly non-operational (failing all tasks except seriation). Although this same relationship was indicated by the classification task, differences in syntax scores between operational and non-operational children did not reach the .05 level of significance. During the testing sessions, it was noted by the examiners that the classification task was difficult for many of the students to understand. For example, when a question like, "Do you see more birds, or do you see more white animals? Or are they the same 
(equa1)?" (see Appendix D), several students responded with a number. It is likely that, more than the other operational tasks, the classification task was confounded by difficulty in understanding the directions.

The presentation of the directions was somewhat of a dilemma on the other tasks as well. While remaining faithful to Piaget's original directions was a worthwhile goal, it was also necessary to explain the tasks in such a way that deaf second-graders could understand them. The screening items, passed by a 11 students, demonstrated in a gross way an understanding of the concepts "how many", "more", and "equal". As the classification task indicated, however, comprehension of general directions was more difficult, even when Rittenhouse and Spiro's (1979) attribute-specific instructions were used. Yet, at least for the conservation, seriation, and numeration tasks, it seems that the use of simplified directions, and the imediate comprehension of the task requirements shown by most students, more than compensated for the modification of Piaget's original instructions.

The present study supported the findings of Rittenhouse et a]. (1981) that operational abilities relate to language abilities in deaf children. The Rittenhouse et al. study examined only conservation abilities in relation to metaphor comprehension, while the present study related general syntactic comprehension to operational skills in four different areas. The present findings indicated that deaf children have a great deal of difficulty understanding the for-to structure ("The baby gives the ball for the cat 
to the dog"), the most difficult structure for Tremaine's hearing children as well. Although the general pattern of errors is similar for the Tremaine study and the present study, on all structures except the reflexive-reciprocal ("The boys see themselves; the boys see each other") hearing children, who averaged 4.28 years younger than the deaf group, made fewer errors. In addition, proportionately more of these same hearing children demonstrated operational thinking than did their deaf counterparts. This finding that deaf children are delayed in reaching concrete operations has been we 11-documented by others (Furth, 1964, 1966, 1971; 01eron and Herren, 1961; Templin, 1967), who have found lags generally ranging between two and six years.

The differences between deaf and hearing children in the relative number of errors made can perhaps be attributed to deafness itself. While normal children are likely to hear the passive voice and other complex structures used several times throughout the day, profoundly deaf children seldom are exposed to them and, as Russell et al. (1976, p. 96) and the present study indicated, have little mastery of them. Easier structures are those to which students have had more exposure ("The baby sees the girl") or which make logical sense based, for example, on word proximity within the phrase ("The dog with a big bal1"). More difficult are those structures which offer no word proximity clues ("The girl shows the cow to the dog") or which are not used in daily conversation with and by deaf children ("The plane of the pilot"). It should be noted that the one structure in which operational deaf children out- 
performed non-operational hearing children, the reflexive-reciprocal, was considered a poor test item by Tremaine. She noted that in this contrast ("The boys see themselves; the boys see each other"), the picture of the boys seeing themselves in the mirror could have been interpreted as the boys seeing each other. To get the item correct, the child had to pay close attention to the eyes of the people in the pictures. It is possible that deaf children have a greater tendency to note visual cues, such as the direction in which the eyes were gazing and, for that reason, scored higher.

As in the Tremaine study, the present study found that the number of non-operational children on the seriation task was very small in comparison with the other tasks and that the numeration task was the best overall predictor of syntactic comprehension. Tremaine attributed this latter finding to the nature of the numeration task, in which the child reasoned about seriated objects while imposing a hierarchy on the series. According to Tremaine, the analytic properties of syntax for comprehension of speech (and, presumably, sign language) are similar in that to understand what is said, the listener (or viewer) must impose a hierarchical structure (syntax) on a series of meaningful units which temporally unfold. Differences between operational and non-operational deaf children on the numeration task were most pronounced for the passive, from-to ("The baby goes from the window to the door"), possessive $x$ of $y$ ("The plane of the pilot"), and active structures. Non-operational deaf students, however, made fewer errors on the direct object-indirect object structure ("The girl shows the cow 
to the dog") than did their operational deaf counterparts, a relationship which also held true for the conservation and seriation tasks as we 11 as for those students considered predominantly operational or non-operational. Reasons to explain the superiority of nonoperational children on the direct object-indirect object structure are admittedly speculative, but it is possible that the operational children were consistently applying a rule, albeit incorrectiy, while the non-operational children were making choices more at random which, in this case, resulted in more correct answers.

Despite this one exception, it seems clear that deaf and hearing operational children generally demonstrated greater understanding of English syntactic structures than did deaf and hearing non-operational children. Researchers (for example, Tremaine, 1975, p. 56) offer an explanation for this finding by suggesting that reaching the concrete operational level influences syntactic development in that new abilities for reordering and reclassifying units become available. Through reversibility principles, operational thought allows the child to consider structures as identical, even when their parts are regrouped or serially arranged.

\section{Discussion Related to Hypothesis 2}

Hypothesis 2 stated that significant differences exist between deaf children's English syntactic abilities depending on their language backgrounds. Both the ASL and MCE groups were superior to the NCL group, a finding which supports the research of Brasel and Quigley (1975) dealing with sign language differences. They found that ASL and MCE groups were superior to chi Tdren with 
intensive oral practice or with no special method and that the MCE group held a slight, though statistically insignificant lead over the ASL group. While the present study found that the ASL group was somewhat superior, again to a statistically insignificant degree, both studies confirmed the importance of a consistent language background.

At first glance, it may seem strange in the present study that the ASL group outperformed the MCE group in the area of English syntax, since, presumably, English functions as a first language for the MCE group and a second language for the ASL group and since the structure of ASL is very different from that of English (Bellugi, 1980). When one takes into consideration, however, the differences in language consistency between children in the ASL and MCE groups, the better performance of ASL children is not as difficult to understand. Deaf children of deaf parents have probably had about as much exposure to language as hearing children of hearing parents. But except in a few homes, the exposure is likely to be considerably less for deaf children of hearing parents. In many cases, these parents, as well as siblings, use MCE only to communicate directly with the deaf child who, for that reason, misses the "eavesdropping" opportunities afforded to his or her ASL peers. In addition, because most hearing parents and siblings learn MCE only after the birth of the deaf child, they are not as comfortable using it as are deaf parents and are more likely to communicate only essential information. 
MCE groups call attention to the difficulty of objectively classifying students according to sign language background. In responding on the sociolinguistic questionnaire that the child's. family signs "very consistently" at home, the teacher may be using different standards of consistency (that is, consistently signing directly to the child versus consistently signing in 211 conversations) for children with hearing parents than for children with deaf parents. A kind of "halo effect" may also be in evidence, with those children known to have good English syntactic skills also judged to have consistent sign language input at home. While the rather unscientific, yet systematic way in which sign language background and sign language consistency were determined (through the use of a questionnaire) may be considered a weakness of this project, Spragins and Cokely (1980) noted that no quantifiable methods exist at the present time. In addition, the very close agreement between teachers and the children themselves concerning the degree of sign consistency at home may lend credibility to the use of the questionnaire to group the children.

One point which bears emphasizing is that the test of English syntactic comprehension is not synonymous with either expressive English skills or with linguistic competence in general. An initial concern was that a test of English syntax would not adequately tap the language skills of any group whose primary language was not English. The point is well-taken. Although Tremaine (7975, p. 48) suggested that when children learning a second language (English for the ASL group) reach the level of concrete operations, 
comprehension of the syntax of both their native and second language improves greatly, a test of ASL comprehension may have been able to discern with more accuracy differences between operational and non-operational children whose primary language was ASL. The administrative and methodological problems involved, however, precluded such an undertaking. Not only would it have been difficult to administer a test of ASL comprehension which tapped the areas covered by the test of English comprehension for the MCE group, it would have been almost impossible to find an equivalent test to give to the $\mathrm{NCL}$ group which, by definition, had no adequate language background. It must be admitted, therefore, that the present study had a bias toward English competence. While such competence cannot be equated with general linguistic ability, it serves as the primary focus of most school programs for the deaf in the United States and, for that reason, is of interest in its own right.

\section{Discussion Related to Hypothesis 3}

Results related to Hypothesis 3 indicated a limited relationship between sign language background (ASL, MCE, or NCL) and operational ability. Classification, seriation, and numeration were not related to the language background of the child, but children with ASL backgrounds performed significantly better on the conservation task. When Method 2 scoring was used or when language groups were chosen by the children, however, a significant relationship was also found for the numeration and classification tasks (see Appendix I).

At first glance, these results are puzzling. Finding no 
relationship at al1 between sign 1 anguage background and operational ability would offer support for the Piagetian view (1973, p. 118) that a strong language background is not sufficient to assure the development of operational structures. Yet, the fact that a significant relationship exists between ASL background and conservation does not allow for unconditional support of Piaget's hypothesis. Likewise, the fact that no significant relationship was found between ASL and numeration, for example, or between MCE and any of the four tasks makes it difficult to accept the view that ASL in itself or a consistent language background of any kind is the critical factor in determining operational success. The picture is further complicated by results from the Method 2 scoring system or when language groups were determined by the child; under various combinations of these conditions, all tasks except seriation were at some point related to language background.

The very smal1 number of children who were consistently operational or consistently non-operational from each of the three language backgrounds made a factorial comparison of these groups impossible. Nevertheless, a trend may be seen. Twentynine percent of both the ASL and MCE groups were predominantly operational, with only 15 percent of the NCL-group at this leve1. None of the ASL group was consistently non-operational, but 29 percent of the MCE group and 40 percent of the $N C L$ group were. Although specifying a general relationship between sign language background and operational skills is not possible, the results of this study are consistent with those of Furth (1964, 
1971, 1975) and others, who compared deaf to hearing children. Children with stronger language backgrounds (hearing children) often scored somewhat better on cognitive tasks than did children with weaker language backgrounds (deaf children). The poorer performance of children with weaker language backgrounds, however, was not consistent across tasks and took the form of a delay rather than clearcut cognitive inferiority. Similarly, results from the present study found that those deaf children with stronger sign language backgrounds (especially ASL) tended to perform better on cognitive tasks than did deaf children with poorer sign language backgrounds. Yet, like Furth's studies comparing deaf to hearing children, results do not consistently or strongly support the thesis that language is critical for the development of cognitive structures. Discussion Related to Hypothesis 4

The fourth hypothesis found that a relationship exists between IQ and the conservation, classification, and numeration tasks and that predominantly operational deaf children had higher IQs than predominantly non-operational deaf children. Only the seriation task revealed no relationship to IQ score. This finding may be explained by the fact that 45 of the 50 children for whom IQ scores were available passed the seriation task. Because of this very high success rate, it is not surprising that performance on the seriation task did not differentiate between children with higher and lower IQs.

Differences between intelligence tests and operational tasks deserve some mention. An intelligence test is designed 
to discriminate children at one-year intervals and, for that reason, most children experience steady, gradual gains in raw scores unti 1 about the age of 18. Operational intelligence, however, does not improve as a linear function of age but follows a pattern of sudden and rapid improvements followed by a plateau period. Despite these differences, the findings of the present study indicating that IQ is related to operational tasks in deaf children were consistent with studies of hearing children, Orpet and Meyers (1970) found that the picture arrangement task on the Wechsler Scale of Inte1ligence for Children (WISC) differentiated conserving from nonconserving children, and Dudek et a1. (1969) found that Piagetian tasks were highly correlated with WISC subtests in general. Discussion Related to Hypothesis 5

Results from testing this hypothesis indicated that age is related to operational thinking beyond the .02 level of significance for the conservation, classification, and seriation tasks and that predominantly operational children were older than predominantly non-operational children. Although the relationship between age and numeration ability was not strong enough to be statistically significant under Method 1 scoring (the relationship was significant under Method 2 scoring; see Appendix $H)$, the trend points to an association between these two variables.

The discovery that age was related to operational ability is not surprising. In Piaget's theory, stages of cognitive development are characterized as occuring within certain age boundaries. While the delay experienced by deaf children in 
reaching the operational stage has been noted by other researchers (Furth, 1964, 1966, 1971; 0leron and Herren, 1961; Templin, 1967) and corroborated by the present study, a relationship between age and operational thinking apparently exists for both hearing and deaf children.

\section{Discussion Related to Hypothes is 6}

Like results from Hypothesis 5 , the finding related to Hypothesis 6 that age was related to syntactic development in deaf children is not unexpected. In her study, Tremaine (1975, p. 49) found that children in the higher grades had better syntactic comprehension skills than children in lower grades. Despite the existence of a relationship between age and syntactic development, however, simple and multiple regression analyses indicated that age was a relatively poor predictor of syntactic skills in comparison to operational abilities, sign language skills, and sign language background.

\section{Discussion Related to Hypothesis 7}

Results from Hypothesis 7 indicated no relationship between IQ and syntactic comprehension skills in deaf children. Tremaine (1975, p. 48) pointed out that mental age should be related to syntactic comprehension because both improve with chronological age. Recognizing differences between the concepts of IQ and mental age (IQ compares the child to same-age peers while the mental age score compares him to children at his intellectual level), one might still expect IQ to be correlated with syntactic comprehension skills. That such a relationship did not exist in deaf children lends credence to the claim of lack of language bias in the per- 
formance scales of the WISC-R and other tests frequently administered to hearing impaired children. These findings also demonstrate the relative importance of factors within the parents' control (sign language consistency at home) in developing syntactic competence over factors which, arguably, are less within their control (performance IQ scores). Finally, they offer strong supportive evidence for the efficacy of looking at intellectual structures within an operational rather than an IQ framework, at least in relation to syntactic abilities. While numeration and seriation skills together accounted for almost half of the total variability on the test of syntactic comprehension, IQ alone accounted for less than six percent.

General Discussion and Implications for Further Research

Kessler (1971) observed that rule stabilization in syntax and equilibration in Piagetian theory occur in conjunction with each other, just as results from this study and Tremaine's (1975) have indicated that syntactic comprehension skills take a leap forward when the child (even one with a severe sensory deficit) reaches the level of concrete operations. However, Menyuk (1975) noted the difficulty of assigning causality in the areas of language and cognition. Even when relationships between the two areas exist, it is scientifically unjustifiable to claim that one is a prerequisite for the other. Both the present research project and Tremaine's work were correlational in nature, and it is not within the scope of these studies to state that the acquisition of syntactic comprehension skills is the result of 
operational thinking or vice versa, Nevertheless, the possibility of such a cause-and-effect relationship cannot be ruled out.

In addition to addressing global questions pertaining to language acquisition and cognitive development, the present study has addressed itself to issues specific to the field of deafness. The not-unexpected result from the multiple regression analysis that sign consistency at home and the age that the child learned signs, as well as operational ability, relate to English comprehension skills has important implications for the education of deaf children and their parents. The statistically insignificant superiority of ASL users over MCE users is not great enough to justify Stokoe's (1974) claim that all deaf children should first gain competence in ASL and then learn English (and MCE) as a second language. Knight's (1979) view that consistency is the key, rather than a particular language form, seems more on target. Because ASL is a difficult language for hearing adults to learn and because the slight superiority in English skills found in ASL users cannot necessarily be attributed to ASL in itself, this researcher found no justification for advocating the use of ASL to teach English syntactic skills. What is important, however, is some type of consistent language exposure. The $\mathrm{NCL}$ group had poorer English skills and tended to lag behind their deaf peers in operational abilities as well. The possibility that lack of language input may lead to organismic differences in brain hemispheric laterality (Kelly and Tomlinson-Keasey, 1977) underscores the importance of providing the deaf child with as many language- 
related experiences as possible,

Further research in the area of deafness, operational thinking, and language skills might delve further into the implications of bilingualism. Tremaine (1975, p. 50) has suggested that Englishspeaking children improved in both English and French syntactic comprehension when they reached the operational level because of the similarities between the two languages. Bellugi (1980) has pointed out that ASL is more like Navajo, Greek, and Russian than English, and the present study showed that ASL users make syntactic gains in their non-native language (English) upon the attainment of concrete operations. The question remains: What kind of linguistic gains are made in their native language, ASL, and do these gains parallel in form and extent those made in English comprehension? Coupled with this research suggestion is the necessity to improve instruments for studying sign language variations. Although questionnaires and interviews define the current state of the art, more objective measures should be developed, perhaps through the use of videotapes, to determine the deaf child's preferred mode of communication. Another possibility for further research is to extend this study to other groups of children with special characteristics. How do oral deaf children, hearing children from culturally deprived homes, blind children, or learning disabled children perform linguistically when they reach the level of concrete operations? Are certain aspects of operational intelligence more specifically related to syntactic comprehension than others for these and for normal children? 
The present study has not attempted to define whether thought determines language or whether language determines thought. Piaget (1967, p. 98) said that "language and thought are linked in a genetic circle where each necessarily leans on the other in interdependent formation and continuous reciprocal action", but he went on to say that language is not a sufficient condition for the construction of logical operations. While results from the present study do not warrant statements of causality, it is clear that when children, even profoundly deaf children, begin to think operationally, corresponding changes occur or have already occured in their ability to manipulate language. 
CHAPTER VI

SUMMARY

Tremaine (1975) found that bilingual hearing children made gains in both native and second language comprehension when they reached the level of concrete operations. Building on this finding, the present study examined the linguistic and cognitive skills of 59 severe-to-profound and profoundly deaf children between the ages of seven and 12. Through the use of manually coded English, students were administered four Piagetian operational tasks in the areas of conservation, classification, seriation, and numeration and a test of syntactic comprehension modeled after Tremaine's. In addition, students and teachers were given a sociolinguistic questionnaire to determine the hearing status of the child's parents, the age the child learned signs, the sign language consistency at home, and other information pertaining to the child's Tinguistic background. Teachers and students showed a high degree of agreement in their responses to this questionnaire.

Results indicated that operational deaf children performed significantly better than non-operational deaf children on the test of syntactic comprehension, although both groups of children had poorer English skills and a lower rate of operational thinking than did the much younger hearing students in Tremaine's sample. A relationship was found between operational thinking, age, and 
IQ of the subjects as well as between age and syntactic skills, but no relationship was indicated between syntactic skills and IQ, Students whose parents consistently signed to them, whether through American Sign Language or manually coded English, showed greater English syntactic comprehension than did students whose parents signed less consistently. The children with more consistent sign language exposure at home also tended to have more advanced operational skills, though not to a statistically significant degree. In both operational level and English syntactic skills, a slight advantage was found for those children using American Sign Language at home rather than manually coded English. This finding may be explained by the greater degree of sign consistency likely to be experienced by those children whose deaf parents use American Sign Language. The tendency toward greater operational abilities in children with more consistent sign language background supports other research which views language as facilitative but not critical for the development of cognitive abilities. Finally, a multiple regression analysis indicated that more than half of the total variability on the test of syntactic comprehension could be predicted from success or failure on two of the operational tasks (numeration and seriation) and the child's overall signing ability, with age and IQ much less predictive of English proficiency. 


\section{REFERENCES}

Anastasi, A. Psychological testing. New York: Macmillan, 1976. Anderson, R. J., and Sisco, F. H. Standardization of the WISC-R performance scale for deaf children. Series T, Number 1 . Washington, D. C.: Office of Demographic Studies, Gallaudet College, 1977.

Anthony, D. Signing essential English. Anaheim, Ca.: Anaheim Union School District, 1971.

Balow, I. H. and Brill, R. An evaluation study of reading and academic achievement levels of 16 graduating classes of the California School for the Deaf, Riverside. Mimeo report, Contract \#4566 with the State of California, Department of Education, 1972.

Bellugi, U. How signs express complex meaning. In C. Baker and R. Battison (Eds.), Sign language and the deaf community. Washington, D. C.: National Association of the Deaf, 1980, 53-74.

Bellugi, U. Learning the language. Psychology Today, $1970, \underline{4}$, 33-35.

Bellugi, U. and Klima, E. S. The roots of language in the sign talk of the deaf. Psychology Today, $1972,6,61-64 ; 76$. Benderly, B. Dancing wi thout music. Garden City, New York: Anchor Press/Doub leday, 1980. 
Best, B. Development of classification skills in deaf children with and without early manual communication. Unpublished PhD. dissertation, University of California, Berkeley, 1970. Bever, T. Associations to stimulus-response theories of language. In T. R. Dixon and D. L. Horton. (Eds.), Verbal behavior and general behavior theory. Englewood Cliffs, N. J.: Prentice Hal1, 1968, 478-494.

Bever, T. Some theoretical and empirical issues that arise if we insist on distinguishing language and thought. Annals of the New York Academy of Sciences, $1975,263,76-83$.

Blank, M. Mastering the intangible through language. Annals of the New York Academy of Sciences, 1975, 263, 44-58.

Blank, M. Use of the deaf in language studies: A reply to Furth. Psychological Bulletin, 1965, 63, 442-444.

Bonvillian, J. D., Nelson, K. E., and Charrow, V. E. Language and language-related skills in deaf and hearing children. Sign Language Studies, $1976, \underline{12}, 211-250$.

Bornstein, H. New signs ... the pros. Gallaudet Today, 1974, $\underline{5}, 4-5$.

Bornstein, H., Saulnier, K. L., and Hamilton, L. B. Signed English:

A first evaluation. American Annals of the Deaf, 1980, 125, $467-481$.

Bornstein, H., Saulnier, K., Hamilton, L., Kannapell, B., and Roy, H. Basic pre-school signed English dictionary. Washington, D. C.: Gallaudet College, 1973.

Brasel, K., and Quigley, S. P. The influence of early language 
environments on the development of language in deaf children.

Champaign, I11.: Institute for Research on Exceptional Children, 1975.

Brill, R. The education of the deaf. Washington, D. C.: Gallaudet College, 1974.

Bri11, R. Mainstreaming: Format or quality? American Annals of the Deaf, $1975,120,377-381$.

Bril1, R. Problems in testing and evaluating deaf students. First Friday Research Seminar. Washington, D. C.: Mode1 Secondary School for the Deaf, 1977.

Bruner, J. The course of cognitive growth. American Psychologist, $1964, \underline{19}, 1-15$.

Caccamise, F., Hatfield, N., and Brewer, L. Manual/simultaneous communication research: Results and implications. American Annals of the Deaf, 1978, 123, 803-823.

Charrow, V. Deaf English: An investigation of the written English competence of deaf adolescents, Psychology and Education Series, Institute for Mathematical Studies in the Social Sciences. Stanford University. Technical report No. 236, September 30, 1974.

Chomsky, N. The case against B. F. Skinner. New York Review of Books, December 30, 1971, 18-24.

Chomsky, N. Language and the mind. Psychology Today, 1968, 2 , $48,50-51,66-68$.

Chomsky, N. Review of Skinner's Verbal Behavior. Language, $1959, \underline{35}, 26-58$. 
Cokely, D. R. A discussion of assessment needs in manual com-

munication for pre-college students. First Friday Research

Seminar. Washington, D. C.: Model Secondary School for the Deaf, 1978.

Dale, P. S. Language development. New York: Holt, Rinehart, and Winston, 1976.

DeZwart, H. Developmental psycholinguistics. In D. Elkind and J.

Flavel1 (Eds.), Studies in cognitive development. New York:

Oxford University Press, 1971.

DiFrancesca, S. Academic achievement test results of a national

testing program for hearing impaired students, United States:

Spring 1971. Series D, Number 9. Washington, D. C.: Office

of Demographic Studies, Gallaudet College, 1972.

DiFrancesca, S. and Carey, S. Item analysis of an achievement

testing program for hearing impaired students, United States:

Spring 1971. Series D, Number 8. Washington, D. C. Office

of Demographic Studies, Gallaudet College, 1972.

Dudek, S. Z., Lester, E. P., Goldberg, J. S., and Dyer, G. B. Re-

lationship of Piaget measures to standard intelligence and motor scales, Perceptual and Motor Ski11s, 1969, 28, 351-362.

Emmerich, W. Personality development and concepts of structure. Child Development, 1968, 39, 671-690.

Fant, L. Ameslan. Gallaudet Today, 1974, ㅁ, 1-3.

Fillmore, C. J. The case for case. In E. Bach and R. J. Harms (Eds.), Universals in linguistic theory. New York: Holt, Rinehart, and Winston, 1968, ]-87. 
Flavell, J. H. The developmental psychology of Jean Piaget,

Princeton, N. J.: D. Van Nostrand, 1963.

Francis, H. Toward and explanation of the syntagmatic-paradigmatic shift. Child Development, 1972, 43, 949-958.

Furth, H. A comparison of reading test norms of deaf and hearing children. American Annals of the Deaf, 1966a, 111, 461-462.

Furth, H. Influence of language on the development of concept formation in deaf children. Journal of Abnormal and Social and Social Psychology, 1961, 63, 386-389.

Furth, H. Linguistic deficiency and thinking: Research with deaf subjects 1964-1969. Psychological Bulletin, 1971, 76, 58-72. Furth, $H$. On the nature of language from the perspective of research with profoundly deaf children. Annals of the New York Academy of Sciences, $1975,263,70-75$.

Furth, H. Research with the deaf: Implications for language and cognition. Psychological Bulletin, 1964, 62, 145-164.

Furth, H. The role of language in the child's development. Proceedings of the 1973 convention of American instructors of the deaf. Washington, D. C.: U. S. Government Printing Office, 1974, 258-261.

Furth, H. Thinking without language. New York: The Free Press, 1966.

Gentile, A., and DiFrancesca, S, Academic achievement test performance of hearing impaired students, United States: Spring 1969. Series D, Number 1. Washington, D. C.: Office of Demographic Studies, Gallaudet College, 1969. 
Ginsburg, H. and Opper, S. Piaget's theory of intellectual development: An introduction. Englewood Cliffs, N. J.: Prentice HalT, 1969. Glowatsky, E. The verbal element in the intelligence scores of congenitally deaf and hard-of-hearing children. American Annals of the Deaf, 1953, 98, 328-335. Goetzinger, C. P. and Rousey, C. L. A study of the Wechsler Performance Scale (Form II) and the Knox Cube Test with deaf adolescents. American Annals of the Deaf, 1957, 102, 388-398. Goldin-Meadow, S. and Feldman, H. The creation of a communication system: A study of deaf children of hearing parents. Paper presented to the Society for Research in Child Development, Denver, Apri $7,1975$.

Graham, E. E., and Shapiro, E. Use of the performance scale of the WISC with the deaf child, Journal of Consulting Psychology, $1953,17,396-398$.

Gustason, G. Does signing exact English work? Teaching English to the Deaf, $1980, \underline{7}, 16-20$.

Gustason, G. Signing exact English. Gallaudet Today, 1974, $\underline{5}$, $17-12$.

Gustason, G., Pfetzing, D., and Zawolkow, E. Signing exact English. Rossmoor, Ca.: Modern Signs Press, 1972. Hatfield, N., Caccamise, F., and Siple, P. Deaf students' language competency: A bilingual perspective. American Annals of the Deaf, $1978, \underline{123}, 847-851$.

Heider, F., and Heider, G. M. Studies in the psychology of the 
deaf, No. 1 Psychological Division, Clarke School for the

Deaf. Psychological Monographs, 1940, 52, No. 232.

Hiskey, M. S. Nebraska test of learning aptitude for young deaf

children. Lincoln: University of Nebraska, 1941.

Hornby, P. A., Haas, W. A., and Feldman, C. A developmental analysis

of the "psychological" subject and predicate of the sentence.

Language and Speech, $1970,13,182-193$.

Huttenlocher, J. Language and intelligence. In L. B. Resnick (Ed.), The

nature of intelligence. Hilkside, N. J.: Lawrence Erlbaum, 1976.

Inhelder, B. and Piaget, J. The early growth of logic in the child: Clas-

sification and seriation. London: Routledge and Kegan Paul, 1964.

Inhelder, B and Piaget, J. The growth of logical thinking from child-

hood to adolescence. New York: Basic Books, 1958.

Jordan, I. K., Gustason, G., and Rosen, R. Current communication trends

at programs for the deaf. American Annals of the Deaf, 1976,

121, 527-532.

Jordan, I. K., Gustason, G., and Rosen, R. An update on communica-

tion trends at programs for the deaf. American Annals of the Deaf, 1979, 124, 350-357.

Kelly, R. R. and Tomlinson-Keasey, C. Hemispheric laterality of deaf children for processing words and pictures visually presented to the hemifields. American Annals of the Deaf, 1977, 122, 525-533. Kessler, $C$. The acquisition of syntax in bilingual children. Washington, D. C.: Georgetown University Press, 1971.

Kirk, R. E. Experimental design: Procedures for the behavioral

sciences. Belmont, Ca.: Wadsworth, 1968. 
Klima, E. and Bellugi, U. The signs of language. Cambridge, Mass.: Harvard University Press, 1979.

Knight, D. L. A general model of English language development in hearing-impaired children. Directions, 1979, I, 9-28.

Lenneberg, E. Biological foundations of language. New York: John Wiley and Sons, 1967.

Lenneberg, E. On explaining language. In M. Lester (Ed.),

Readings in applied transformational grammar. New York:

Holt, Rinehart, and Winston, 1970, 46-80.

Lerner, R. M. Concepts and theories of human development. Reading, Mass.: Addison-WesTey, 1976.

Levine, E. S. Psychological testing: Development and practice.

In J. D. Rainer, K. Z. Altshuler, and F. J. Kallman (Eds.),

Family and mental health problems in a deaf population.

Springfield, I11.: C. C. Thomas, 1969.

Levine, E. S. The psychology of deafness. New York: Columbia University Press, 1960.

Levine, E. S. Youth in a soundless world. New York: New York University Press, 1956.

MacPherson, J. and Lane, H. S. A comparison of deaf and hearing

on the Hiskey test and in performance scales, American

Annals of the Deaf, 1932, 77, 292-304.

Meadow, K. P. Deafness and child development. Berkeley: University of California Press, 1980.

Meadow, K. P. The effect of early manual communication and family climate on the deaf child's development. Unpublished PhD. 
dissertatation, University of California, Berkeley, 1966. Menyuk, $P$. The language impaired child: Linguistic or cognitive impairment? Annals of the New York Academy of Sciences, 1975, 263, 59-69. Menyuk, P. Sentences children use, Cambridge, Mass.: M, I. T. Press, 1969. Miller, G. and Chomsky, N. Finitary models of language users, In D,

Luce, R. Bush, and E, Galanter (Eds.), Handbook of mathematical psychology, volume II. New York: Wiley, 1963.

Moores, D. Educating the deaf, Boston: Houghton Mifflin, 1978. Myklebust, $H$. Clinical psychology and children with impaired hearing. The Volta Review, 1948, 50, 55-60; 90. Myklebust, H. Development and disorders of written language: Picture story language test. New York: Grune and Stratton, 1965. Myklebust, H. The psychology of deafness, New York: Grune and Stratton, 1960.

Oleron, P. and Herren, H. L'acquisition des conservations et langage: Etude comparative sur des enfants sourds et entendants. Enface, $1961,14,203-219$.

01son, D. R. The languages of instruction: On the literate bias of schooling. In R. C. Anderson, R. J. Spiro, and W. E. Montague, (Eds.), Schooling and the acquisition of knowledge. Hillside: Erlbaum, 1977. O'Rourke, T. J., Medina, T., Thames, A., and Sullivan, D, National Association for the Deaf Communicative Skills Program. Programs for the Handicapped, Apri1, 1975, 27-30.

Orpet, R. E. and Meyers, C. E. Discriminant function analys is of conservation stages by structure of intellect and conceptual style variables. Proceedings of the 78th Annual Convention 
of the American Psychological Association, 1970, $\underline{5}, 279-280$.

ottem, E. An analysis of cognitive studies with deaf subjects.

American Annals of the Deaf, $1980, \underline{125}, 564-575$.

Paris, S. G. Comprehension of language connectives and prepositional

logical relationships. Journal of Experimental Child Psychology, $1973, \underline{16}, 278-291$.

Peterson, E. G. Testing deaf children with Kohs Block Design, American Annals of the Deaf, $1948,81,55-60 ; 90$.

Piaget, J. The child and reality. New York: Grossman, 1973.

Piaget, J. The child's conception of number. London: Routledge and Kegan Paut, 1941.

Piaget, J. Development and learning. Journal of Research in Science Teaching, 1964, 2, 176-186.

Piaget, J. Problems of equilibration. In C. Nodine, J. Gallagher,

and R. Murphy (Eds.), Piaget and Inhelder on equilibration.

Philadelphia: Jean Piaget Society, 1972.

Piaget, J. Six psychological studies. New York: Random House, 1967.

Pintner, R., and Paterson, D. G. Some conclusions from psychological

tests of the deaf. The Volta Review, 1919, 20, 10-14.

Piattelli-Palmarini, M. (Ed.). Language and learning. Cambridge,

Mass.: Harvard University Press, 1980.

Quigley, S. P. Personal communication, May, 1979.

Quigley, S. P. and Frisina, D. R. Institutionalization and psycho-

educational development of deaf children. Council for Excep-

tional Children Research Monographs, Series A, No. 3, 1961.

Quigley, S. P., Smith, N, L., and Wilbur, R. B. Comprehension of 
relativized sentences by deaf students. Journal of Speech and Hearing Research, 1974, 17, 325-341.

Quigley, S. P., Wi lbur, R. B., and Montanelli, D. S. Question formation in the language of deaf students. Journal of Speech and Hearing Research, 1974, 17, 699-713.

Quigley, S. P., Wi lbur, R., Power, D., Montanel1i, D., and Stein-

kamp, M. Syntactic structures in the language of deaf children.

Champaign, I11.: University of Illinois, 1976.

Rainer, J. D., Altshuler, K. Z., and Kallmann, F. J. (Eds.).

Fami ly and mental health problems in a deaf population.

Springfield, I11.: C. C. Thomas, 1969.

Rawlings, B. Characteristics of hearing impaired students by

hearing status: 1970-71. Series D, Number 10. Washingtion,

D. C.: Office of Demographic Studies, Gallaudet College, 1973.

Ries, P., Trybus, R., Sepielli, P., and Buchanan, C. Further

studies in achievement testing, hearing impaired students,

United States: Spring 1971. Series D, Number 13. Washington

D. C.: Office of Demographic Studies, Gallaudet College, 1973.

Rittenhouse, R. K., Morreau, L. E., and Iran-Nejad, A. Metaphor and conservation in deaf and hard-of-hearing children. American Annals of the Deaf, $1981, \underline{126}, 450-453$.

Rittenhouse, R. K. and Spiro, R, J. Conservation performance in day and residential school deaf children. The Volta Review, $1979,81,501-509$.

Roscoe, J. T. Fundamental research statistics. New York: Holt, 
Rinehart, and Winston, 1969.

Ross, G. Testing intelligence and maturity of deaf children,

Exceptional Children, 1953, 20, 23-24; 42.

Russe11, W. K., Quigley, S, P., and Power, D. J. Linguistics and

deaf children. Washington, D, C.: Alexander Graham Bell Association, 1976.

Schlesinger, H. S. and Meadow, K. P. Emotional support for parents.

In D. L. Lillie, P. L. Trohanis, and K. W. Goin (Eds.).

Teaching parents to teach. New York: Walker and Company, $1976,35-47$.

Schreiber, F. C. New signs ... the cons. Gallaudet Today, 1974, $\underline{5}, 5-6$.

Scyster, M. Summary of four years' experiment with preschool

children at the Illinois School for the Deaf. American Annals of the Deaf, $1936,81,212-230$.

Shirley, M. and Goodenough, F. Intelligence of deaf children in Minnesota. American Annals of the Deaf, 1932, 77, 238-247,

Silverman, R. Categorization behavior and achievement in deaf and hearing children. Exceptional Children, 1967, 34, 241-250.

Spragins, A. B. and Cokely, D. R. Assessing communication skills. Directions, $1980,1,36-38$.

Springer, N. N. A comparative study of the intelligence of a group of deaf and hard-of-hearing children. American Annals of the Deaf, $1938,83,138-152$.

Statistical Analysis System, Cary, N. C.: SAS Institute, 1979. Stevenson, E. A. A study of the educational achievement of deaf 
children of deaf parents, California News, 1964, 80, 1-3. Stokoe, W. C. Sign language structure: An outline of the visual communication systems of the American deaf. Studies in linguistics. Occasional Paper No. 8. Washington, D. C.: Gallaudet College Press, 1960.

Stokoe, W. C. The view from the lab -- two ways to English competence for the deaf. Gallaudet Today, $1974, \underline{5}, 31-32$.

Stuckless, E. R. and Birch, J.W. The influence of early manual communication on the linguistic development of deaf children. American Annals of the Deaf, $1966,111,452-460 ; 499-504$.

Swartz, K. and Hal1, A. E. Development of relational concepts and word definitions in children five through eleven. Child Development, 1972, 433, 239-244.

Taylor, L. A. A language analysis of the writing of deaf children. Unpublished PhD. dissertation, Florida State University, 1969.

Templin, M. Methodological variations in language research with deaf subjects. Proceedings of the International Conference on Oral Education of the Deaf. Washington, D. C.: Alexander Graham Bel1 Association, 1967, 11, 1428-1440.

Thinking in questions. Northwestern Alumni News, October, 1980, $\underline{9}, 8$.

Thompson, W. H. An analysis of errors in written compositions of deaf children. American Annals of the Deaf, 1936, 81, 95-99.

Tremaine, R. V. Syntax and Piagetian operational thought. Wash- 
ington: Georgetown University Press, 1975.

Trybus, R, , Buchanan, C., and DiFrancesca, S. Studies in achievement testing, United States: Spring 1971. Series D, Number 11. Washington, D. C.: Office of Demographic Studies, Gallaudet College, 1973.

Trybus, R. and Karchmer, M. A, School achievement scores of hearingimpaired children: National data on achievement status and growth patterns. American Annals of the Deaf, 1977, 122, 62-69.

Turiel, E. Developmental processes in the child's moral thinking. In P. H. Mussen, J. Langer, and M. Covington (Eds.), Trends and issues in developmental psychology. New York: Holt, Rinehart, and Winston, 1969.

Vasta, R. and Liebart, R. M. Auditory discrimination of novel prepositional construction as a function of age and syntactic background. Developmental Psychology, 1973, $\underline{9}$, 79-82.

Vernon, M. Characteristics associated with post-rubella children: Psychological, educational, and physical. The Volta Review, $1967,69,176-185$.

Vernon, M. Sociological and psychological factors associated with hearing 1oss. Journal of Speech and Hearing Research, 1969 , 12, $541-563$.

Vernon, M. and Brown, D. W. A guide to psychological tests and testing procedures in the evaluation of deaf and hard-ofhearing children. Journal of Speech and Hearing Disorders, 
$1964, \underline{29}, 414-423$.

Vernon, M. and Koh, S, D. Early manual communication and deaf children's achievement. American Annals of the Deaf, 1970, $115,527-536$.

Vygotsky, L. Thought and language. Cambridge, Mass,: M. I. T. Press, 1962.

Wadsworth, B. Piaget's theory of cognitive development. New York: Longman, 1979.

Wampler, D. Linguistics of manual English. Santa Rosa, Ca.:

Santa Rosa City Schools, 1971.

Wechsler, D. Manual for the WISC-R. New York: The Psychological Corporation, 1974. Woodward, J. Some observations on sociolinguistic variation and American Sign Language. Kansas Journal of Sociology, 1973, Fal1, 191-198.

Wrightstone, J. W., Aronow, M. S., and Moskowitz, S. Developing reading test norms for deaf children. American Annals of the Deaf, 1963, 108, 311-316.

Zeckel, A. and Kalb, J. J. A comparative test of groups of children born deaf and of good hearing by means of the Porteous Maze Test. American Annals of the Deaf, 1939, 84, 114-123. 
APPENDIX A 
736 Dobson Street

Evanston, I71, 60202

November 15, 1981

Mr. and Mrs.

Dear Mr. and Mrs.

I am a doctoral student at Loyola University and am working in the area of educational psychology. I have spent several years teaching hearing impaired children, and I am now researching the relationship between thinking skills and language development in deaf children.

I am writing to ask permission to spend 30 to 45 minutes evaluating your child's thinking and language skills through the use of a few games and some pictures. This project has been approved by $\mathrm{Mr}$. John Shipman., Superintendent of the Wisconsin School for the Deaf, and Dr. Kenneth Brasel, Principal. I will be evaluating several other students at the school as well and, of course, all results will be completely confidential. Testing will be done during school hours, but only at a time which is acceptable to your child's teacher.

Participation in this project is completely voluntary, with no penalty whatsoever if you do not choose for your child to participate. If you are willing, however, for your child to be involved, please send back the parental permission slip in the enclosed self-addressed, stamped envelope. If you would like to know the results of the research later in the spring, check both blanks and I wi 17 send you a summary when the work is completed.

Sincerely,

David Dolman

Doctoral Candidate

Foundations of Education

Loyola University of Chicago 


\section{PARENTAL PERMISSION SLIP}

Check

below:

I give permission for my child to participate in the 30 to 45 minute research project concerning thinking and language skills. I understand that my child's participation is voluntary, and that non-participation will not be penalized.

I would like a summary of the results of this research when work is completed in the spring.

Signature of Parent or Guardian 
APPENDIX B 
SOCIOLINGUISTIC QUESTIONNAIRE

Child's Name

Today's Date

PLEASE CIRCLE THE APPROPRIATE LETTER.

1. Are this child's parents:
a. both deaf
b. one hearing, one deaf
c. both hearing

2. To the best of your knowledge, are any other family members deaf?
a. brother(s) or sister(s)
b. grandparent(s)
c. aunt(s) or uncle(s)
d. other fami ly member(s)
e. none

3. How old do you think this child was when he or she learned sign language?
a. less than 3 years old
b. 3-5 years old
c. 5-10 years o1d
d. 10-16 years old
e. has never learned it

4. Who taught this child to sign?
a. family
b. friends
c. teachers
d. others

5. How consistently do you feel that this child's family signs to him or her at home?
a. very consistently
b. somewhat consistently
c. inconsistently
d. almost never
e. never 
6. How does this child communicate with friends most frequently?
a. predominantly American Sign Language (ASL or Ames lan)
b. predominantly a form of signed English
c. signs in no systematic order; neither American Sign Language nor signed English is predominant
d. predominantly Rochester method (fingerspeliing)
e. predominantly speech only

7. How does this child communicate with teachers most frequently?
a. predominantly American Sign Language (ASL or Ameslan)
b. predominantly a form of signed English
c. signs in no systematic order; neither American Sign Language nor signed English is predominant
d. predominantly Rochester method (fingerspelling)
e. predominantly speech only

8. How do you think that this child communicates with his or her parents most frequently?
a. predominantly American Sign Language (ASL or Ameslan)
b. predominantly a form of signed English
c. signs in no systematic order; neither American Sign Language nor signed English is predominant
d. predominantly Rochester method (fingerspelling)
e. predominantly speech only

9. How would you rank this child's overall signing ability?
a. excellent
b. good
c. fair
d. poor
e. can't sign 


\section{APPENDIX C}




\section{SCREENING ITEMS}

Student's name

Today's date

Establish a non-threatening atmosphere with the student. Let him know that you like him and that he will enjoy the tasks you are presenting to him.

1. Present card \#1. Say: How many stars are here (point to upper left corner)?

Answer:

2. Continue with card \#1. Say: How many stars are here (point to lower right corner)?

Answer:

3. Say: Are more stars here (point to upper left corner), or are more stars here (point to lower right corner)? Or are they (point to both corners) the same -- equal?

Answer:

upper left

lower right

equal

4. Present card \#2. Say: How many stars are here (point to upper left corner)?

Answer:

5. Continue with card \#2. Say: How many stars are here (point to lower right corner)?

Answer:

6. Say: Are more stars here (point to upper left corner), or are more stars here (point to lower right corner)? Or are they (point to both corners) the same -- equal?

Answer: upper left

lower right equal 
APPENDIX D 
Student's name

Today's date

(Say and sign the underlined portions.)

I. Conservation task

1. Fill 2 identical cups with approximately equal amounts of water.

Say: Imagine that you are very thirsty. You really want some water. Does this cup have more water (point to cup) or does this cup have more water (point to other cup), or do you feel they are the same (equal)? Continue to adjust the water in cups until the child agrees they are the same.

After adjustment, does the child agree that the cups have the same amount of water?

Yes No

2. Say: Now, watch me. I will pour this cup into this (point to bow1). Pour the water into the bow1. Say: Imagine now that you are very thirsty and you really want some water. Does this have more water (point to cup) or does this have more water (point to bowl), or are they the same (equal)?

Answer:

II. Classification task

1. Spread the 10 pictures out. Ask: How many birds can you find?

Answer:

2. Ask: How many white animals can you find?

Answer:

3. Say: Do you see more birds, or do you see more white animals? Or are they the same (equal)?

Answer: 
4. Spread a 11 the pictures out. Ask: How many animals are here?

Answer:

5. Say: Do you see more white animals, or do you see more animals? or are they the same (equal)?

Answer:

6. Say: Do you see more birds, or do you see more animals? Or are they the same (equal)?

Answer:

III. Seriation task

1. Say: Watch me. I will make some stairs. Take the first set of 10 slats (numbered 1-10) and make a staircase. Then break up the staircase and say: Now you do the same. You make some stairs, too. If the child does this correctly, go to item 8 below.

Right

Wrong

2. If the child can't seriate (put in order) the 10 slats, let him seriate the 5 largest (numbered 1-5). Say: Now make some stairs for me.

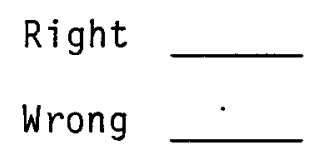

3. IF THE CHILD CAN'T SERIATE 5, DISCONTINUE THE EXPERIMENT. DO NOT GO ON TO SECTION IV.

4. If the child correctly seriates 5 , break up the staircase and give him 7 slats to seriate.

$$
\begin{aligned}
& \text { Right } \\
& \text { Wrong }
\end{aligned}
$$

5. IF THE CHILD CAN'T SERIATE 7, DISCONTINUE THE EXPERIMENT. DO NOT GO ON TO SECTION IV. 
6. If the child correctly seriates 7 , break up the staircase and give him 10 slats to seriate.

Right

Wrong

7. IF THE CHILD CAN'T SERIATE 10, DISCONTINUE THE EXPERIMENT. DO NOT GO ON TO SECTION IV.

8. If the child correctly seriates 10 slats, produce the second set of 9 slats and say: We want to make very long stairs now. Put the new stairs in the right place with the old stairs. If the child doesn't understand that the slats should be put in between the original ones, you can say: Make some very long stairs. Put the new stairs between the old stairs... Imagine that you forgot the new stairs. Now put them in the right place to make some very long stairs.

\section{Right}

Wrong

9. IF THE CHILD CAN'T DO \#8 CORRECTLY, STOP! DO NOT GO ON TO SECTION IV.

IV. Numeration task

1. Place the correctly seriated set of 10 slats in front of the child and produce the plastic figure. Say: The man (or woman) wants to go here (point to first stair; then move the man (or woman) to the first stair). How many stairs will he climb?

\section{Right}

Wrong

2. Put the figure back on the ground. Say: Now the man (or woman) wants to go here (point to the second stair; then move the figure to the second stair). Say: How many stairs will he climb? Place the plastic figure on the third stair and follow the same procedure; continue to the tenth stair.

$$
\begin{array}{lllllllll}
2 & 3 & 4 & 5 & 6 & 7 & 8 & 9 & 10
\end{array}
$$

Right:

Wrong:

3. IF THE CHILD FAILS 6 OR MORE ITEMS ON \#2, DISCONTINUE THE EXPERIMENT. 
4. Break up the staircase so that the slats are disarranged on the table. Say: Imagine that the stairs were the same as as before. The man (or woman) wants to go here (point to the second stair). How many stairs will he climb?

Right

Answers without rebuilding

Wrong

(What was Rebuilds to 2 answer?)

Rebuilds beyond 2

5. If the child answers wrong without rebuilding, suggest rebuilding the staircase. Say: How can you find the answer? Put the stairs together again. See if you can find the answer.

Right

Wrong Answers without rebuilding

Rebuilds to 2

Rebuilds beyond 2

6. Break up the staircase if the child has rebuilt it. Say:

The man wants to go here (point to fifth stair). How many stairs will he climb? (answer is 5)

Right

(What was

answer?)

Answers without rebuilding

Wrong

(What was Rebuilds to 5 answer?)

Rebuilds beyond 5

7. If the child answers wrong without rebuilding, suggest rebuilding the staircase. Say: How can you find the answer? Put the stairs together again. See if you can find the answer.

Right

Wrong (What was answer?)
Answers without rebuilding

Rebuilds to 5

Rebuilds beyond 5

8. IF THE CHILD FAILS BOTH \#5 AND \#7, DISCONTINUE THE EXPERIMENT.

9. Break up the staircase if the child has rebuilt it. Put the man on the second stair. Say: The man is on this stair (point to the second stair). He wants to go to the top. How many stairs will he climb? (answer is 8) 
Right

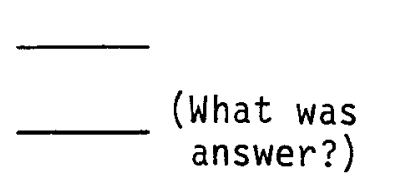

Wrong answer?)
Subtracts mentaily
Seems to count the disarranged slats

Rebuilds again and appears to count

10. Break up the staircase if the child has rebuilt it. Put the man on the fifth stair. Say: The man is on this stair (point to the fifth stair). He wants to go to the top. How many stairs will he climb? (answer is 5)

Right

Wrong
Subtracts mentally

(What was Seems to count the answer?) disarranged slats

Rebuilds again and appears to count 
APPENDIX E 


\section{GRAMMAR TEST}

Student's name

Age

Grade

School

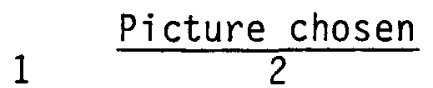

1. They write.

2. She sees him.

3. They open the window.

4. The grandfather.

5. Their dog.

5. He buys a ticket.

7. The girl.

8. He pushes her.

9. He is eating.

10. His dog.

11. The boy.

12. He bought a ticket.

13. Their ball.

14. The dog.

15. He will buy a ticket.

16. He opens the window.

17. He writes.

18. The books. 
19. He pushes him.

20. He ate.

21. He will eat.

22. The grandmother.

23. The dogs.

24. She sees her.

25. The book.

26. His ball.

27. The baby on the table eats the cake.

28. The black ball is bigger than the white ba11.

29. The boy hits the ball.

30. The cat scares the bird which is on the chair.

31. The car is longer than the truck.

32. The baby sees the girl.

33. The baby gives the ball for the dog to the cat.

34. The girl is seen by the baby.

35. The dog with a big ball.

36. The big cat with a bird.

37. The boys see each other.

38. The pilot of the plane. 


\section{$1 \quad \frac{\text { Picture chosen }}{2}$}

39. The white ball is bigger than the black ball.

40. The castle of the king.

41. The girl brings the ball for the mother to the baby.

42. The baby goes from the window to the door.

43. The mother brings the dog to the boy.

44. The girl shows the cow to the dog.

45. The plane of the pilot.

46. The baby eats the cake which is on the table.

47. The ball hits the boy.

48. The boy shows the cat the bird.

49. The girl brings the ball for the baby to the mother.

50. The boys see themselves.

51. The girl gives the ball to the baby.

52. The big dog with a ball.

53. The cat jumps from the table to the floor.

54. The ball is hit by the boy. 


\section{$1 \quad \frac{\text { Picture chosen }}{2}$}

55. The baby gives the ball for the cat to the dog.

56. The girls see each other.

57. The baby goes from the door to the window.

58. The cat with a big bird.

59. The boy brings the cat to the mouse.

60. The girl sees the baby.

61. The cat on the chair scares the bird.

62. The king of the castle.

63. The cat jumps from the floor to the table.

64. The girl shows the dog to the cow.

65. The truck is longer than the car.

66. The baby is seen by the giri.

67. The baby gives the ball to the girl.

68. The boy shows the bird the cat.

69. The boy is hit by the ball.

70. The boy brings the dog to the mother. 


\section{$1 \quad \frac{\text { Picture chosen }}{2}$}

71. The girls see themselves.

72. The boy brings the mouse to the cat.

1. The truck pushes the car.

a. The car is pushed by the truck.

b. The truck is pushed by the car.

2. The ball which is white is near the dog.

a. The white ball is near the dog.

b. The ball is near the white dog.

3. The cat has a ball which is black.

a. The black cat has a ball.

b. The cat has a black ball.

4. The car is pushed by the truck.

a. The truck pushes the car.

b. The car pushes the truck.

5. The boy pushes the girl.

a. The boy pushes her.

b. The boy pushes him.

6. The boy hits the ball.

a. The ball is hit by the boy.

b. The boy is hit by the bal1.

7. I see the mother of the boy.

a. I see the mother.

b. I see the boy.

8. The boy is hit by the ball.

a. The boy hits the ball.

b. The ball hits the boy.

9. I see the friend of the girl.

a. I see the girl.

b. I see the friend.

10. The boy sees the flower.

a. The boy sees it.

b. The boy sees her. 


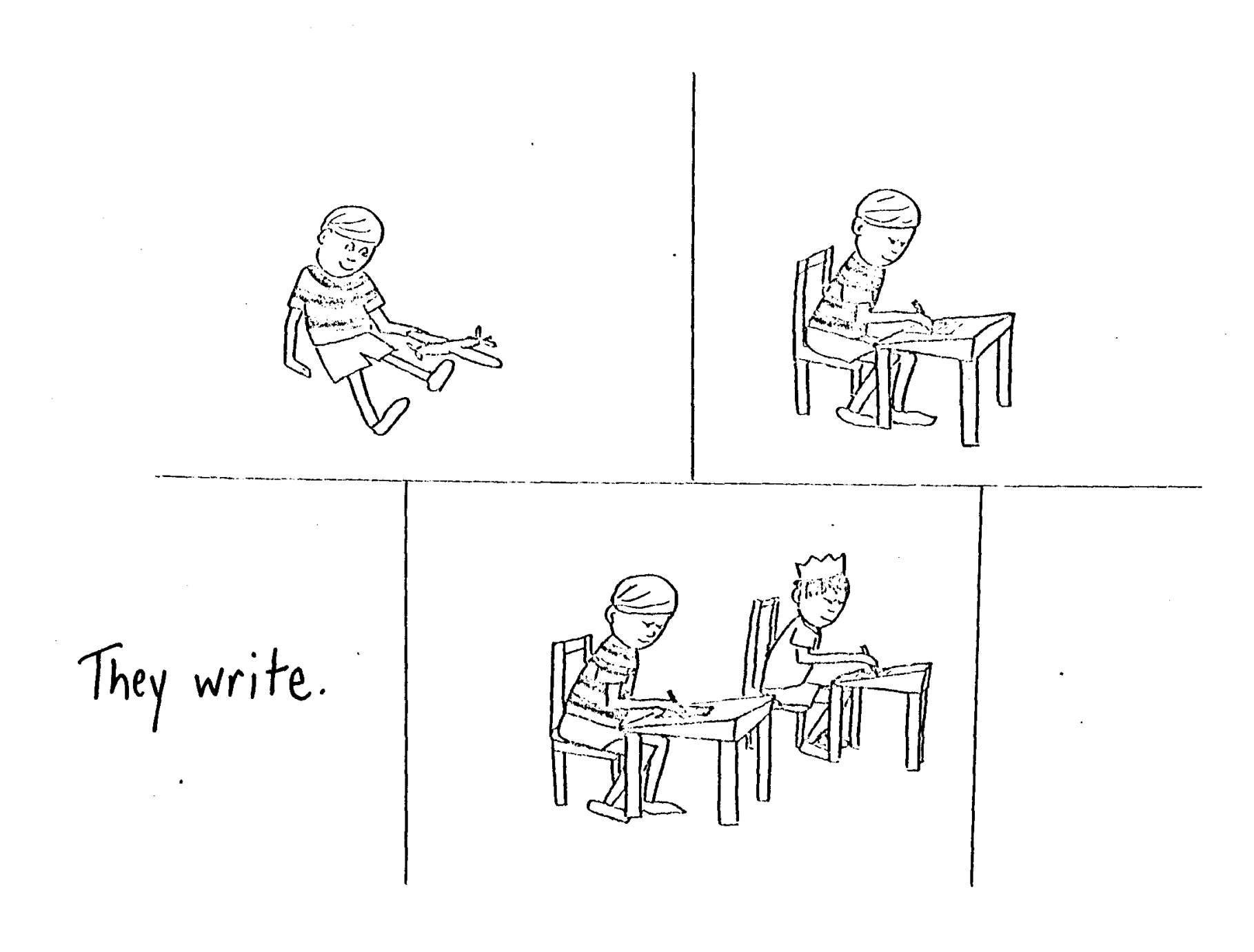


욤

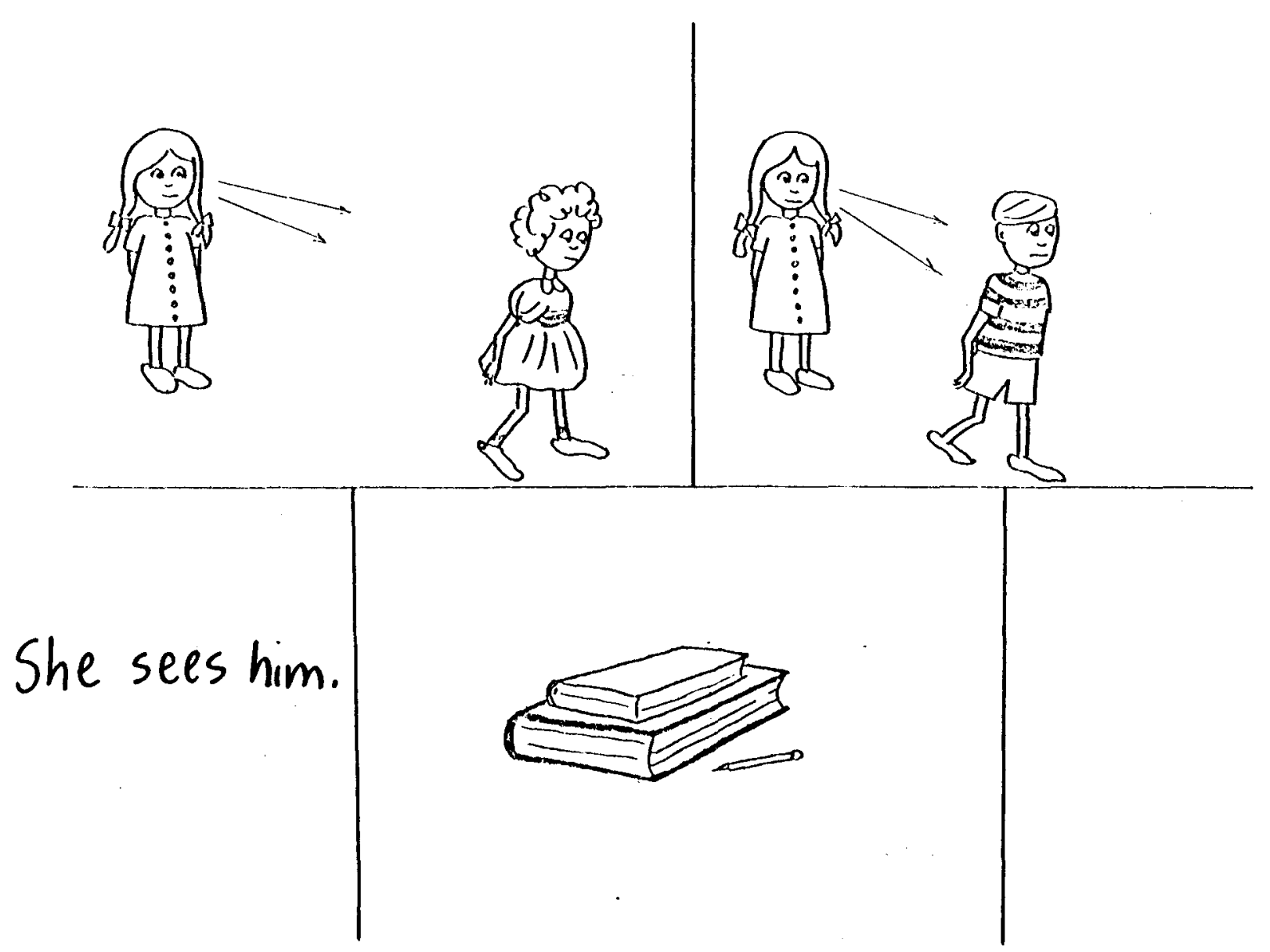


도

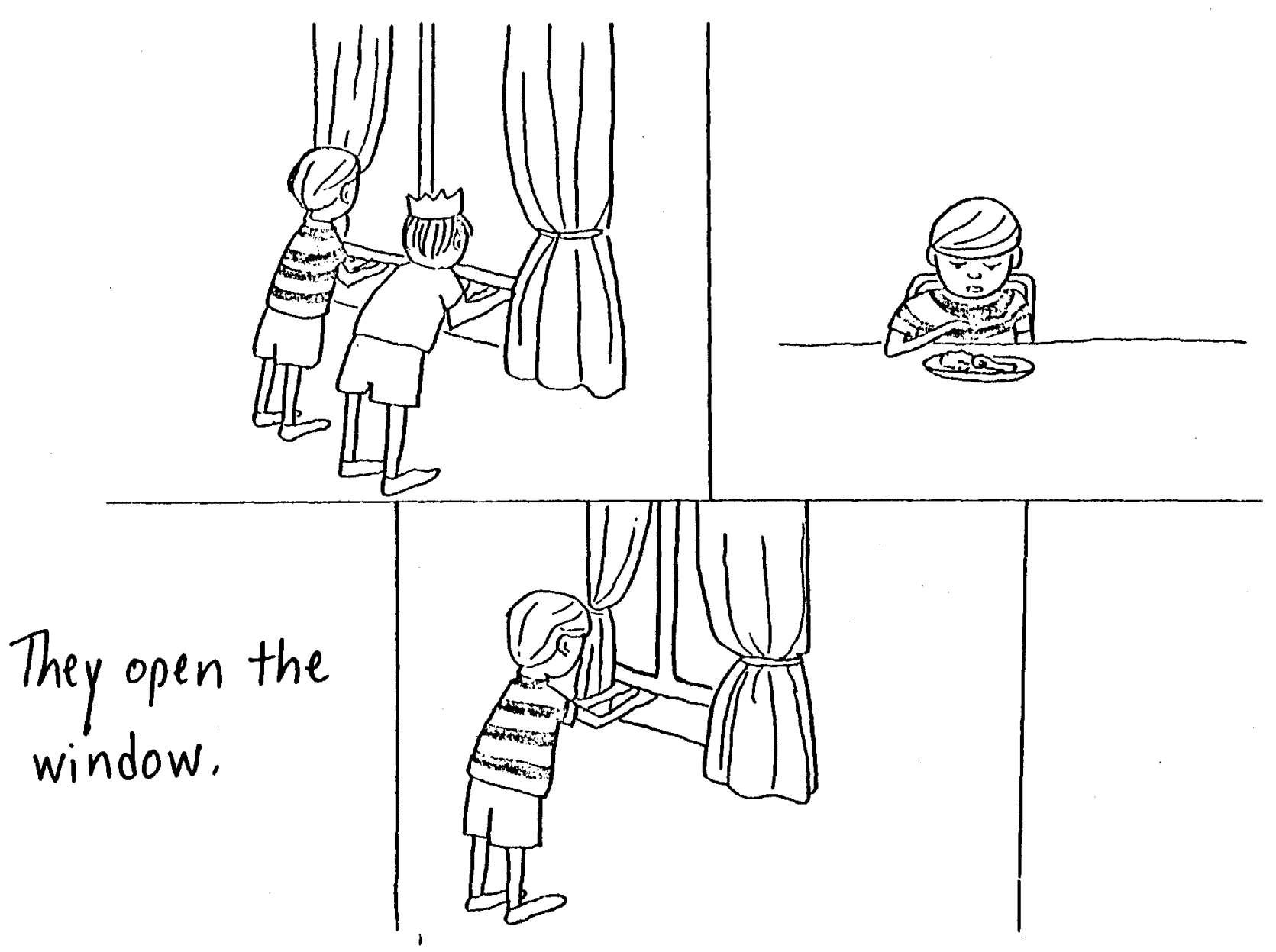




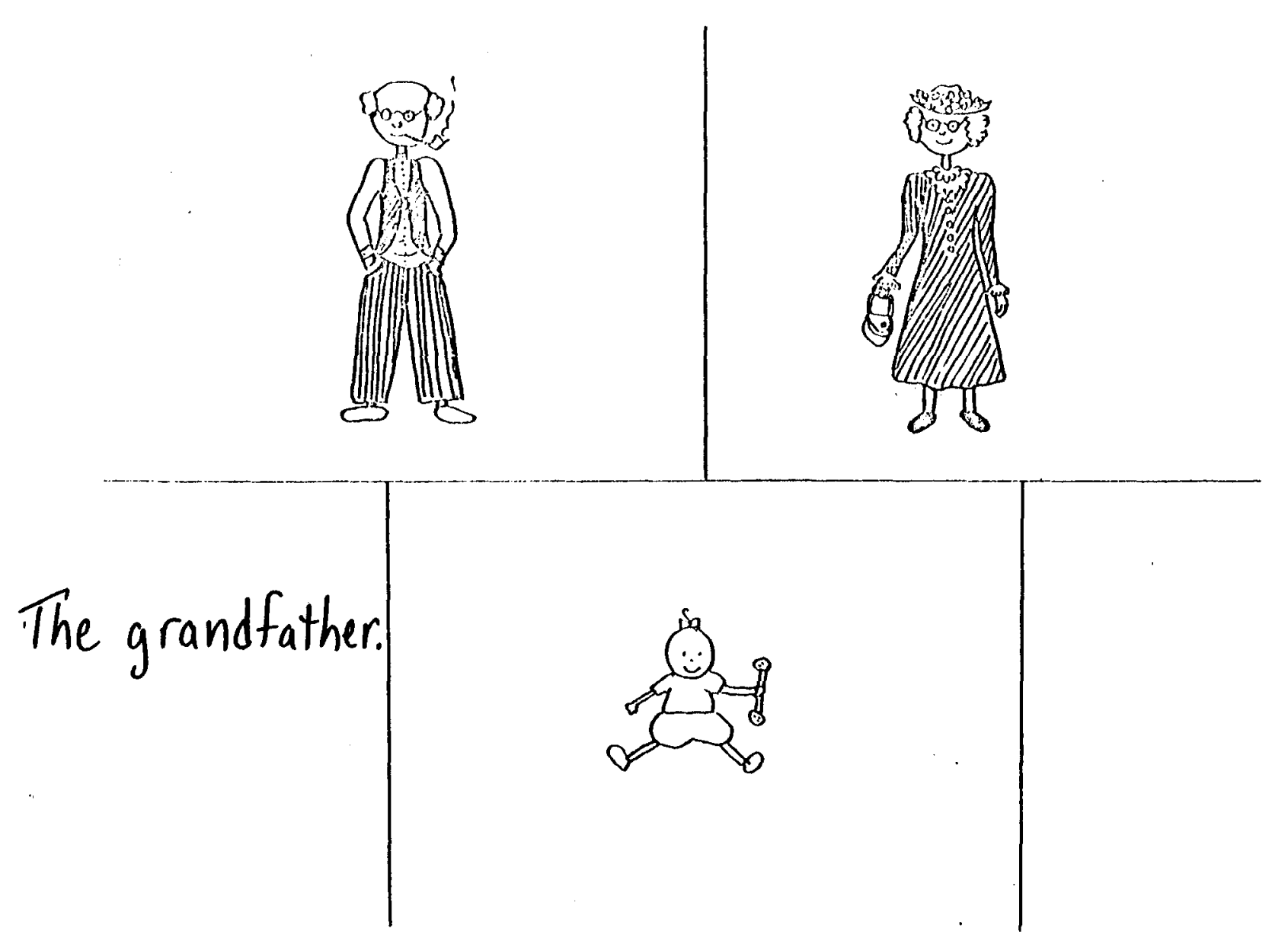


ํㅗㅁ

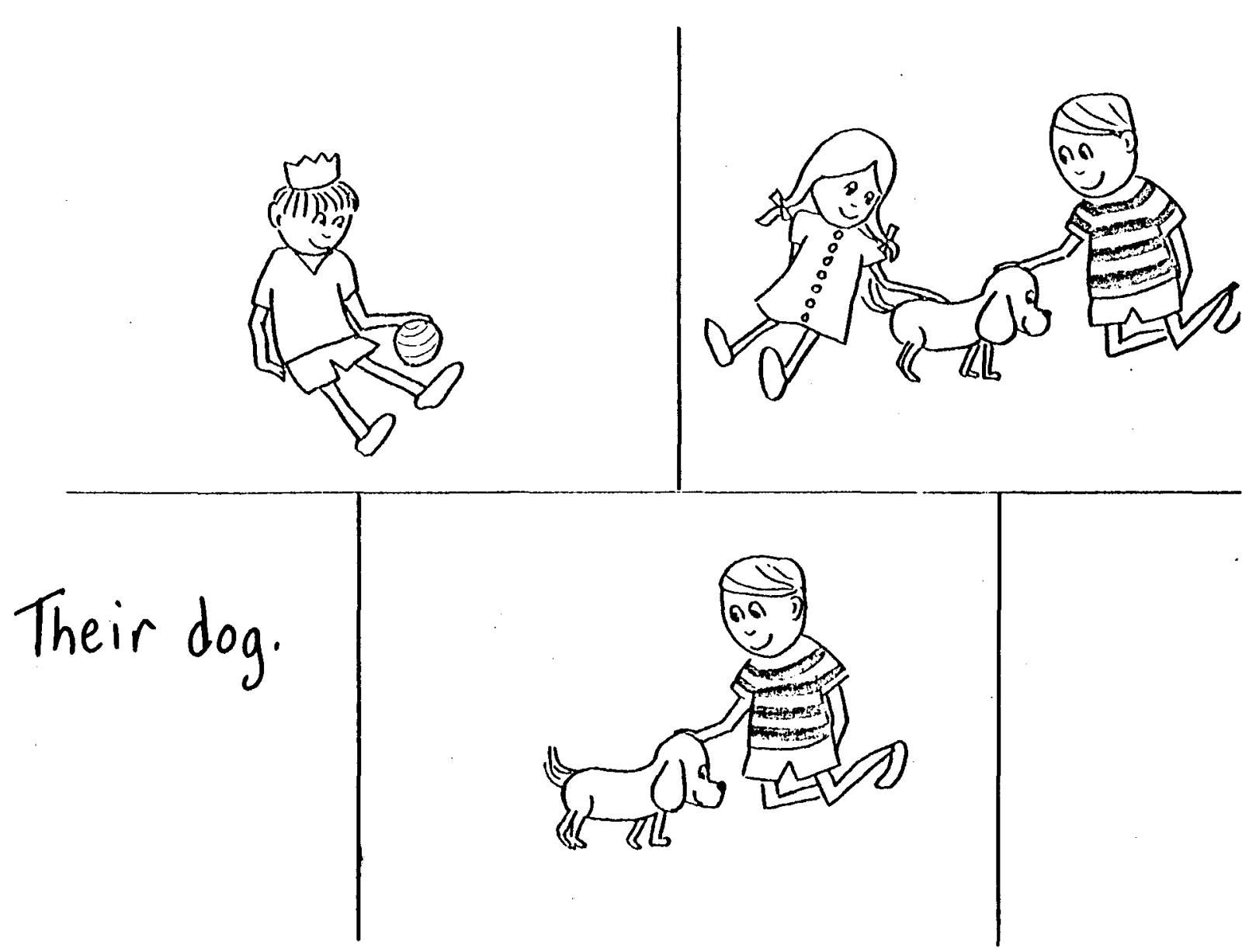


芯

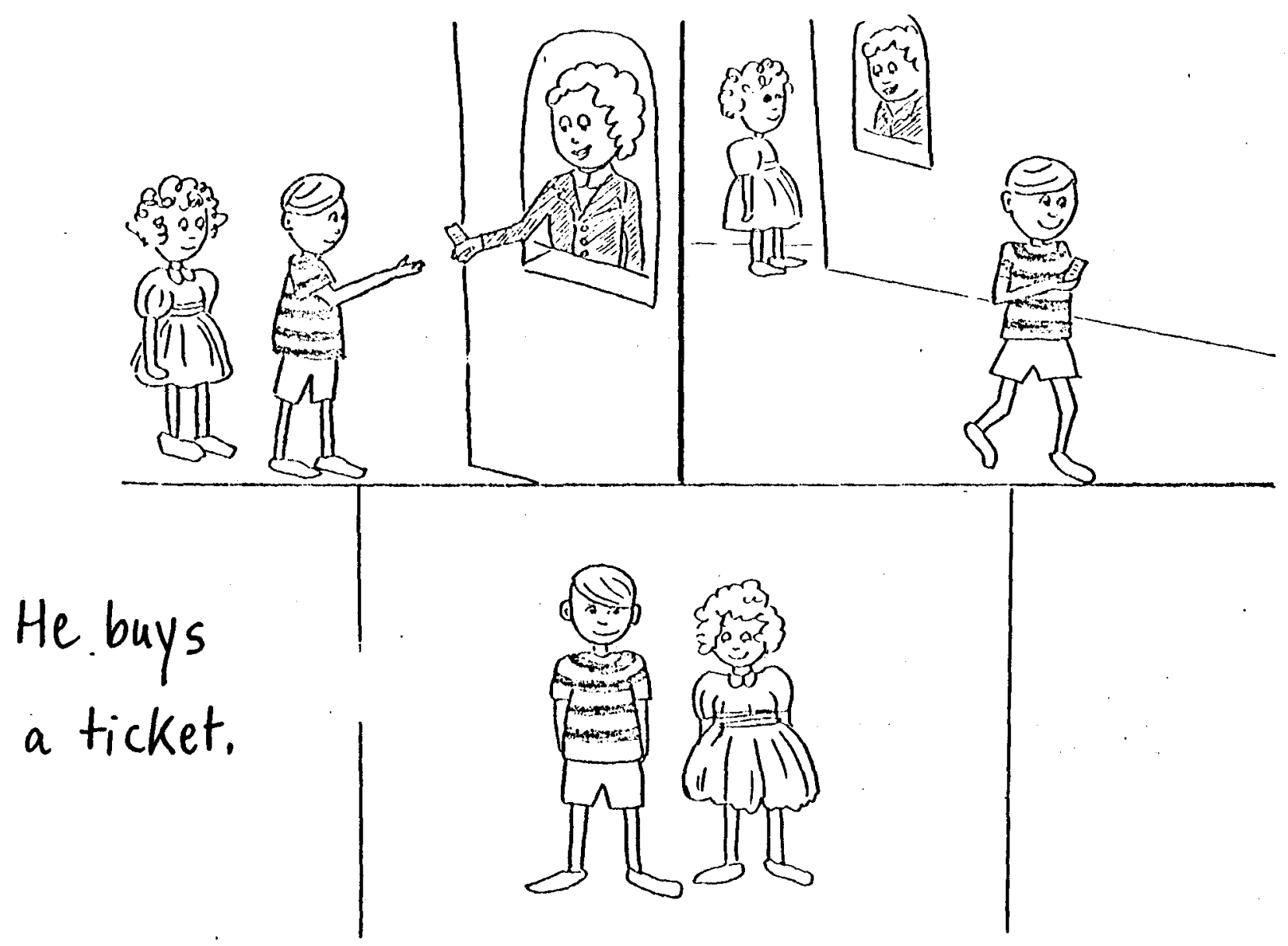


吕

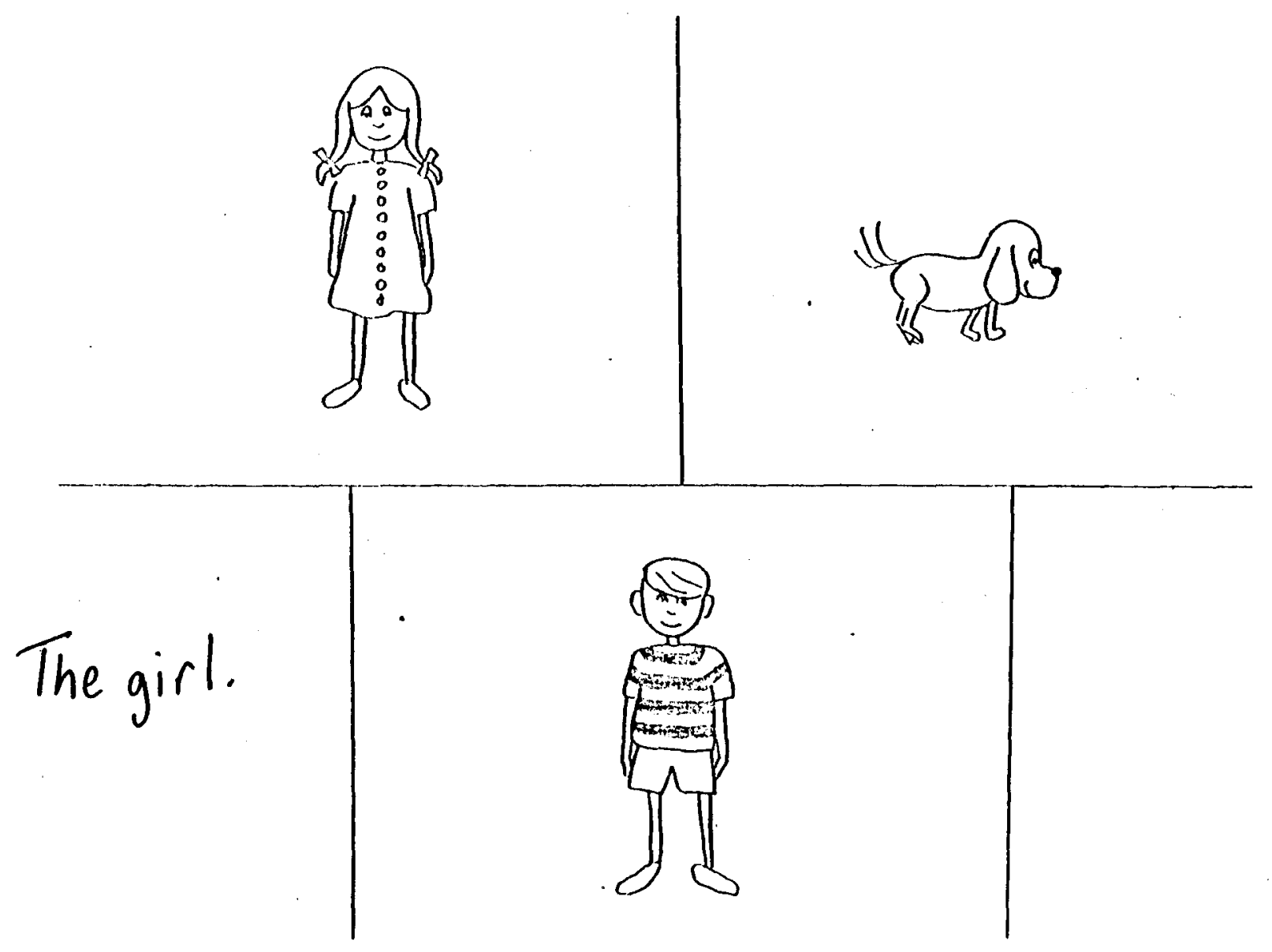

7 
$\stackrel{\circ}{\circ}$

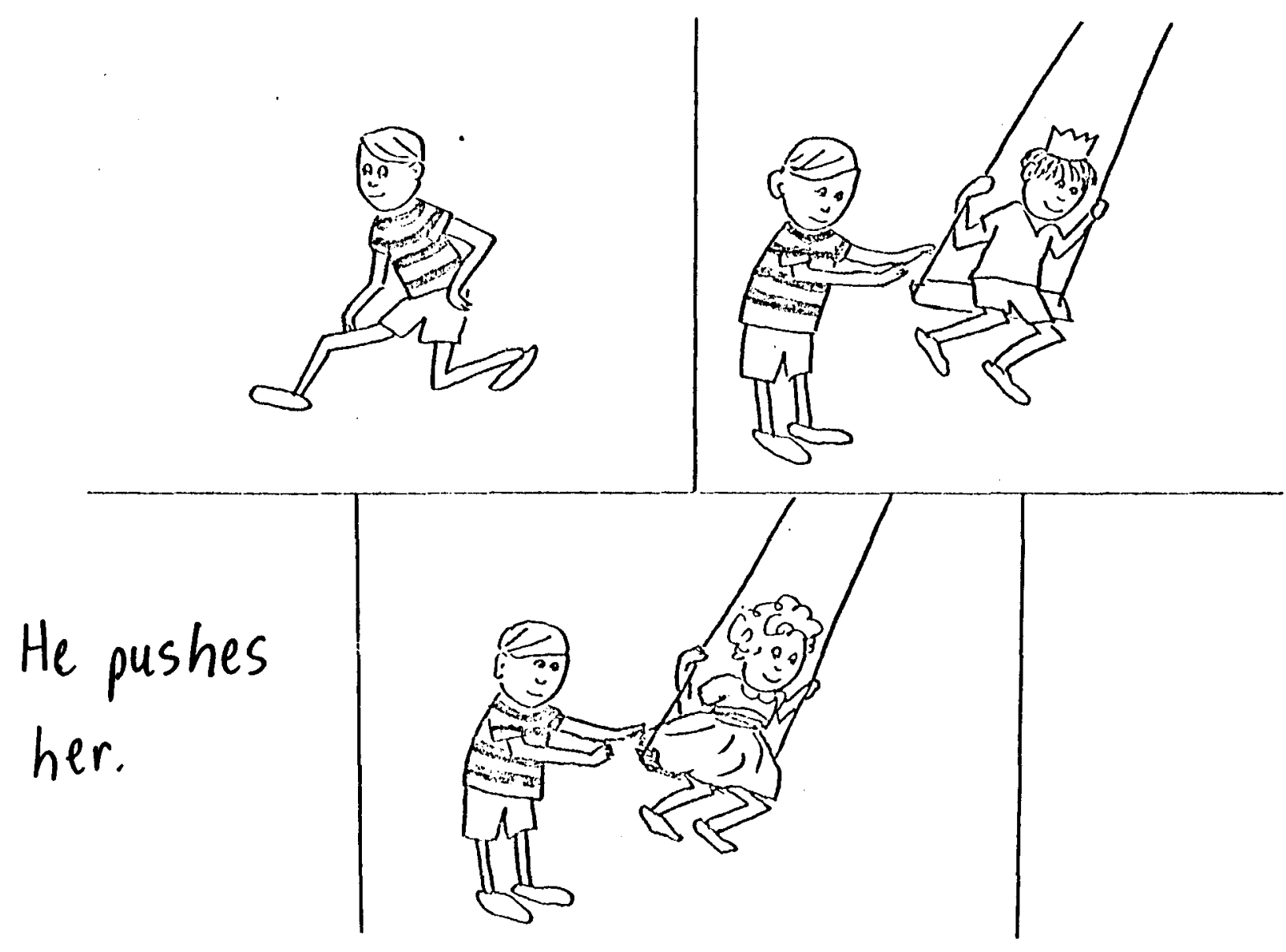


온

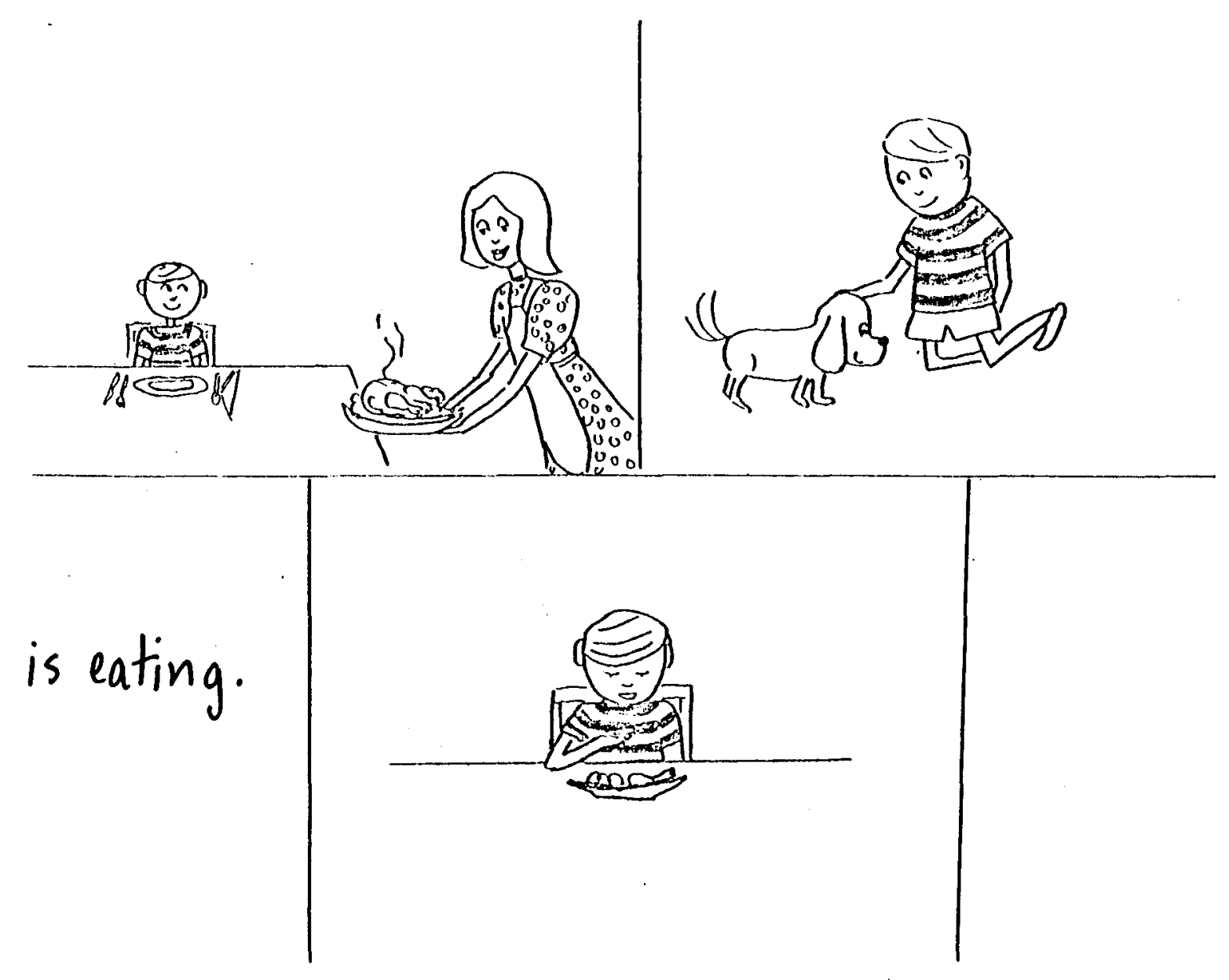

9 
$\stackrel{\infty}{\stackrel{0}{⿴ 囗 十 ~}}$

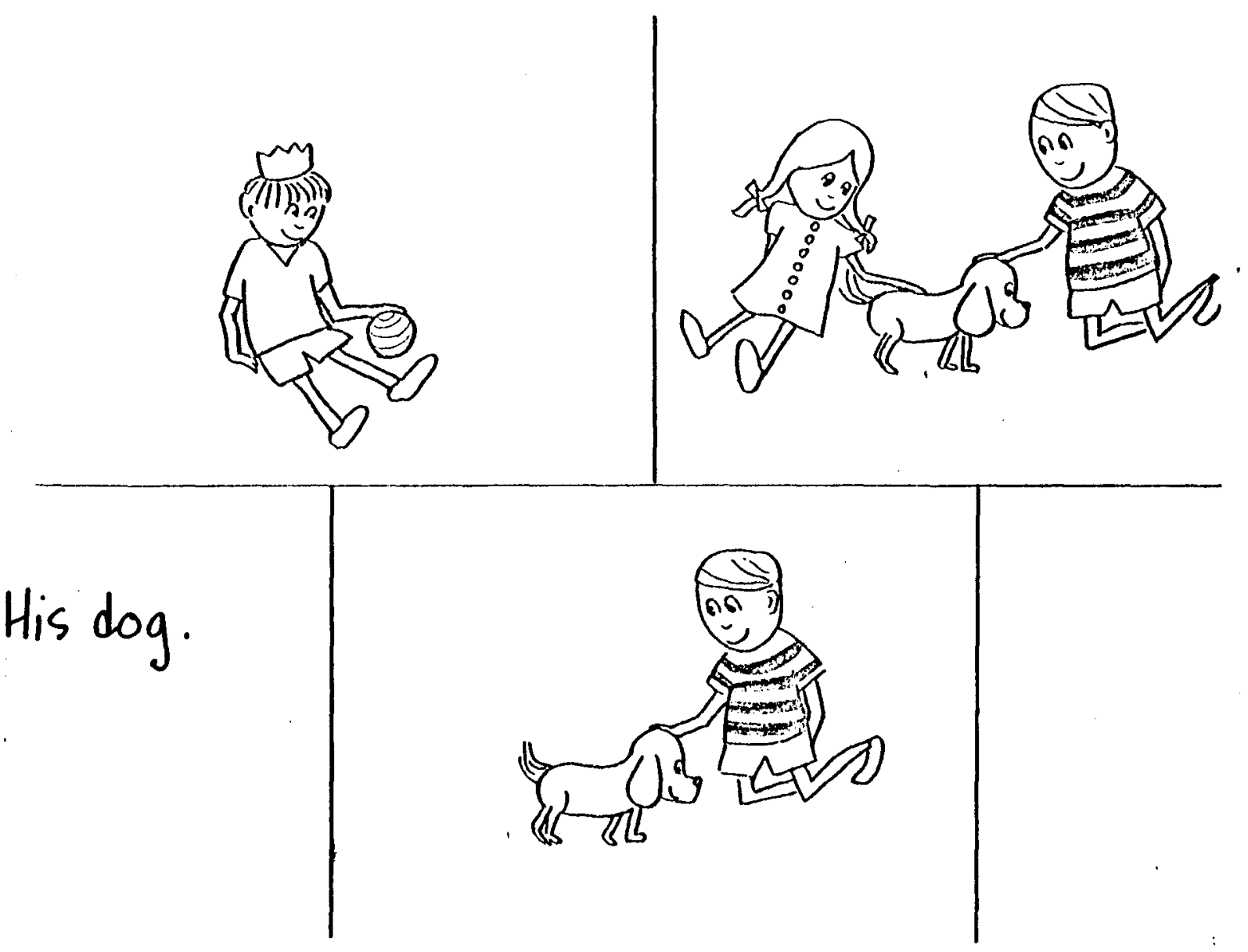


용

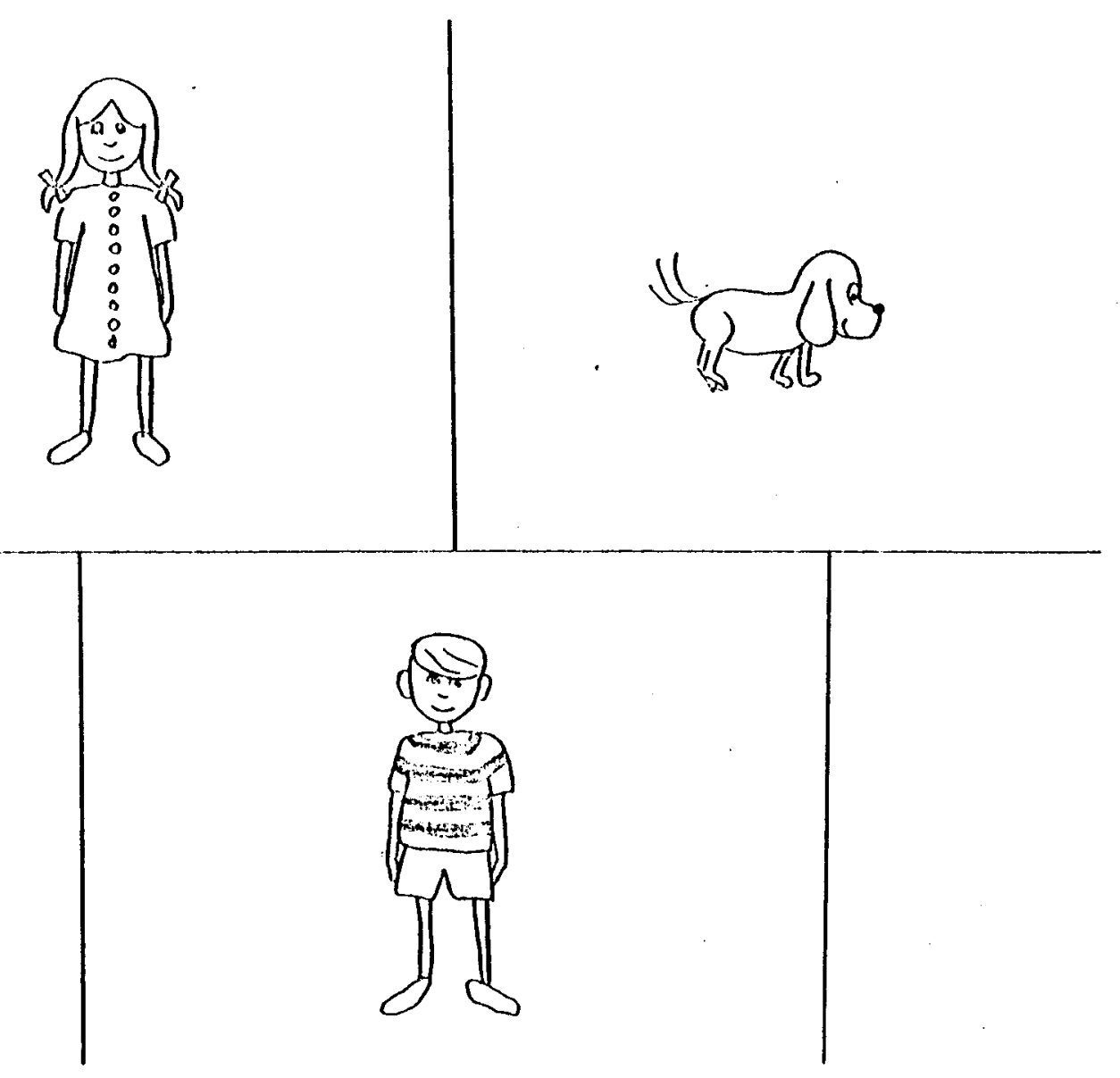

11 


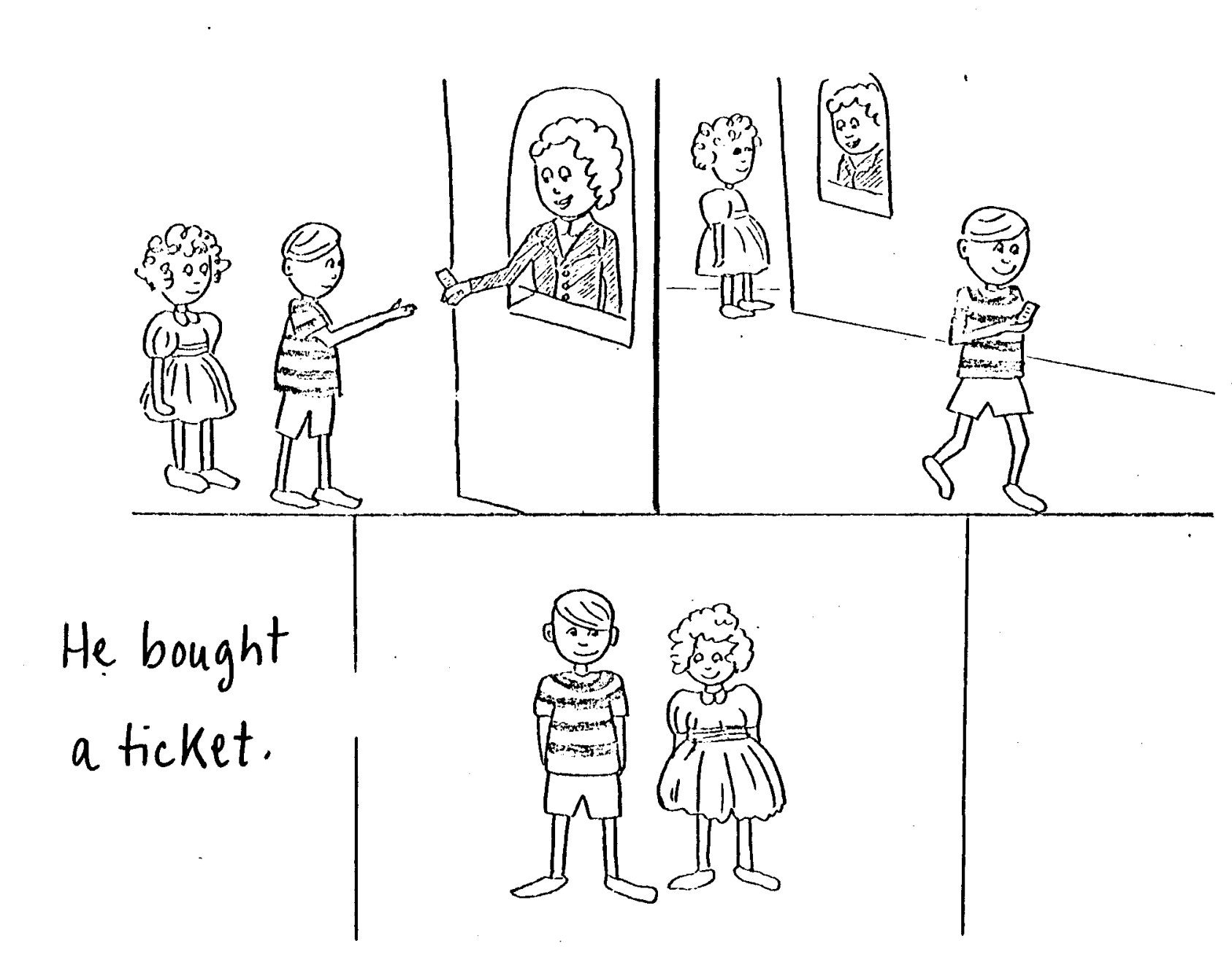


$\sqsubseteq$

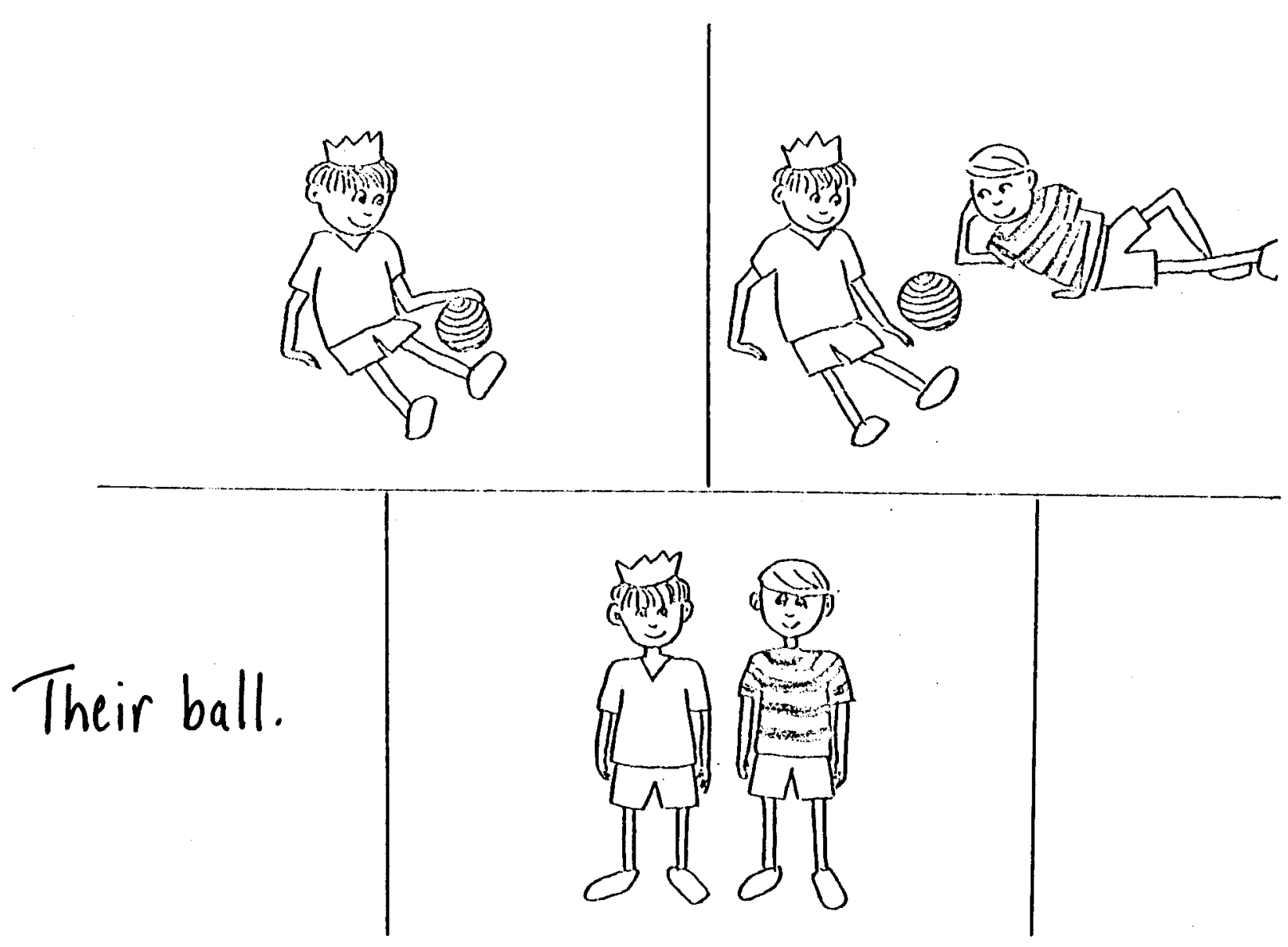

13 


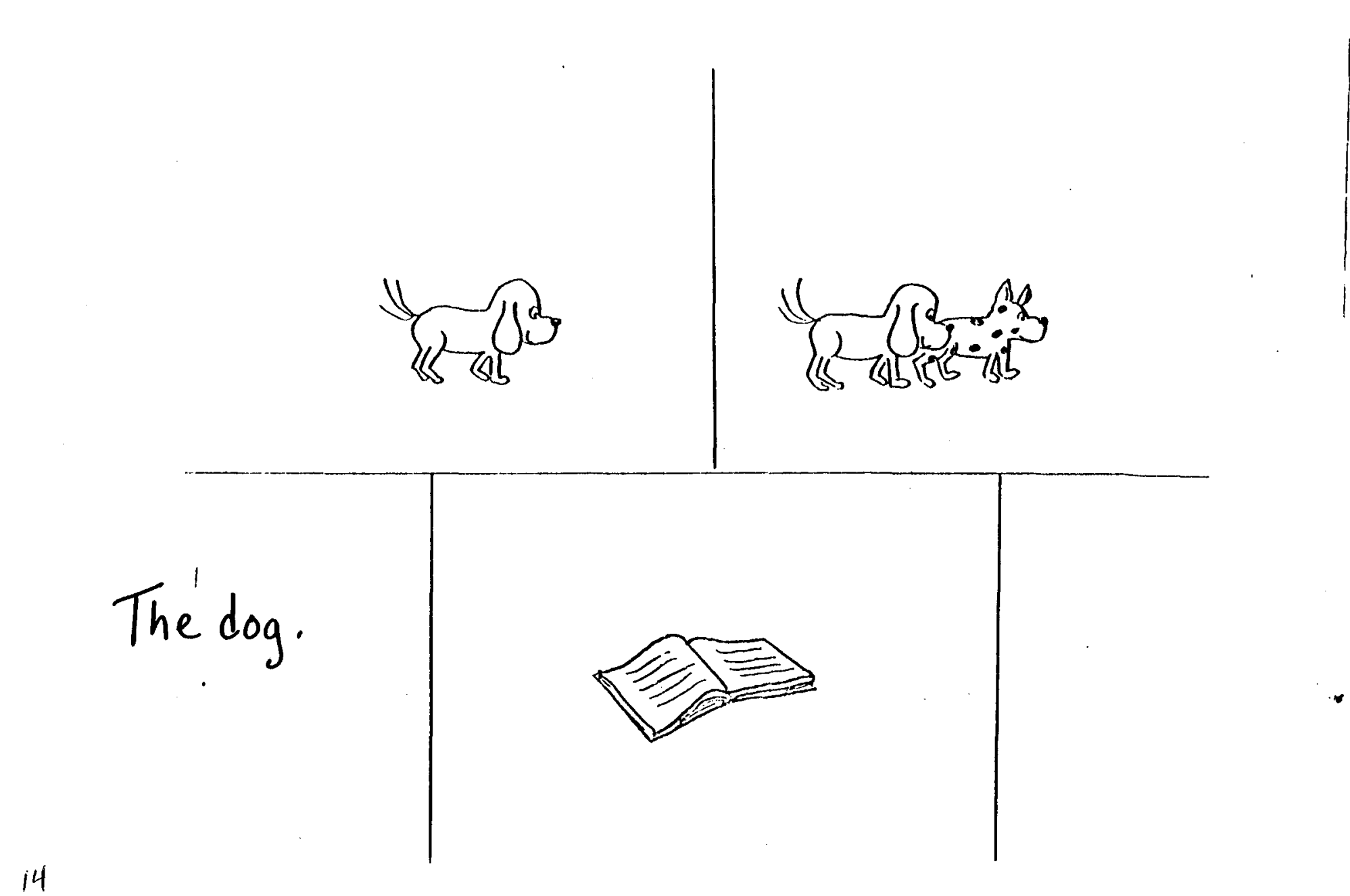


$\stackrel{9}{9}$

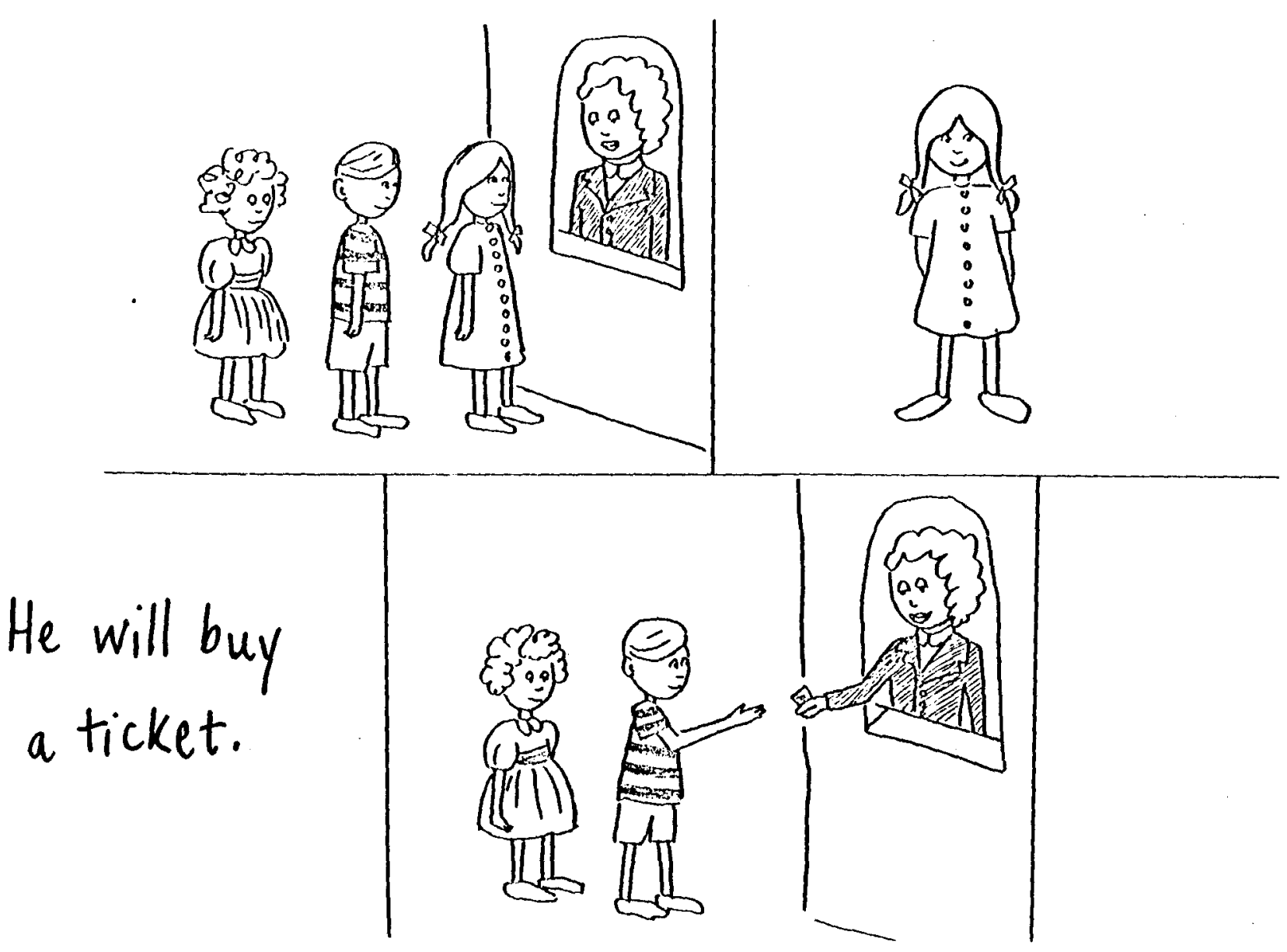

15 
$\stackrel{5}{\circ}$

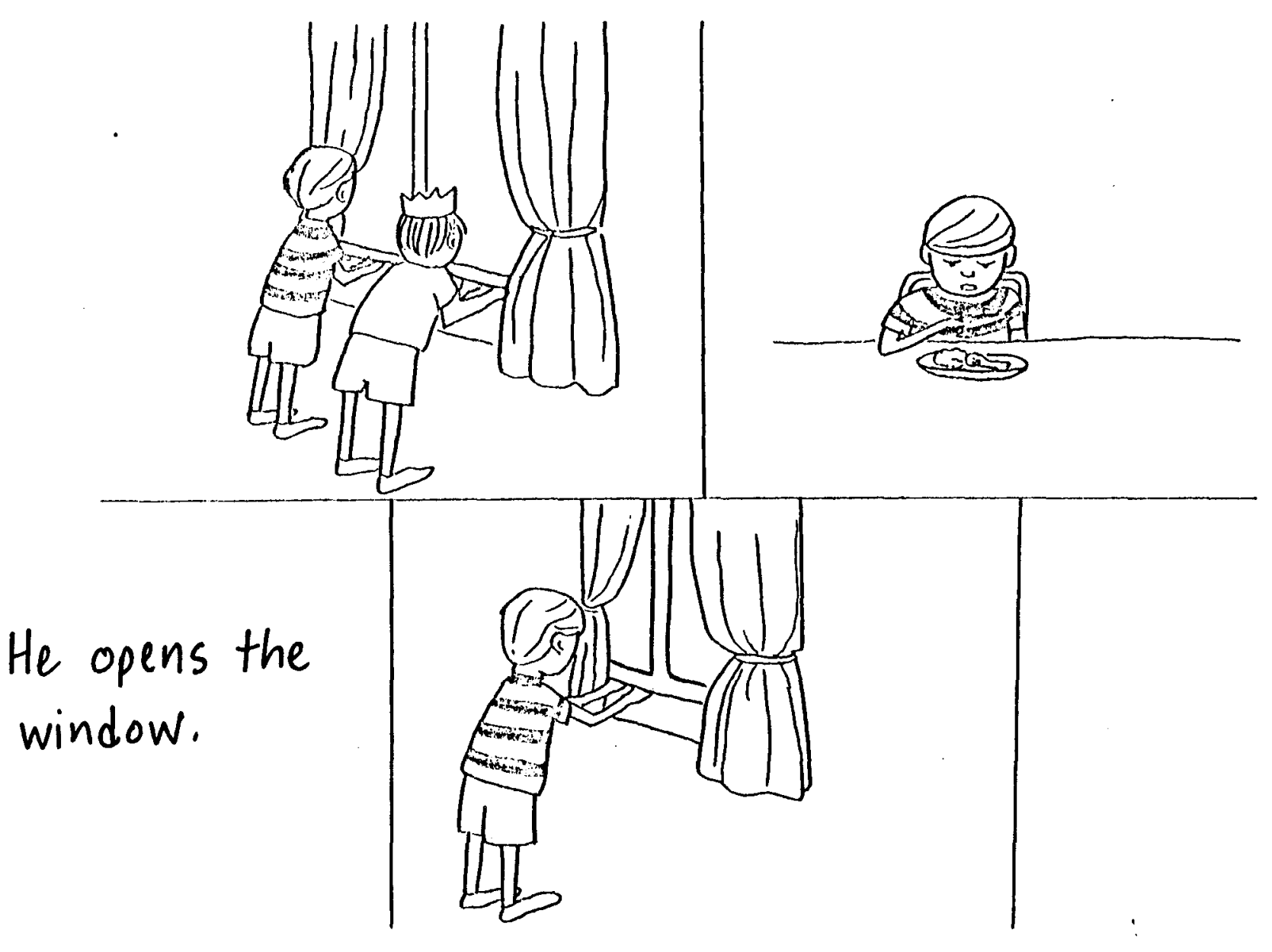


$\stackrel{8}{0}$

He writes.
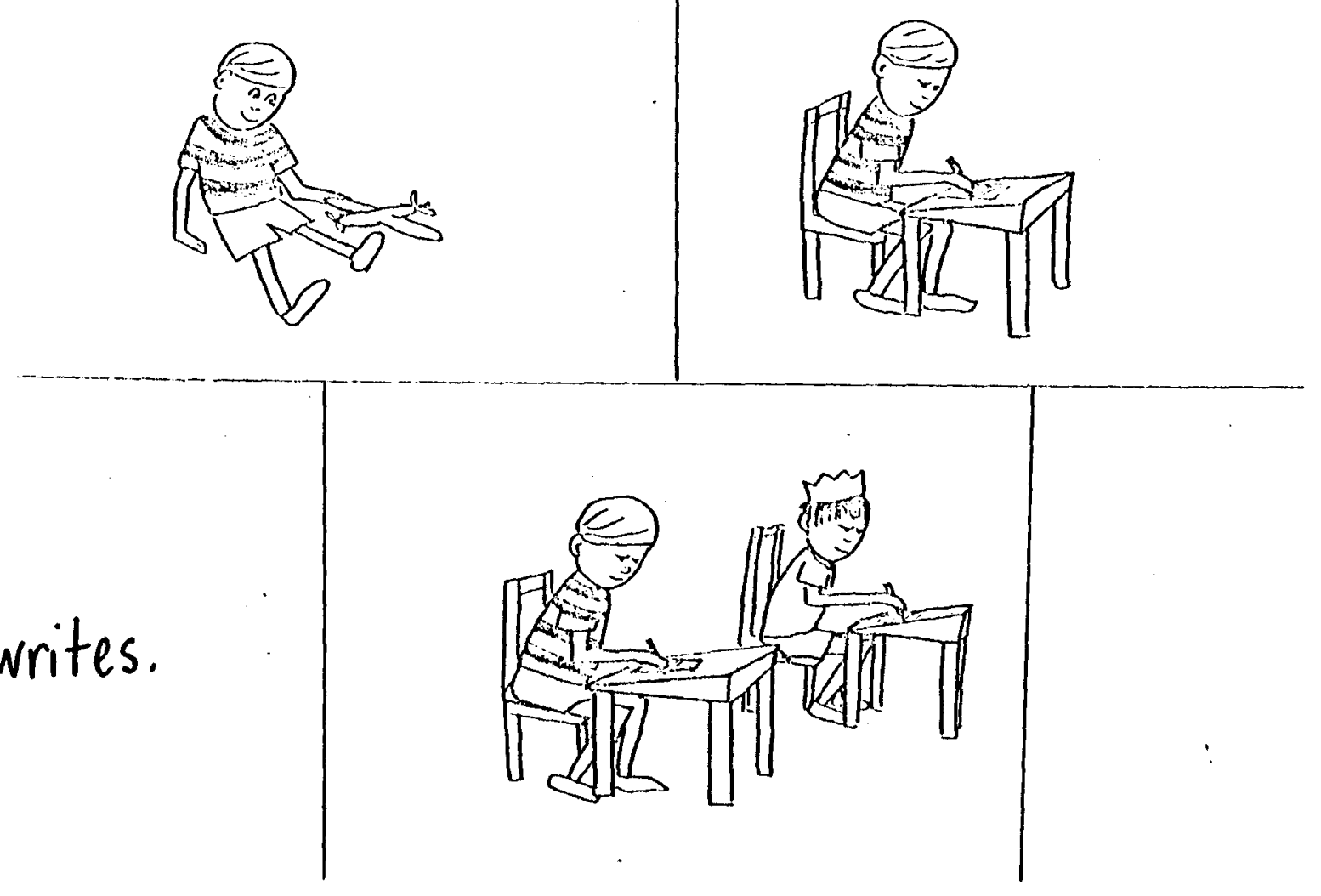

17 
$\stackrel{\circ}{\circ}$

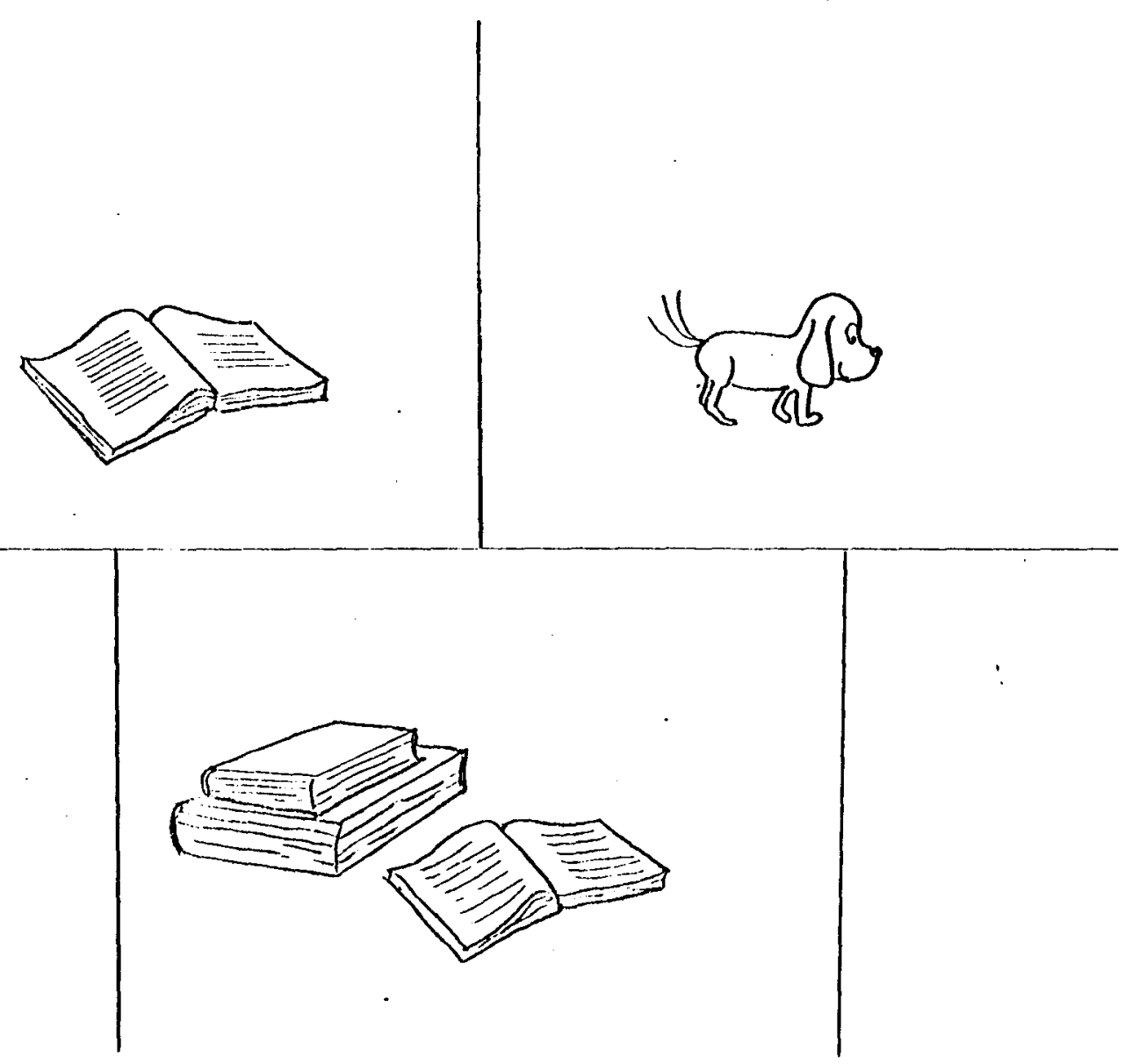

18 
ڤิ

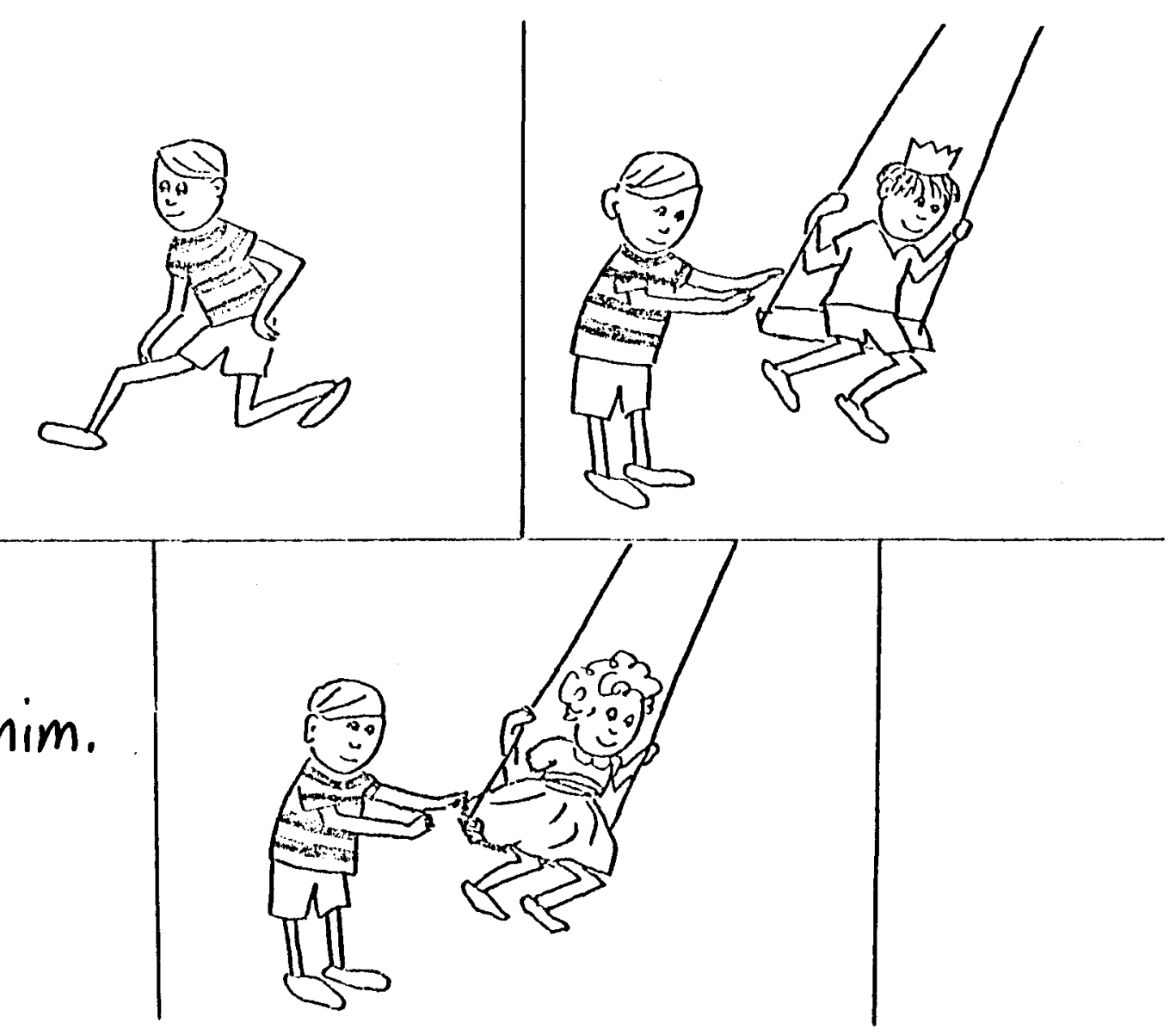

14 
$\stackrel{\infty}{\circ}$

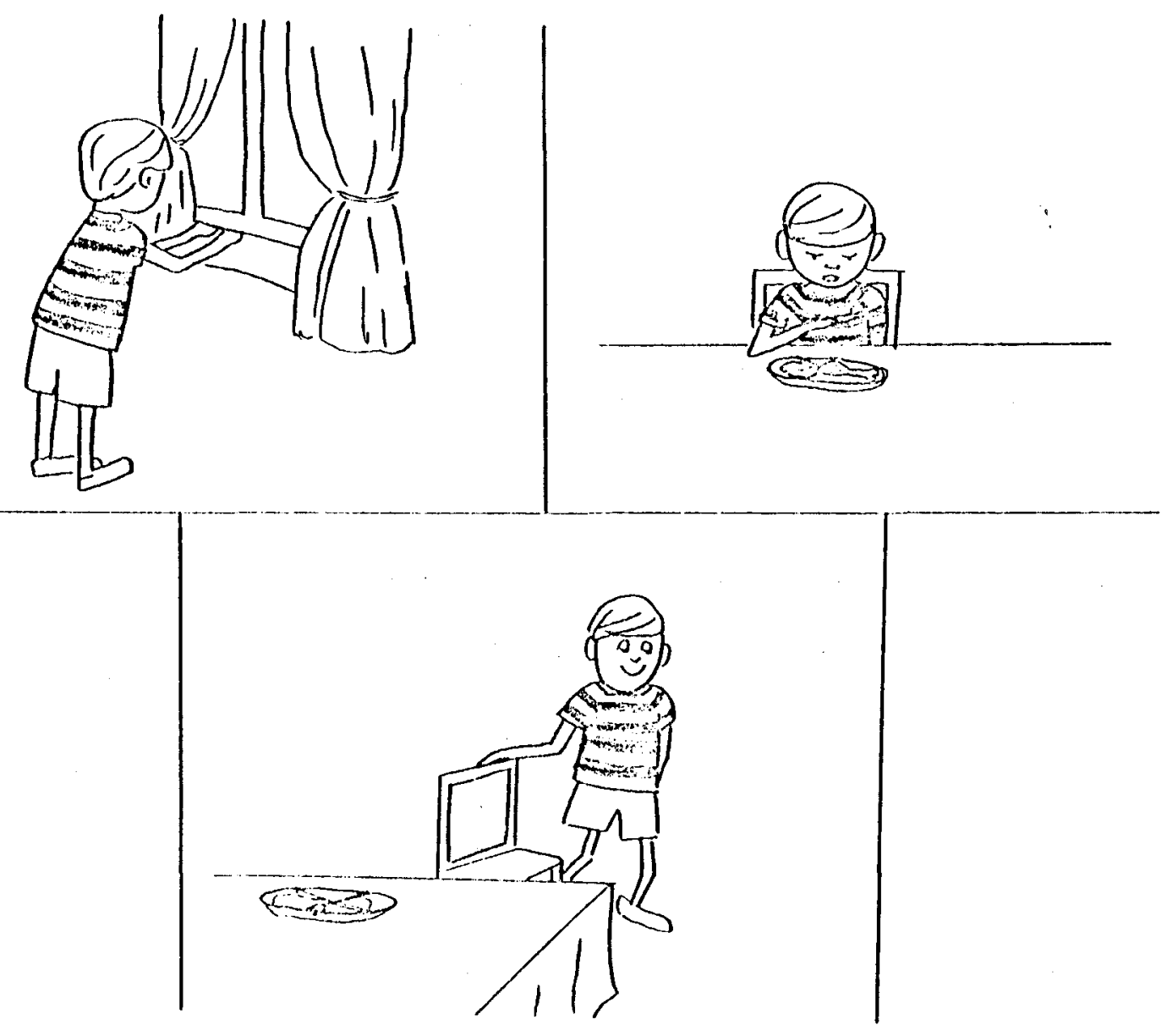

.20 


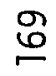

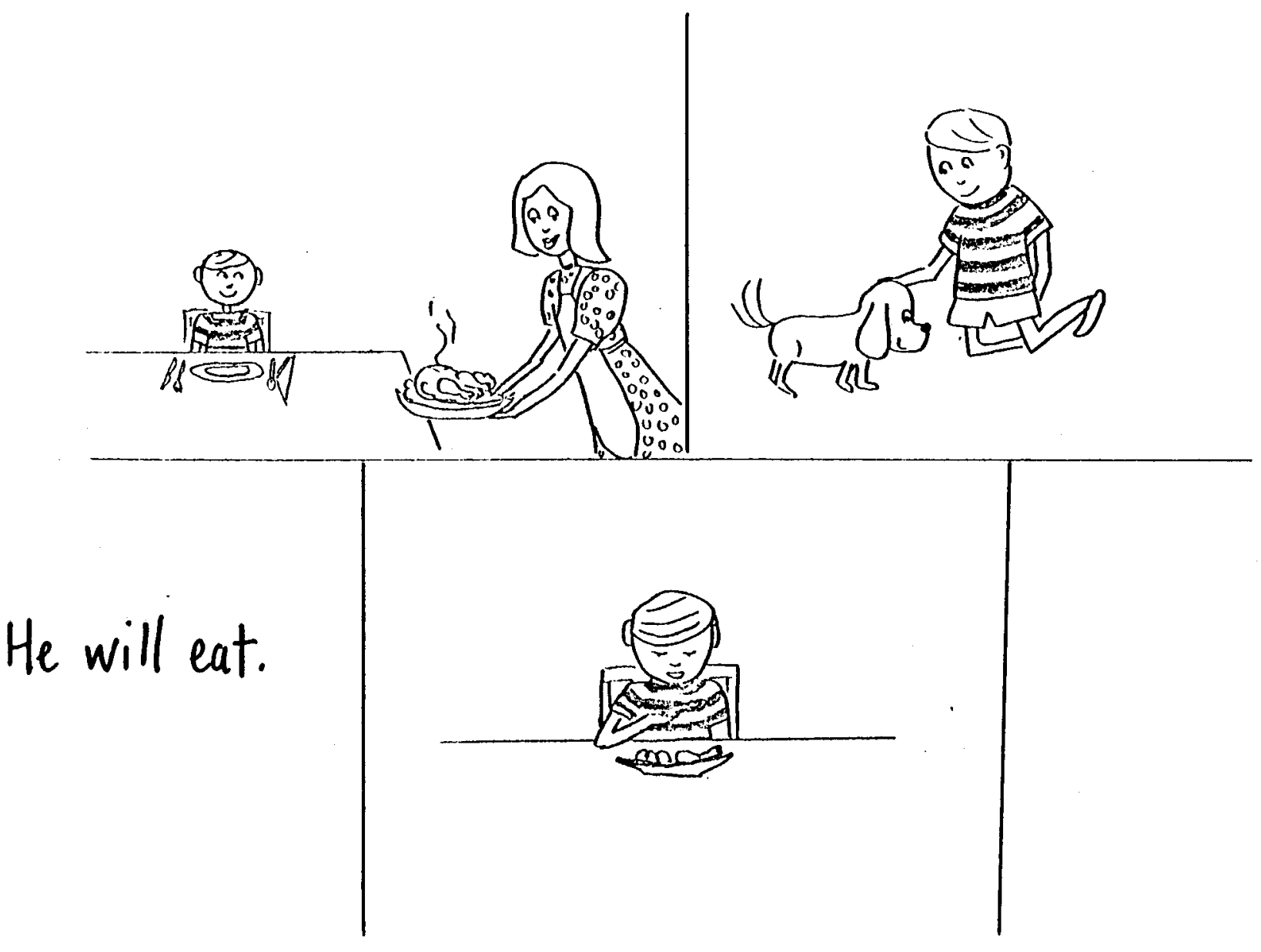




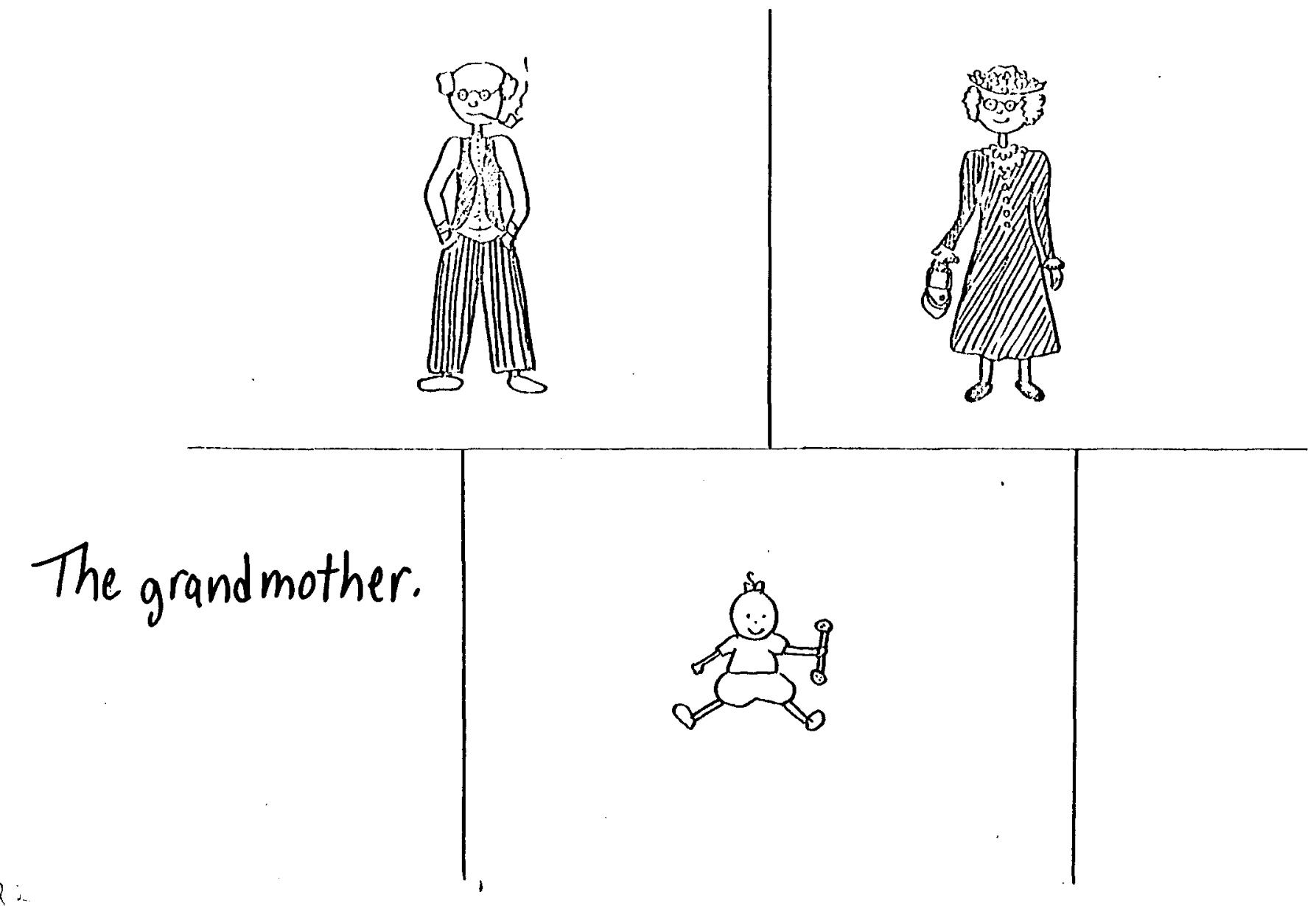


$\Sigma$

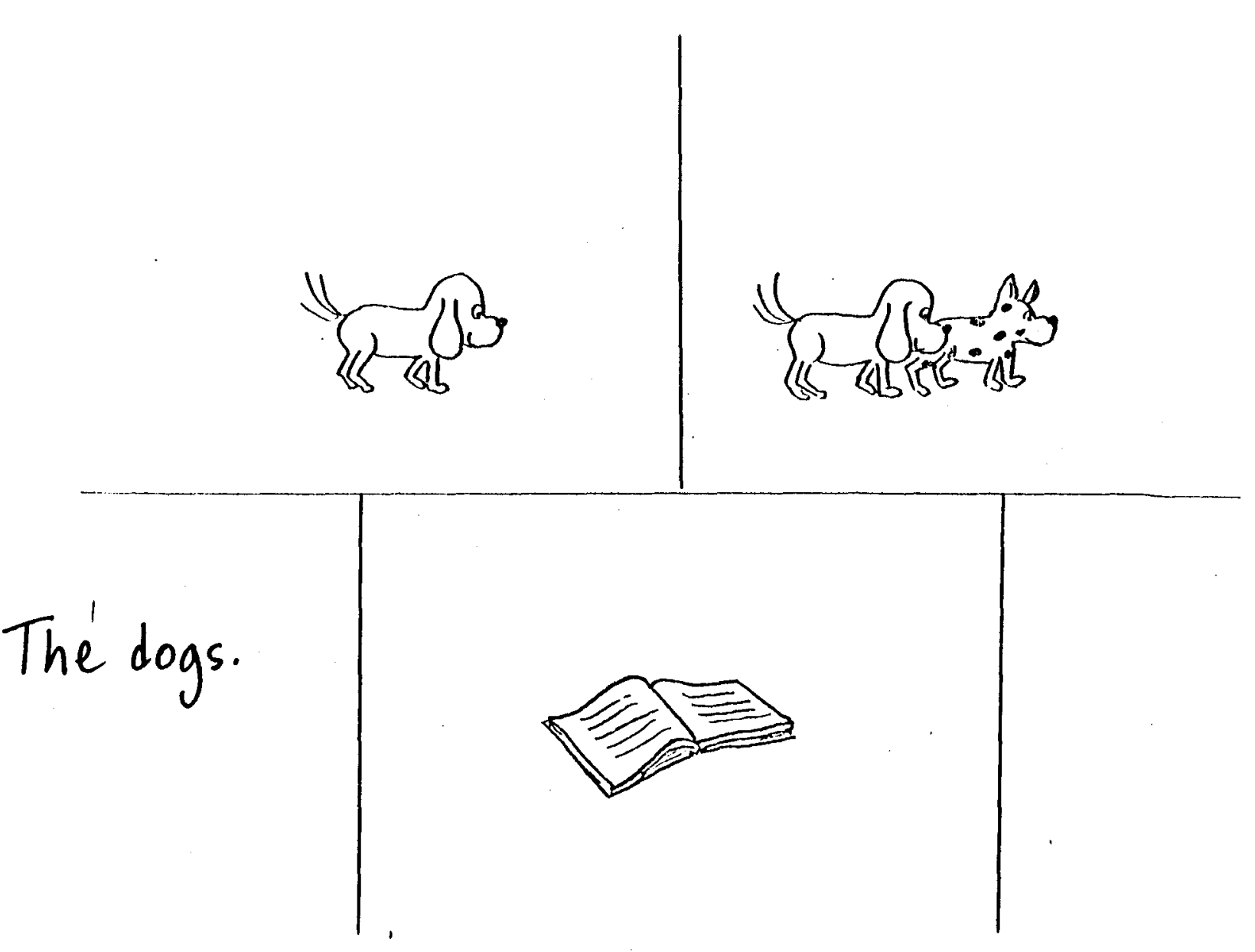


$\cong$

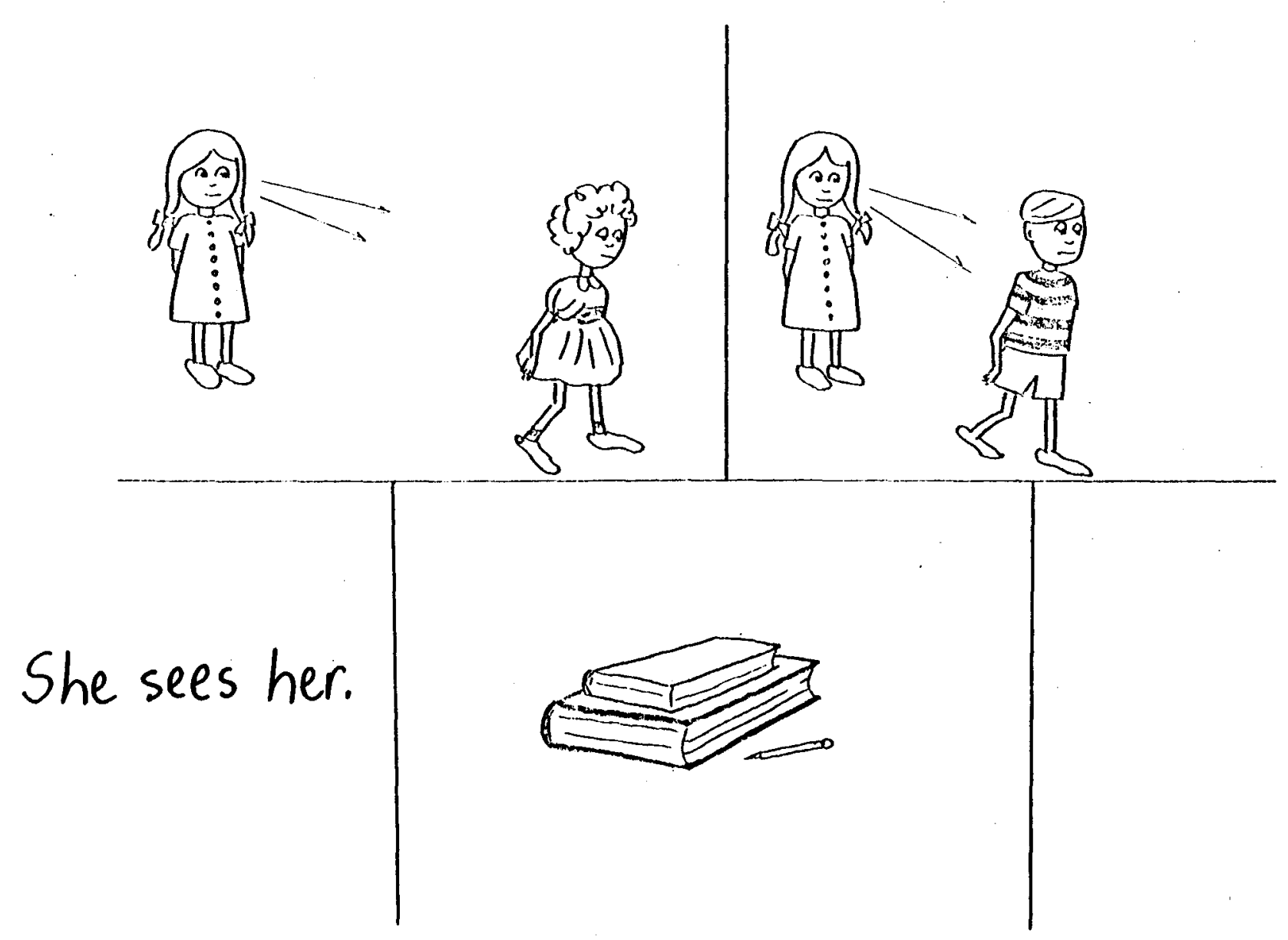

24 
$\stackrel{2}{=}$

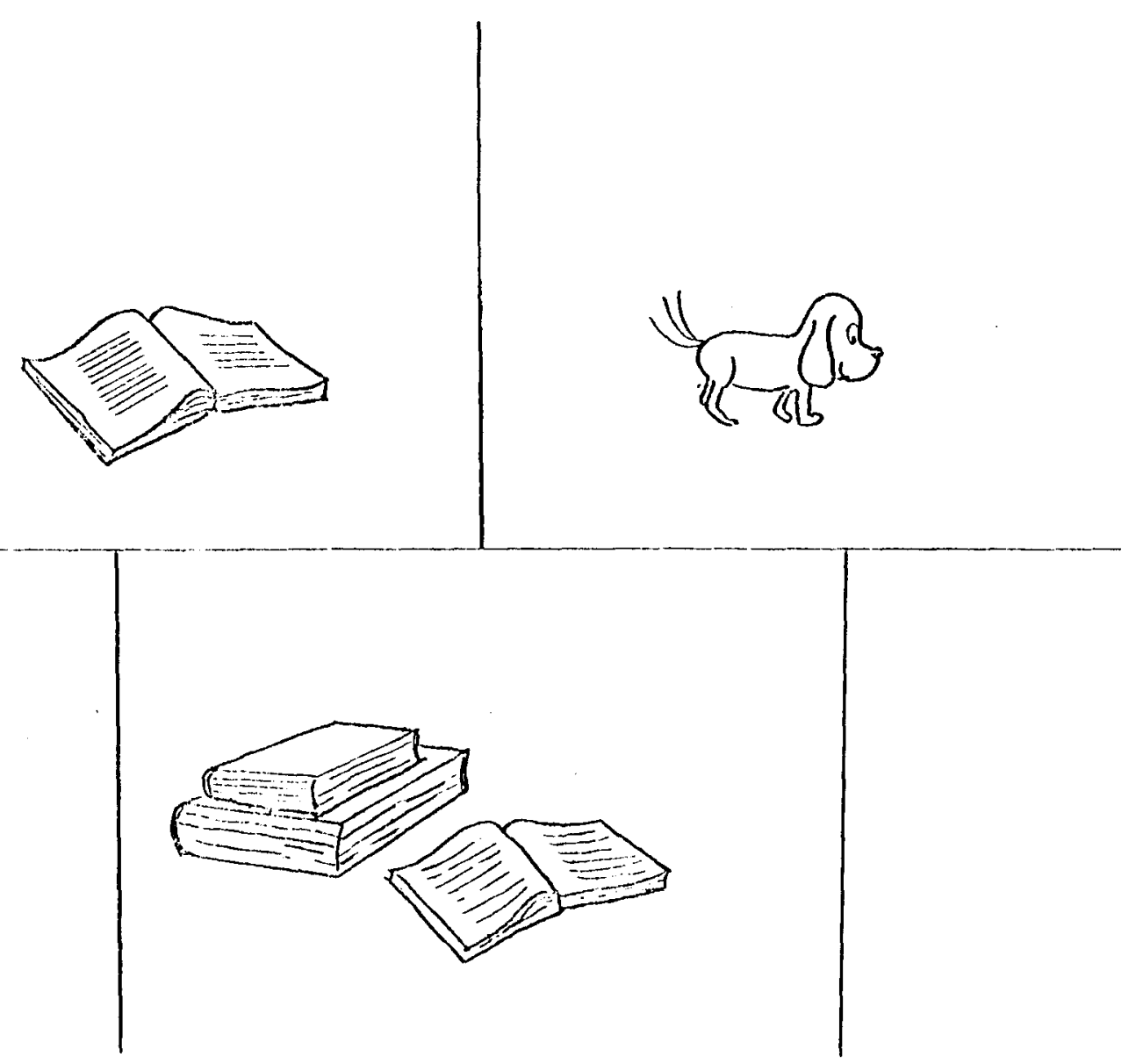

25 
$\stackrel{+}{I}$

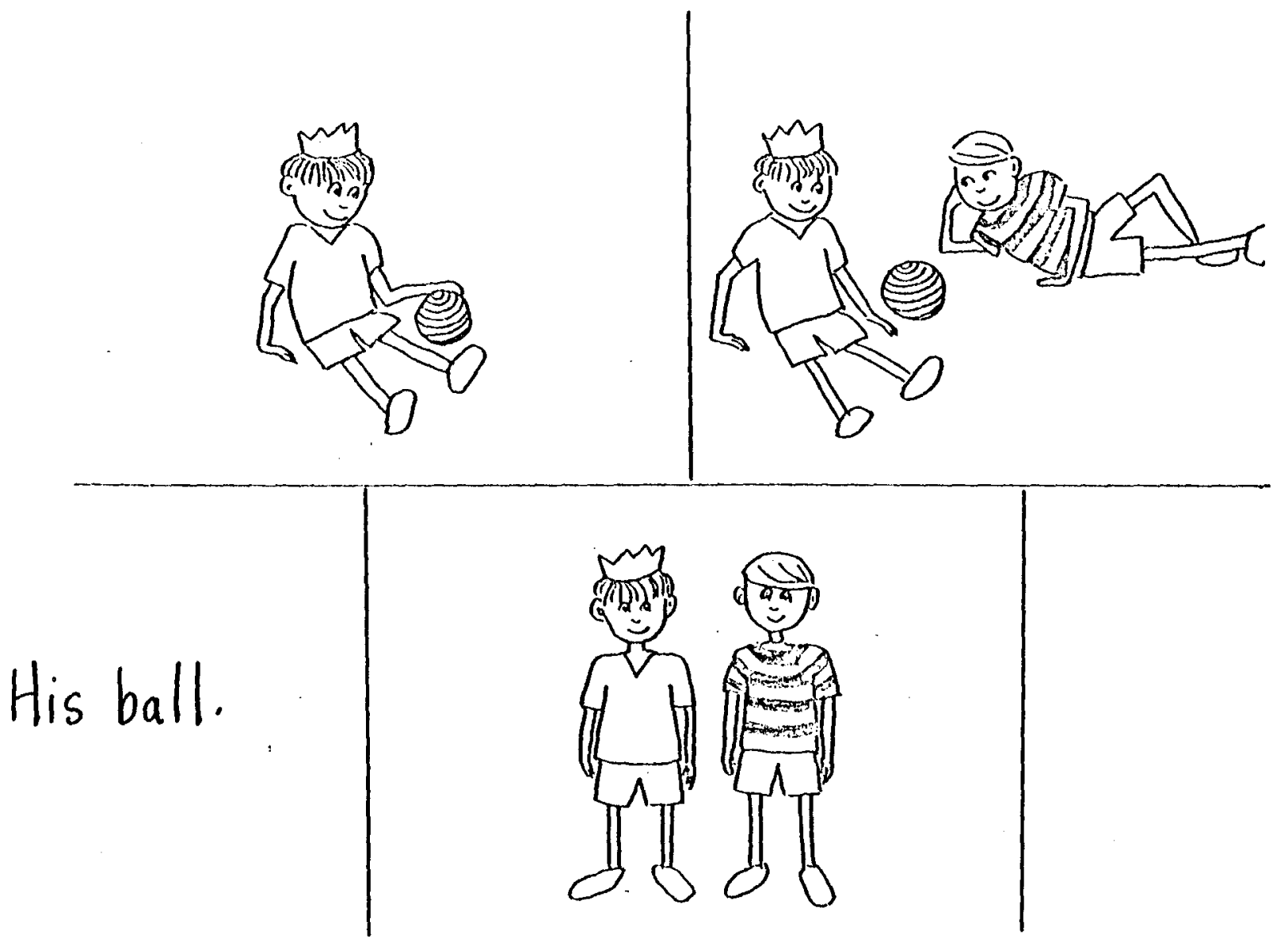

21 


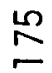

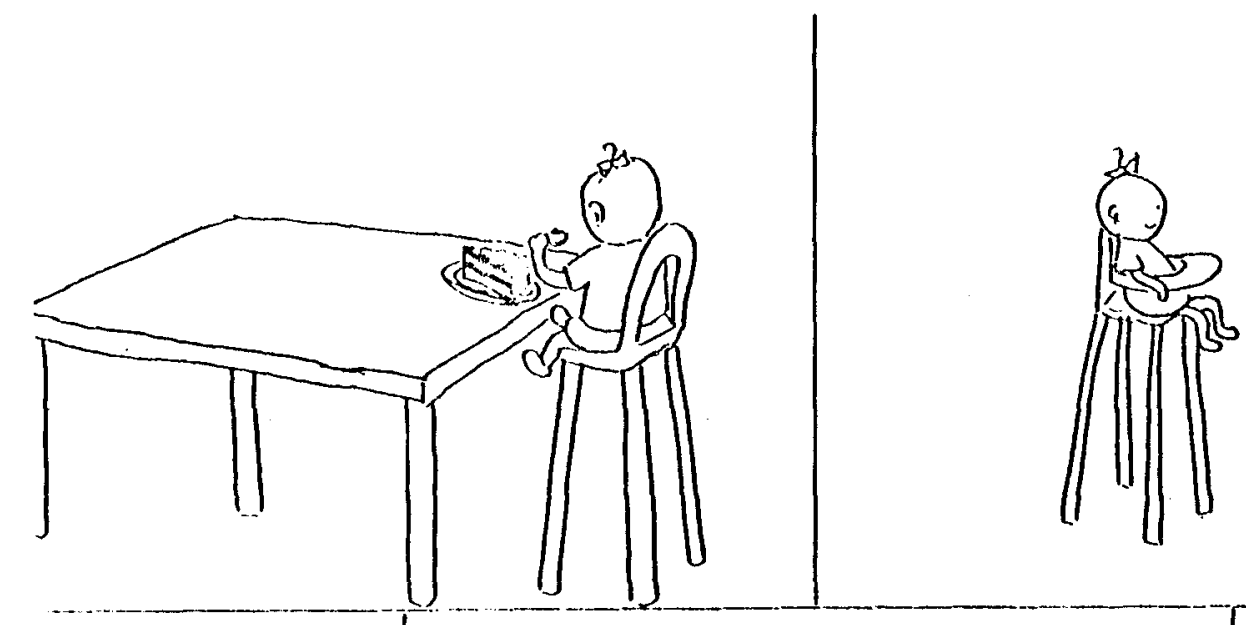

The baby on the table eats the cake.

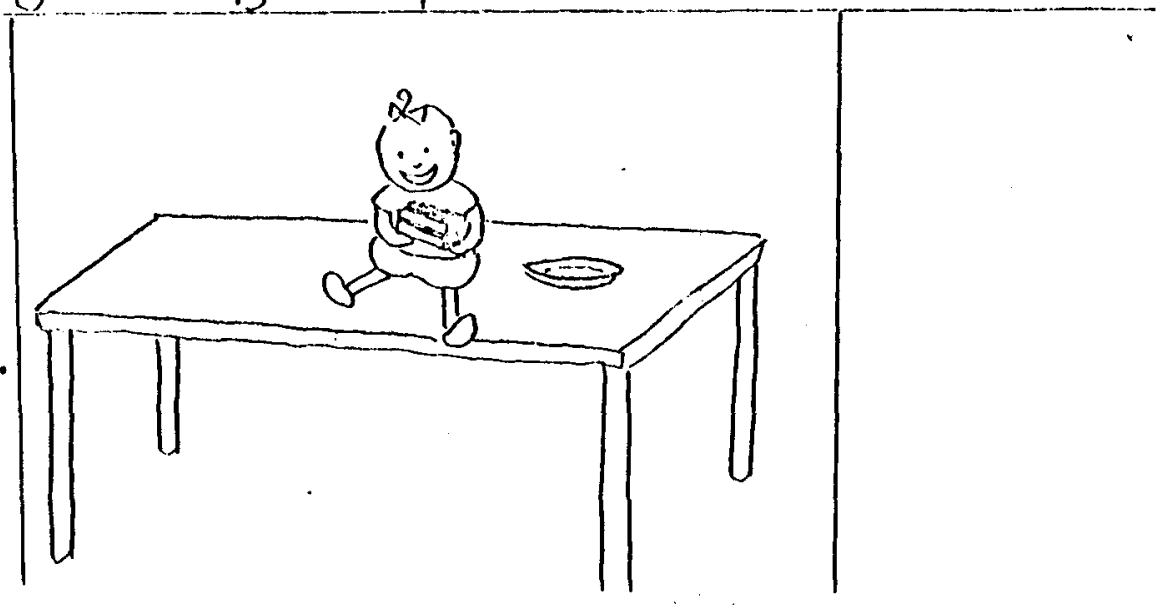

27 
$\stackrel{ }{\longleftarrow}$

The black ball is bigger than the white ball.

25

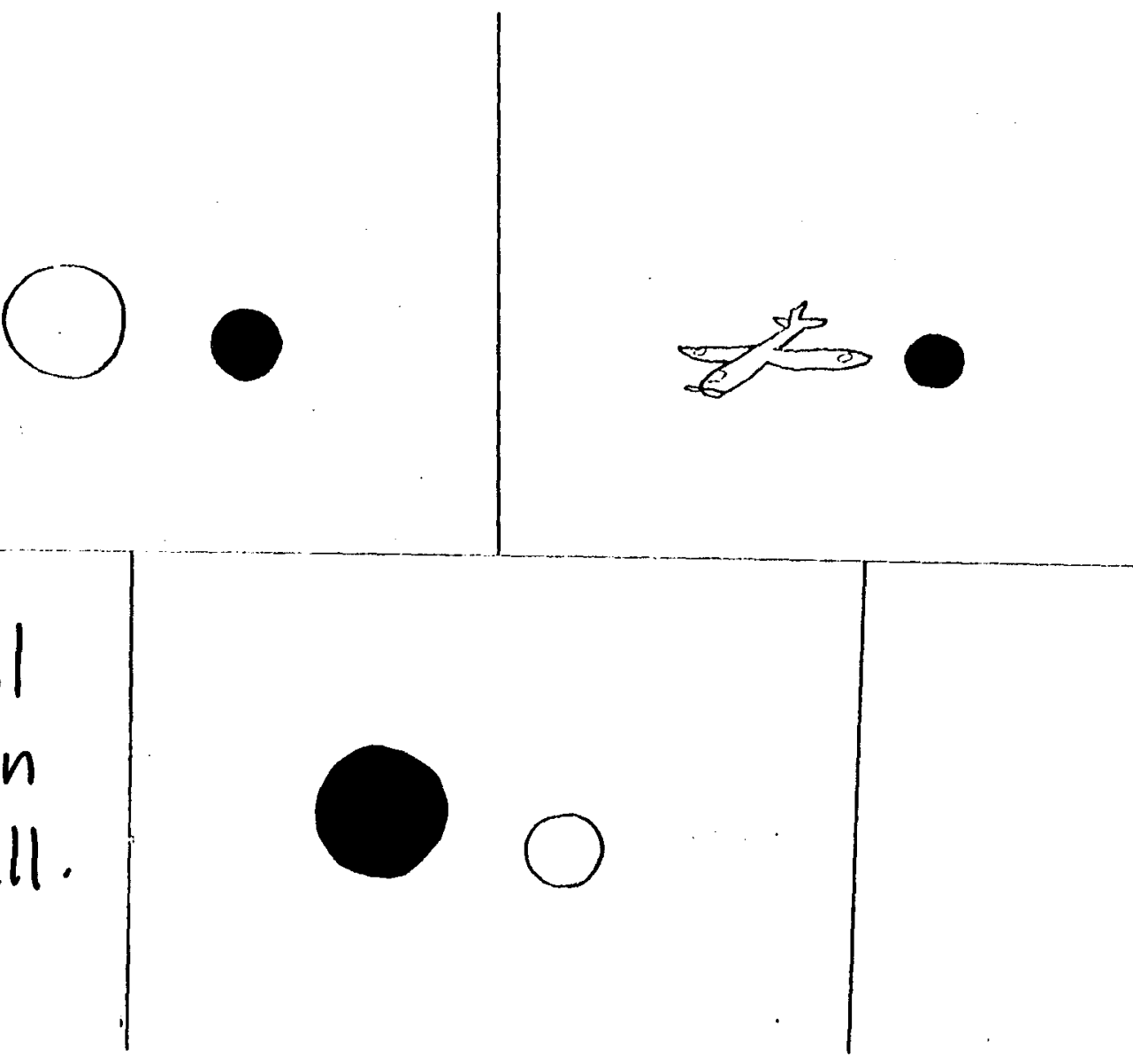


$\Sigma$

The boy hits the ball.

21

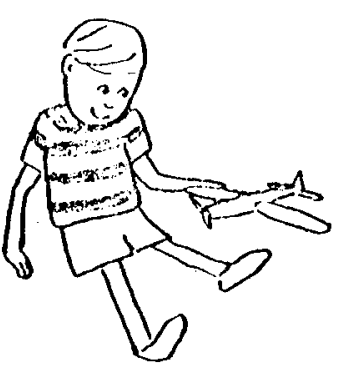




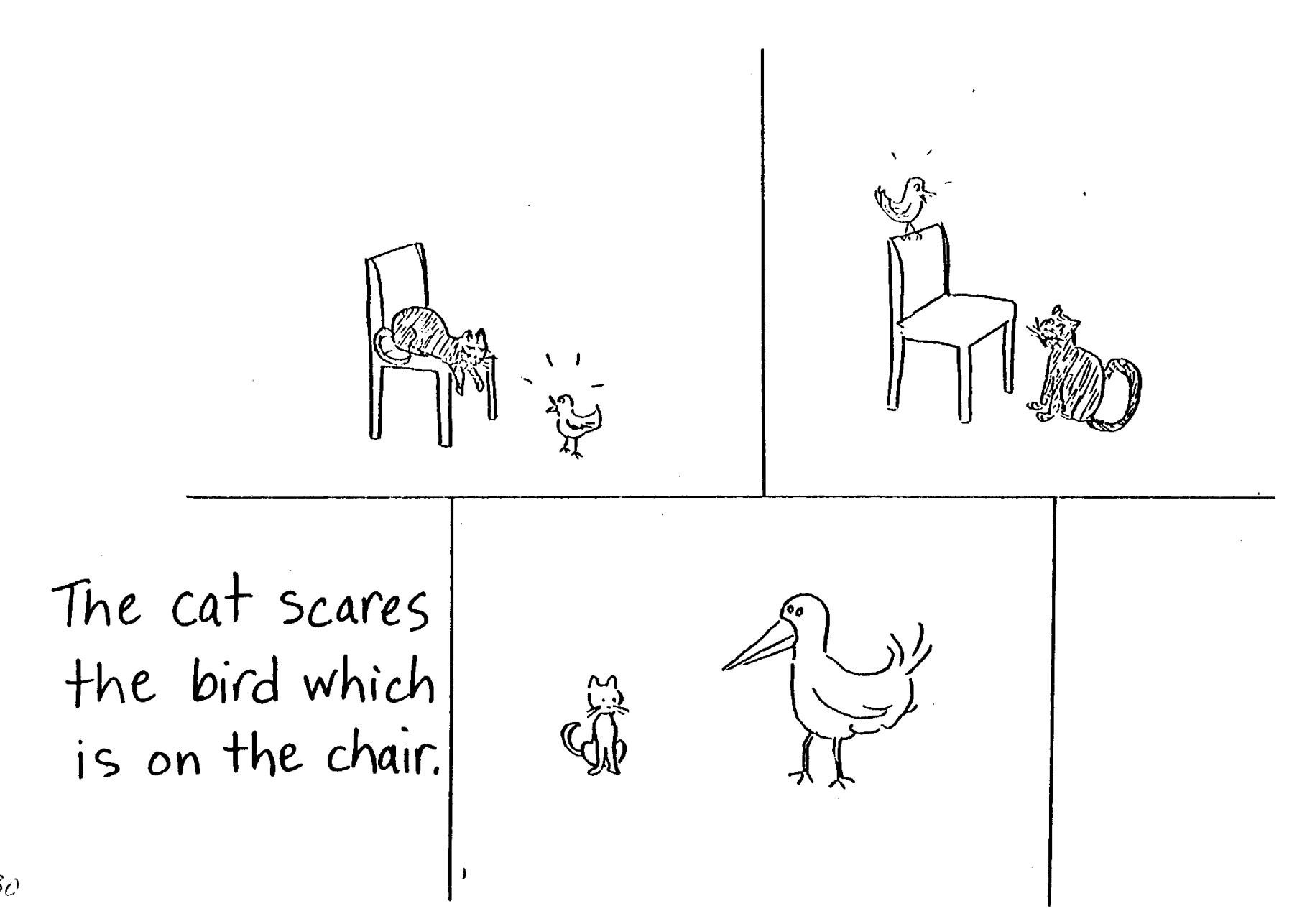


$\stackrel{9}{2}$

31 
$\stackrel{0}{\circ}$

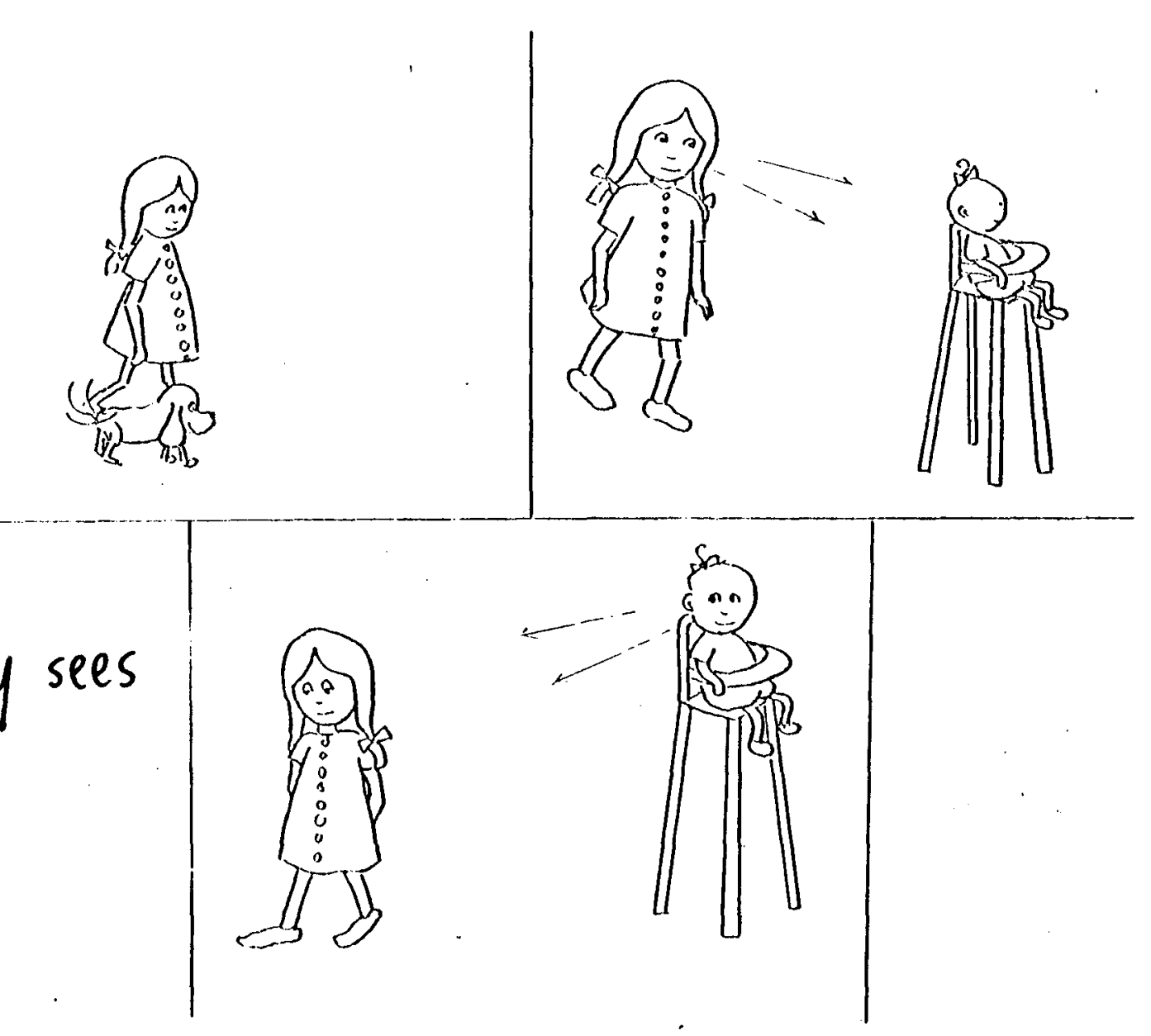

32 
$\stackrel{\square}{\stackrel{0}{2}}$
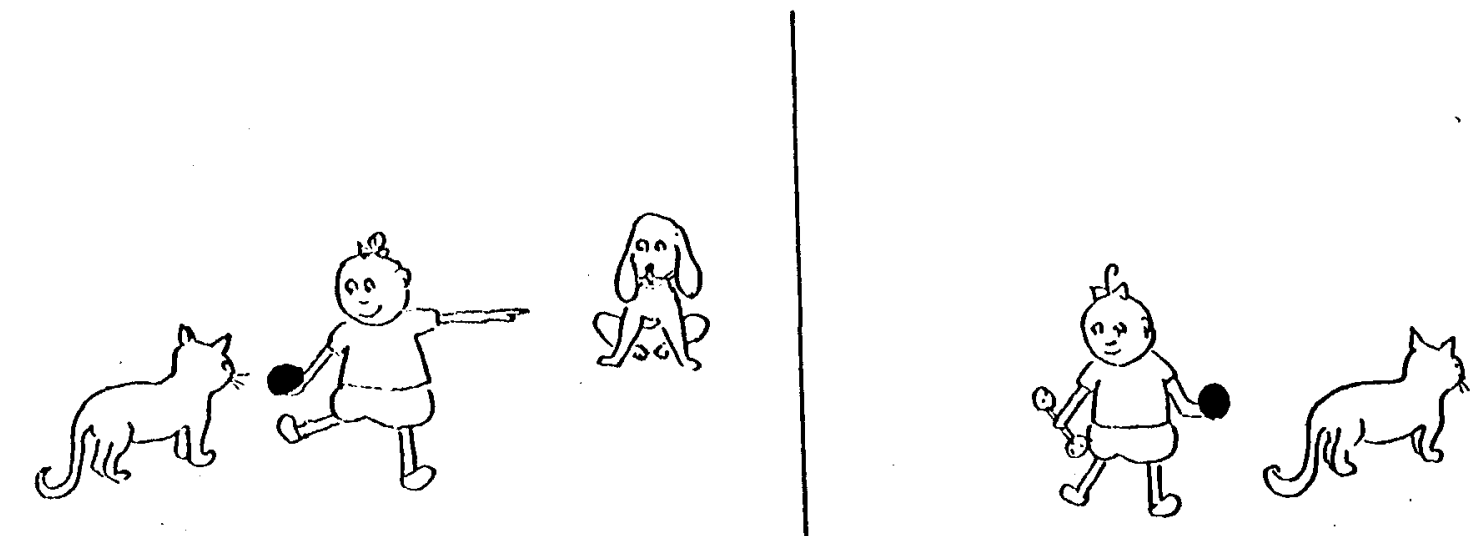

The baby gives the ball for the dog to the cat.

.33

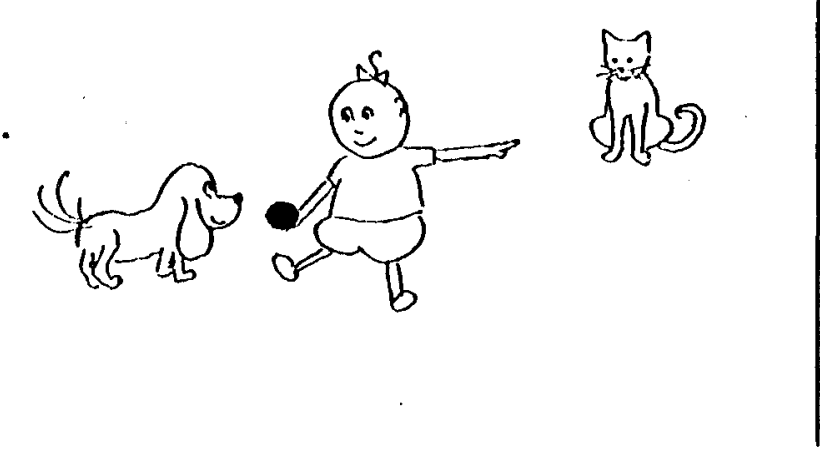




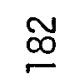

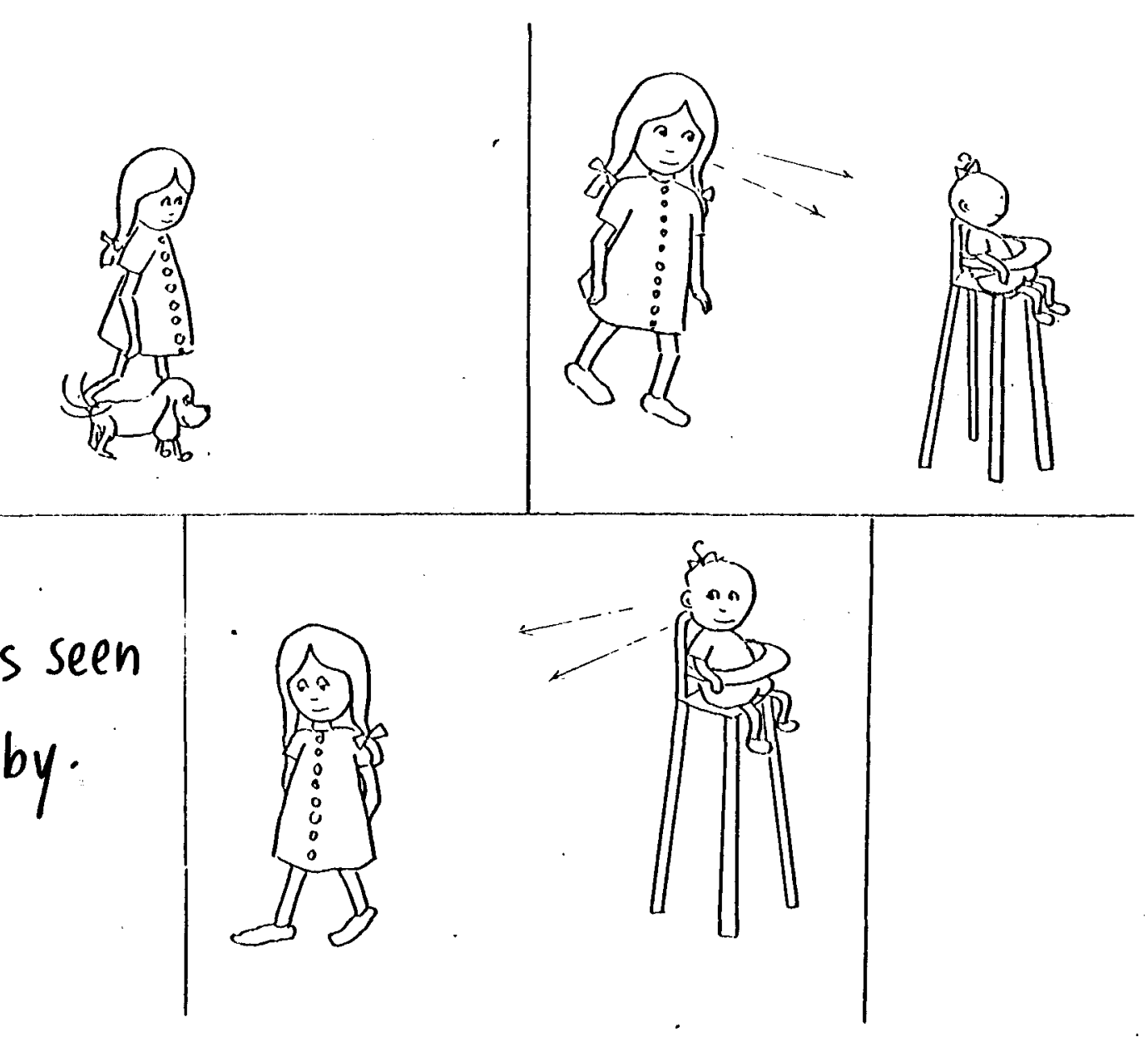

34 


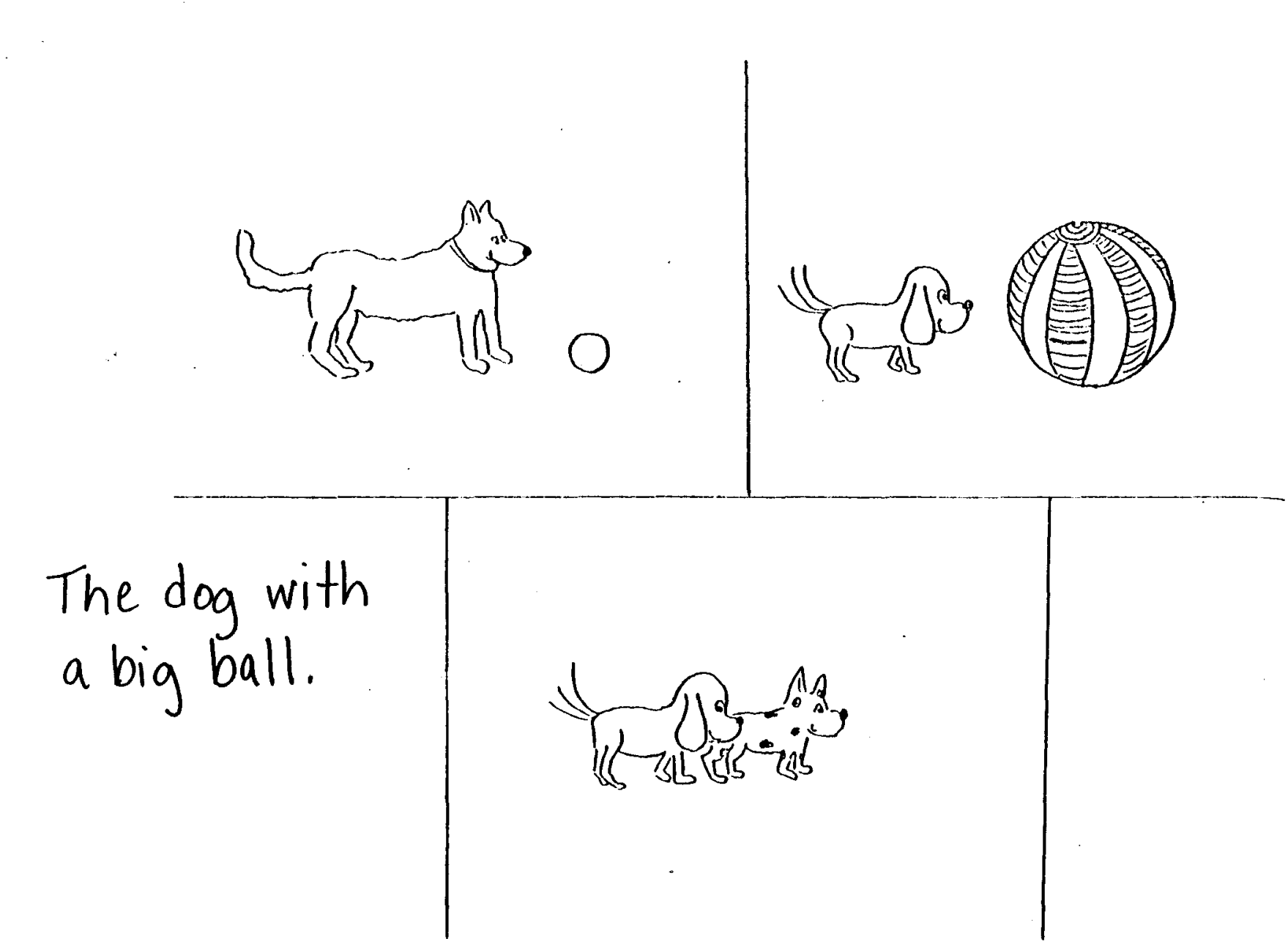




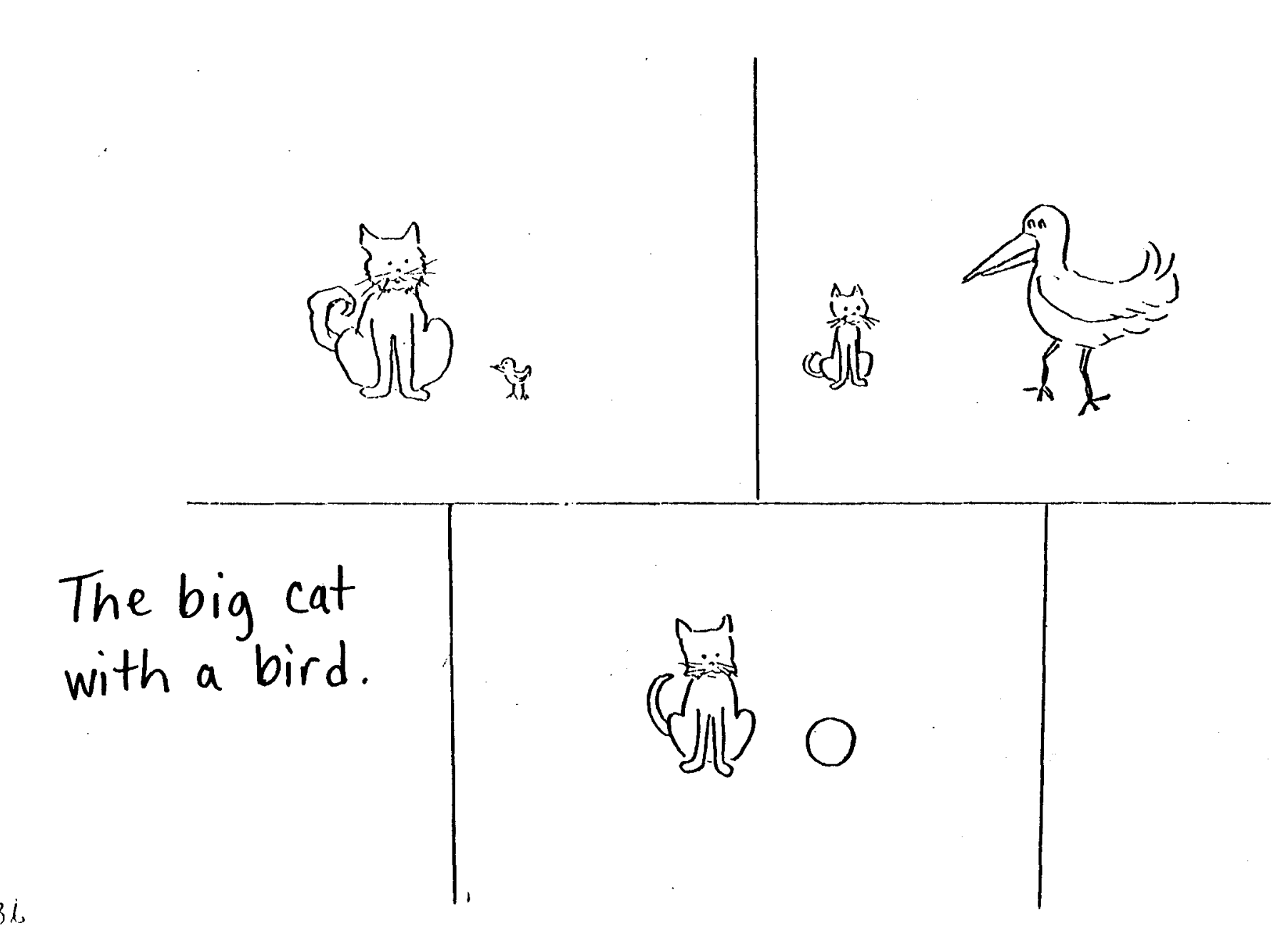


$\stackrel{\leftrightarrow}{\infty}$

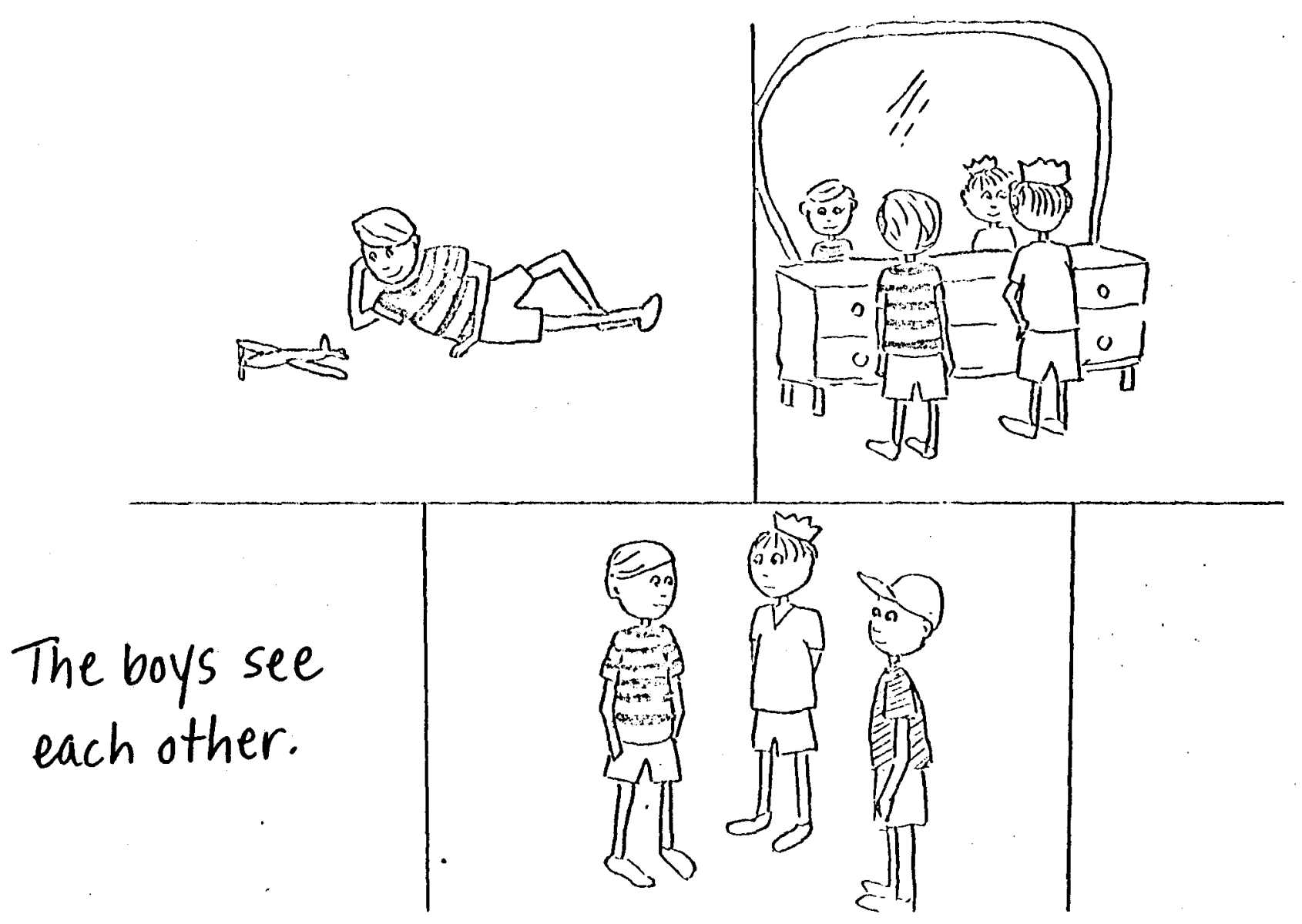

37 
$\stackrel{8}{\circ}$

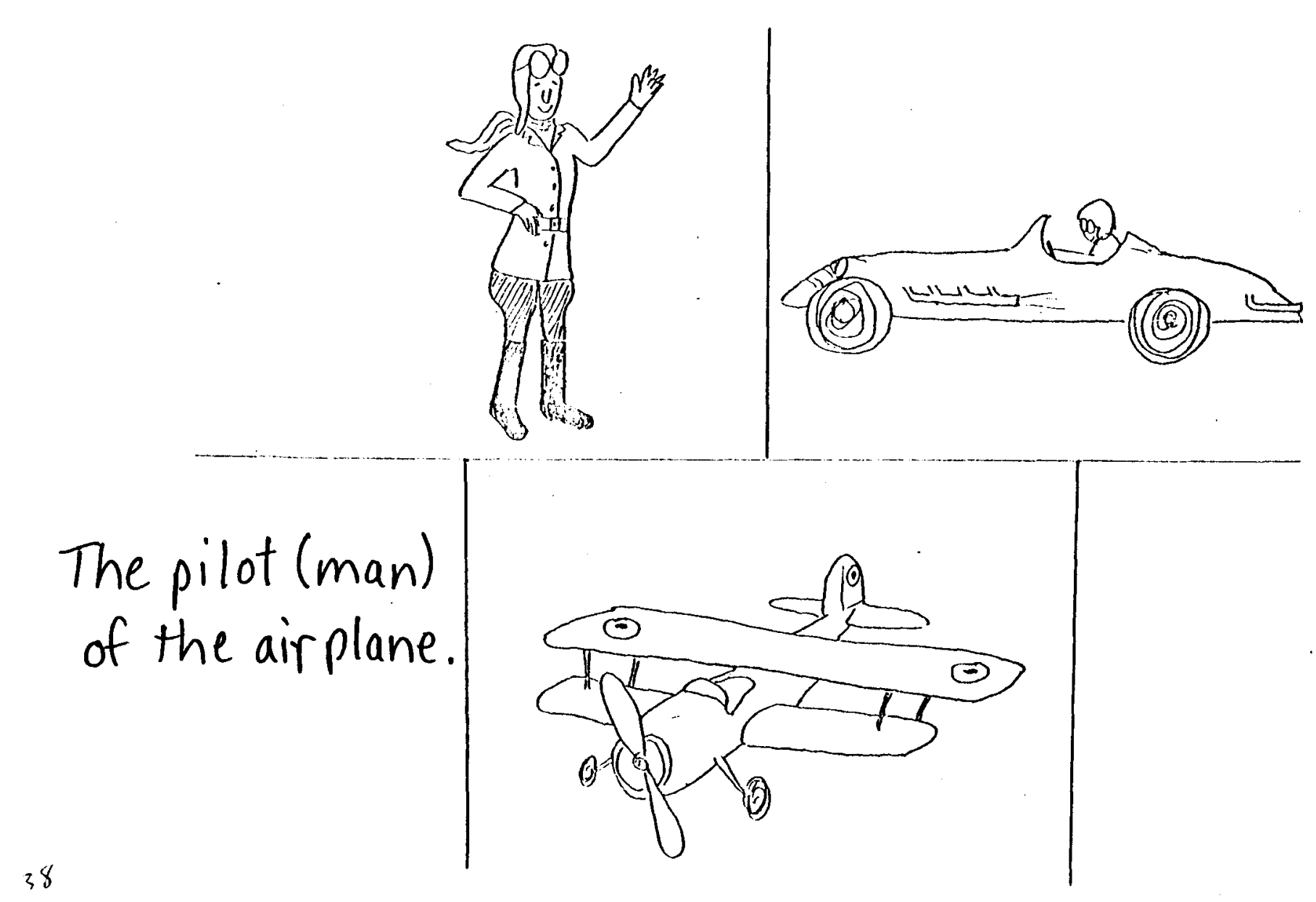


$\stackrel{\infty}{\infty}$

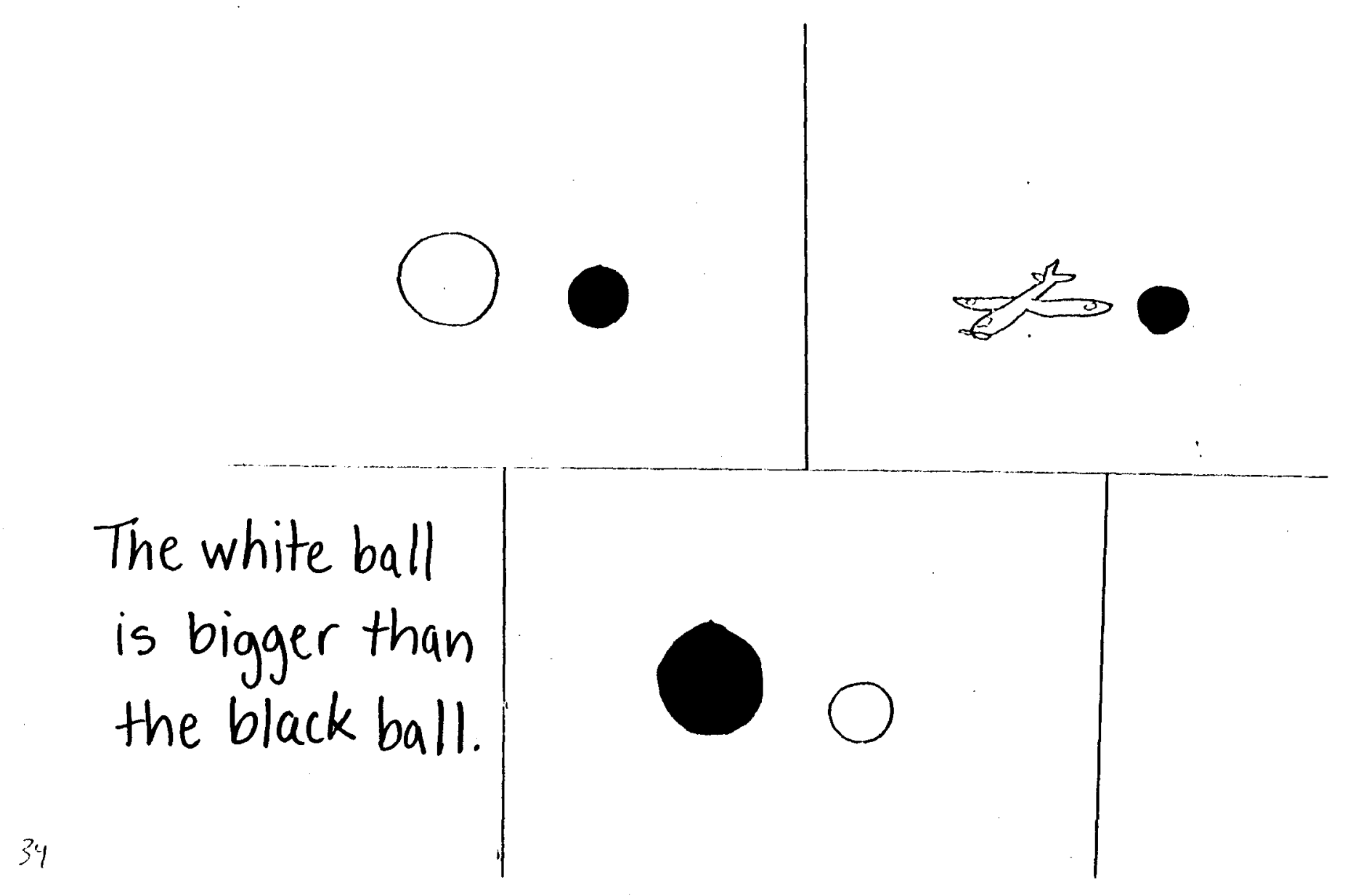


$\stackrel{\infty}{\infty}$

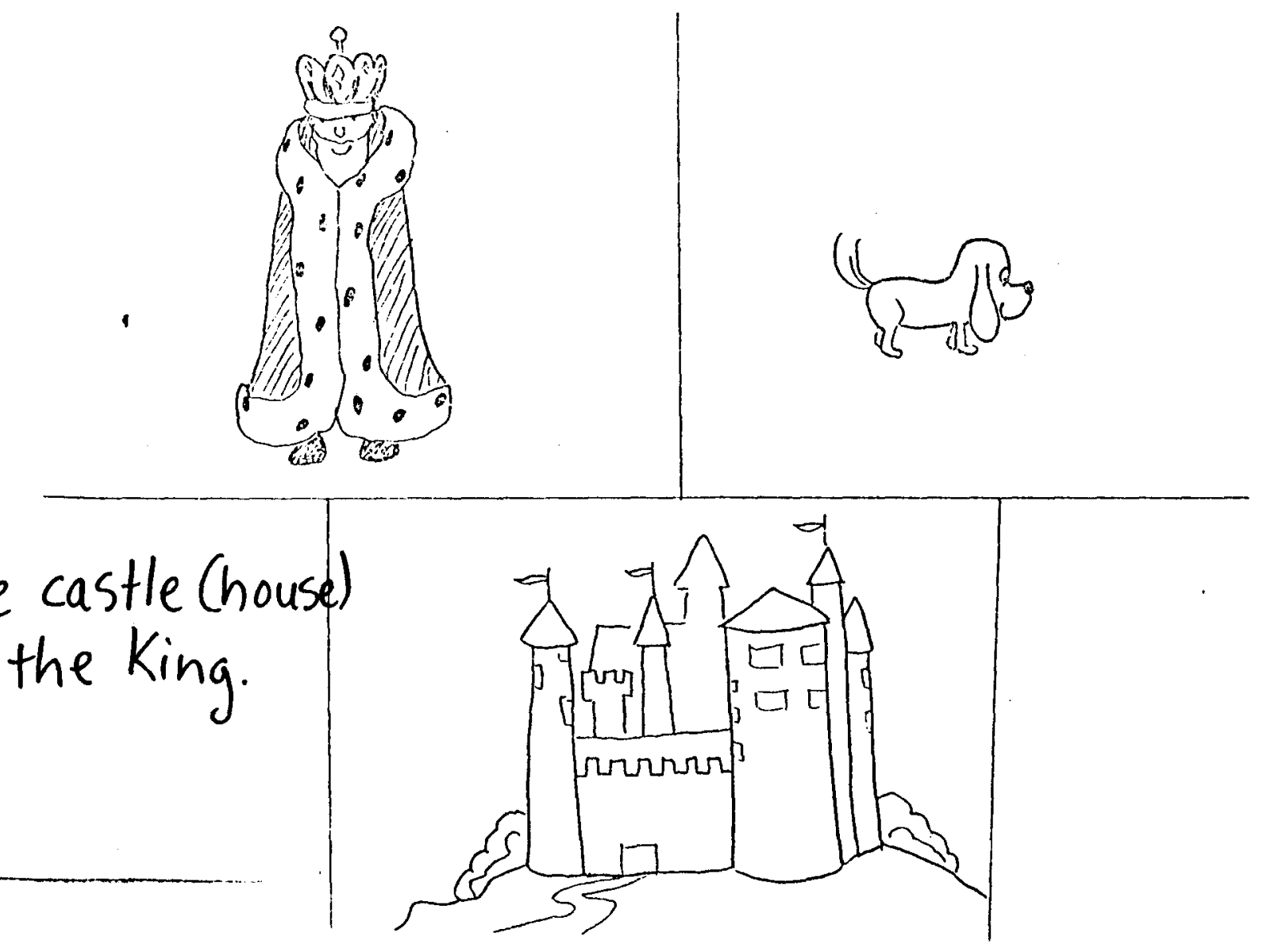


$\stackrel{\infty}{\check{\infty}}$

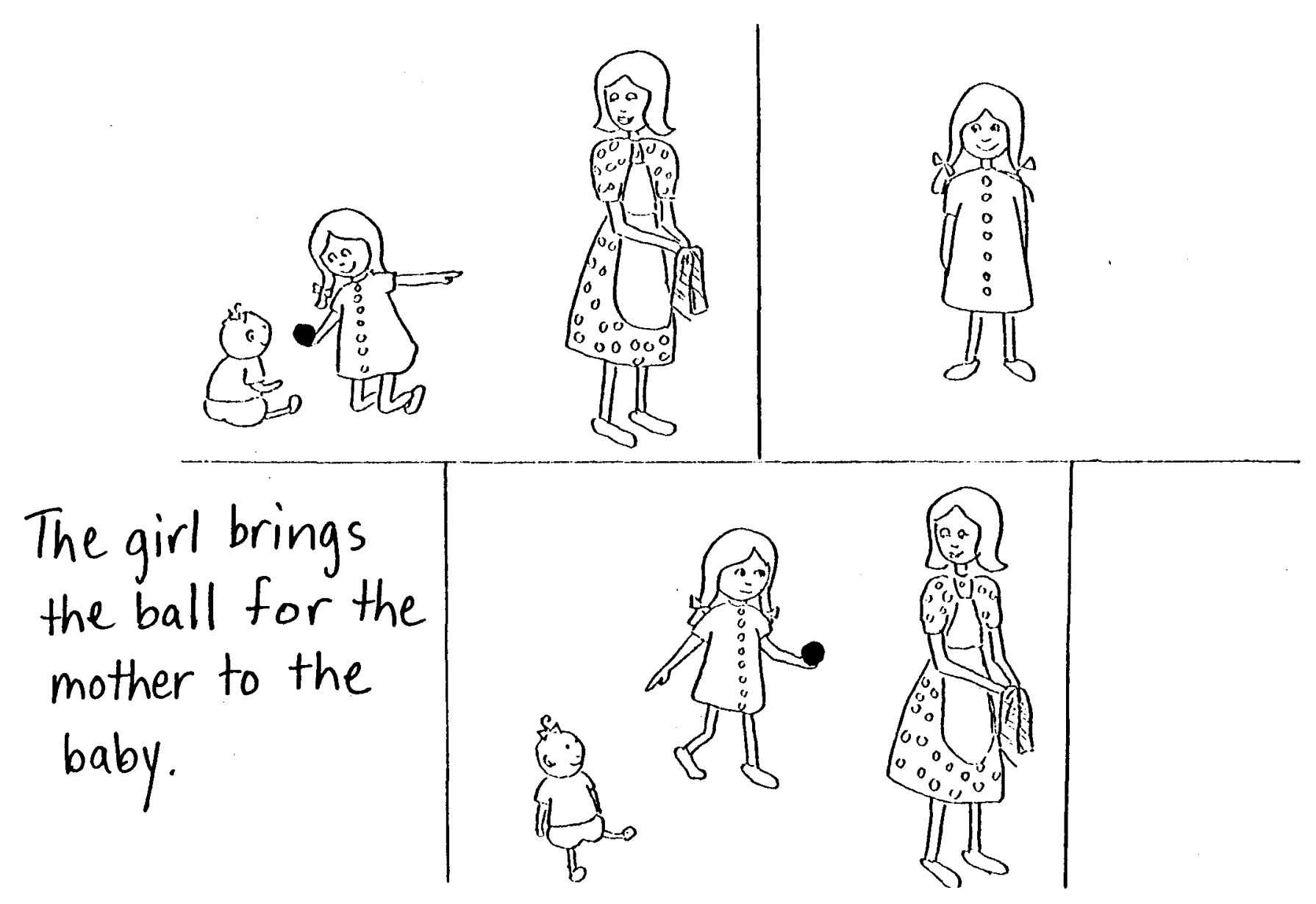

41 
욤

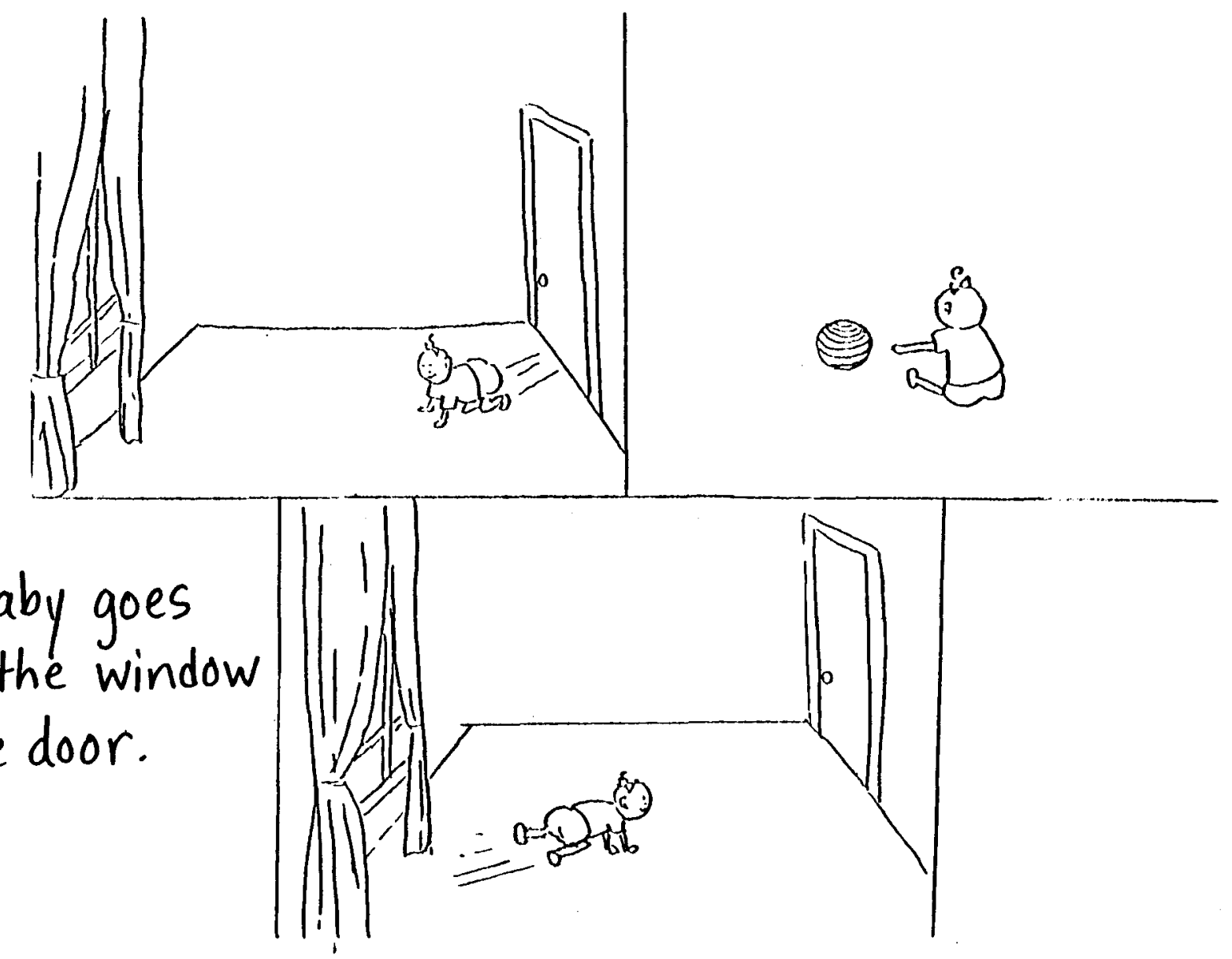

42

The baby goes from the window to the door. 
호

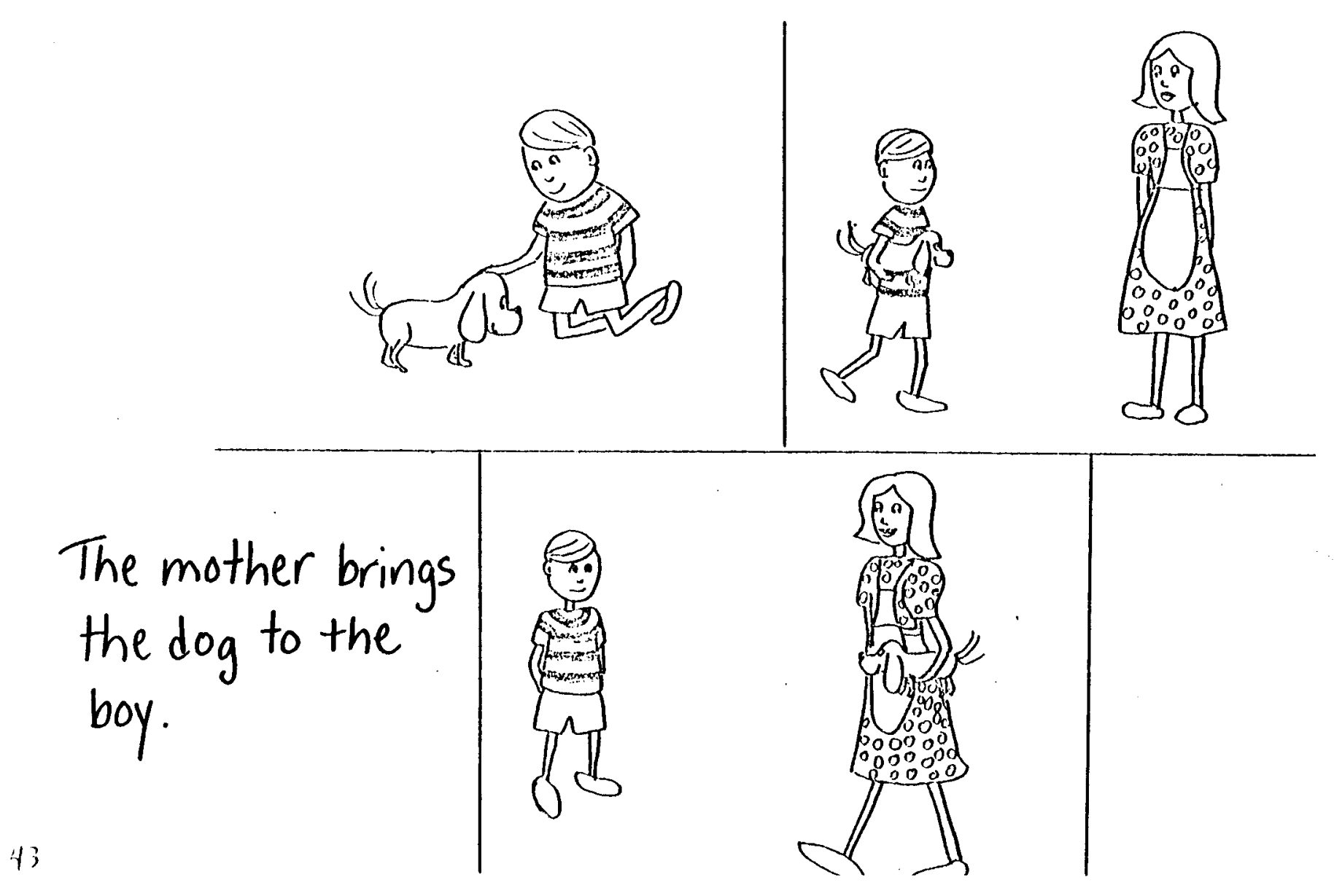




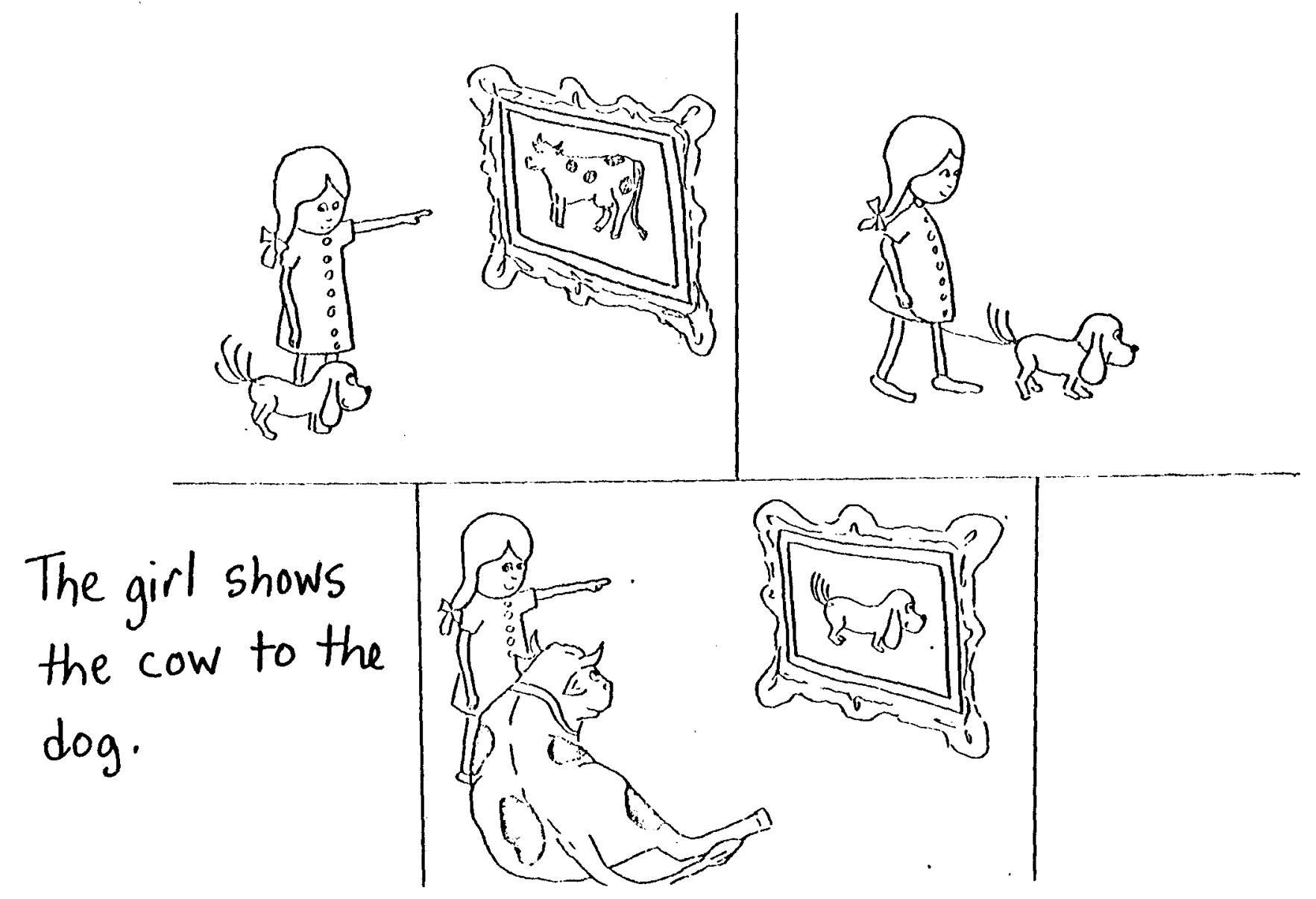


$\stackrel{9}{9}$

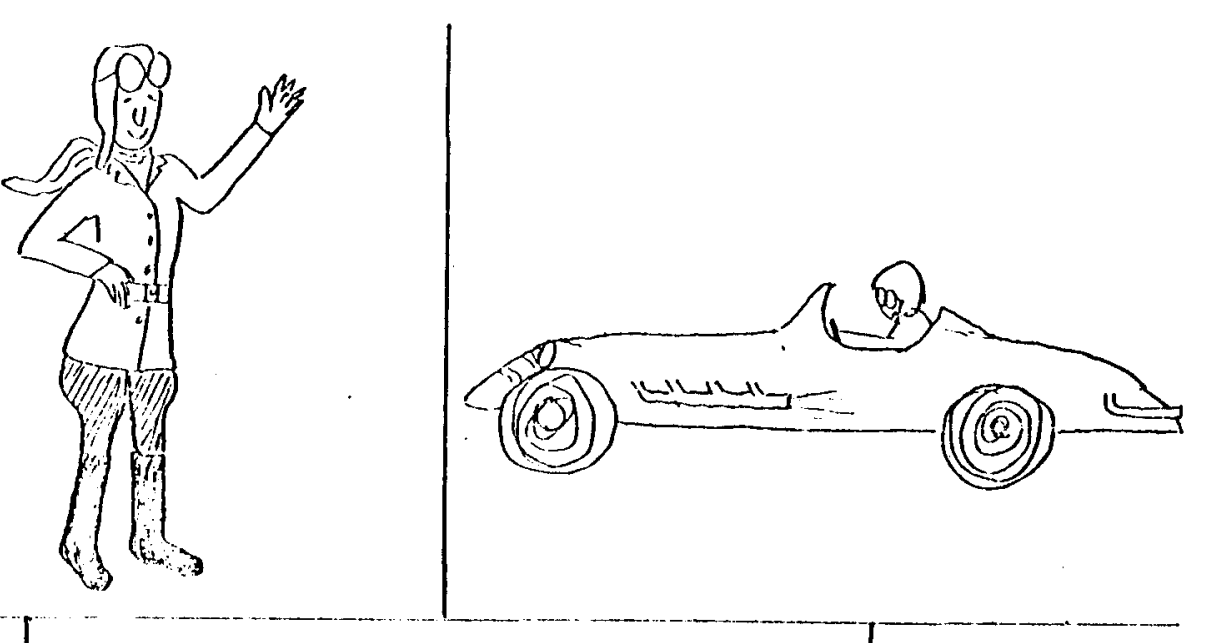

The airplane of the pilot (man).

45

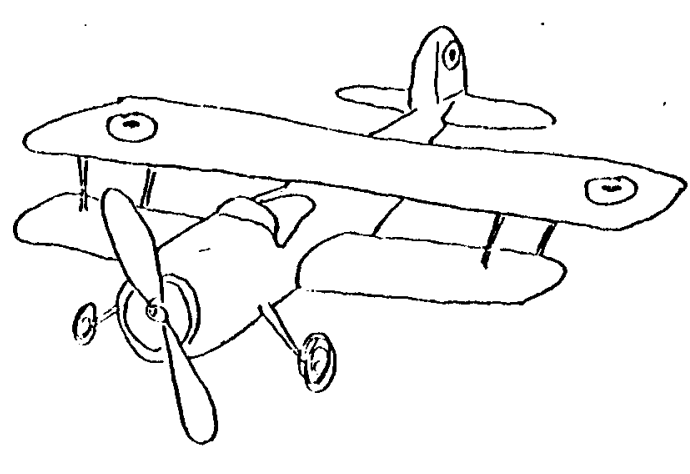


$\stackrel{5}{\circ}$

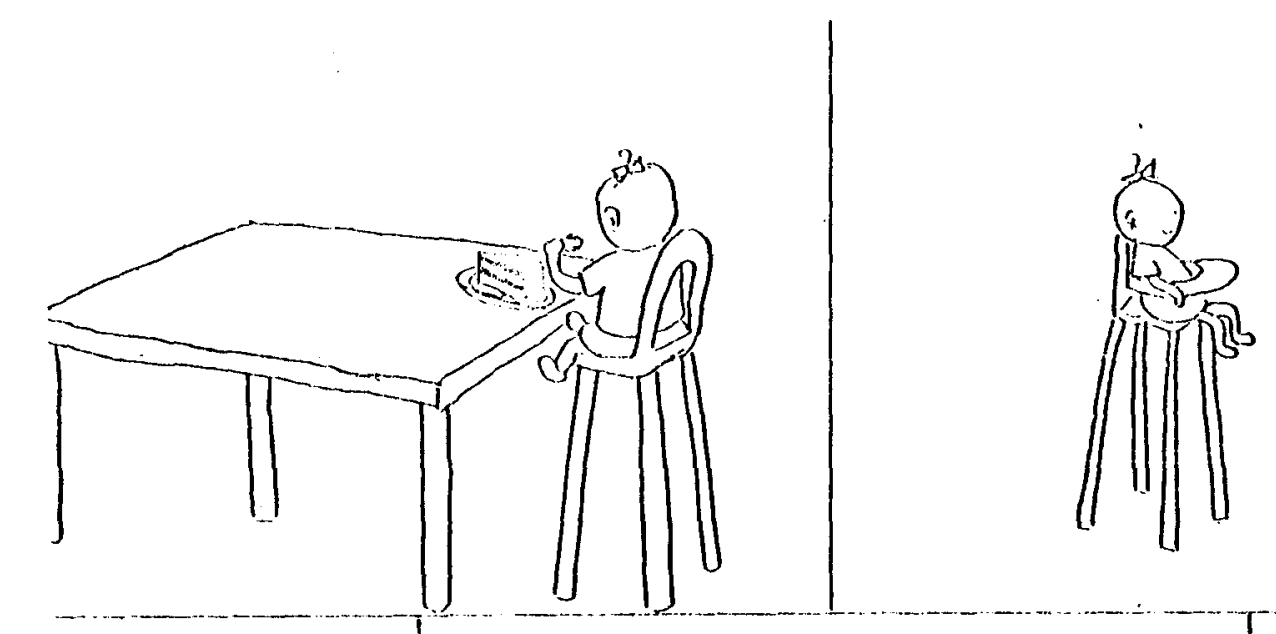

The baby eats the cake which is on the table.

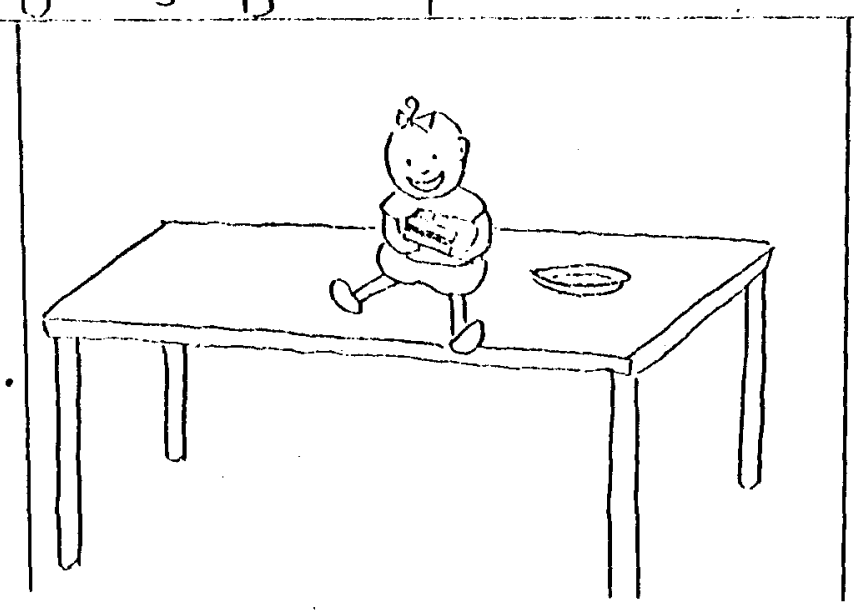

th 


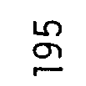

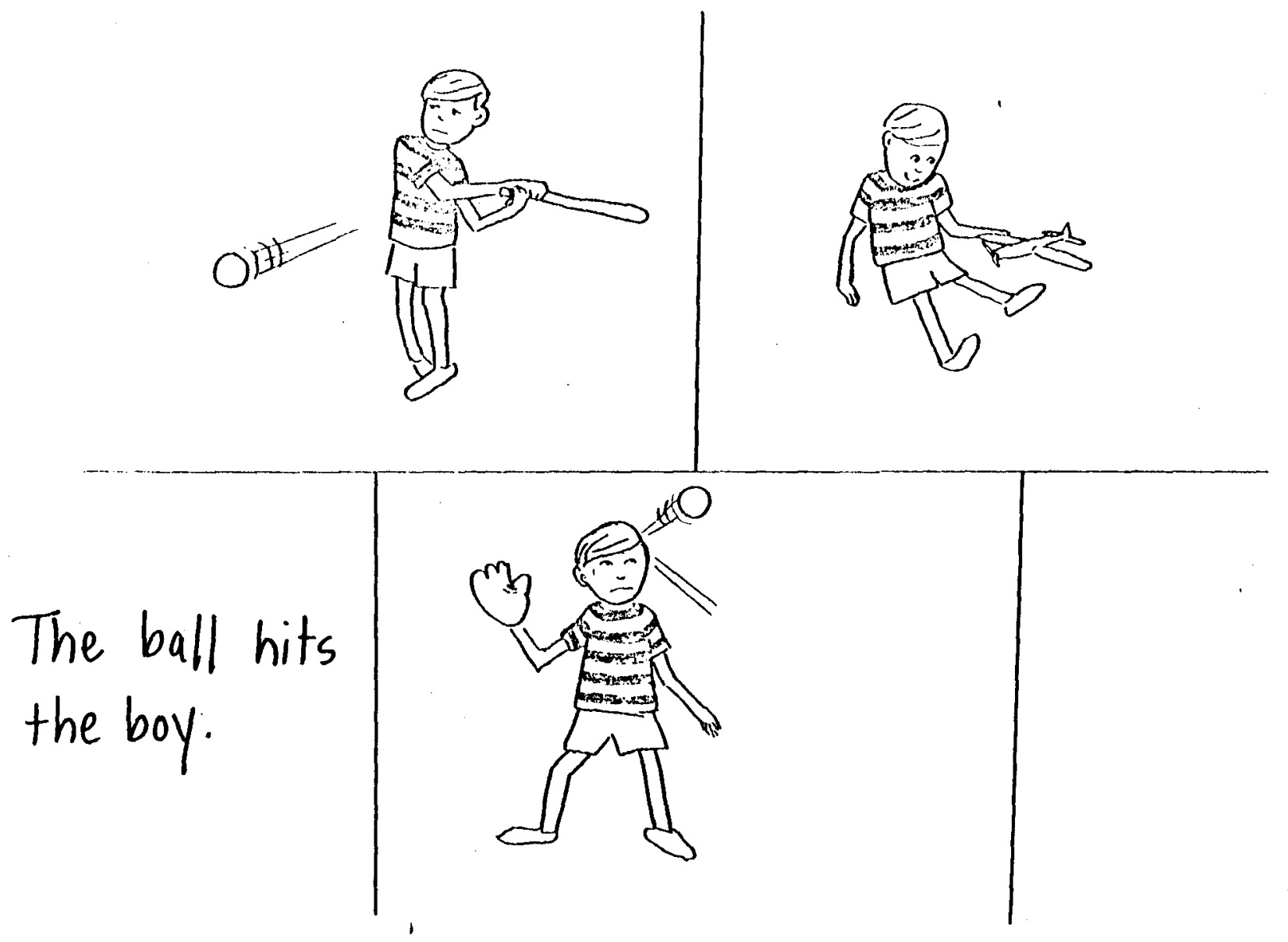


욤

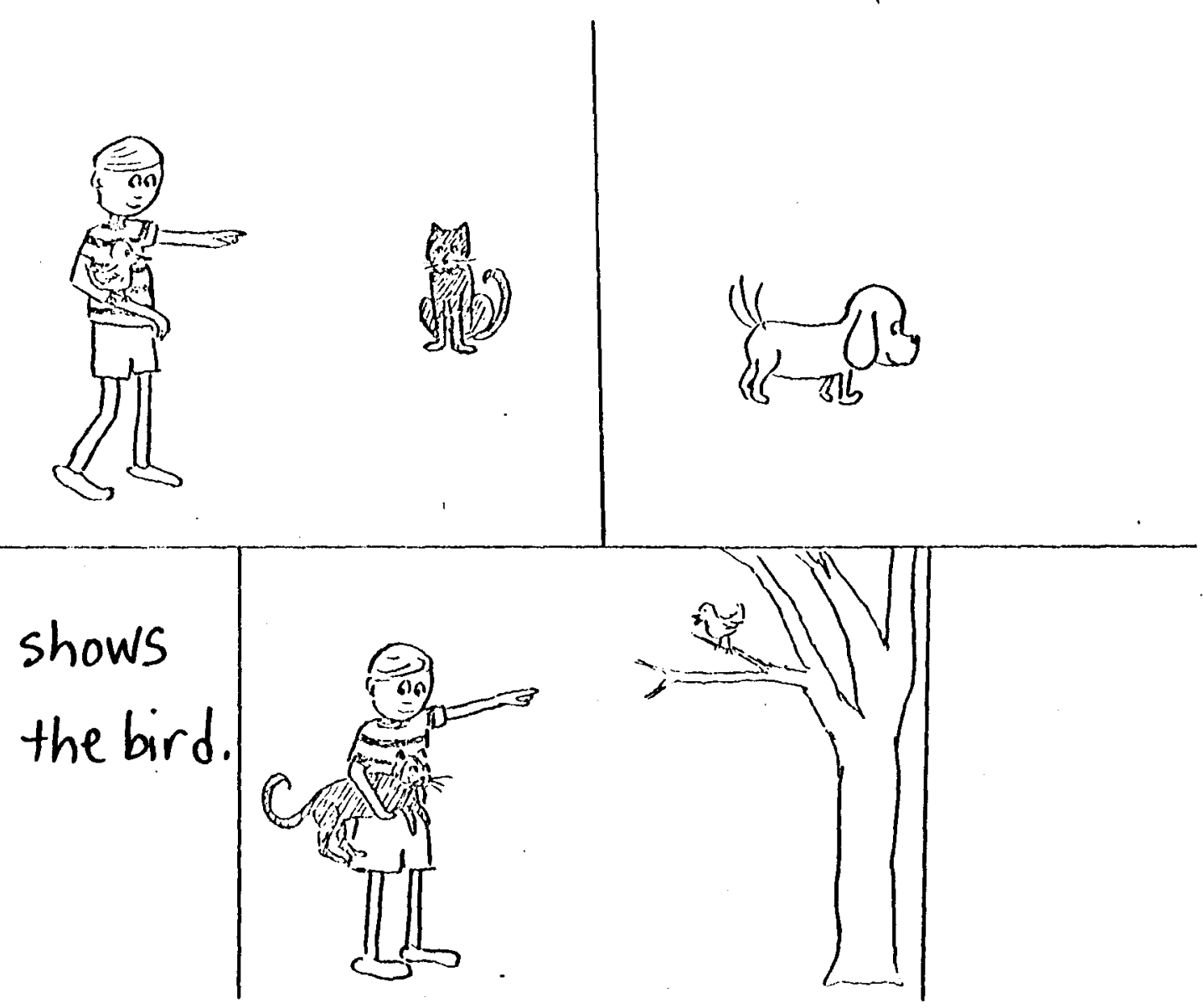

19 
옹

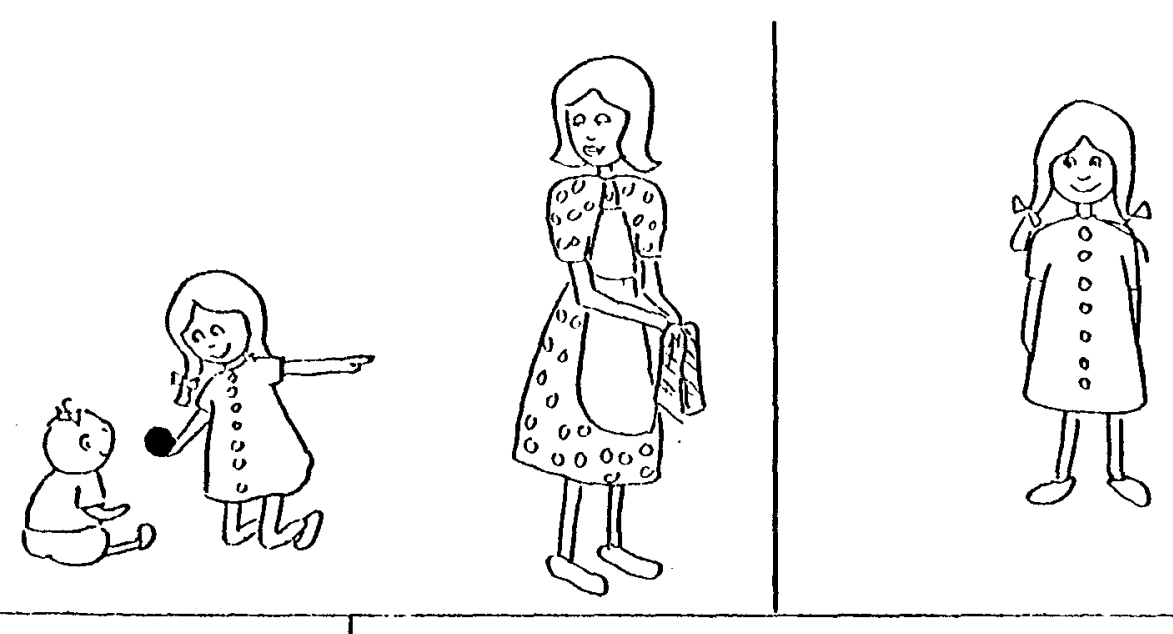

The girl brings the ball for the baby to the mother.

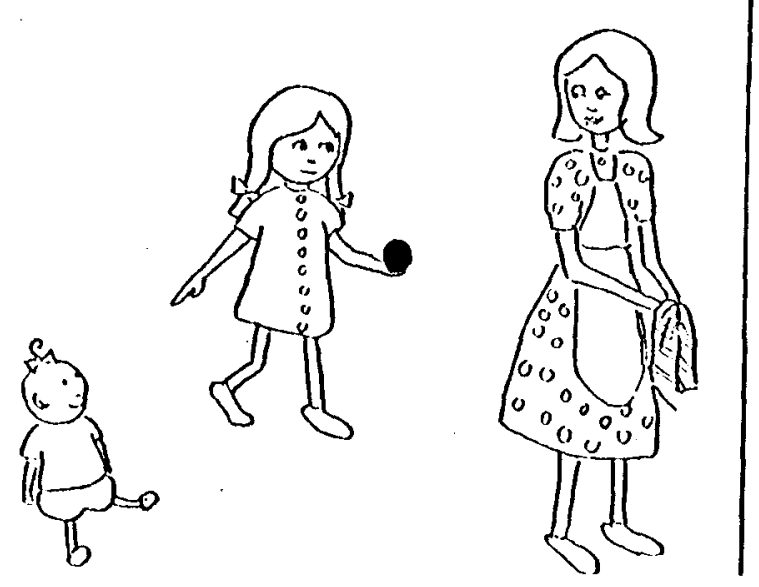

is 
$\stackrel{\infty}{\circ}$

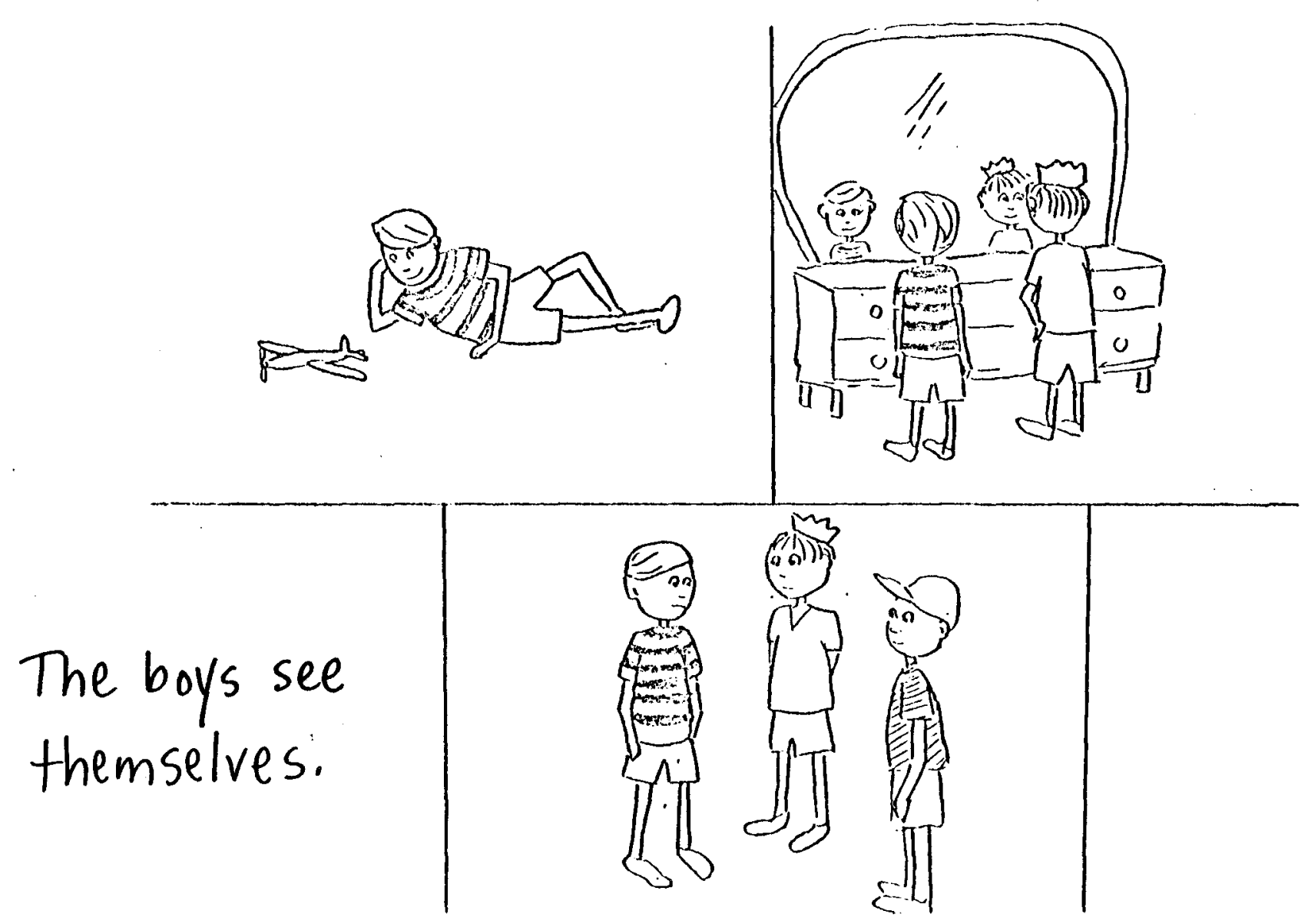

50 
옴

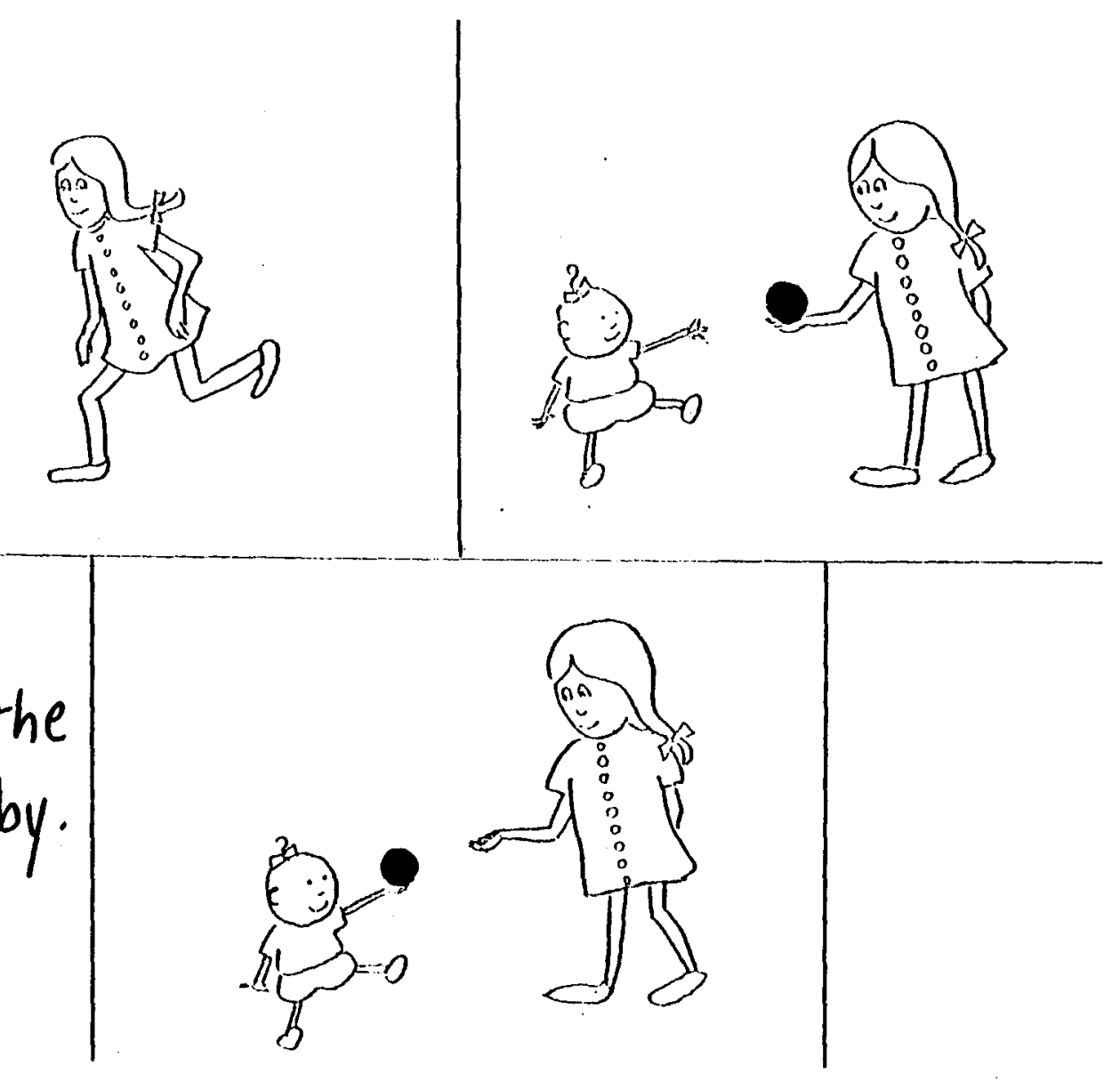

The girl gives the ball to the baby.

51 
요

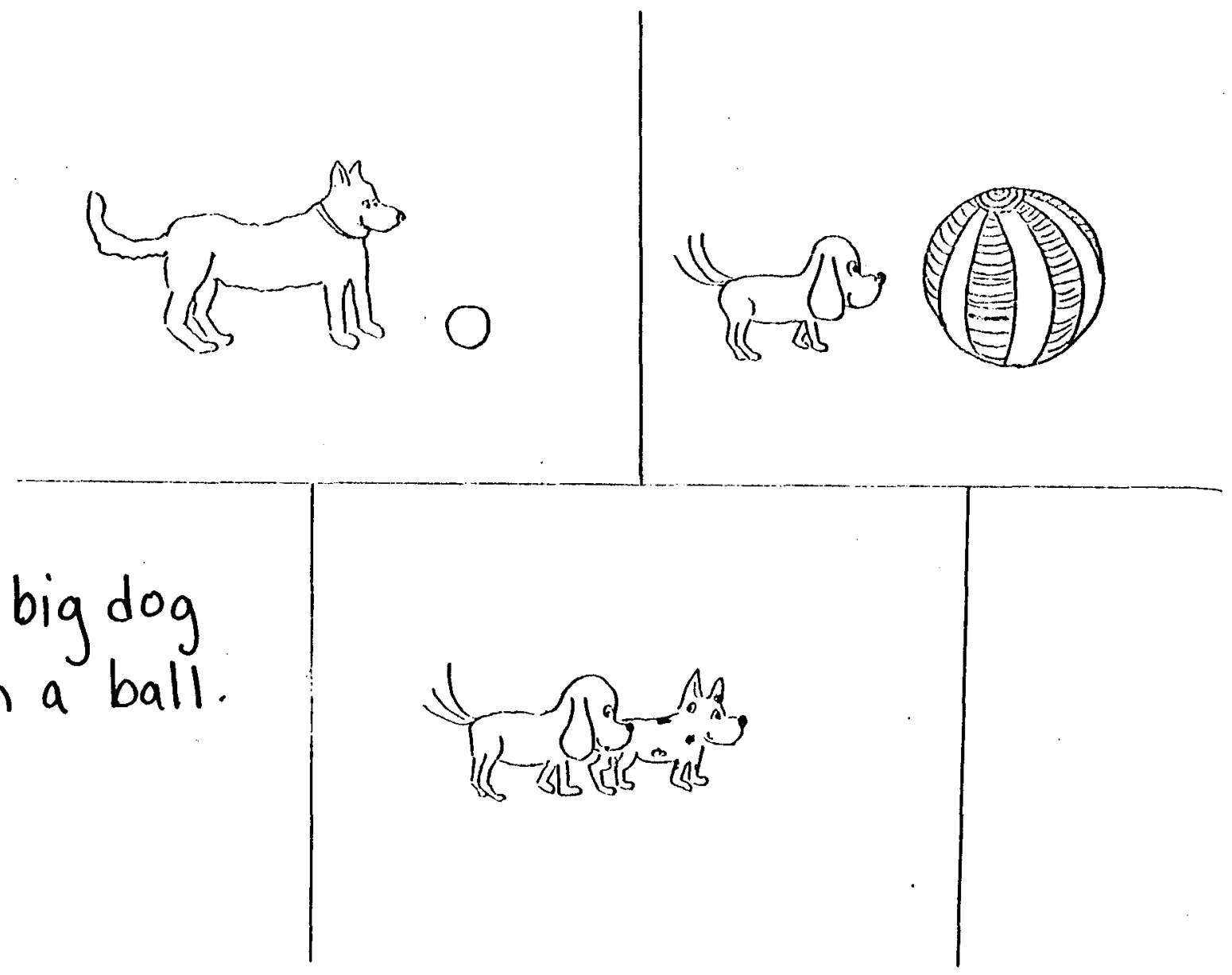

The big dog with a ball.

52 


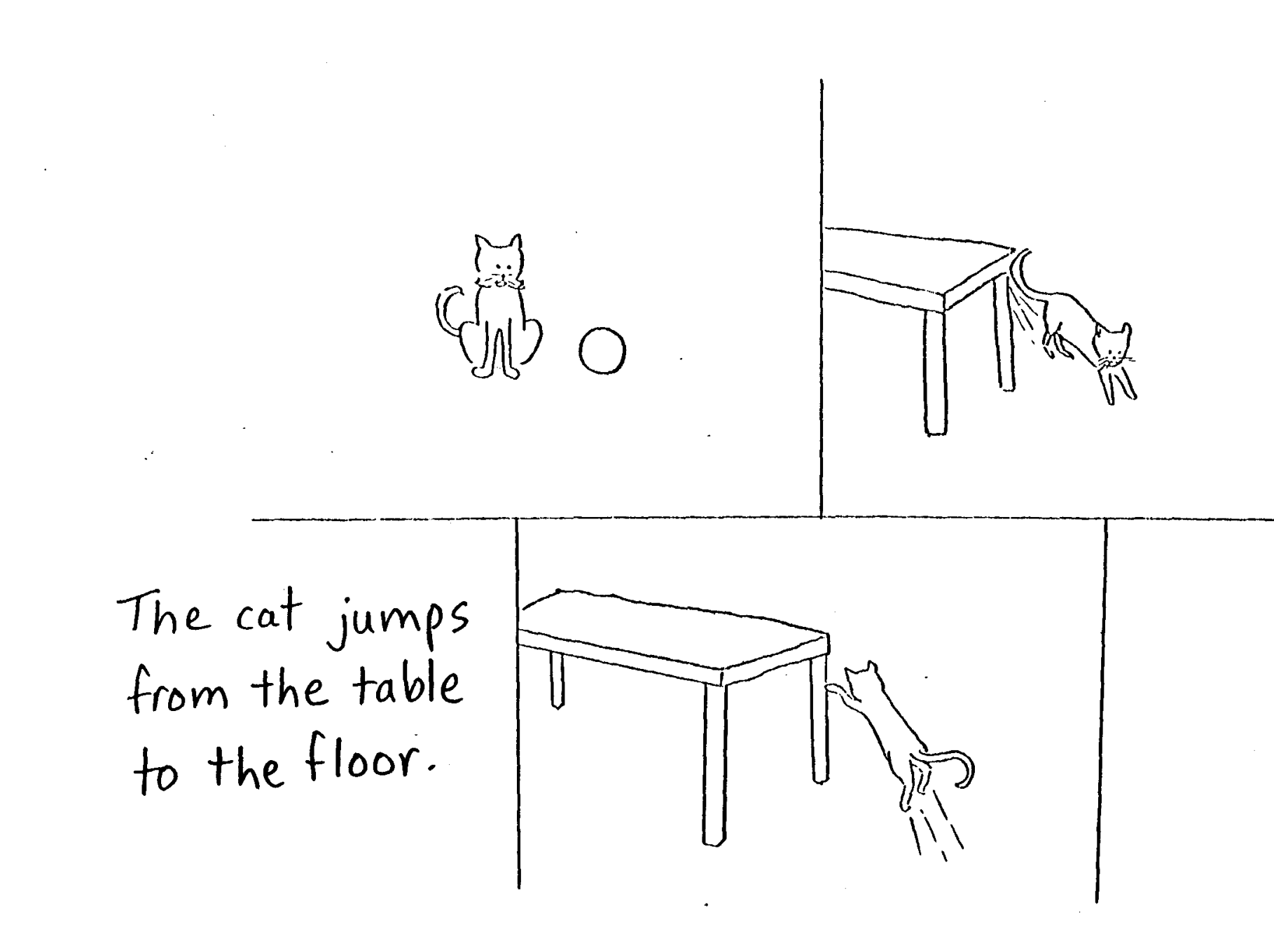


๙

The ball is hit by the boy.
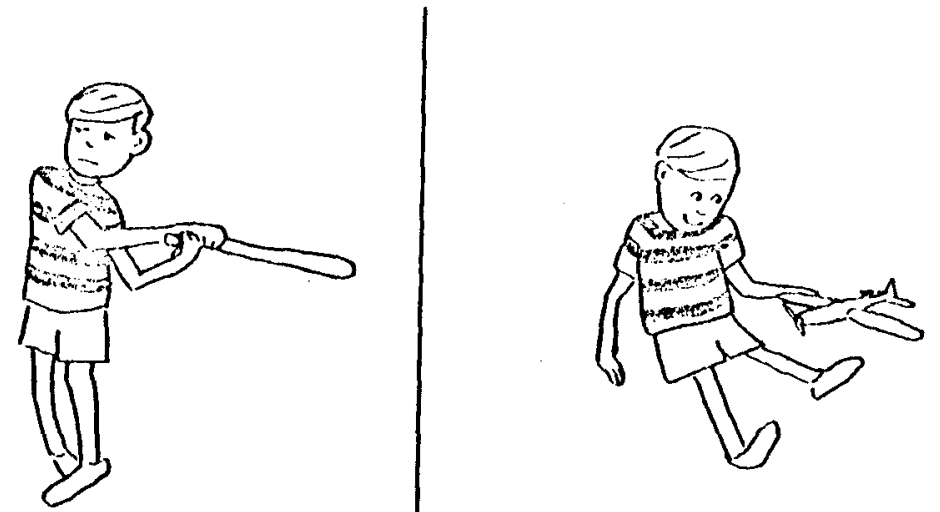

54
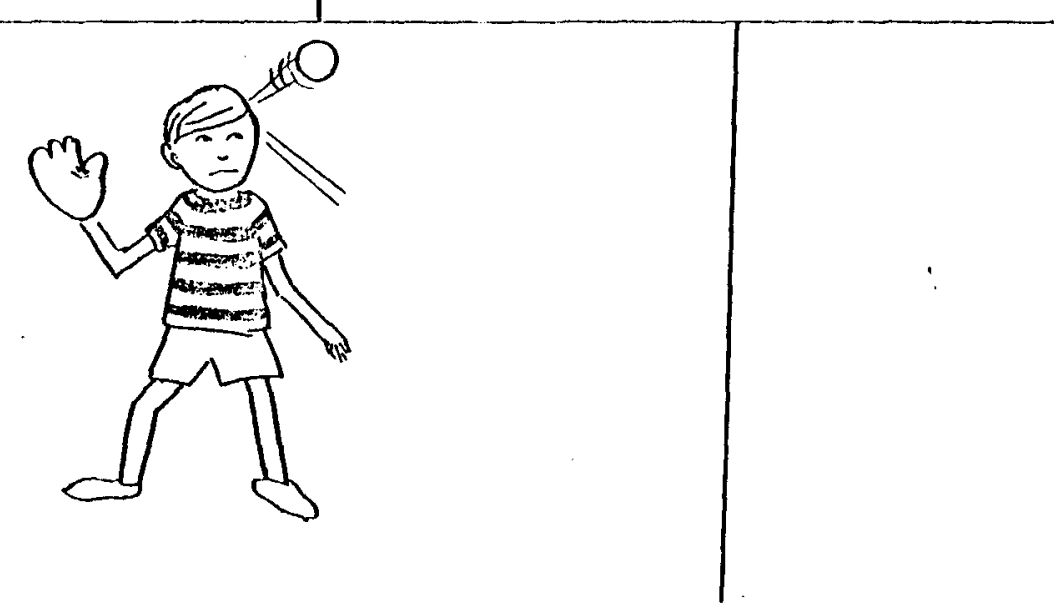
$\stackrel{\infty}{N}$
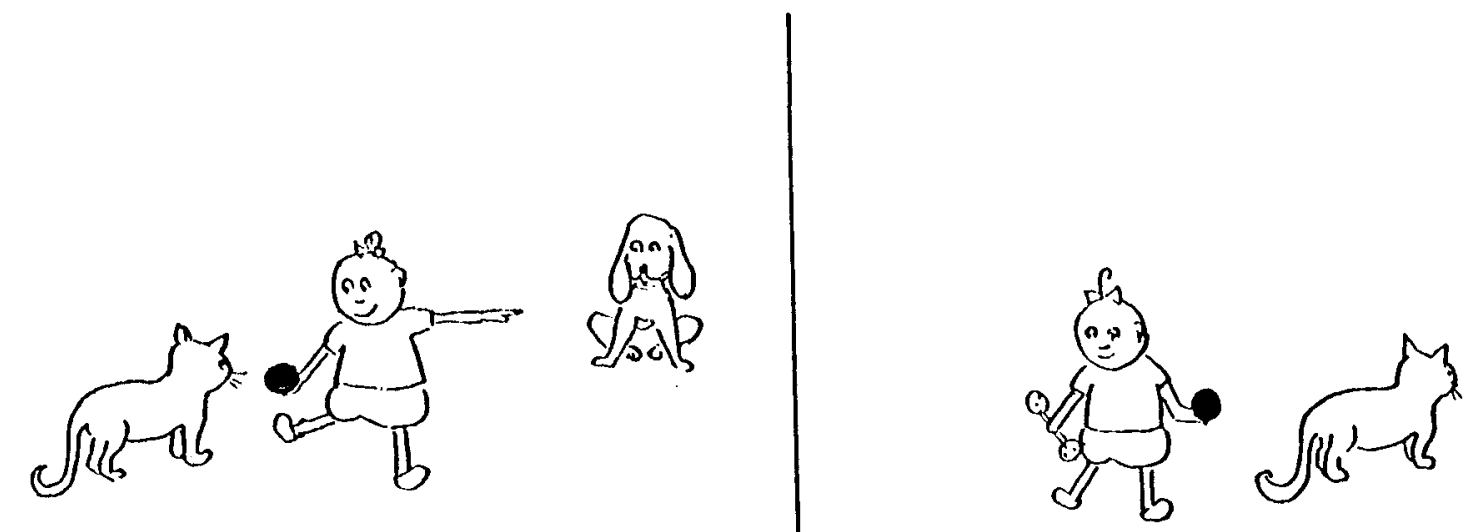

The baby gives the ball for the cat to the dog.

55

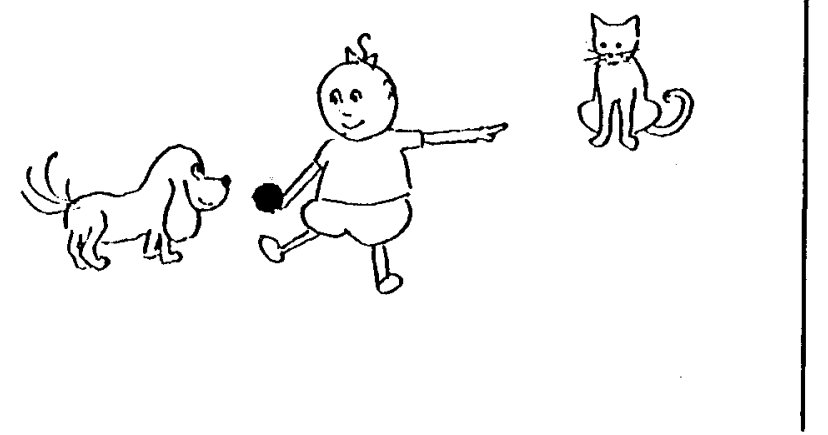




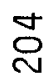
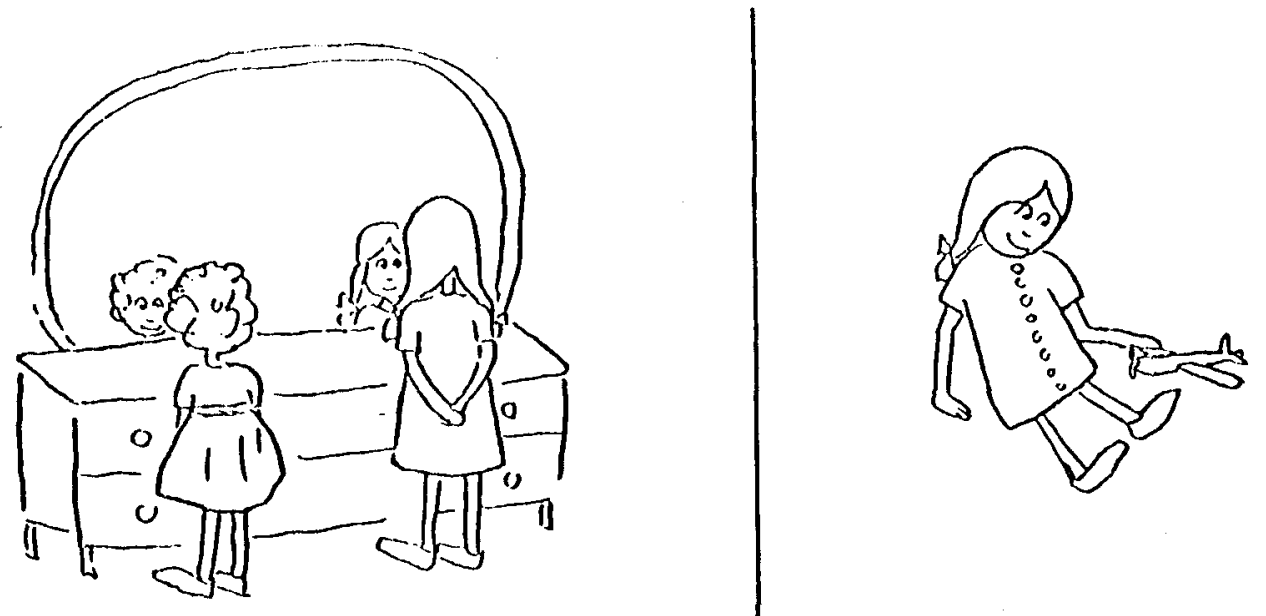

The girls see each other,
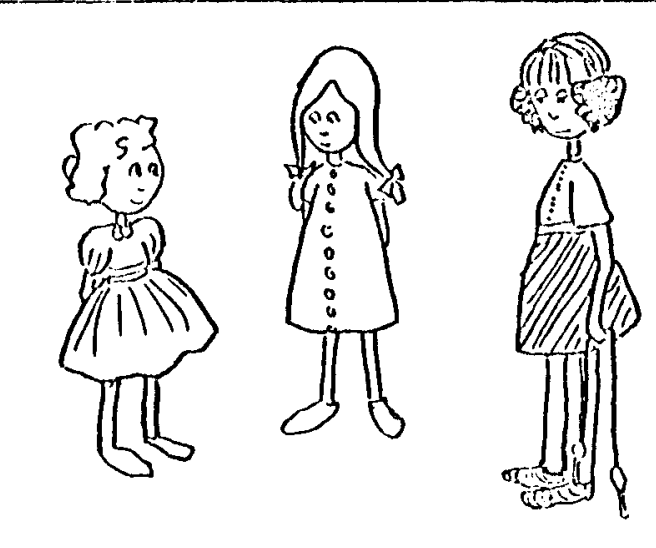

56 
$\stackrel{\circ}{\sim}$

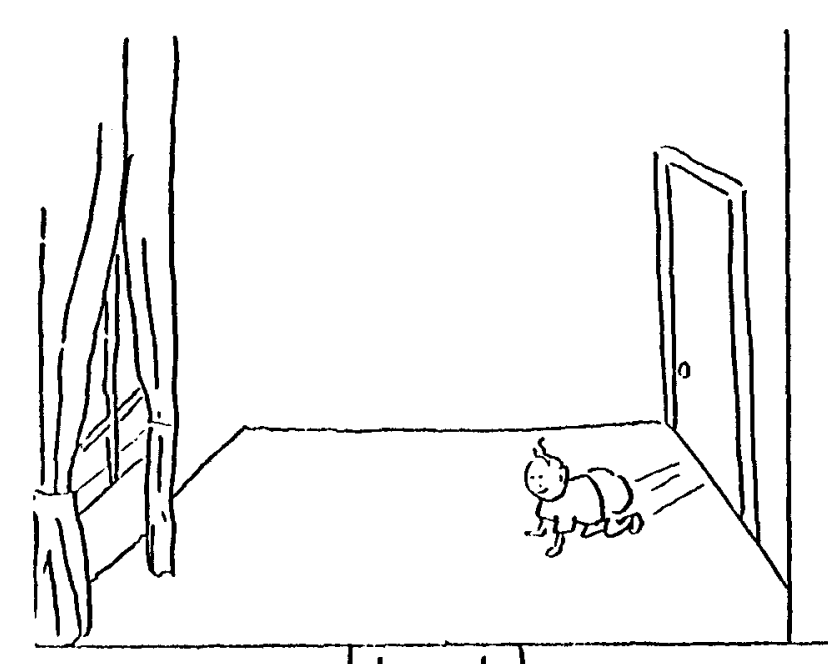

The baby goes from the door to the window.

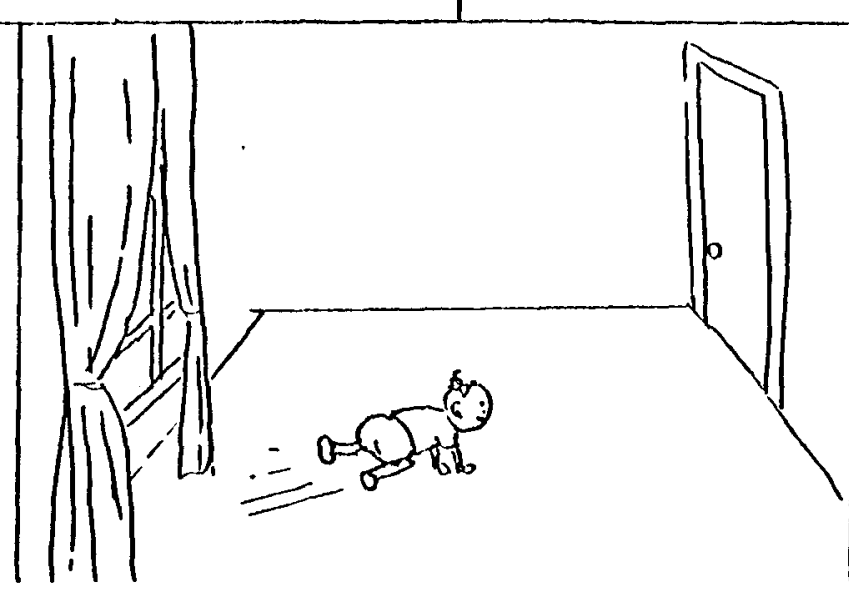

57

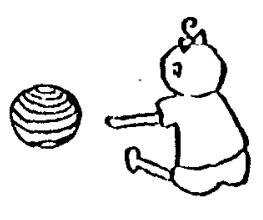

1 
<smiles>C#CC(C)(C)C(C)(C)C</smiles> 
ar

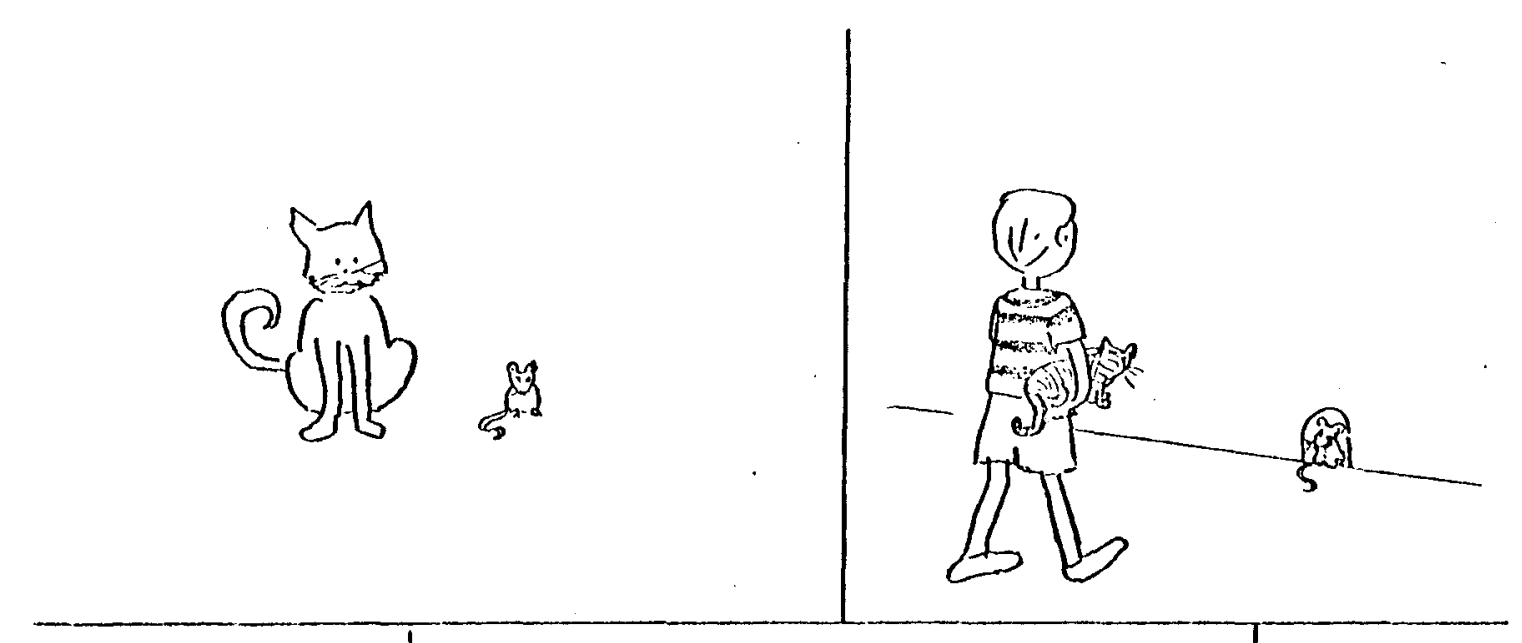

The boy brings the cat to the mouse.

59
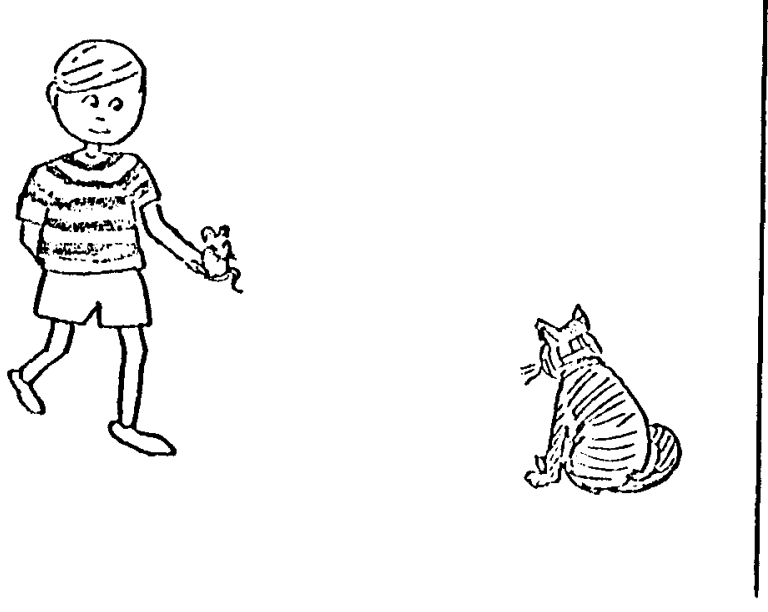
$\stackrel{\infty}{\sim}$

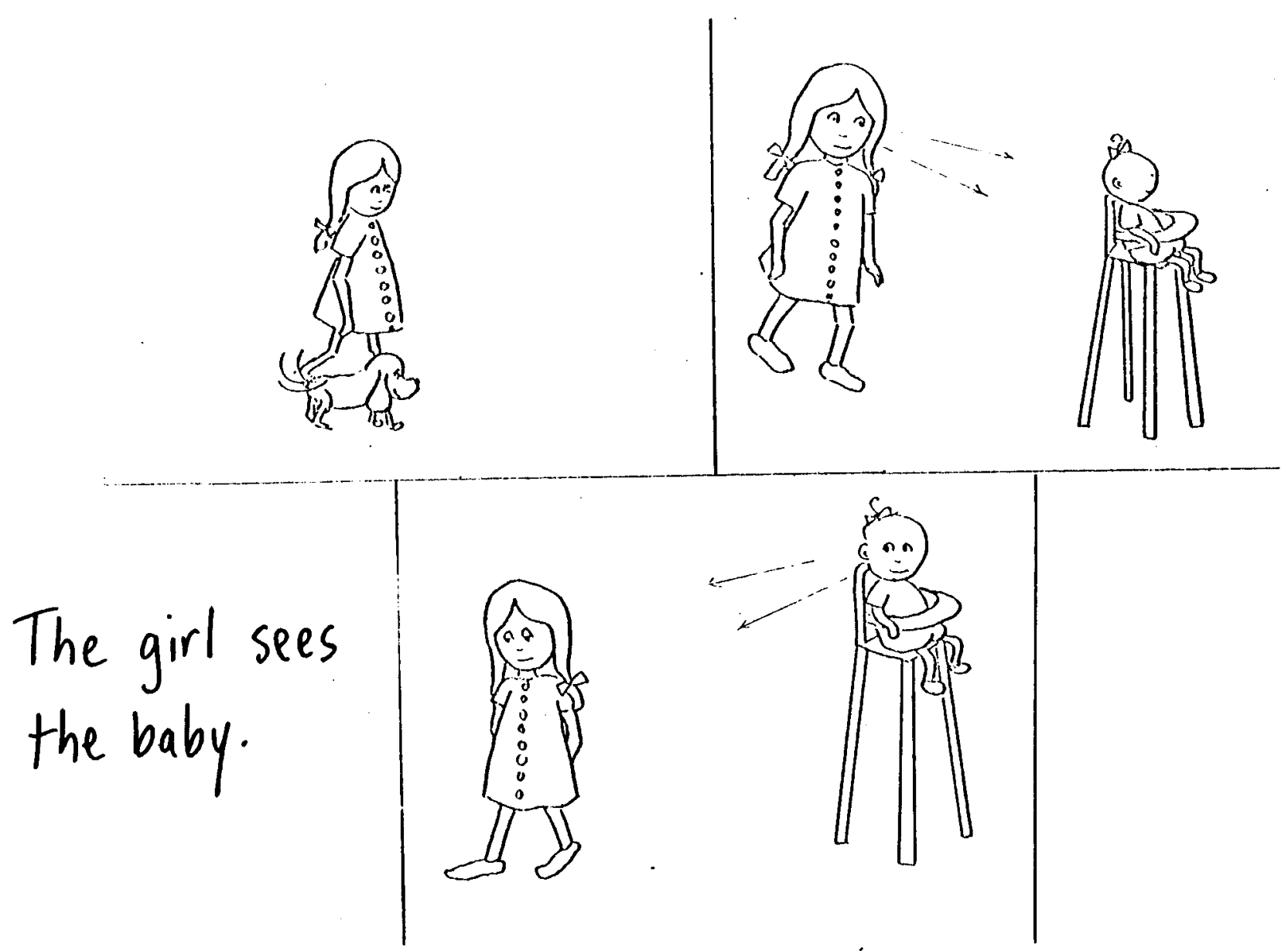

60 


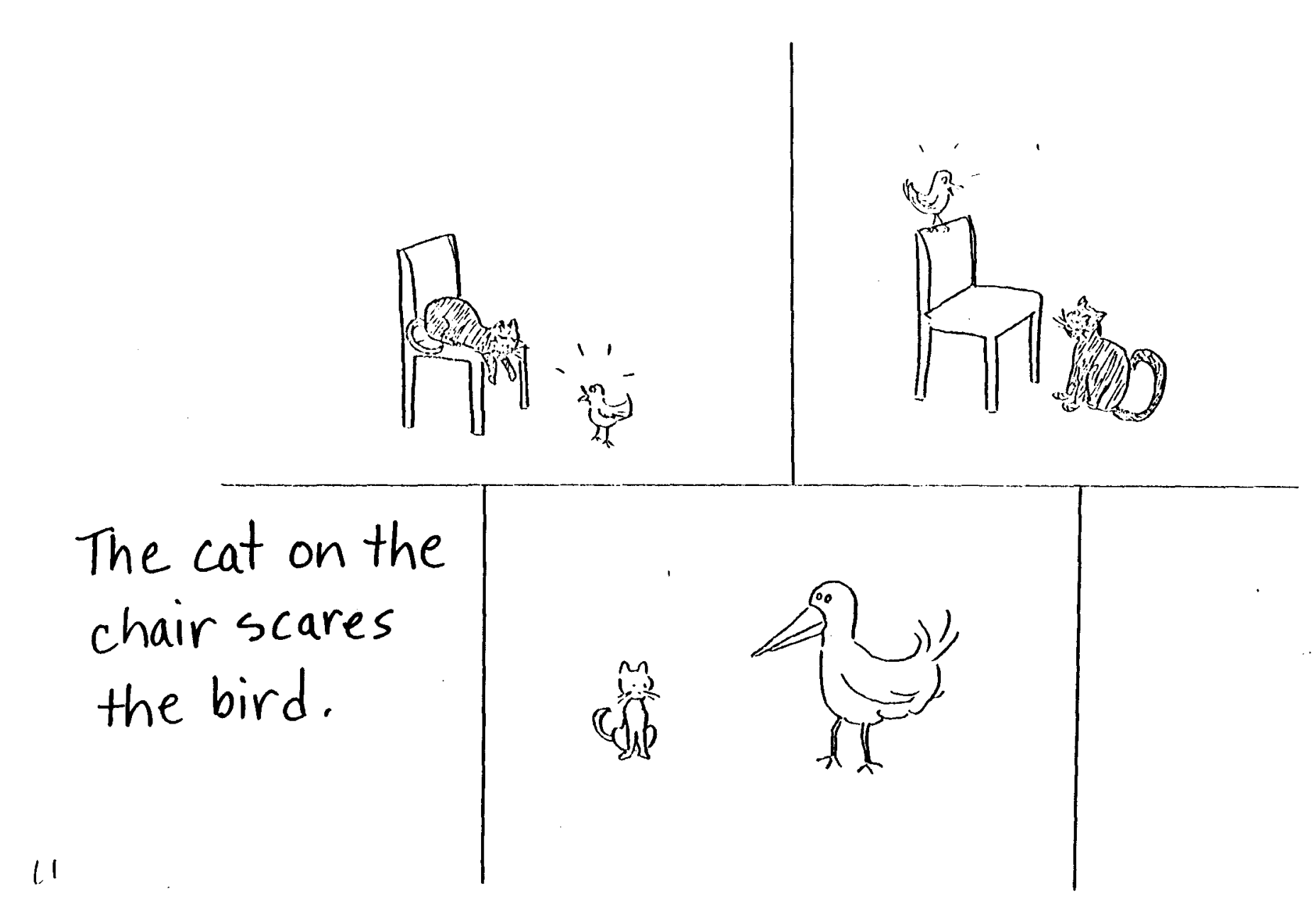


$\stackrel{ }{\sim}$

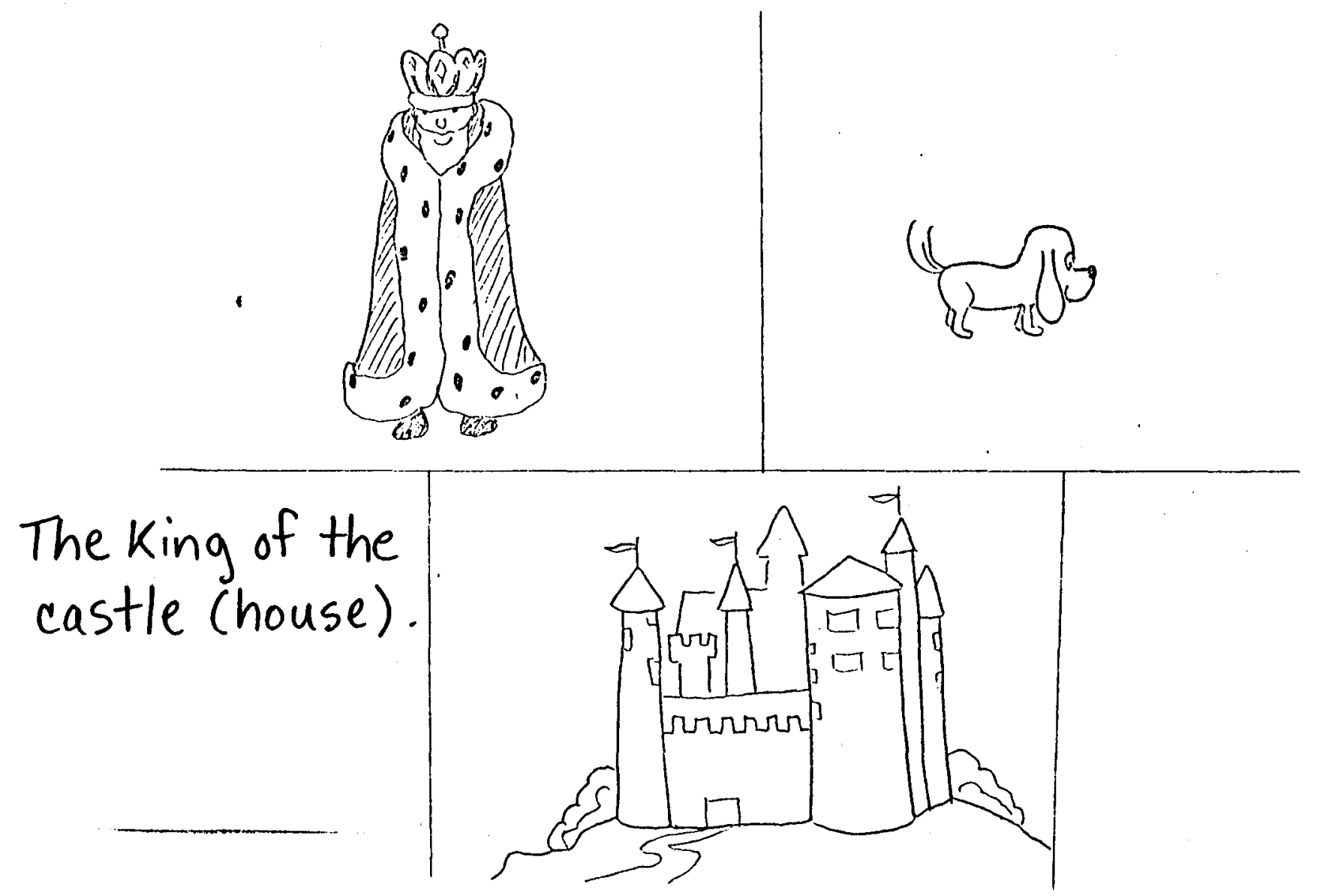


$\overline{\text { }}$

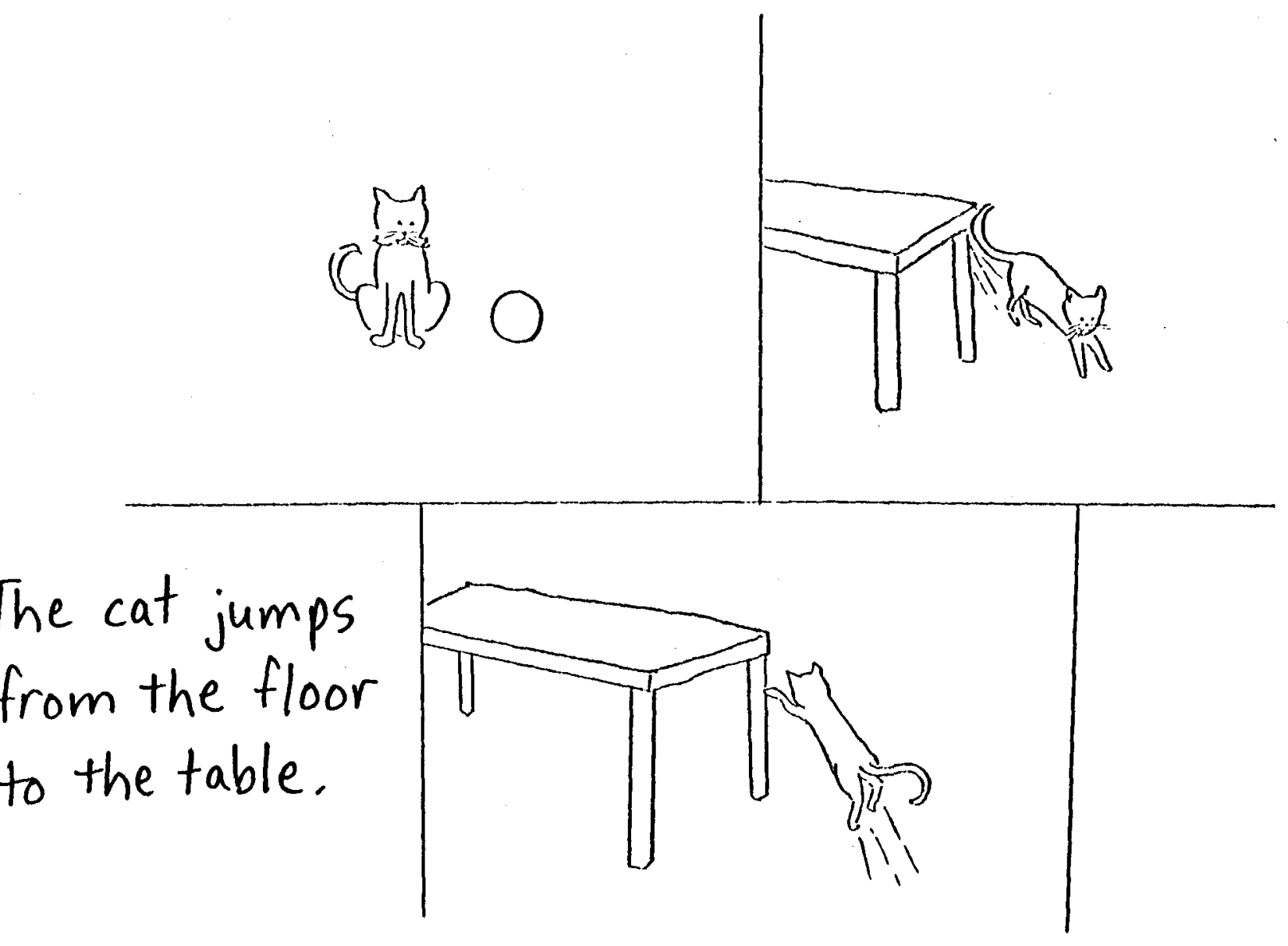

63 


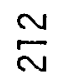

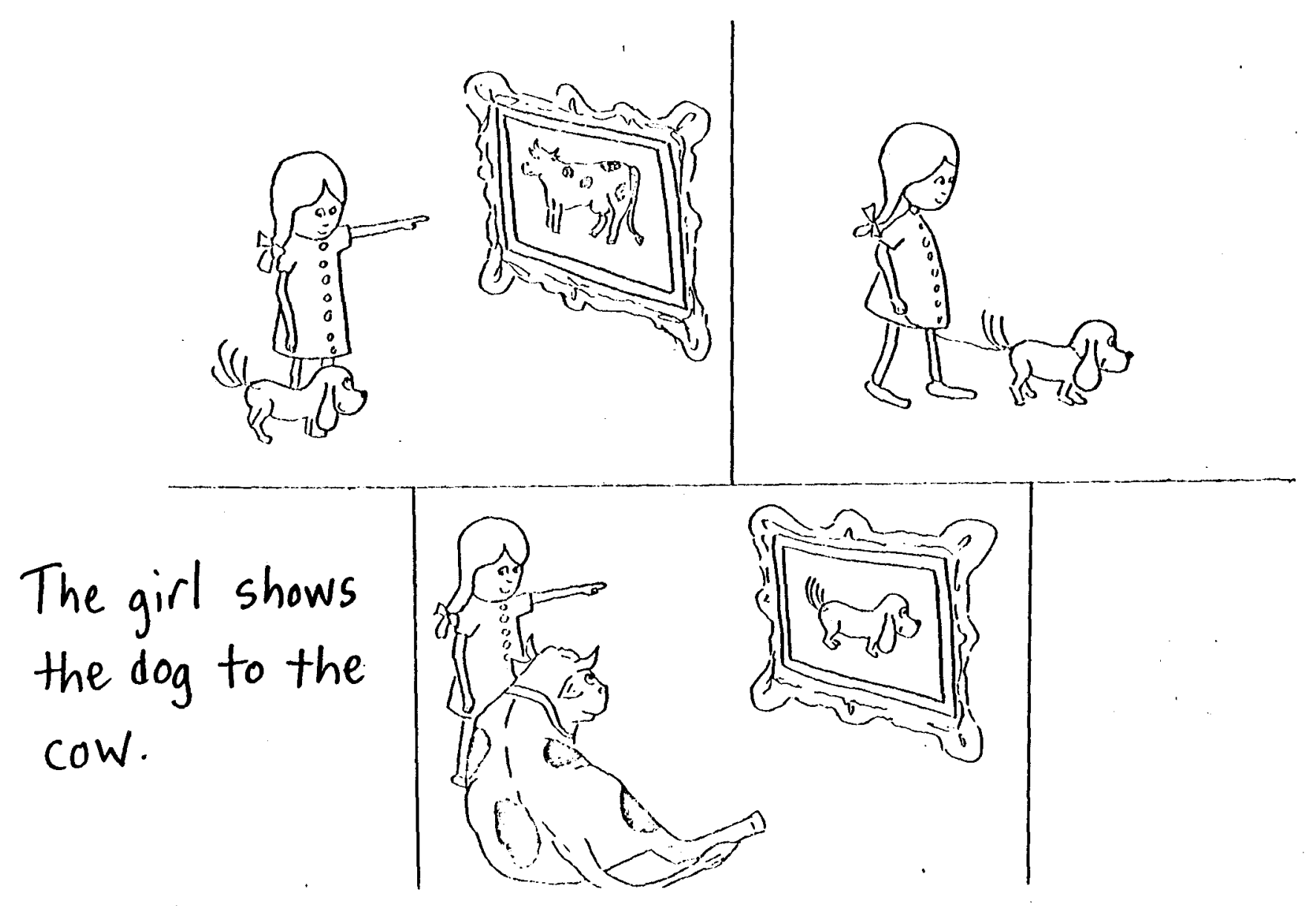

44 
$\stackrel{m}{\sim}$

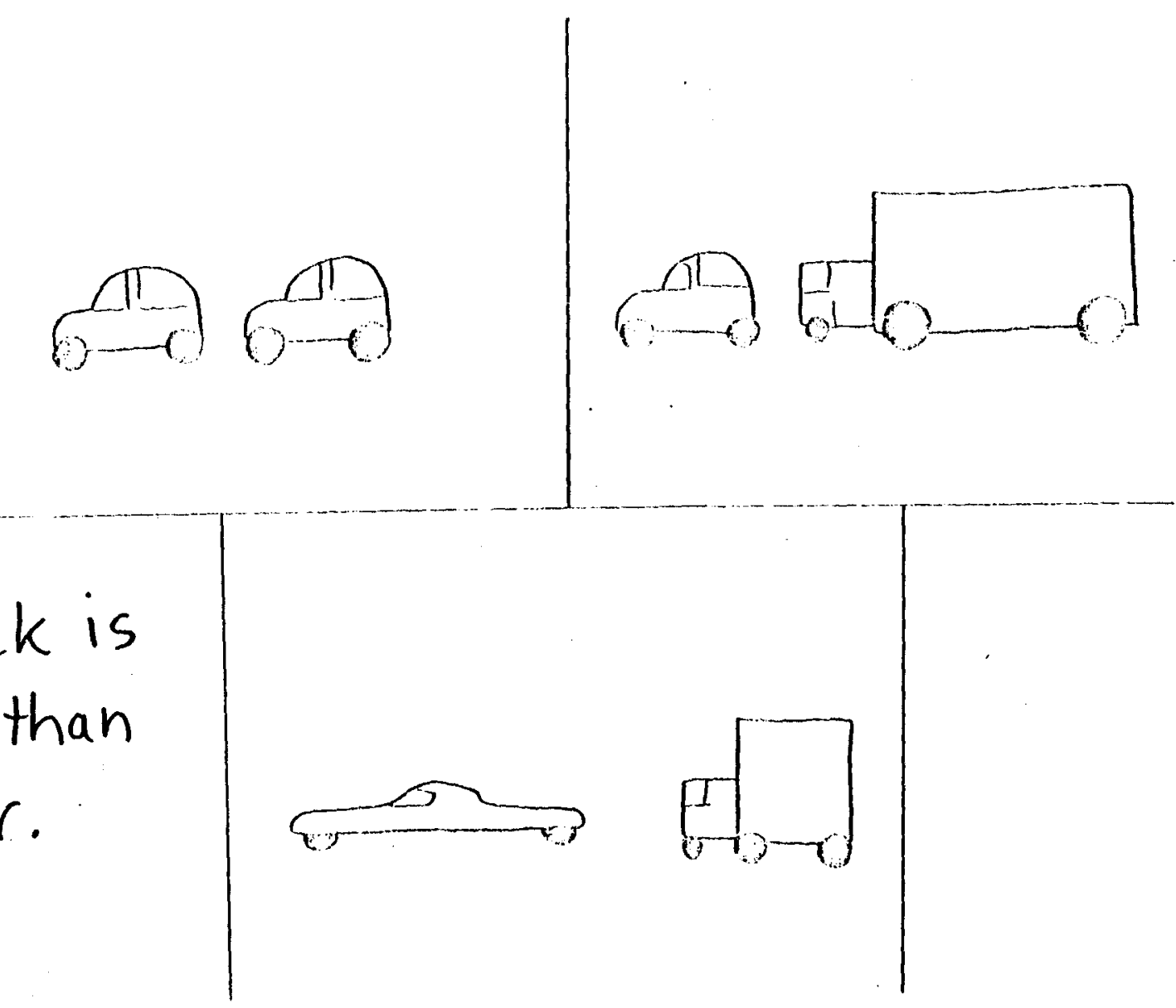


$\stackrel{d}{\sim}$

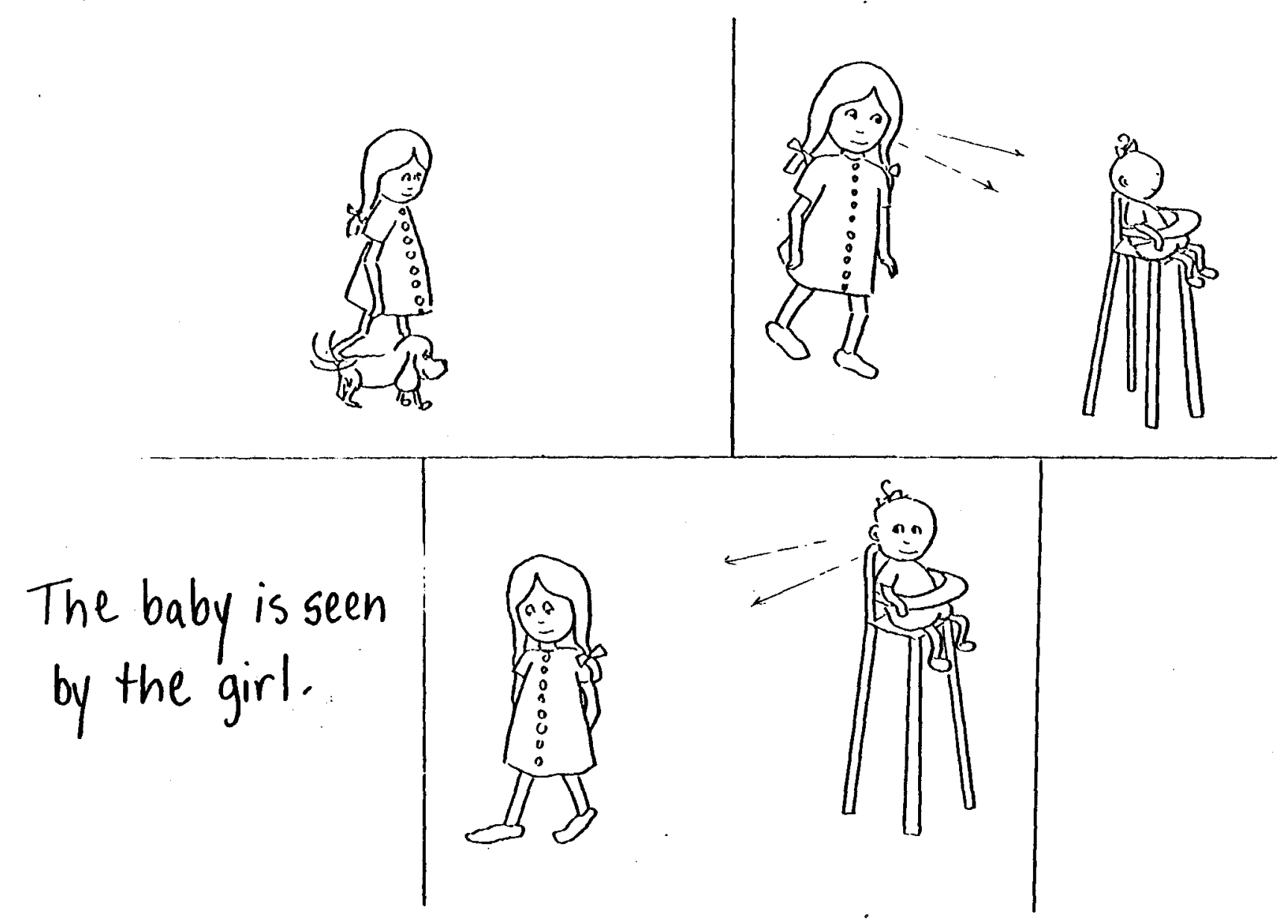

6. 
$\stackrel{n}{N}$

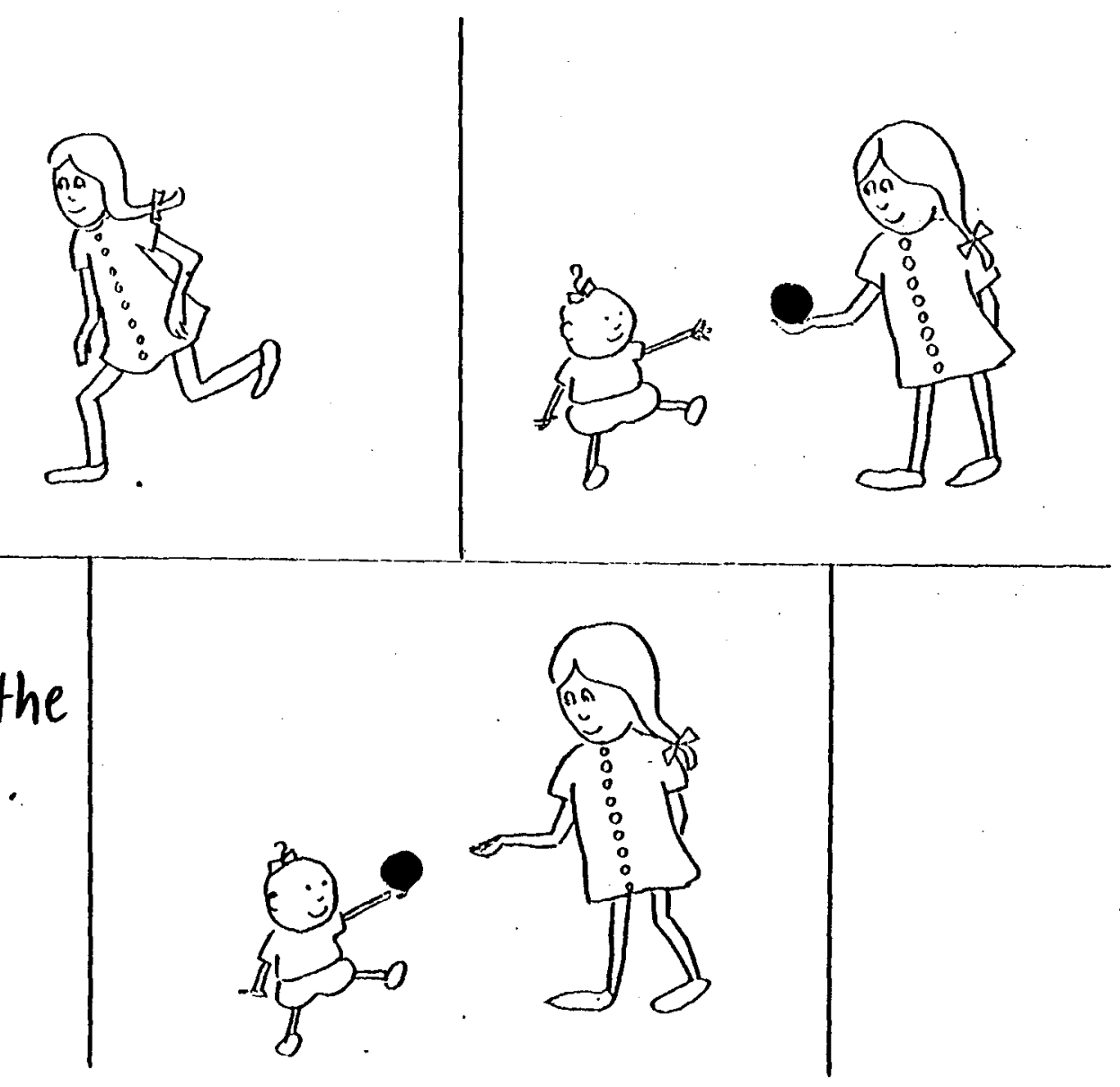

67 
$\stackrel{\circ}{\sim}$

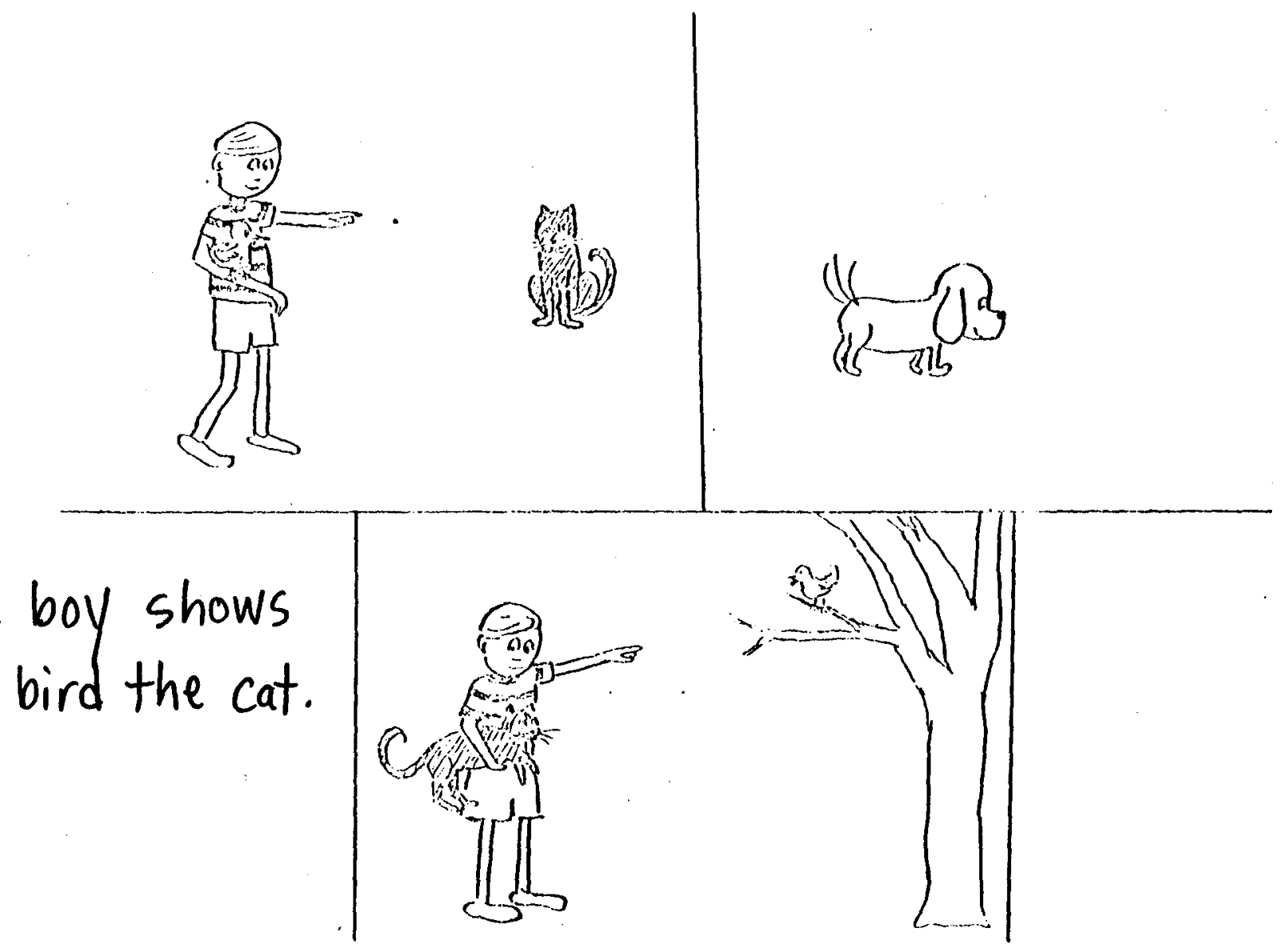

68 
స

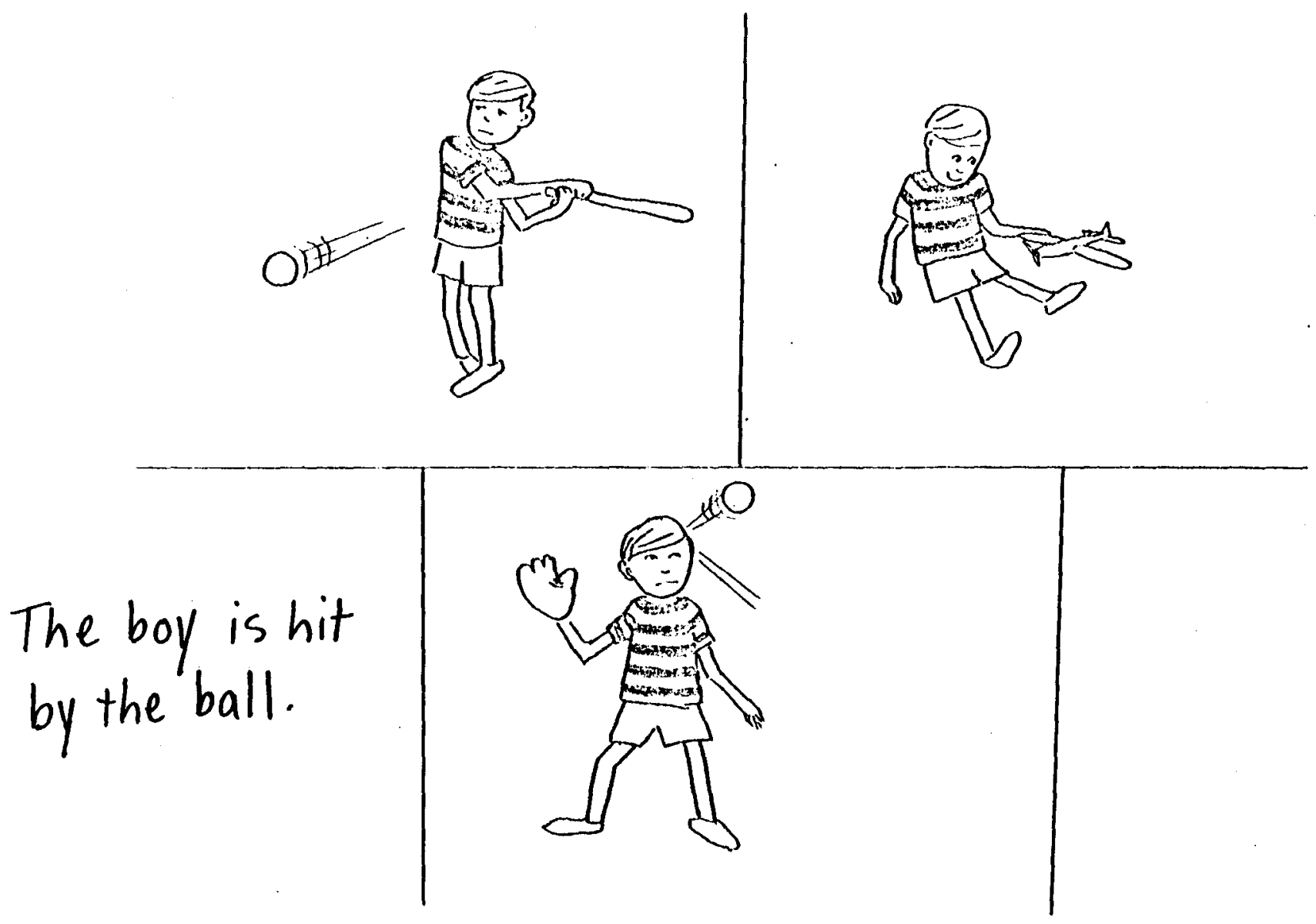

64 


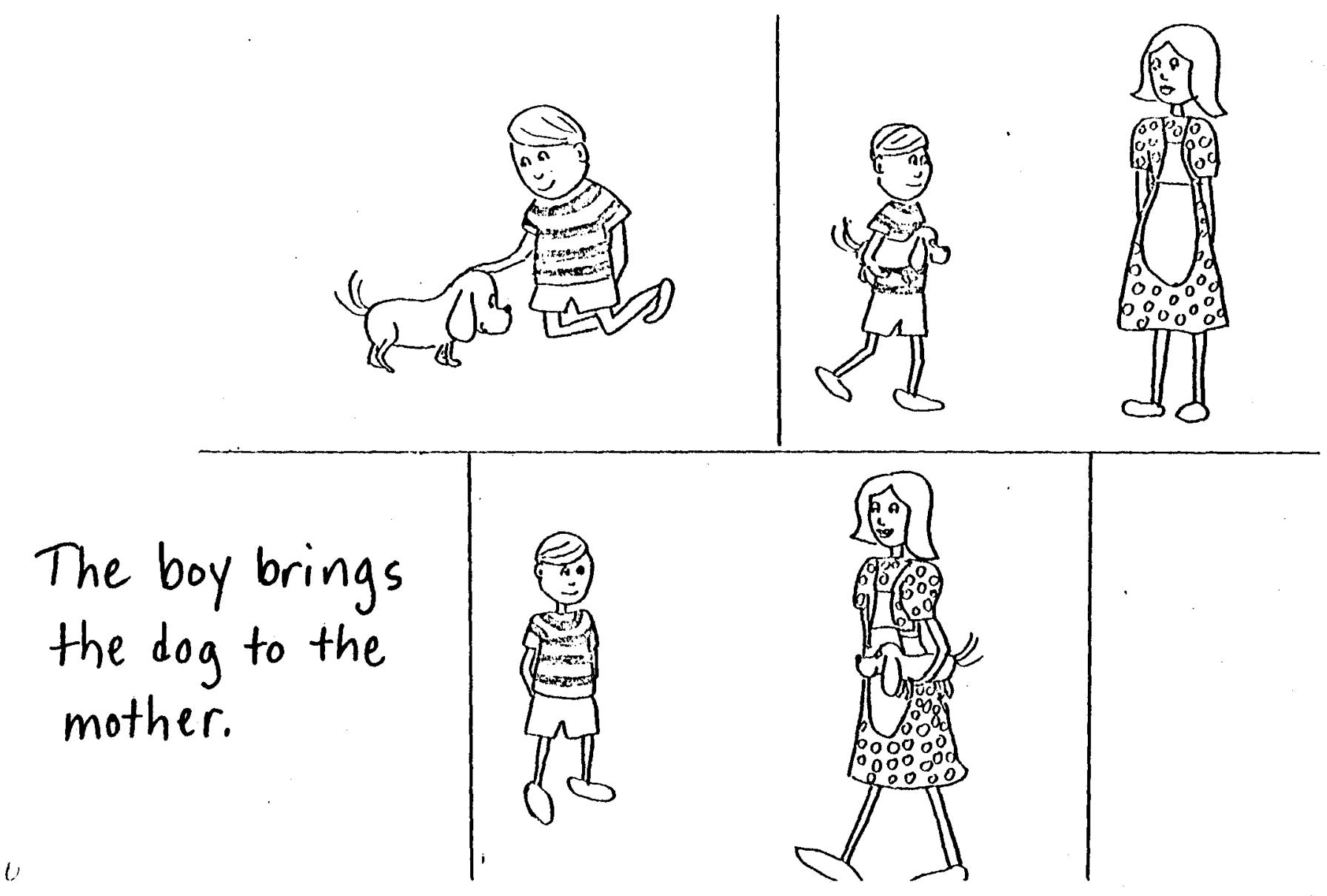


$\stackrel{9}{\sim}$

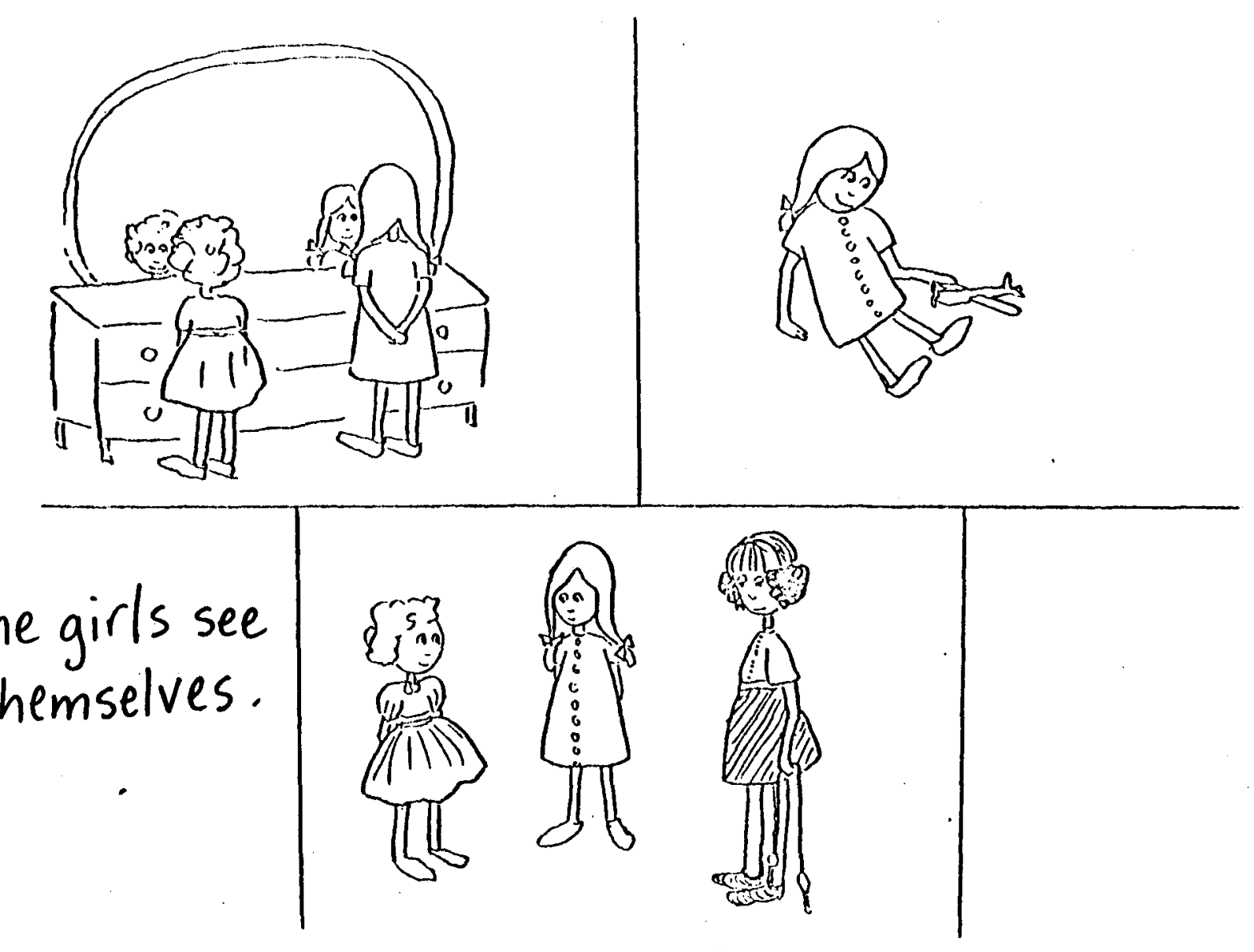

71 
ิ

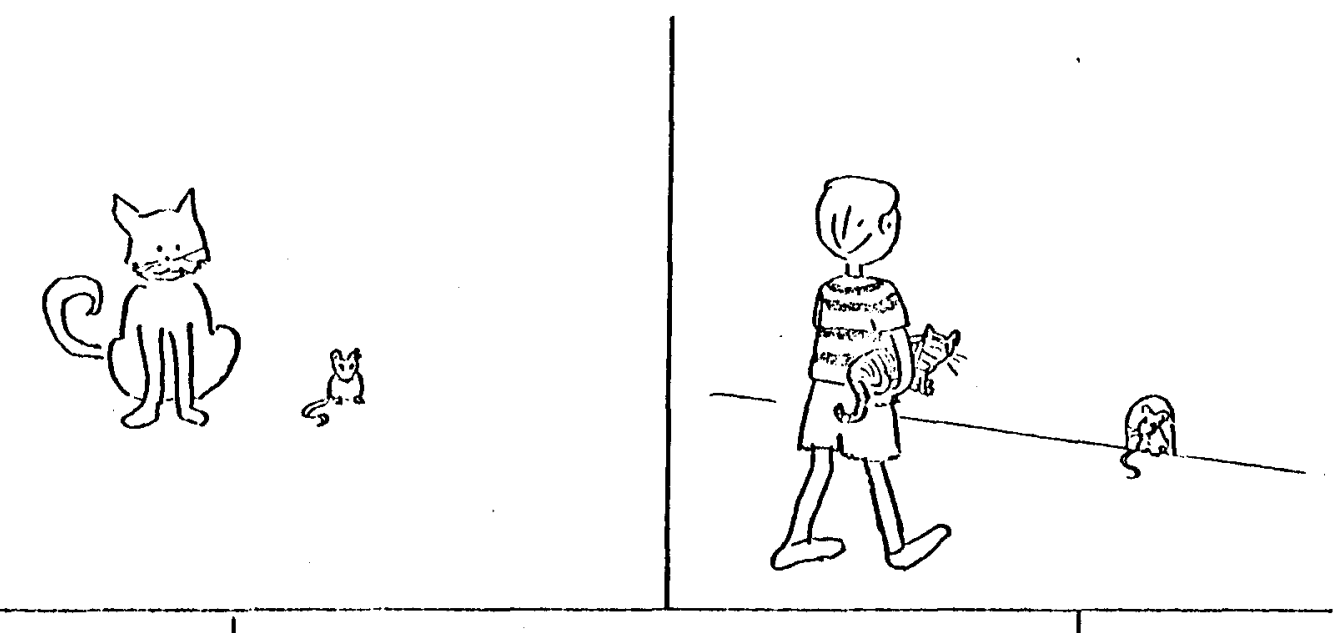

The boy brings the mouse to the cat.

72

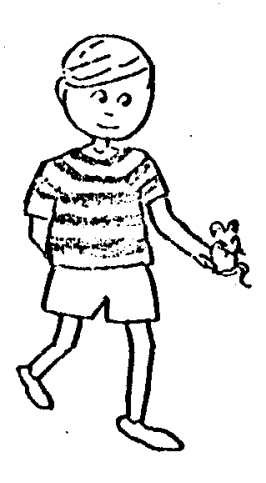


$\overline{\text { N }}$

1. The truck pushes the car.

a. The car is pushed by the truck.

b. The truck is pushed by the car. 
2. The ball which is white is near the dog. a. The white ball is near the dog.

$b$. The ball is near the white dog. 


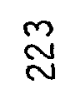

3. The cat has a ball which is black. $a$. The black cat has a ball.

b. The cat has a black ball. 
N

4. The car is pushed by the truck. $a$. The truck pushes the car. $b$. The car pushes the truck. 
$\stackrel{\sim}{N}$

5. The boy pushes the girl.

a. The boy pushes her.

b. The boy pushes him. 
ํํำ

6. The boy hits the ball.

$a$. The ball is hit by the boy.

$b$. The boy is hit by the ball. 
ลิ

7. I see the mother of the boy. a. I see the mother.

b. I see the boy. 
$\stackrel{\infty}{N}$

8. The boy is hit by the ball.

a. The boy hits the ball.

$b$. The ball hits the boy. 
ลิ

9. I see the friend of the girl.

a. I see the girl.

b. I see the friend. 
요

10. The boy sees the flower. $a$. The boy sees it. $b$. The boy sees her. 
APPENDIX $F$ 
Student's name

Test date

TEST OF GRAMMATICAL UNDERSTANDING -- DAVE DOLMAN

Inflectional Category

1. Verb tense

2. Pronoun direct object gender.

3. Verb person/number

4. Possessive adjective/number

5. Noun gender

6. Noun number

Syntactic Structure

1. Active

2. Passive

3. Reflexive/reciprocal

4. Subject/indi rect object

5. Direct/indirect object

5a. Di rect/indi rect object inversion

6. From-to

7. For-to

8. Noun/adjective
Example

He will eat.

She sees him.

He writes.

Their ball.

The grandmother.

The books.

Examp le

Right Wrong

The baby sees the girl.

The ball is hit by the boy.

The boys see themselves.

The baby gives the ball to the girl.

The girl shows the cow to the dog.

The boy shows the cat the bird.

The baby goes from the window to the door.

The baby gives the ball for the dog to the cat.

The dog with a big ball.

Right Wrong
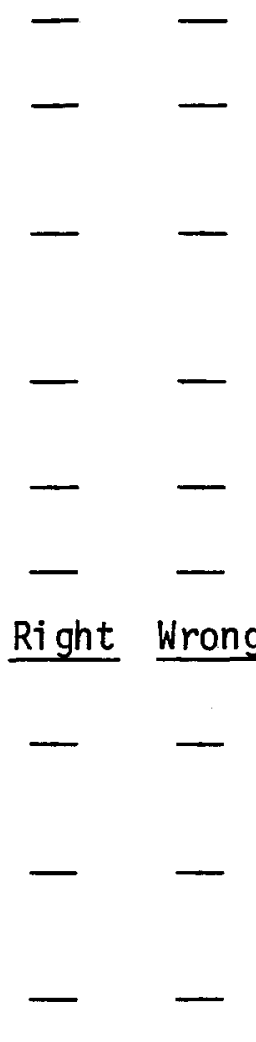
9. Comparative adjective The truck is longer than the car.

10. Relative clause The baby eats the cake which is on the table.

11. Possessive $x$ of $y$ The pilot of the plane.

Syntactic Variant

Example

Right Wrong

1. Active/passive

The boy hits the ball. -The ball is hit by the boy.

-The boy is hit by the ball.

2. Passive/active

The boy is hit by the ball.

-The boy hits the ball.

-The ball hits the boy.

3. Rerative clause/ adjective

The cat has a ball which

is black.

-The black cat has a

ball.

-The cat has a black

ball.

4. Possessive noun phrase/noun phrase

I see the castle of the king,

-I see the castle.

-I see the king.

5. Noun phrase/object

The boy sees the flower. pronoun (direct) -The boy sees her.

-The boy sees it. 
APPENDIX G 
736 Dobson Street

Evanston, IL 60202

June 1,1982

Dear Parent:

You may remember that last fall you gave permission for your child to participate in a research study through Loyola University of Chicago, and you requested to know the results.

Fifty-nine deaf children were tested, and your child's teacher was sent an analys is of his or her grammatical strengths and weaknesses. In general, we found that deaf children with more advanced thinking skills (called concrete operational) had a better understanding of English grammar than deaf children with less advanced thinking skills (called pre-operational). The deaf children in our study lagged behind most hearing children, however, in their overall grammar skills and in the age they reached the more advanced level of thinking. We also found that children whose parents signed to them consistently had a better understanding of English grammar than those who did not.

Thanks for allowing your child to participate in this study. Your cooperation has been much appreciated.

Sincerely,

David Dolman

Doctoral Candidate

Foundations of Education

Loyola University of Chicago 
THE RELATIONSHIP BETWEEN SYNTACTIC DEVELOPMENT AND CONCRETE OPERATIONS IN

DEAF CHILDREN： SUMMARY OF FINDINGS

by Dave Dolman

Tremaine (1975) found that bilingual hearing children made gains in both native and second language comprehension when they reached the level of concrete operations, Building on this finding, the present study examined the linguistic and cognitive skills of 59 severe-to-profound and profoundly deaf children between the ages of seven and 12. Through the use of manually coded English, students were administered four Piagetian operational tasks in the areas of conservation, classification, seriation, and numeration and a test of syntactic comprehension modeled after Tremaine's. In addition, students and teachers were given a sociolinguistic questionnaire to determine the hearing status of the child's parents, the age the child learned the signs, the sign language consistency at home, and other information pertaining to the child's linguistic background. Teachers and students showed a high degree of agreement in their responses to this questionnaire.

Results indicated that operational deaf children performed significantly better than non-operational deaf children on the test of syntactic comprehension, although both groups of children had poorer English skills and a lower rate of operational thinking than did the much younger hearing students in Tremaine's sample. A relationship was found between operational thinking, age, and IQ of the subjects as well as between age and syntactic skills, 
but no relationship was indicated between syntactic skills and IQ. Students whose parents consistently signed to them, whether through American Sign Language or manually coded English, showed greater English syntactic comprehension than did students whose parents signed less consistently. The children with more consistent sign language exposure at home also tended to have more advanced operational skills, though not to a statistically significant degree. In both operational level and English syntactic skills, a slight advantage was found for those children using American Sign Language at home rather than manually coded English. This finding may be explained by the greater degree of sign consistency likely to be experienced by those deaf children whose parents (a17 of whom are deaf) use American Sign Language. This tendency toward greater operational abilities in children with more consistent sign language background supports other research which views language as facilitative but not critical for the development of cognitive abilities. Finally, a multiple regression analysis indicated that more than half of the total variability on the test of syntactic comprehension could be predicted from success or failure on two of the operational tasks (numeration and seriation) and the child's overall signing ability, with age and IQ figuring as much poorer predictors of English skills.

Tremaine, R. Syntax and Piagetian operational thought. Washington, D. C.: Georgetown University Press, 1975. 
APPENDIX H 
METHODS 1 AND 2 SCORING SYSTEMS FOR OPERATIONAL TASKS

\section{Method 1 Scoring}

1. Conservation - all items must be answered correctly.

2. Classification - \#3, 5, and 6 must be answered correctly.

3. Seriation - \# 1 and 8 must be answered correctly.

4. Numeration - no more than one incorrect response is acceptable for \#1-8; \#9 and 10 must both be answered correctly by subtracting mentally, rather than counting or rebuilding.

\section{Method 2 Scoring}

1. Conservation -

1. +3 points

2. +3 points

2. Classification -

1. +1 point

2. +1 point

3. +1 point

4. +1 point

5. +1 point

6 . +1 point

3. Seriation -

1. or $6 .+3$ points

2. +1 point

4. +1 point

8. +3 points

4. Numeration -

1. +1 point

2. +1 point

4. or $5 .+1$ point if the child does not rebuild beyond 2 .

6 . or $7 .+1$ point if the child does not rebuild beyond 5 .

9. +1 point if the child subtracts mentally rather than counting or rebuilding.

10. +1 if the child subtracts mentally rather than counting or rebuilding. 
APPENDIX I 
Results Related to Hypothesis 2: Analysis of Variance for the Total Score on the Test of Syntactic Comprehension in Relation to the Child's Sign Language Background (ASL, MCE, or NCL) according to the Child $(n=46)$

\begin{tabular}{lrrrrr} 
Source & d.f. & S.S. & M.S. & F. & Sig. \\
Between & 2 & 454.47 & 227.23 & 3.44 & .0412 \\
Within & 43 & 2840.94 & 66.07 & & \\
\hline
\end{tabular}


Results Related to Hypothes is 2: Tukey's HSD Tests for Differences among ASL, MCE, and NCL Groups, according to the Child $(n=46)$, in the Total Score on the Test of Syntactic Comprehension

Mean Difference

Sig.

ASL/MCE groups

$66.14-63.61=2.53$

n.s.

ASL/NCL groups

$66.14-58.24=7.90$

n.s.

MCE/NCL groups

$63.61-58.24=5.37$

n.s. 
Results Related to Hypothesis 3: Analysis of Variance for Operational Tasks (Method 2 Scoring) in Relation to the Child's Language Background (ASL, MCE, or NCL), according to the Teacher $(n=44)$

Source $\quad \underline{\text { d.f. }} \quad \underline{\text { S.S. }} \quad \underline{\text { M.S. }} \quad \underline{\text { Sig. }}$

Conservation

Between

2

20.17

$10.09 \quad 5.30$

.0090

Within

41

78.01

1.90

Classification

Between

2

2.36

1.18

.73

.4884

Within

41

66.43

1.62

Seriation

Between

2

1.60

.80

.62

.5426

Within

41

52.83

1.29

Numeration

Between

2

24.43

$12.22 \quad 3.56$

.0376

Within

41

140.75

3.43 
Results Related to Hypothesis 3: Analys is of Variance for Operational Tasks (Method 1 Scoring) in Relation to the Child's Language Background (ASL, MCE, or NCL), according to the Child $(n=46)$

\section{Source}

$$
\text { d.f. S.S. }
$$

M.S.

F.

$\underline{\text { Sig. }}$

Conservation

Between

2

1.44

.72

3.25

.0483

Within

43

9.52

.22

\section{Classification}

Between

2

.89

.45

1.91

.1607

Within

43

10.06

.23

Seriation

Between

2

.11

.05

.53

.5921

Within

43

4.35

.10

Numeration

Between

2

.58

.29

1.32

.2776

Within

43

9.52

.22 
Results Related to Hypothesis 3: Analysis of Variance for Operational Tasks (Method 2 Scoring) in Relation to the Child's Language Background (ASL, MCE, or NCL), according to the Child $(n=46)$

Source

d.f. S.S. M.S. F.

Conservation

Between

Within

Classification

Between

Within

Seriation

Between

Within

Numeration

Between

Within
2

43

12.97

85.64

6.48

3.25

.0483

1.99
2

9.19

4.59

3.11

.0545

43

63.42

1.47 0545 
Results Related to Hypothes is 3: Tukey's HSD Tests for Differences among ASL, MCE, and NCL Groups, according to the Teacher $(n=44)$, on the Conservation and Numeration Tasks under Method 2 Scoring

Conservation

ASL/MCE groups

$$
6.00-4.77=1.23
$$

n.s.

ASL/NCL groups

$6.00-4.05=1.95$

$<.01$

MCE/NCL groups

$$
4.77-4.05=.72
$$

n.s.

Numeration

ASL/MCE groups

$5.43-4.47=.96$

n.s.

ASL/NCL groups

$5.43-3.40=2.03$

$<.05$

MCE/NCL groups 
Results Related to Hypothes is 3: Tukey's HSD Tests for Differences among ASL, MCE, and NCL Groups, according to the Child $(n=46)$, on the Conservation and Classification Tasks under Method 2 Scoring

Mean Difference

Conservation

ASL/MCE groups

$$
6.00-4.83=1.17
$$

n.s.

ASL/NCL groups

$6.00-4.43=1.57$

$<.05$

$\mathrm{MCE} / \mathrm{NCL}$ groups

$4.83-4.43=.40$

n.s.

Classification

ASL/MCE groups

$5.00-5.72=-.72$

n.s.

ASL/NCL groups

$5.00-4.76=.24$

n.s.

MCE/NCL groups

$5.72-4.76=.96$

n.s. 
Results Related to Hypothesis 4: The Relationship between IQ and Operational Ability under Method 2 Scoring $(n=50)$

\section{Correlation Coefficient}

Sig.

Conservation

.461

.0008

Classification

Seriation

.123

Numeration 
Results Related to Hypothesis 5: The Relationship between Age and Operational Ability under Method 2 Scoring ( $n=59)$

\section{Correlation Coefficient}

Sig.

Conservation

.552

.0001

Classification

.402

.004

Seriation

.562

.0001

Numeration

.630

.0001 
Stepwise Multiple Regression Analys is for the Best Predictors of the Total Score on the Test of Syntactic Comprehension (Method 2 Scoring System, Teacher-reported Information)

\section{Variable}

Numeration

Overall Signing Ability

Seriation

Conservation

Parents' Hearing Status

Age

Classification

Age Child Learned Signs, Teacher Report

IQ

Sign Consistency at Home, Teacher Report
B value 
Stepwise Multiple Regression Analysis for the Best Predictors of the Total Score on the Test of Syntactic Comprehension (Method 1 Scoring System, Child-reported Information)

\section{$\underline{\text { Variable }}$}

Numeration

Overall Signing Ability

Seriation

Parents' Hearing Status

Sign Consistency at Home, Child Report

Age

Classification

Conservation

IQ

Age Child Learned Signs, Child Report
$\underline{B \text { value }} \quad \underline{R^{2}}$

$\begin{array}{ll}-8.125 & .370\end{array}$

$\begin{array}{ll}-2.627 & .479\end{array}$

$\begin{array}{ll}-6.534 & .540\end{array}$

$3.007 \quad .545$

$\begin{array}{ll}-.812 & .551\end{array}$

$.022 \quad .556$

$\begin{array}{ll}1.211 & .559\end{array}$

$\begin{array}{ll}-1.058 & .561\end{array}$

$.014 \quad .561$

$.078 \quad .561$ 
Stepwise Multiple Regression Analys is for the Best Predictors of the Total Score on the Test of Syntactic Comprehension (Method 2 Scoring System, Child-reported Information)

\section{$\underline{\text { Variable }}$}

Numeration

Overall Signing Ability

Age Child Learned Signs, Child Report

Seriation

Parents' Hearing Status

IQ

Conservation

Classification

Sign Consistency at Home, Child Report
B Value

$\underline{R^{2}}$

1.687

.366

$-2.897$

$-.901$ .448

1.398 .458

4.002 .465

.046 .473

.583 .475

$-.449$

$-.342$ .478

$-.015$ 
APPENDIX J 
Scores on the Four Operational Tasks for All Subjects, according to the Method 1 Scoring System

$$
(0=\text { Operational; } N=\text { Non-operationa } 1)
$$

Subject Conservation Classification Seriation Numeration

\begin{tabular}{|c|c|c|c|c|}
\hline 1 & 0 & $N$ & 0 & 0 \\
\hline 2 & 0 & 0 & 0 & $\mathrm{~N}$ \\
\hline 3 & 0 & $\mathrm{~N}$ & 0 & 0 \\
\hline 4 & 0 & 0 & 0 & $N$ \\
\hline 5 & $\mathrm{~N}$ & 0 & 0 & 0 \\
\hline * 6 & 0 & 0 & 0 & 0 \\
\hline 7 & $N$ & 0 & 0 & $\mathrm{~N}$ \\
\hline * 8 & 0 & 0 & 0 & 0 \\
\hline 9 & $N$ & 0 & 0 & $\mathrm{~N}$ \\
\hline 10 & 0 & $\mathrm{~N}$ & 0 & 0 \\
\hline 11 & 0 & 0 & 0 & $\mathrm{~N}$ \\
\hline$\star \star 12$ & $N$ & $\mathrm{~N}$ & 0 & $\mathrm{~N}$ \\
\hline 13 & 0 & $N$ & 0 & $N$ \\
\hline$\star \star 14$ & $\mathrm{~N}$ & $\mathrm{~N}$ & 0 & $\mathrm{~N}$ \\
\hline$\star 15$ & 0 & 0 & 0 & 0 \\
\hline 16 & 0 & $N$ & 0 & 0 \\
\hline *17 & 0 & 0 & 0 & 0 \\
\hline 18 & 0 & 0 & 0 & $N$ \\
\hline 19 & 0 & 0 & 0 & $N$ \\
\hline$\star \star 20$ & $N$ & $\mathrm{~N}$ & $N$ & $N$ \\
\hline$\star \star 21$ & $N$ & $\mathrm{~N}$ & $N$ & $N$ \\
\hline$\star \star 22$ & $N$ & $\mathrm{~N}$ & 0 & $\mathrm{~N}$ \\
\hline 23 & $N$ & 0 & 0 & $N$ \\
\hline 24 & 0 & 0 & 0 & $\mathrm{~N}$ \\
\hline 25 & $N$ & 0 & 0 & $\mathrm{~N}$ \\
\hline 26 & $N$ & 0 & 0 & $\mathrm{~N}$ \\
\hline 27 & $N$ & 0 & 0 & $N$ \\
\hline$\star 28$ & 0 & 0 & 0 & 0 \\
\hline 29 & 0 & $N$ & 0 & $N$ \\
\hline$\star \star 30$ & $\mathrm{~N}$ & $\mathrm{~N}$ & 0 & $\mathrm{~N}$ \\
\hline 31 & $\mathrm{~N}$ & $\mathrm{~N}$ & 0 & 0 \\
\hline$\star \star 32$ & $N$ & $\mathrm{~N}$ & 0 & $\mathrm{~N}$ \\
\hline$* * 33$ & $\mathrm{~N}$ & $\mathrm{~N}$ & $\mathrm{~N}$ & $\mathrm{~N}$ \\
\hline 34 & 0 & 0 & 0 & $\mathrm{~N}$ \\
\hline$* * 35$ & $N$ & $\mathrm{~N}$ & 0 & $\mathrm{~N}$ \\
\hline
\end{tabular}


Subject $\quad$ Conservation Classification Seriation Numeration

\begin{tabular}{|c|c|c|c|c|}
\hline$\star * 36$ & N & $N$ & $N$ & $\mathrm{~N}$ \\
\hline 37 & 0 & 0 & 0 & $\mathrm{~N}$ \\
\hline 38 & 0 & 0 & 0 & $N$ \\
\hline 39 & 0 & 0 & 0 & $\mathrm{~N}$ \\
\hline$\star 40$ & 0 & 0 & 0 & 0 \\
\hline$\star \star 41$ & $N$ & $\mathrm{~N}$ & $N$ & $\mathrm{~N}$ \\
\hline 42 & 0 & 0 & 0 & $\mathrm{~N}$ \\
\hline 43 & $\mathrm{~N}$ & $N$ & 0 & 0 \\
\hline 44 & 0 & $\mathrm{~N}$ & 0 & $N$ \\
\hline$\star 45$ & 0 & 0 & 0 & 0 \\
\hline *46 & 0 & 0 & 0 & 0 \\
\hline 47 & 0 & 0 & 0 & $N$ \\
\hline$\star \star 48$ & $\mathrm{~N}$ & $\mathrm{~N}$ & 0 & $N$ \\
\hline *49 & 0 & 0 & 0 & 0 \\
\hline 50 & 0 & $N$ & 0 & $\mathrm{~N}$ \\
\hline 51 & $N$ & 0 & 0 & 0 \\
\hline$\star 52$ & 0 & 0 & 0 & 0 \\
\hline *53 & 0 & 0 & 0 & 0 \\
\hline$\star \star 54$ & $\mathrm{~N}$ & $N$ & 0 & $\mathrm{~N}$ \\
\hline$\star 55$ & 0 & 0 & 0 & 0 \\
\hline 56 & $\mathrm{~N}$ & 0 & 0 & $\mathrm{~N}$ \\
\hline 57 & 0 & 0 & $N$ & $\mathrm{~N}$ \\
\hline 58 & 0 & $\mathrm{~N}$ & 0 & $\mathrm{~N}$ \\
\hline$\star \star 59$ & $\mathrm{~N}$ & $\mathrm{~N}$ & $\underline{0}$ & $\mathrm{~N}$ \\
\hline $\begin{array}{c}\text { TOTAL } \\
\text { OPERATIONAL }\end{array}$ & 34 & 34 & 53 & 20 \\
\hline
\end{tabular}

${ }^{*}$ considered predominantly operational

**considered predominantly non-operational 


\section{APPROVAL SHEET}

The dissertation submitted by David Dolman has been read and approved by the following committee:

Dr. Ronald R. Morgan, Director

Associate Professor of Educational Foundations, Loyola

Dr. Carol Harding

Assistant Professor of Educational Foundations, Loyola

Dr. Todd Hoover

Assistant Professor of Curriculum \& Instruction, Loyola

Dr. Patricia Scherer

Director, Center on Deafness, Glenview, Illinois

The final copies have been examined by the director of the dissertation and the signature which appears below verifies the fact that any necessary changes have been incorporated and that the dissertation is now given final approval by the Committee with reference to content and form.

The dissertation is therefore accepted in partial fulfillment of the requirements for the degree of Doctor of Philosophy.
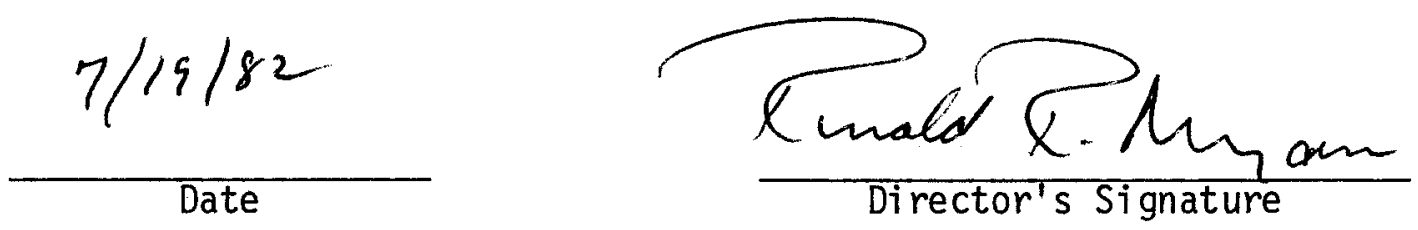